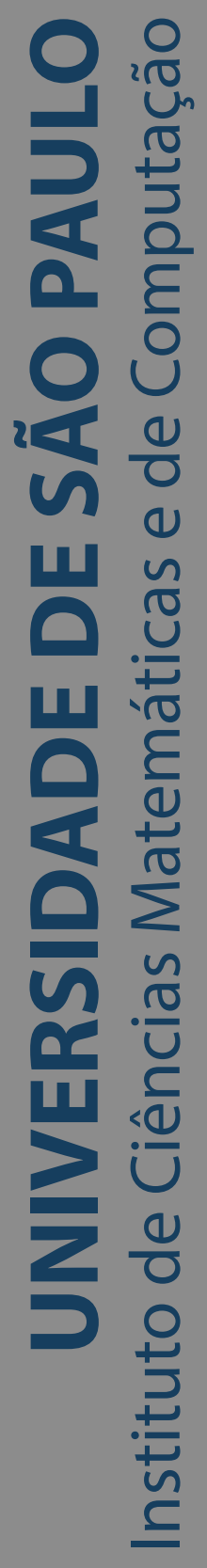

Reference architectures: factors for their sustainability

\title{
Tiago Volpato
}

Dissertação de Mestrado do Programa de Pós-Graduação em Ciências de Computação e Matemática Computacional (PPG-CCMC) 

SERVIÇO DE PÓS-GRADUAÇÃO DO ICMC-USP

Data de Depósito:

Assinatura:

\title{
Tiago Volpato
}

\section{Reference architectures: factors for their sustainability}

\author{
Dissertation submitted to the Institute of Mathematics \\ and Computer Sciences - ICMC-USP - in \\ accordance with the requirements of the Computer \\ and Mathematical Sciences Graduate Program, for \\ the degree of Master in Science. EXAMINATION \\ BOARD PRESENTATION COPY \\ Concentration Area: Computer Science and \\ Computational Mathematics
}

Advisor: Profa. Dra. Elisa Yumi Nakagawa

\section{USP - São Carlos}

August 2018 
Ficha catalográfica elaborada pela Biblioteca Prof. Achille Bassi e Seção Técnica de Informática, ICMC/USP, com os dados inseridos pelo(a) autor(a)

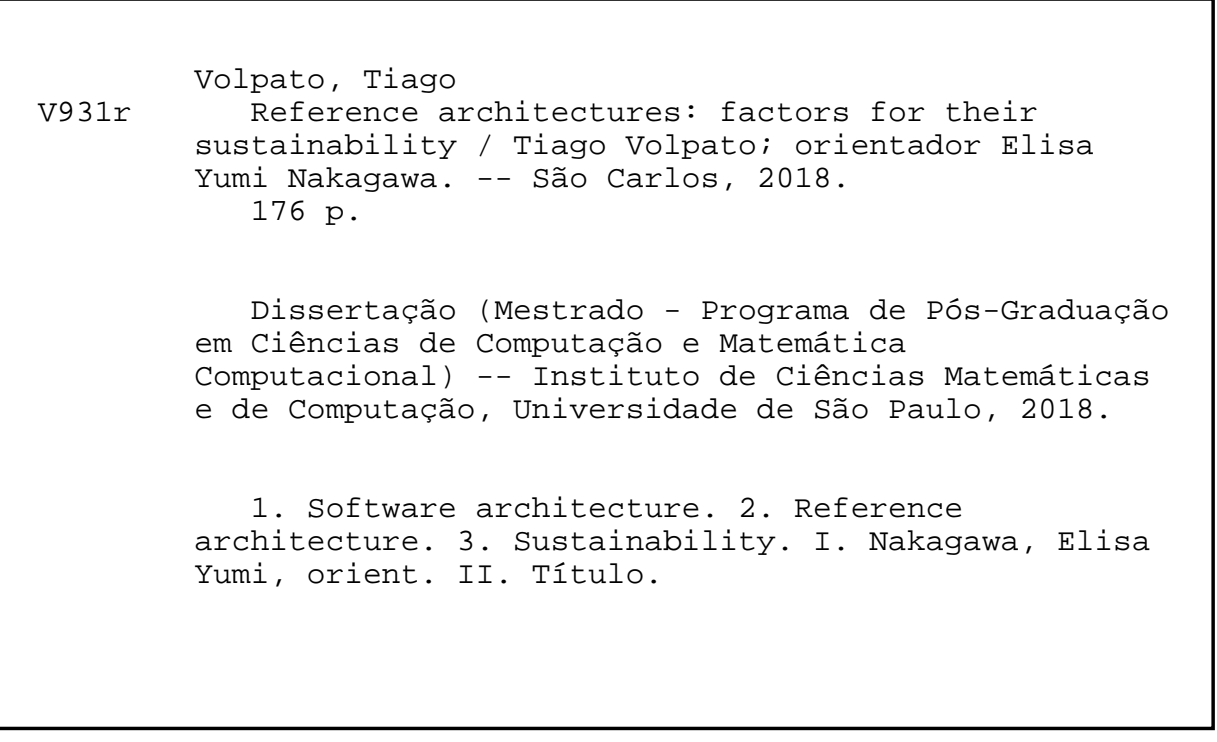

Bibliotecários responsáveis pela estrutura de catalogação da publicação de acordo com a AACR2: Gláucia Maria Saia Cristianini - CRB - 8/4938 Juliana de Souza Moraes - CRB - 8/6176 


\section{Tiago Volpato}

\section{Arquiteturas de referência: fatores para sua sustentabilidade}

Dissertação apresentada ao Instituto de Ciências Matemáticas e de Computação - ICMC-USP, como parte dos requisitos para obtenção do título de Mestre em Ciências - Ciências de Computação e Matemática Computacional. EXEMPLAR DE DEFESA

Área de Concentração: Ciências de Computação e Matemática Computacional

Orientadora: Profa. Dra. Elisa Yumi Nakagawa 

Agradeço imensamente a Prof. Elisa Yumi Nakagawa por me orientar neste projeto. Sua atenção, dedicação e cuidado foram fundamentais pro meu crescimento profissional e pessoal.

Agradeço a Prof. Claudete Werner, a Prof. Edwirge Vieira Franco e a todo o colegiado do curso de Sistemas de Informação da Universidade Paranaense - Unidade de Paranavaí, por terem acreditado no meu sonho.

À minha família, por entender minha ausência e pela confiança depositada em mim.

À Bruna Abreu Valente, Pedro Tessarolo, Kayan Rossy, Jessica Garcia e Rogério Albuquerque por sempre acreditarem no meu potencial.

Ao Edmar Moreira Homem Junior, pelos inúmeros conselhos e incentivos.

Ao José Gonçalves por me inspirar a seguir um sonho.

Ao João Paulo Bounassar, por estar presente no início dessa trajetória e me apoiar em algumas mudanças que ela trouxe.

Ao Cássio Vinícius Borges, por estar presente em momentos difíceis e decisivos durante este projeto.

Ao Vicente Conde e Miriam Fegasa, por terem me acolhido durante o estágio em Madrid.

Ao Prof. Rafael Capilla, pela generosidade em compartilhar seu conhecimento e tempo durante o estágio na Universidad Rey Juan Carlos, em Madrid, Espanha.

À CAPES e FAPESP (Processo ${ }^{\circ}$ 2016/16870-2, Fundação de Amparo à Pesquisa do Estado de São Paulo (FAPESP)) pelo financiamento deste projeto. 



\section{RESUMO}

VOLPATO, T. Arquiteturas de referência: fatores para sua sustentabilidade. 2018.176 p. Dissertação (Mestrado em Ciências - Ciências de Computação e Matemática Computacional) Instituto de Ciências Matemáticas e de Computação, Universidade de São Paulo, São Carlos SP, 2018.

Arquiteturas de software desempenham um papel essencial na determinação da qualidade de sistemas de software. Nesse cenário, arquitetura de referência é um tipo especial de arquitetura de software que tem apoiado com êxito o desenvolvimento, padronização e evolução dos sistemas. Considerando sua relevância, muitas arquiteturas de referência foram estabelecidas para diversos domínios, tais como saúde, automotivo e robótica. No entanto, esses domínios de aplicações continuamente evoluem e suas arquiteturas de referência também precisam evoluir para continuar apoiando tais domínios. Diversos elementos, tais como as decisões do projeto e aderência às boas práticas de projeto, influenciam a capacidade das arquiteturas de referência para suportar mudanças contínuas, mantendo sua eficiência. Portanto, um grande desafio é garantir a sustentabilidade em arquiteturas de referência. Assim, o objetivo principal deste projeto de Mestrado é estabelecer um modelo com fatores para analisar a sustentabilidade em arquiteturas de referência. Para avaliar nossa proposta, um survey com especialistas foi conduzido vala validar tal modelo. $90 \%$ dos especialistas concordam que o modelo pode ser usado para indicar se uma arquitetura de referência é sustentável ou não, e $80 \%$ dos especialistas consideram que nosso modelo pode ser útil para projetar novas arquiteturas de referências sustentáveis.

Palavras-chave: Arquitetura de software, Arquitetura de Referência, Sustentabilidade. 



\section{ABSTRACT}

VOLPATO, T. Reference architectures: factors for their sustainability. 2018. 176 p. Dissertação (Mestrado em Ciências - Ciências de Computação e Matemática Computacional) Instituto de Ciências Matemáticas e de Computação, Universidade de São Paulo, São Carlos SP, 2018.

Software architectures have played an essential role in determining the quality of software systems. In this scenario, reference architectures is a special type of software architecture that has successfully supported the development, standardization, and evolution of a set of systems. Considering their relevance, many reference architectures are established for diverse domains, such as health, automotive, robotics, and transportation systems. These application domains continually evolve and their reference architectures also need to evolve to continue to be efficient for such domains. However, many of them have not been adequately evolved. Diverse elements, such as design decisions and adherence to good design practices, influence the ability of reference architectures to support continuous changes while maintaining their efficiency; therefore, a major challenge is to ensure the sustainability in reference architectures. Hence, it is quite interesting to be able to analyze the sustainability of these architectures. The main objective of this Master's project is to establish a model concerning factors for analyze sustainability in reference architectures. In order to evaluate our proposal, a survey was conducted with experts to validate such model. $90 \%$ of experts agree that the model can be useful to indicate whether a reference architecture is sustainable or not, and $80 \%$ of experts think that our model can be useful for building newly sustainable reference architectures.

Keywords: Software architecture, Reference Architecture, Sustainability. 

Figure 1 - Workflow between global analysis and architecture view design . . . . . . 28

Figure 2 - RUP's $4+1$ views . . . . . . . . . . . . . . . . . . . . . . . . 29

Figure 3 - Architectural design activities . . . . . . . . . . . 30

Figure 4 - Reference architecture $v s$ reference model . . . . . . . . . . . 33

Figure 5 - Reference architecture $v s$ product line architecture . . . . . . . . . . 34

Figure 6 - Instantiation of a Reference Architecture . . . . . . . . . . . . . . . 37

Figure 7 - Structure of RAModel . . . . . . . . . . . . . . . . . 40

Figure 8 - Structure of ProSA-RA . . . . . . . . . . . . . . 41

Figure 9 - Number of studies per database . . . . . . . . . . . . . . 49

Figure 10 - Distribuction of selected studies over time period. . . . . . . . . . . . 51

Figure 11 - Distribution of selected studies over a) author types; and b) publication types. 51

Figure 12 - Process to adapt quality attributes to the standard ISO/IEC $25010 \ldots \ldots 4$

Figure 13 - Amount of studies addressing QAs. . . . . . . . . . . . . . . 55

Figure 14 - Quality attributes found in selected studies . . . . . . . . . . . . . 57

Figure 15 - Methodology for Establishment of RASModel . . . . . . . . . . . . . . . 61

Figure 16 - Reference Architecture Sustainability Model . . . . . . . . . . . . . . . . . 63

Figure 17 - Activities in the process to perform survey. . . . . . . . . . . . . . . 70

Figure 18 - Participant information summary . . . . . . . . . . . . . . 77

Figure 19 - Documentation statistics . . . . . . . . . . . . . . 78

Figure 20 - Document and Artifact statistics _ . . . . . . . . . . . . 80

Figure 21 - Support and Dissemination statistics . . . . . . . . . . . . . . 81

Figure 22 - Training and Tool statistics . . . . . . . . . . . . . . 82

Figure 23 - Factor Stakeholder and subfactor Partner statistics . . . . . . . . . . . . 84

Figure 24 - Attendee and Maintainer statistics _ . . . . . . . . . . . . 85

Figure 25 - Factor Economy and subfactor Value-added statistics ～. . . . . . . . . . 86

Figure 26 - Economic viability and Financial investment statistics . . . . . . . . . . . 87

Figure 27 - Motivation and Scope size statistics . . . . . . . . . . . . . . . . . . 89

Figure 28 - Vision Statement and State-of-the-art alignment statistics . . . . . . . . . 90

Figure 29 - Regular updates statistics . . . . . . . . . . . . . . . . . . . 91

Figure 30 - Boxplot of each factor and subfactor regarding score achieved in linkert-scale 92

Figure 31 - Usefulness of the RASModel for sustainability analysis . . . . . . . . . . 93

Figure 32 - Usefulness of the RASModel for building reference architectures sustainable 94

Figure 33 - Timeline with ARC-IT releases . . . . . . . . . . . . . . . . 97 
Figure 34 - ARC-IT Overview . . . . . . . . . . . . . . . . . . . . . . . . . . 99

Figure 35 - Example of a Enterprise View with Physical View diagram . . . . . . . 101

Figure 36 - Example of ARC-IT Funciontal View . . . . . . . . . . . . . . . . 103

Figure 37 - Example of ARC-IT Communication View . . . . . . . . . . . . 106

Figure 38 - Vision statement with financial investment over 20 years of ARC-IT . . . 112

Figure 39 - Updates in DSRC-UDP Communication Profile . . . . . . . . . . . . 114

Figure 40 - ARC-IT updates . . . . . . . . . . . . . . . . . . 115 
Table 1 - Reference Architectures analyzed . . . . . . . . . . . . . . . 21

Table 2 - Final list of selected studies . . . . . . . . . . . . . 50

Table 3 - Publication source of selected studies . . . . . . . . . . . 52

Table 4 - ISO/IEC 25010 Characteristics . . . . . . . . . . . . . 53

Table 5 - Goals, questions, and metrics for survey . . . . . . . . . . . 71

Table 6 - Available ARC-IT documents . . . . . . . . . . . . . . . . . . . . . . . . . . . . . . . . .

Table 7 - Available ARC-IT databases . . . . . . . . . . . . . 107

Table 8 - ARC-IT training . . . . . . . . . . . . . . 108

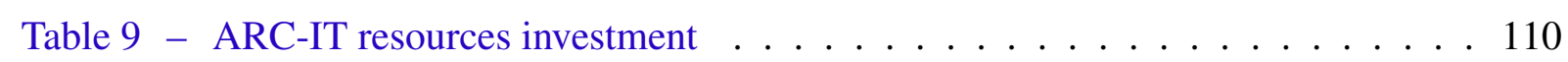



INTRODUCTION . . . . . . . . . . . . . . . . . . 19

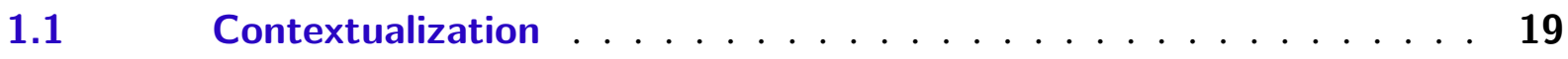

1.2 Motivation ..................... 20

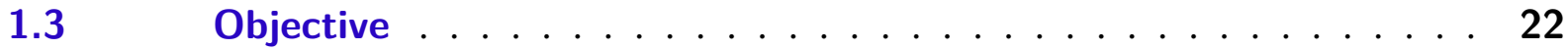

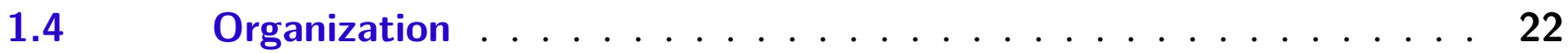

2 SOFTWARE ARCHITECTURE AND REFERENCE ARCHITECTURE 25

$2.1 \quad$ Initial Remarks . . . . . . . . . . . . . . . . . . 25

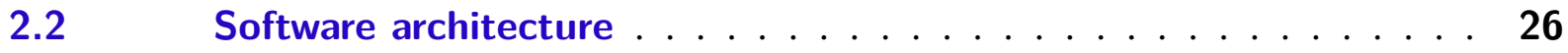

2.2.1 Architectural Processes . . . . . . . . . . . . . . . 27

$2.3 \quad$ Reference Architecture . . . . . . . . . . . . . . . 32

2.3.1 Types of Reference Architectures . . . . . . . . . . . . . . . . . . . . 34

2.3.2 Uses of Reference Architectures . . . . . . . . . . . . . . . . 36

2.3.3 Examples of Reference Architectures . . . . . . . . . . . . . . 39

2.3.4 Designing Reference Architectures . . . . . . . . . . . . . . . 39

$2.4 \quad$ Final Remarks . . . . . . . . . . . . . . . . . . . 42

3 SUSTAINABILITY IN THE CONTEXT OF SOFTWARE AND REFERENCE ARCHITECTURES . . . . . . . . . . . . . . 43

$3.1 \quad$ Initial Remarks . . . . . . . . . . . . . . . . . . 43

3.2 Dimensions of Sustainability . . . . . . . . . . . . . 45

3.3 Software and Reference Architecture Sustainability: a systematic mapping study . . . . . . . . . . . . . . . . . 48

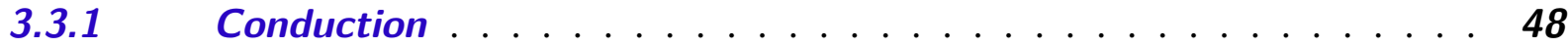

3.3.2 Demographic results . . . . . . . . . . . . . . 51

3.3.3 RQ-1 Characteristics of software architecture sustainable . . . . . 52

$3.4 \quad$ Final Remarks . . . . . . . . . . . . . . . . . . 56

4 A MODEL FOR REFERENCE ARCHITECTURE SUSTAINABILITY 59

$4.1 \quad$ Initial Remarks . . . . . . . . . . . . . . . 59

4.2 Methodology . . . . . . . . . . . . . . . 59

$4.3 \quad$ Reference Architecture Sustainability Model . . . . . . . . . . . 62

$4.4 \quad$ Use of the Model . . . . . . . . . . . . . . . 67

$4.5 \quad$ Final Remarks .................... 67 
$5.1 \quad$ Conducting a survey $\ldots \ldots \ldots \ldots \ldots$

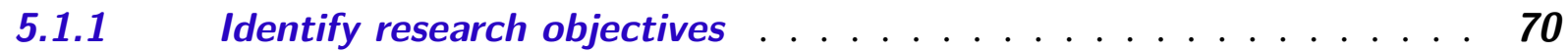

5.1.2 Identify \& characterize target audience . . . . . . . . . . 71

5.1.3 Design sampling plan . . . . . . . . . . . . . . 72

5.1.4 Design \& write questionnaire . . . . . . . . . . . . 72

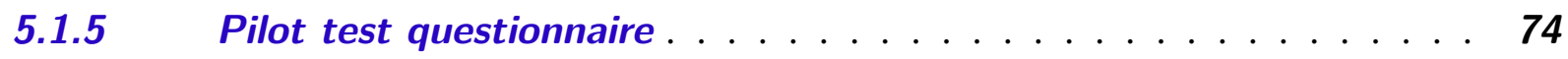

5.1.6 Distribute the questionnaire . . . . . . . . . . . . . 75

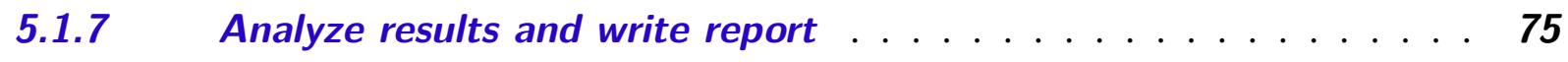

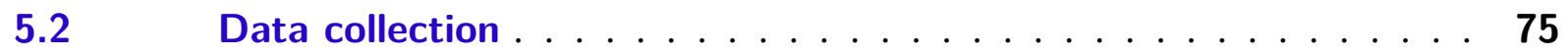

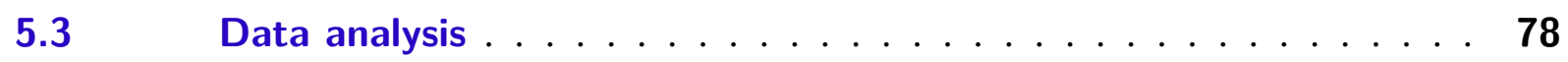

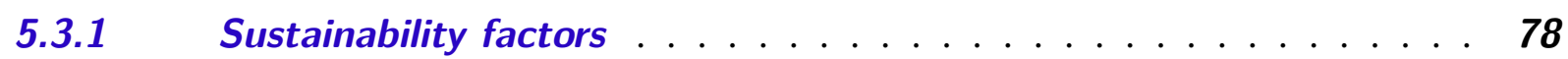

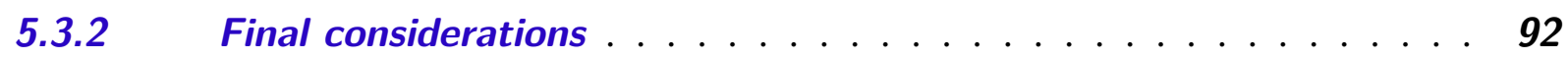

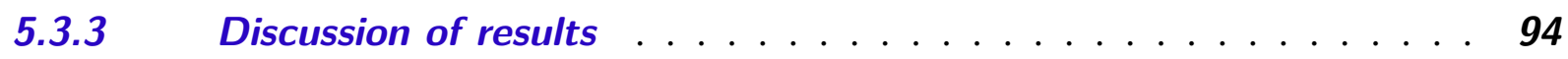

$6 \quad$ RASMODEL APPLICATION EXAMPLE $\ldots \ldots \ldots 7$

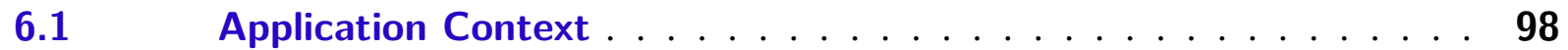

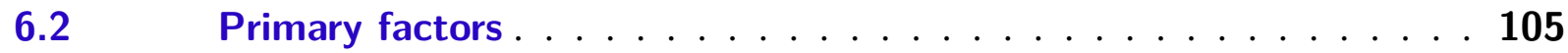

6.2 .1 Documentation . . . . . . . . . . . . . . . . . 106

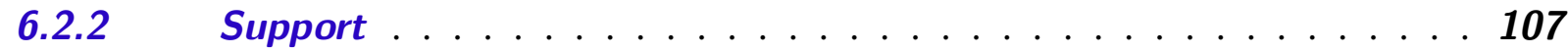

6.2.3 Stakeholders . . . . . . . . . . . . . . . . . . 109

6.2.4 Economy . . . . . . . . . . . . . . . . . . . . . 109

$6.3 \quad$ Crosscuting factors $\ldots \ldots \ldots \ldots \ldots \ldots \ldots \ldots \ldots$

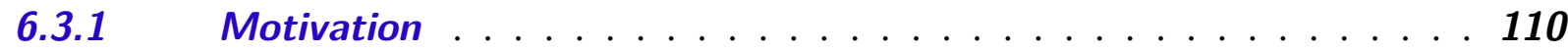

6.3 .2 Vision Statement . . . . . . . . . . . . . . . . 110

6.3.3 State-of-the-art Alignment . . . . . . . . . . . . . . 113

6.3.4 Scope Size . . . . . . . . . . . . . . . . . . . . . . 113

6.3.5 Regular Update . . . . . . . . . . . . . . . . . . 115

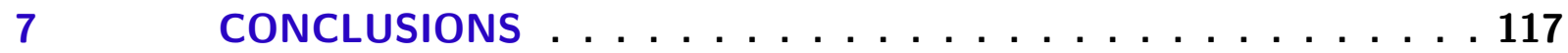

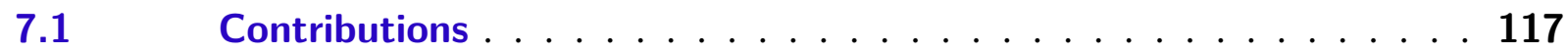

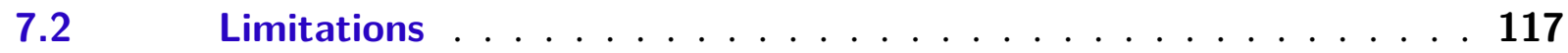

$7.3 \quad$ Future works $\ldots \ldots \ldots \ldots \ldots \ldots \ldots \ldots \ldots \ldots$

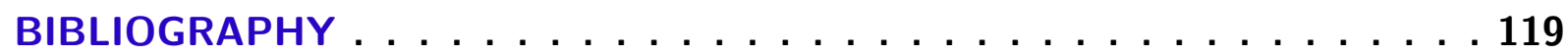

APPENDIX A SYSTEMATIC MAPPING PROTOCOL ABOUT SUS- 
APPENDIX B

APPENDIX C
PAPER: TWO PERSPECTIVES ON REFERENCE ARCHITECTURE SUSTAINABILITY . . . . . . . . . 149 QUESTIONNAIRE FOR RASMODEL EVALUATION 157 

CHAPTER

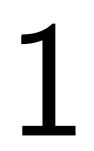

INTRODUCTION

\subsection{Contextualization}

Software architectures have played a significant role to the current society. They are also considered as one of the main artifacts or the backbone to improve the quality of software systems in several application domains, including critical ones, such as telecommunication, transportation, robotics, health, and smart grid.

Software architectures is defined as the structure of a system that should be designed in early phases of the projects to reduce efforts in later phases, such as implementation and maintenance. (BASS; CLEMENTS; KAZMAN, 2012; CLEMENTS; BASS, 2010). Many definitions are given to software architecture, but, in general, there is an agreement that software architecture deals with the macroscopic and sweeping issues of the software design (GEORGE, 2010). (BASS; CLEMENTS; KAZMAN, 2012) list 13 reasons they consider the most important to justify the importance of software architectures. Some of them are (BASS; CLEMENTS; KAZMAN, 2012): (i) a software architecture inhibits or enables system's quality attributes; (ii) a software architecture allows developers to reason about the system during its evolution; (iii) if documented, it enhances communication among stakeholders; (iv) an software architecture carries the early and most fundamental, hardest-to-change design decisions; and (v) it allows system qualities prediction through early architectural evaluations.

In this scenario, reference architecture has emerged as an important research area in software architecture. Reference architecture is also considered the blueprint of software development, since it guides the design of concrete architectures of systems for a given application domain (ANGELOV; TRIENEKENS; GREFEN, 2008; MüLLER, 2008; NAKAGAWA; OQUENDO; BECKER, 2012). The purpose of a reference architecture is to mainly provide guidance for the development, standardization, and evolution of software systems (NAKAGAWA; OQUENDO; MALDONADO, 2015). Besides, they facilitate and guide the design of concrete 
architectures of new systems, also contributing to the evolution of a set of systems that come from the same reference architecture, or ensuring the standardization and interoperability of different systems (GALSTER; AVGERIOU, 2011). Moreover, designed for various application domains and purposes, they have increasingly impacted important aspects of software systems development, such as productivity and quality of these systems (NAKAGAWA; OQUENDO; MALDONADO, 2015). Good examples of reference architectures are AUTOSAR (AUTomotive Open System ARchitecture) (AUTOSAR., 2017), for automotive domain, Continua (CONTINUA., 2017), for ambient assisted living (AAL) (BROEK; CAVALLO; WEHRMANN, 2014), IIRA (Industrial Internet reference Architecture) (CONSORTIUM, 2017b) for IoT (Internet of Things), DRA 5.0 (Mars Design Reference Architecture) (DRAKE; HOFFMAN; BEATY, 2010) for space exploration, and ARC-IT (Architecture Reference for Cooperative and Intelligent Transportation) (USA, 2018) for transportation systems.

In another perspective, research on sustainability in software engineering has gained importance as a result of the need to create better software and therefore avoid compromising future generations opportunities (PENZENSTADLER et al., 2014; AMSEL et al., 2011). In the context of software systems, technical sustainability addresses the long-term use of such systems and their appropriate evolution in a constantly changing execution environment (LAGO et al., 2015; RAZAVIAN; PROCACCIANTI; TAMBURRI, 2014). In industrial automation, for instance, the sustainability of software systems is necessary, because industrial devices have long life-cycles (KOZIOLEK et al., 2013). Moreover, sustainability of software systems is closely related to the sustainability of their architectures (KOZIOLEK et al., 2013). In this scenario, sustainability can be defined as the architecture's capacity to endure different types of changes through efficient maintenance and orderly evolution over its entire life cycle (AVGERIOU; STAL; HILLIARD, 2013). Many aspects influence the sustainability, including design decisions, ease for evolutionary changes, adherence to good design practices, and all related technology choices (KOZIOLEK et al., 2013).

\subsection{Motivation}

Some works discuss the engineering of reference architectures (NAKAGAWA; OQUENDO; BECKER, 2012; ANGELOV; GREFEN; GREEFHORST, 2009; BAYER et al., 2004; MULLER, 2008; REED, 2002), however, in general, they are high-level guidelines, principles, and recommendations or domain-specific processes and, perhaps because of this fact, they have not been widely adopted yet. Besides that, no study addresses the evolution or continuation of these architectures.

The main problem that motivated the conduction of this Master's project is the difficulty of keeping sustainable reference architectures due to continued changes in the domains, without compromising their efficiency to support the development, evolution, and standardization of 


\begin{tabular}{|c|c|c|c|c|}
\hline ID & Reference Architecture & Publication Year & Update & Authors \\
\hline RA-1 & Reference Architecture for the Ground Segment Software & 2005 & No & (DURO et al., 2005) \\
\hline RA-2 & S3 - Service-Oriented Solution Stack & 2007 & Yes & (ARSANJANI et al., 2007) \\
\hline RA-3 & FERP Reference Architecture for ERP Systems & 2007 & No & (BREHM; MARX, 2007) \\
\hline RA-4 & Reference Architecture for Service-Oriented Computing & 2007 & No & (DILLON; WU; CHANG, 2007) \\
\hline RA-5 & AXMEDIS Architecture for Automating Production of Cross Media Content & 2007 & Yes & (FIORAVANTI; SPINU; CAMPANAI, 2007) \\
\hline RA-6 & Reference Architecture for Precision Agriculture (PA) & 2007 & No & (MURAKAMI et al., 2007) \\
\hline RA-7 & Reference Architecture for Image Processing System & 2008 & No & (HEMALATHA; ATHISHA; JEYANTHI, 2008) \\
\hline RA-8 & Reference Architecture for e-Commerce Patterns & 2008 & No & (LAN; LIU; CHAI, 2008) \\
\hline RA-9 & Reference Architecture for Self-organizing Service-Oriented Computing & 2008 & No & (LIU; THANHEISER; SCHMECK, 2008) \\
\hline RA-10 & inContext Pervasive Collaboration Services Architecture (PCSA) & 2008 & No & (REIFF-MARGANIEC et al., 2008) \\
\hline RA-11 & SOELA - Service-oriented e-Learning Reference Architecture & 2008 & No & (ZHENG et al., 2008) \\
\hline RA-12 & Reference Architecture for Telecommunications Service Providers (TSPs) & 2008 & Yes & (RAMANATHAN; ALEXANDER; KERR, 2008) \\
\hline RA-13 & $\begin{array}{l}\text { Reference Architecture for National Science and Technology Information Service } \\
\text { Development }\end{array}$ & 2009 & No & (CHOI; LIM; KIM, 2009) \\
\hline RA-14 & $\begin{array}{l}\text { CERA - Reference Architecture for interoperable Collaborate Work Environment } \\
\text { Systems }\end{array}$ & 2009 & No & (PERISTERAS et al., 2009) \\
\hline RA-15 & Reference Architecture for Situational Awareness Systems & 2009 & No & (LEPPANIEMI et al., 2009) \\
\hline RA-16 & Service-Oriented Architecture Infrastructure Reference Architecture & 2009 & Yes & (ZIMMERMANN; KOPP; PAPPE, 2009) \\
\hline RA-17 & AUTOSAR - AUTomotive Open System ARchitecture & 2013 & Yes & (AUTOSAR., 2017) \\
\hline RA-18 & IIRA - Industrial Internet Reference Architecture & 2017 & Yes & (CONSORTIUM, 2017b) \\
\hline RA-19 & CONTINUA & 2013 & Yes & (CONTINUA., 2017) \\
\hline RA-20 & DRA 5.0 - Mars Design Reference Architecture & 2010 & Yes & (DRAKE; HOFFMAN; BEATY, 2010) \\
\hline RA-21 & ARC-IT - Architecture Reference for Cooperative and Intelligent Transportation & 2013 & Yes & (USA, 2018) \\
\hline
\end{tabular}

Table 1 - Reference Architectures analyzed

systems. Although many reference architectures have been established for diverse domains, is noticed that most of them are not update, hence, a rich knowledge contained in reference architectures could become outdated or be simply wasted.

In spite of the relevance of reference architectures and their important role for the software systems development and evolution, several architectures are outdated. For instance, analyzing all 16 reference architectures found in a systematic literature review (SLR) (OLIVEIRA et $a l ., 2010)$, and other reference architectures previously known and investigated in our research group, we have observed that 12 are outdated, i.e., they were published from 2005 to 2010 and after conduction of this SLR in 2010, none publications, projects or websites were developed indicating updates or initiatives for using or disseminating them. Table 1 summarizes all these reference architectures (together with their target domains), when they were published, authors, and whether they are updated.

Among these 21 reference architectures, we can cite the reference architecture for disasters and emergencies management (LEPPANIEMI et al., 2009). This architecture was designed based on a reference model for SOA published in 2006 and called OASIS (MACKENZIE et al., 2006). This model was updated in recent years (i.e., in 2009 and 2012), with updates in normative and support for new technologies. However, this reference architecture was not updated with new versions of OASIS. Considering that OASIS provides common language for understanding important features of SOA and also provides new directions of what has worked in service-oriented systems (BROWN et al., 2012), it is important that reference architectures based on this reference model are also updated.

Also found in the SLR, another reference architecture that has not been evolved intends to support projects of Web services applications (DILLON; WU; CHANG, 2007). More specifically, this architecture includes three architectural styles, namely Matchmaker Styles, Broker Styles, and Peer-to-Peer Styles (DILLON; WU; CHANG, 2007). However, we observed an evolution in 
the way how Web services are developed, e.g., how to exchange coherent information and services among systems (DELGADO, 2013). More specifically, new architectural styles, such as liquid Web Services (BONETTA; PAUTASSO, 2011) and Structural Service (DELGADO, 2013), were proposed to improve implementation of Web services, making them able to combine resource with flexible services and providing mechanisms for interoperability, scalability, deployment, and composability (BONETTA; PAUTASSO, 2011; DELGADO, 2013). Regarding the reference architecture for Web services, we observe that this reference architecture for Web services does not follow these evolutions and, consequently, Web services applications designed from this architecture are not benefited by these improvements. If this reference architecture is continuously updated, it could serve as a support for the development and standardization of Web services, such as for telecommunication (SAFY; RAMLY; SALAH, 2013) and cloud computing (PUTHAL et al., 2015), which have required more and more integration and interoperability.

In the same way, several other reference architectures were proposed (BREHM; MARX, 2007; CHOI; LIM; KIM, 2009; DURO et al., 2005; LIU; THANHEISER; SCHMECK, 2008); however, no studies are found indicating their updates and any consortium or institution disseminating or using them, differently than it is observed in other reference architectures that are constantly updated and are in fact widely used (AUTOSAR., 2017; CONTINUA., 2017; USA, 2018; CONSORTIUM, 2017b). Therefore, it is evident that certain reference architectures have become more successful than other (ANGELOV; GREFEN; GREEFHORST, 2009). A great effort is necessary to design reference architectures; hence, it is quite interesting to keep it useful in middle- and long-time. However, if these architectures are outdated and do not follow changes in the application domains, they will no longer support the development, standardization, and evolution of systems of such domains. In this way, reference architectures must evolve continuously and must be actively maintained and refactored because older reference architectures may stifle changes and innovation (CLOUTIER et al., 2010; MüLLER; HOLE, 2007).

\subsection{Objective}

In this context, the main objective of this Master's project was to establish RASModel, Reference Architecture Sustainability Model. Such model can be used to analyze factors that indicate sustainability in reference architectures.

In this sense, we expected to point out how much reference architectures can survive and, as a consequence, to improve the ability to develop sustainable reference architectures.

\subsection{Organization}

This dissertation is structured in seven chapters. Chapter 2 presents an overview of software architecture and reference architecture, including their definitions, a brief history of 
this research areas, and the general architectural process. Chapter 3 reports some results of a systematic mapping conducted to investigate how sustainability is considered in software architecture and reference architecture. Chapter 4 describes RASModel and its description. Chapter 5 describes the evaluation of our model through a survey with experts with experience in reference architecture and the analysis of results. As a complement, Chapter 6 presents an example of applying the RASModel in a reference architecture for intelligent transport systems. Finally, Chapter 7 presents the conclusions of the author about the development of this work. 

CHAPTER

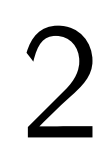

(2)

\section{SOFTWARE ARCHITECTURE AND REFERENCE ARCHITECTURE}

\subsection{Initial Remarks}

In 1980's, software architecture emerged as an important research area for the study of large-scale structures of software systems (SHAW; CLEMENTS, 2006). As a result, research on this area has matured to encompass broad explorations of notations, tools, and analysis techniques, offering concrete guidance for large, complex software design and development (SHAW; CLEMENTS, 2006). Since then, as the complexity and size of software systems have increased, software engineers have adopted design principles, such as the modularization and information hiding, to obtain systems with lower cost and higher quality. For this, the overall structure of software systems, i.e., the software architecture, is a matter that must be considered. The appropriate use of software architectures can have a positive impact on various aspects of software development, such as understanding, reuse, evolution, analysis, and management of systems, being then a factor of extreme importance on the quality of software systems (GARLAN; PERRY, 1995).

Maturation of software technologies typically takes from 15 to 20 years to enter in widespread use, in which it evolves through six typical phases (REDWINE JR.; RIDDLE, 1985): (i) basic research; (ii) concept formulation; (iii) development and extension; (iv) internal enhancement and exploration; (v) external enhancement and exploration; and (vi) popularization. Currently, software architecture research is on the last phase, which began in 2000 (SHAW; CLEMENTS, 2006). There is already a large research community and the demand for large, complex systems is still increasing. Thus, this chapter presents an overview of software architecture, including the architectural process, which covers activities including architectural analysis, synthesis, and evaluation. 


\subsection{Software architecture}

A study of the main works in the literature allows to identify important definitions for software architecture. One of the main was stated by (BASS; CLEMENTS; KAZMAN, 2012), who defined software architecture as "the set of structures needed to reason about the system, comprising software elements, relations among them, and properties of both". In another definition, (DAGNINO; STOLL; WEISS, 2011) described that the study of software architecture is, in large part, a study of software structures and their interactions. To the author, "software architecture can be visualized as if the constituent components were buildings in a city. In the physical world, a secure building could, for example, be realized by allowing only one road, guarded by a watchman requiring a password, to lead to it. The software corollary would allow only one access possibility, from secure, authorized sources, to a software component. Software architecture researchers are constantly seeking innovative ways to design their "city plans" in order to positively influence software usability, security, performance, reliability or energy efficiency". From a more specific perspective, (CLEMENTS; BASS, 2010) documented that "architecture is what makes the set of parts work together as a coherent and successful whole. Architecture documentation helps architects make the right decisions; it tells developers how to carry them out; and it records those decisions to give a system's future caretakers insight into the architect's solution".

Hence, software architectures have a fundamental role in determining the quality of software systems, which are constructed to satisfy organization's business goals. The architecture is a bridge between those (often abstract) business goals and the final (concrete) resulting system (BASS; CLEMENTS; KAZMAN, 2012). While the path from abstract goals to concrete systems can be complex, software architectures can be designed, analyzed, documented, and implemented using techniques that support the achievement of these business goals. Many other definitions are given to software architecture, but, in general, there is an agreement that software architecture deals with the macroscopic and sweeping issues of the software design (GEORGE, 2010). A software architecture acts as the skeleton abstraction of the system, and, therefore, is present in any system, even if it was not designed during early phases of the software project. (BASS; CLEMENTS; KAZMAN, 2012) list 13 reasons they consider the most important to justify the importance of the software architecture discipline. Some of these reasons are: (i) a software architecture inhibits or enables system's quality attributes; (ii) it allows developers to reason about the system during its evolution; (iii) if documented, it enhances communication among stakeholders; (iv) the architecture carries the early and most fundamental, hardest-tochange design decisions; and (v) it allows system qualities prediction through early architectural evaluations.

Software architecture is quite important to preserve the intent of designers on the structure and behavior of software systems, and also to offer an important anti-aging protection of software (KRUCHTEN; OBBINK; STAFFORD, 2006). In another perspective, (BABAR et al., 2009), 
summarize the main contributions obtained by the construction of a software architecture as being: (i) it serves as a vehicle of communication among stakeholders during the analysis and development of systems; (ii) it captures important design decisions that impact subsequent development phases; and (iii) it serves as an abstraction of the system that can be read and inspected by people and will be the base to support reuse. In addition, it is important to highlight the role of architectures for quality requirements, such as performance and compatibility between software systems (KRUCHTEN; OBBINK; STAFFORD, 2006).

The desired quality attributes of a system cannot be assured to be on the final product by the software architecture itself. That is, the software architecture does not exactly satisfy non-functional or quality attribute requirements. Instead, the architecture enables the remaining phases of software development to be done concerning the satisfaction of system qualities, which, in turn, allows the final product to exhibit its required quality attributes (BASS; CLEMENTS; KAZMAN, 2012). Some examples apply: if a system requires high performance, then it's necessary to manage the communication frequency, time, and volume among its structures. To enable a system to be easily modifiable, then the design must follow high cohesion and low-coupling approaches, so further changes to the system do not reach far consequences. If security is priority, it is required to manage the communication among system structures and which elements can access which information. These and other similar examples are supremely architectural (BASS; CLEMENTS; KAZMAN, 2012). But, as said before, the architecture "enables" the system to inhibit its quality attributes, that is, the architecture cannot guarantee quality, i.e., poor downstream design or implementation can always undermine an adequate architectural design (BASS; CLEMENTS; KAZMAN, 2012). Additionally, since the architecture is designed in early phases of the development process, it can be studied to support the prediction of quality (BASS; CLEMENTS; KAZMAN, 2012). This is useful because enable early design changes, which are less expensive and requires less efforts. In this sense, architectural evaluation methods can be conducted to support top-down insight into the attributes of software product quality that is made possible (and constrained) by software architectures (BASS; CLEMENTS; KAZMAN, 2012).

\subsubsection{Architectural Processes}

An architecture outlines what a system can or cannot do. Attention to software architecture is essential for successful product developments. Therefore, software architecture development is a crucial phase in software development process. As the software intensive systems become complex, software architects face with the challenges of dealing with multiple sometimes conflicting concerns at the same time. Satisfaction of quality requirements can be achieved via a good software architecture design.

Thus, over the last years, various approaches, processes, techniques, best practices (HOFMEISTER; NORD; SONI, 2000; KRUCHTEN, 2004; RAN, 2000; BOSCH, 2000), and 
international standard (ISO/IEC/IEEE 42010., 2010) are developed for system software architecture development process. Their descriptions use different vocabulary and appear quite different from each other and most of these software architecture development approaches are originated from the work conducted in the industry in response to needs for developing a systematic architecture development process. Architecture design methods that were developed in different domains naturally exhibit domain characteristics and emphasize different goals (DEMIR, 2015; HOFMEISTER et al., 2005). For instance, The Siemens Four-Views (S4V) method (SONI; NORD; HOFMEISTER, 1995; HOFMEISTER; NORD; SONI, 2000), developed at Siemens Corporate Research, presents four views (conceptual, execution, module, and code architecture view) that separate different engineering concepts, reducing the complexity of the architecture design task. In this case, these views are developed in the context of a recurring Global Analysis activity, where architects identifies organizational, technological, and product factors (see Figure 1) that influence the architecture, such as requirements, desired system qualities, organizational constraints, and existing technology.

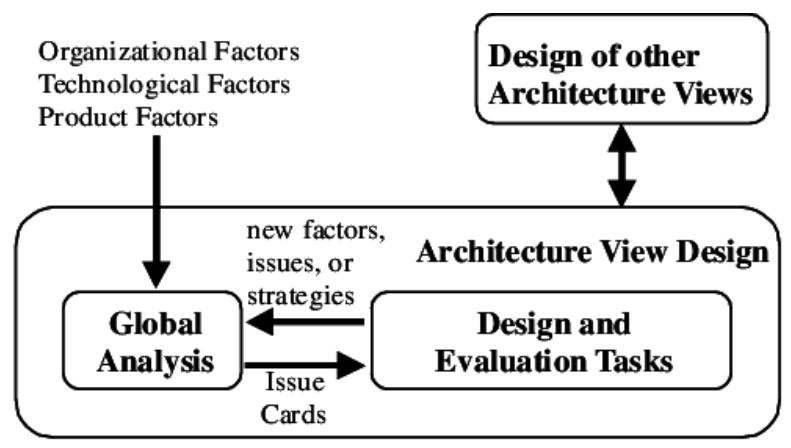

Figure 1 - Workflow between global analysis and architecture view design

(HOFMEISTER et al., 2007)

The purpose of factors is to help architects identifies all influencing factors, including not just requirements but also desired system qualities, organizational constraints, existing technology, etc. These factors are analyzed to determine which factors conflict, what are their relative priorities, how flexible and stable is each factor, what is the impact of a change in the factor, and what are strategies for reducing that impact. During design, design decisions must be evaluated, particularly for conflicts and unexpected interactions. This evaluation is ongoing. Thus, Global Analysis activities are interleaved with view design activities, and design activities of each view are also interleaved.

On the other hand, The Rational Unified Process (RUP) is a software development process developed by Rational Software (now IBM), and includes an architectural design method using the concept of 4+1 views (RUP 4+1) (KRUCHTEN, 2004; KRUCHTEN, 1995), as illustrated in Figure 2.

These views are: logical view, process view, implementation view, and deployment view, in addition a use-case view to relate the design to the context and goals. In this process, 


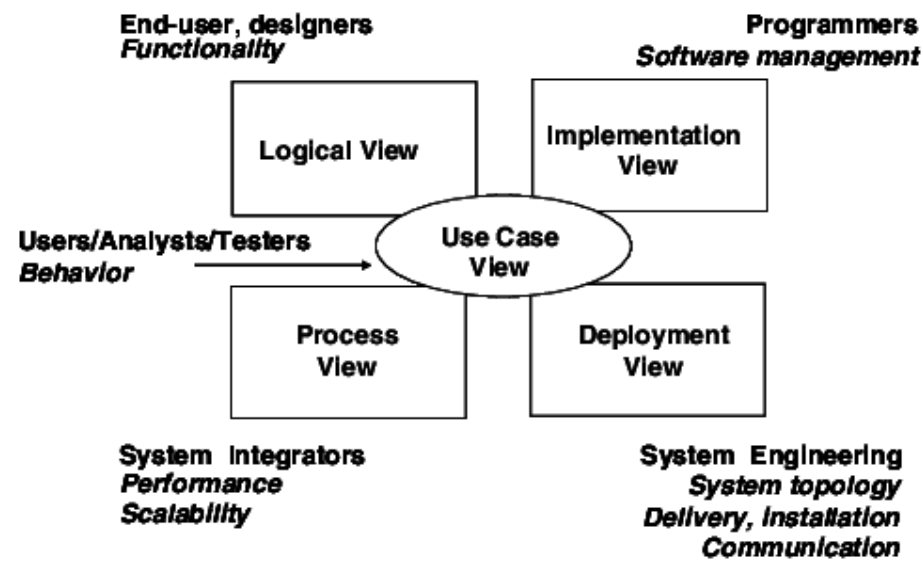

Figure 2 - RUP's 4+1 views

(KRUCHTEN, 2004)

architectural design is spread over several iterations in an elaboration phase, iteratively populating the 4 views, driven by architecturally significant use cases, nonfunctional requirements in the supplementary specification, and risks. Each iteration results in an executable architectural prototype, which is used to validate the architectural design.

Another approach proposed to assist the architecture design is a conceptual framework based on separation of concerns to manage complexity of architecture design, called ARES System of Concepts (RAN, 2000), developed primarily by Nokia. This framework relies on the fact that concerns related to different segments of the software transformation cycle (typically including design, build, upgrade, load, and run time) are often separable. Stakeholders goals are analyzed and the goals that have impact on the architecture are refined into architecturally significant requirements (ASRs). These requirements are grouped under a set of concerns. During the development, how to address each concern and the effects on the architecture are investigated. Each concern is addressed via an architectural solution. In this approach, the development is viewed as a set of transformations that software artifacts turn into other software artifacts. During transformations, architecture evolution is closely controlled, verified, and validated.

In particular, (HOFMEISTER et al., 2007) generalized a model for software architecture design where activities of architectural analysis, synthesis, and evaluation play an important role to the successful deployment of the architectures and, therefore, to the remainder activities of the software development. These activities are not executed sequentially, instead they are conducted repeatedly in many levels of granularity until the architecture is complete and evaluated (HOFMEISTER et al., 2007). The overall process is shown in Figure 3, concerning the three main activities and their input/output artifacts.

\section{Architectural Analysis}

Architectural analysis has as its main objective the definition of problems that the architecture must solve. For this, architectural concerns and the context are examined, and ASRs 


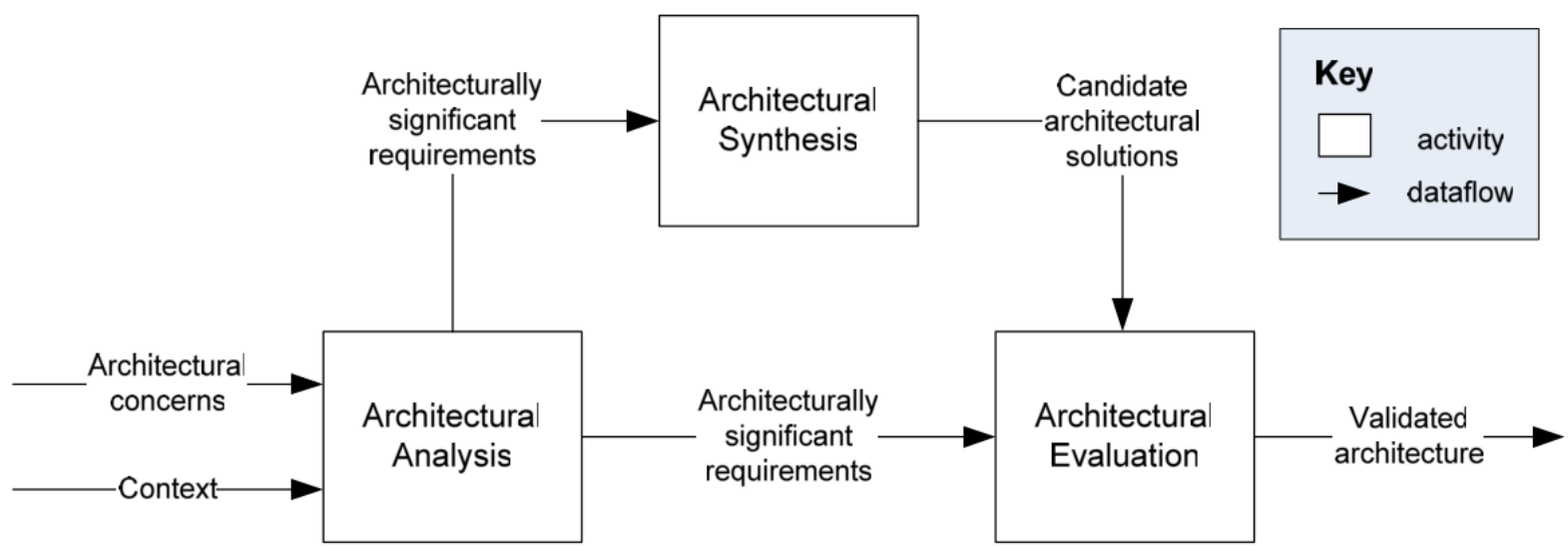

Figure 3 - Architectural design activities

(HOFMEISTER et al., 2007)

are then gathered. Architectural concerns consist of interests in a system relevant to one or more of its stakeholders (ISO/IEC/IEEE 42010., 2010), including system considerations on quality attributes, such as performance and reliability. Most of them are normally expressed as system requirements, but can be expressed in form of design decisions, such as the use of existing standards. Requirement documents are also source of architectural concerns, but they are not likely to be of much use, since their main function is to provide functional requirements (BASS; CLEMENTS; KAZMAN, 2012). The context is all circumstances of developmental, operational, political, and other influences upon a system (ISO/IEC/IEEE 42010., 2010). This context includes business goals (e.g., reduce in production costs and improvement in market position) and characteristics of the organization (e.g., skill of developers and tools available for software development) (HOFMEISTER et al., 2007). The distinction of concerns and the context is sometimes whether it is specifically desired for the system, in this case it's a concern, or is instead, a general characteristic or goal of the organization or a stakeholder, that is not desired for the system (HOFMEISTER et al., 2007).

ASRs gathered/outputted in this activity are requirements that will profoundly affect the architecture, molding it (BASS; CLEMENTS; KAZMAN, 2012). There are three major approaches to gather ASRs during architectural analysis (BASS; CLEMENTS; KAZMAN, 2012). The first and most obvious one is to look at requirements document. Although this approach is not of much help, some ASRs can in fact be gathered off these documents. Secondly, ASRs may be gathered by interviewing stakeholders. In this context, Quality Attribute Workshop (QAW) is a method that engages system stakeholders (e.g., end-users, database administrators, acquirers, software engineers, etc) during early development of software-intensive systems, to discover quality attributes that will drive the design phase. The number of stakeholders varies from five to 30 for a single workshop. Each of them receives a handbook providing examples of quality attribute taxonomies (i.e., quality models), questions, and scenarios. If necessary, this handbook may be customized to the system domain, therefore, its content should be appropriate for the domain and the architectural detail level. During the workshop session, every stakeholder is 
encouraged to intensively participate on the discussion, asking questions if necessary. However, facilitator may have to interrupt if discussions are taking so much time or when it is not focused on QAW outcomes. Finally, ASRs can be gathered from business goals. In this approach, the focus is on what firstly motivates the development of a software system. Pedigreed Attribute eLicitation Method (PALM) is used to derive quality attribute requirements (ASRs) from business goals. PALM has two purposes: (i) give a clear and full picture of the operative business goals to architects and (ii) uncover difficult requirements that may not be necessary, since they do not support any important business goal. The output of PALM is a prioritized list of business goals and associated quality attribute requirements.

\section{Architectural Synthesis}

While architectural analysis articulates ASRs based on the architectural concerns and context, architectural synthesis results in candidate architectural solutions that address these requirements, reflect design decisions about the structure of software, and include information about the design rationale (e.g., commentary on why decisions were made, what decisions were considered and rejected, and traceability of decisions to requirements) (HOFMEISTER et al., 2005).

\section{Architectural Evaluation}

The goal of architecture evaluation is to ensure that architectural design decisions made on architectural synthesis are the right ones to enable achievement of both functional and nonfunctional requirements. For this, candidate architectural solutions are verified upon ASRs outputted from architectural analysis. At the end of multiple iterations, which consist of acceptance or disapproval of candidate solutions, validated architecture is expected as result (HOFMEISTER et al., 2005).

Some approaches to evaluate software architectures were proposed (KAZMAN; KLEIN; CLEMENTS, 2000; Kazman, R. and Asundi, J. and Klein, M., 2001; HEESCH et al., 2014). (BOSCH, 2000) identified four main groups for these evaluation approaches: (i) experiencebased methods that are based on previous experience and domain knowledge of the evaluation team; (ii) simulation-based methods that typically rely on a high level implementation of the software architecture; (iii) mathematical modeling methods that use mathematical proofs to evaluate operational quality requirements, such as performance and reliability; and (iv) scenariobased methods that evaluate a particular quality attribute by creating scenario profiles. Each scenario describes an intended use of the system by means of a concrete description of quality requirements. These scenarios support identification of architectural risks and their potential consequences through an efficient and scalable way. Example of these methods are ATAM (KAZMAN; KLEIN; CLEMENTS, 2000), CBAM (Kazman, R. and Asundi, J. and Klein, M., 2001), and DCAR (HEESCH et al., 2014).

In the context of software architecture, reference architectures can be considered as 
knowledge repositories of a given domain, promoting the reuse of knowledge and supporting the development of software systems. In the next section, reference architecture is discussed in more detail.

\subsection{Reference Architecture}

One of the first definitions of reference architectures that was described Kruchten04 said that "a reference architecture is, in essence, a predefined architectural pattern, or set of patterns, possibly partially or completely instantiated, designed and proven for use in particular business and technical contexts, together with supporting artifacts to enable their use. Often, these artifacts are harvested from previous projects". In another perspective, (MüLLER, 2008) described that reference architecture provides: (i) a common lexicon and taxonomy, for example, by a domain model; (ii) a common (architectural) vision; and (iii) modularization and complementary context. "The common lexicon and taxonomy facilitate communication across multiple dimensions. The common (architectural) vision focuses and aligns efforts of multiple people and teams. Modularization helps to divide the effort, where the context information ensures later integratio" (MüLLER, 2008). Another definition was proposed by (BASS; CLEMENTS; KAZMAN, 2012) and states that "a reference architecture is a reference model mapped onto software elements (that cooperatively implement the functionality defined in the reference model) and the data flows between them".(ANGELOV; GREFEN; GREEFHORST, 2009) think that "a reference architecture is a generic architecture for a class of information systems that is used as a foundation for the design of concrete architectures from this class".

To complete these definitions, more recently, (NAKAGAWA; OQUENDO; MALDONADO, 2015) described reference architecture as an architecture that encompasses the knowledge about how to design concrete architectures of systems of a given application domain; therefore, it must address business rules, architectural styles (sometimes also defined as architectural patterns that can also address quality attributes in the reference architecture), best practices of software development (for instance, architectural decisions, domain constraints, legislation, and standards), and software elements that support development of systems for that domain; all of these must be supported by a unified, unambiguous, and widely understood domain terminology. However, sometimes, the terms reference architecture, reference model, and product line architecture are used interchanged.

- Reference architecture versus Reference Model A reference model can be considered as an abstract framework that presents a set of unifying concepts, axioms, and relationships within a particular problem domain, independently of specific standards, technologies, implementations, or other concrete details (BASS; CLEMENTS; KAZMAN, 2012).

According to (NAKAGAWA; OQUENDO; MALDONADO, 2015), based on one or more existing reference models together with other elements, such as domain expert knowledge, 
architectural styles, and software elements, a reference architecture can be created, as illustrated in Figure 4. Using this architecture as basis, concrete architectures can be created. However, it is worth saying that it is not necessary to previously have these reference models to create reference architectures.

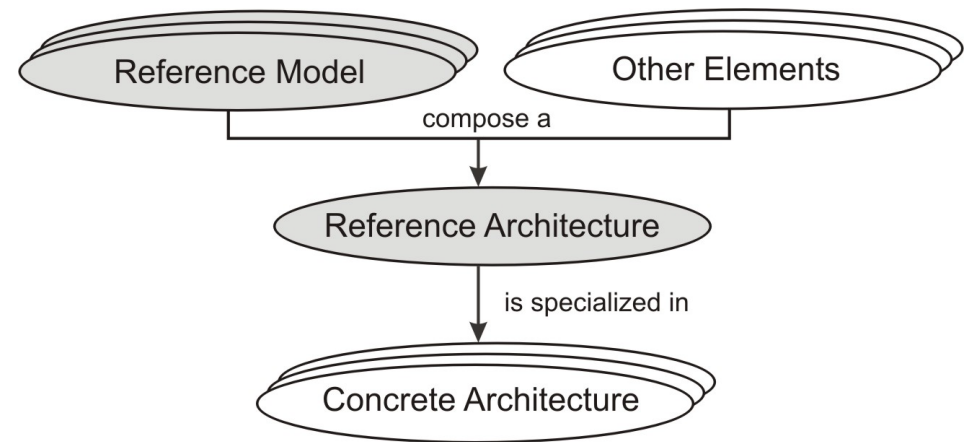

Figure 4 - Reference architecture $v s$ reference model (NAKAGAWA; OQUENDO; MALDONADO, 2015)

- Reference Architecture versus Product Line Architecture Various synonyms are used for the term "product line architecture", such as software product line architecture, domainspecific software architecture, domain architecture, and even reference architecture in (POHL K.AND BOCKLE; LINDEN, 2005) and (DEBAUD; FLEGE; KNAUBER, 1998). However, it seems that "product line architecture" is a term that fits best in the Software Product Line (SPL) context. In parallel, there are also different definitions of this term (NAKAGAWA et al., 2011a). DeBaud et al. (DEBAUD; FLEGE; KNAUBER, 1998) say that product line architecture is an architecture with a required degree of flexibility and is shared by all the members of a product line, ensuring their conceptual integrity. In a similar way, (GOMAA, 2004) described that "product line architecture is an architecture for a family of products, which describes the kernel, optional, and variable components in the SPL, and their interconnections". Software Engineering Institute (SEI, 2017) declares that "The product line architecture is an early and prominent member in the collection of core assets. (...) The architecture defines the set of software components (...) that populates the core asset base. The product line architecture - together with the production plan provides the prescription (...) for how products are built from core assets".

While reference architectures deal with the range of knowledge of an application domain, providing standardized solutions for a broader domain, product line architectures are more specialized, focusing sometimes on a specific subset of the software systems of a domain and providing standardized solutions for a smaller family of systems (NAKAGAWA; OQUENDO; MALDONADO, 2015). Another essential difference is that product line architectures are concerned with the variabilities among products. Furthermore, reference architectures are generally on a higher level of abstraction compared to product line architectures. In (NAKAGAWA; OQUENDO; MALDONADO, 2015), reference architectures 


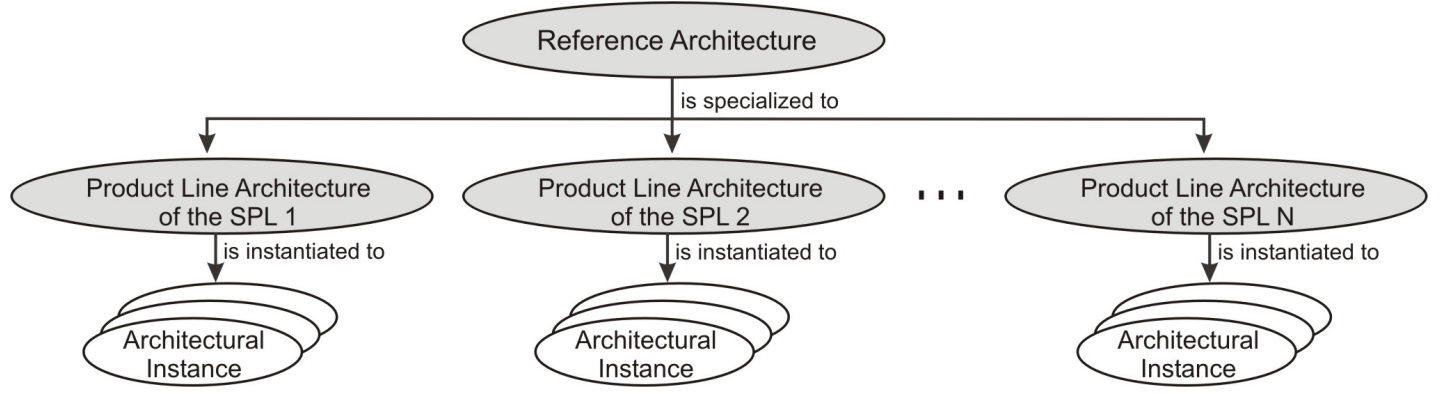

Figure 5 - Reference architecture $v s$ product line architecture (NAKAGAWA; OQUENDO; MALDONADO, 2015)

are considered as a basis for product line architectures, as illustrated in Figure 5. A reference architecture can be specialized to different product line architectures, each for a specific SPL. Besides product line architectures, reference architectures can be used as basis of other elements of the core assets of SPL; for example, variability model, products feature list, products description, and product line components can be created using knowledge contained in reference architectures (NAKAGAWA; ANTONINO; BECKER, 2011).

\subsubsection{Types of Reference Architectures}

Because of the diversity of reference architectures, (ANGELOV; GREFEN; GREEFHORST, 2009) proposed a framework to classification of these architectures in terms of relationships between their context, goals, and architecture design/specification.

To determine the context of a reference architecture are investigated the design and application aspects that can affect your business objectives and architecture specification. These aspects include (ANGELOV; GREFEN; GREEFHORST, 2009): (i) for how many organizations the reference architecture matters, i.e., whether for a single organization or multiple organizations; (ii) categories of stakeholders involved in the design of this architecture, i.e., software organizations, user organizations, research centres, or a standardization organizations; and (iii) when the reference architecture is defined, i.e., before (named preliminary) or after (named classical) of the existence of concrete architectures of the application domain.

To determine objectives of a reference architecture, reasons are evaluated for which this architecture was proposed, i.e., standardization of concrete architectures (aiming at system/component interoperability) or facilitation of the concrete architecture's design (aiming at providing guidelines for the design of systems in the form of blueprints, patterns, etc.).

Finally, to determine the reference architecture's project, are evaluated (ANGELOV; GREFEN; GREEFHORST, 2009): (i) the content of these architectures, i.e., if their describes components, interfaces, protocols, algorithms and/or policies and guidelines; (ii) the level of detail at which the elements of a reference architectures can be defined, i.e., detailed, semi- 
detailed, or aggregated; (iii) the possible levels of abstraction of a reference architecture, i.e., concrete, semi-concrete, and abstract; and (iv) the possible levels of formalization of reference architectures, which can be informal, semi-formal, or formal.

Based on the combinations for the possible values of each criterion, five types of reference architectures were identified:

- Type 1: are classical, standardization architectures designed to be implemented in multiple organizations. Representative sets of user and software organizations should be involved in the architecture definition as standardization requires a consensus in order to be successful. Reference architectures from this type contain a description of the components and interfaces as these are the elements that are target of standardization. Components are defined at a high level of aggregation as standardization of internal component details is unnecessary. Interfaces are defined at more detailed levels as their precise specification is crucial for achieving interoperability. Besides that, type 1 reference architectures are abstract as each organization has the freedom to select the concrete implementation details according to its own settings, and are semi-formal in order to provide a clear standard specification and to allow stakeholders who typically are inexperienced in strong formalization techniques to understand them.

- Type 2: are classical, standardization architectures designed to be implemented in a single organization. These reference architectures are designed to serve as a standardization tool for the design of a set of software solutions within the organization. Representatives of all stakeholders should be involved (software users and designers from the organization, for example). In this case, software designers may be working on a temporary basis for the organization, e.g., on a consultancy project basis. Reference architectures from type 2 define architectural components and interfaces, and are semi-formal. In addition, concrete organization-specific policies and guidelines are defined that will facilitate the usage of the architecture in the organization. The elements of these architectures can be defined at any level of aggregation depending on the specific organization context.

- Type 3: are classical, facilitation reference architectures for multiple organizations designed by a software organization in cooperation with user organizations. Type 3 reference architectures are designed to promote a software product of the designing organization by describing its main components and interfaces, and providing guidelines for their implementation. As a result, these architectures are concrete, with aggregate components and interfaces and detailed guidelines. Besides that, are semi-formal as they should be easily understood but still provide a clear specification of the architecture.

- Type 4: are classical, facilitation architectures designed to be implemented in a single organization. Are designed only as a facilitation (guidance) tool in the design and implementation of systems in the organization. Their facilitation role makes their preferred 
representation to be semi-formal or even informal. An aggregated or semi-detailed component design suffices for achieving the architecture facilitation goal. As they are designed for a concrete organization, they can be technology independent (abstract) or indicate technology choices (semi-concrete, concrete).

- Type 5: are preliminary, facilitation architectures designed to be implemented in multiple organizations. They are designed to facilitate the design architectures of systems that will become needed in the future. As these architectures are preliminary, research centres are typically leading the design effort. These reference architectures are innovative in their nature and have to define the components requires in a system implementing it, algorithms that can be used to support the operation of the components, and protocols that demonstrate the interactions among the components. These elements have to be detailed as they have to provide details for the innovative aspects they define. Besides that, unambiguousness and evidences for their qualities are important to convince the usage of the architecture for the design of the first systems from this class. That is why they are formal or semi-formal architectures.

The match of a reference architecture with one of these types is a pre-condition for its effective usage in the design of concrete architectures. This framework can be used as a tool for the analysis of existing reference architectures and identification of the reasons for their level of success. In addition, the framework can be used as a tool before and during the definition of reference architectures, indicating potential deviations in their congruence between goals, context, and design (ANGELOV; GREFEN; GREEFHORST, 2009).

\subsubsection{Uses of Reference Architectures}

According to (MüLLER, 2008), the level of abstraction of reference architectures makes it more difficult to understand their role. Figure 6 shows an example of instantiations that are needed to transform reference architecture into actual systems.

The first step is to instantiate a system architecture based on a reference architecture. This system architecture is used to design and engineer a system, resulting in engineering documentation that describes how the system can actually be ordered, assembled, and tested. (MüLLER, 2008) points out that creation and evolution of reference architectures is strongly feedback based. Field feedback from actual systems results in updates of the engineering documentation. The design and engineering efforts provide constraints on architectures, but also open opportunities. Finally, the reference architecture itself is largely a mining and extraction effort of existing architectures.

(NAKAGAWA; OQUENDO; MALDONADO, 2015) list five purposes that have guided the adoption and use of reference architectures, namely: 


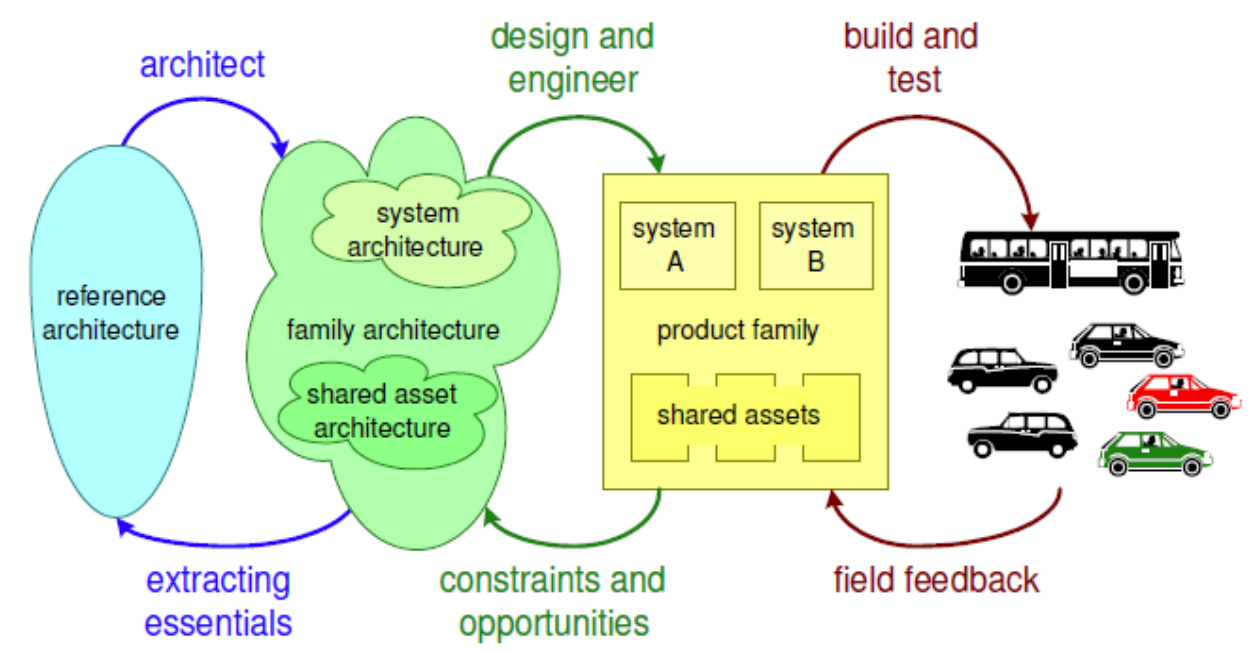

reference

architectures

architecture

\section{engineering documentation}

actual systems

Figure 6 - Instantiation of a Reference Architecture (MüLLER, 2008)

- Building Software Systems: Reference architectures can be considered an important basis from which concrete architectures of software systems are built. For this, activity of instantiation of reference architectures are conduced. In short, instantiation of reference architectures refers to tasks of: (i) reading and understanding the documentation related to the reference architecture; (ii) selecting the whole architecture or their parts that are interesting to be present in the software system to be developed; (iii) refining and adapting the architecture or their parts, using the specification of the software system, including requirements, constraints, context of applications, and so on; (iv) documenting the architectural instance; (v) evaluating the architectural instance; and (vi) concreting the architectural instance, through implementation.

- Domain Standardization: Reference architectures have been adopted as a means to standard software systems of a given domain. This standardization has occurred in the interfaces among subsystems that must establish communications, composing a more complex, large system. Moreover, reference architectures have also established the external interfaces of systems that are built based on these architectures, facilitating the integration of these systems with other ones. Therefore, reference architectures have promoted internal and external interoperability in software systems.

- Evolution of Existing Software Systems: The most software systems present evolution as a natural, needed process, mainly in successful systems. These systems evolve by several purposes, for instance, to adapt to new contexts, modify their functionalities, improve their quality, and so on. During this process, the reuse of knowledge about how to evolve them is certainly important. Reference architectures can be used in this context. In general, for this, it is necessary: (i) selection of one or more reference architectures, if they 
were not selected before; (ii) study of related documentation of these architectures; (iii) investigation of parts/elements contained in the reference architectures that could comply with the requirements of the required evolution; (iv) instantiation of these parts/elements through refinements and adequation; and (v) implementation of such parts/elements.

(NAKAGAWA; OQUENDO; MALDONADO, 2015) highlight that successful use of a reference architecture in this context depends directly on if this architecture matches with the domain of the system to be evolved and also depend on the quality of such architecture. It is also interesting that this architecture has proven experience of use to build software systems.

- Deriving New Reference Architectures: Existing reference architectures can be used as basis to derive new reference architectures, in particular, for the same domain or neighbor ones. For instance, a reference architecture that has as basis a specific architectural style (such as Client-Server) can be derived to an architecture that has the service-oriented architectural style. In this case, modules must be probably mapped to services and other issues that appear with service orientation must be solved, such as quality of service (QoS), orchestration and choreography, publication and discovery of services. Notice that elements contained in previous architectures can be reused and adapted to the new architectures. Reduction in efforts can also be achieved with this approach, mainly when the previous architectures are more mature and have already been successfully used. An example is the establishment of a service-oriented reference architecture for software testing tools (OLIVEIRA; NAKAGAWA, 2011) derived from a previous architecture for testing tools (NAKAGAWA et al., 2007), which was based on two architectural styles: three-tier architecture and MVC.

- Suporting the Building of SPL: Reuse in the large is an important concern in Software Product Line Engineering (SPLE) and, at the same time, in fact, reference architectures have presented a considerable, valuable body of knowledge about how to structure systems of a domain and, therefore, they can be considered as important elements to be reused. In this scenario, the combination of reference architectures and SPL is interesting. In particular, the use of existing reference architectures as basis of SPL can be explored. Reusing knowledge contained in these architectures can contribute to reduce the effort required to build SPL artifacts, such as the variability model and the PL architecture, and, therefore, improve productivity during SPLE.

Hence, a Reference Architecture is created with a certain scope in mind, e.g. a domain of a set of applications. In this scope the reference architecture links to relevant standards, legislation, domain constraints and mandatory framework (MüLLER, 2008). The next section will address examples of reference architectures proposals for different application domains. 


\subsubsection{Examples of Reference Architectures}

Designed for various application domains and purposes, reference architectures have increasingly impacted important aspects of software systems development, such as productivity and quality of these systems (NAKAGAWA; OQUENDO; MALDONADO, 2015). Good examples of reference architectures are AUTOSAR (AUTomotive Open System ARchitecture) (AUTOSAR., 2017), for automotive domain, and Continua (CONTINUA., 2017) and UniversAAL (UNIVERSAAL, 2017) for ambient assisted living (AAL) (BROEK; CAVALLO; WEHRMANN, 2014), DRA 5.0 (Mars Design Reference Architecture) (DRAKE; HOFFMAN; BEATY, 2010) for spacial exploration, and ARC-IT (Architecture Reference for Cooperative and Intelligent Transportation) (USA, 2018) for intelligent transportation systems. These architectures were developed by consortiums that involve major industrial players (such as manufacturers and suppliers) and researchers. In particular, ARC-IT is described in more details in Chapter 6.

Other example of reference architecture is Nexof-RA project ${ }^{1}$ (STRICKER et al., 2010), for service-based systems. On the other hand, more specific reference architectures can be found, e.g., reference architectures for e-contracting (ANGELOV; GREFEN, 2008), security (FAEGRI; HALLSTEINSEN, 2006), web browsers (GROSSKURTH; GODFREY, 2005) and software engineering environments (NAKAGAWA et al., 2011b). Recently, reference architectures have also been proposed to assist in the development of solutions for the Internet of Things (ADOLPHS; EPPLE, 2015; CONSORTIUM, 2017a), which brings up challenges, such as specific software interfaces and software dependability, requiring particular approaches for security, maintainability, and sustainability (WEYRICH; EBERT, 2016).

Besides that, others architectures not related to the specific application domain have also been proposed and widely used as reference architecture. Some good examples are OASIS (BROWN et al., 2012), S3 (ARSANJANI et al., 2007), and IBM's SOA Foundation (HIGH; KINDER; GRAHAM, 2005) for software systems based on SOA (Service-Oriented Architecture) (PAPAZOGLOU et al., 2008), and OSGi (Open Services Gateway initiative framework) (ALLIANCE, 2017), a set of specifications and a layered architecture that define dynamic component systems for Java.

\subsubsection{Designing Reference Architectures}

Despite their relevance, reference architectures have been currently developed without an adequate attention, concern or an a priori knowledge of what should be in fact contained in these architectures, i.e., an ad-hoc approach has been commonly adopted (NAKAGAWA; OQUENDO; MALDONADO, 2015; REED, 2002). Thus, reference architectures have presented different formats regarding elements that they contain. Many architectures present a general structure; however, not all present important information, such as architectural decisions and a terminology

$1<$ http://www.nexof-ra.eu/> 
adopted in the domain. Thus, for designing an effective reference architecture the assignees should consider not only the systems to be designed when defining goals, but also the context in which the architecture is defined and the goals of the architecture itself. Therefore, models could support the reference architecture development, since their developers could have an outline about what could or should be inserted in such architectures. In this sense, (ANGELOV; GREFEN; GREEFHORST, 2009) described a framework that provide a basis for the design of more successfull reference architecture. The framework is constructed with the aim to support analysis of reference architectures in terms of relationships between their context, goals, and architecture design/specification. In short, this framework can be used as a tool for analysis of existing reference architectures and identification of reasons for their level of success. However, this framework does not address the evolution of existing architectures, or their adaptation and refinement.

On the other hand, (NAKAGAWA; OQUENDO; BECKER, 2012) proposed a reference model for reference architectures, named RAModel (Reference $\underline{\text { Architecture Model). }}$.

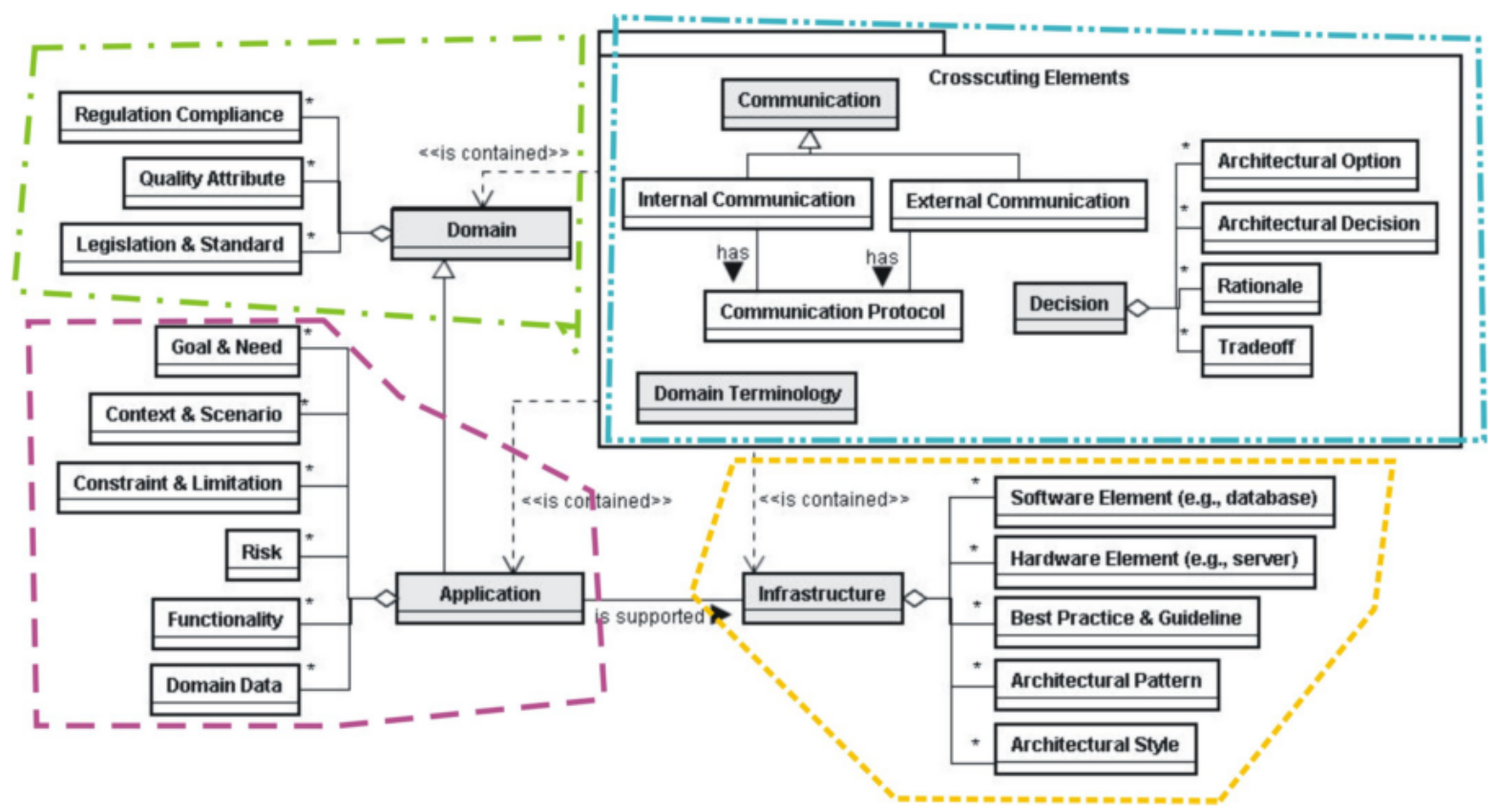

Figure 7 - Structure of RAModel

(NAKAGAWA; OQUENDO; MALDONADO, 2015)

RAModel is a reference model for reference architectures, providing information on the elements and their relationships that could be contained in reference architectures, supporting the establishment, use, and evolution, independently from the application domains or purpose of such architectures. As illustrated in Figure 7, RAModel is composed by four groups of elements (NAKAGAWA; OQUENDO; BECKER, 2012):

- Domain: It contains elements related to self-contained, specific information of the space of human action in the real world, such as domain legislations, standards, and certification 


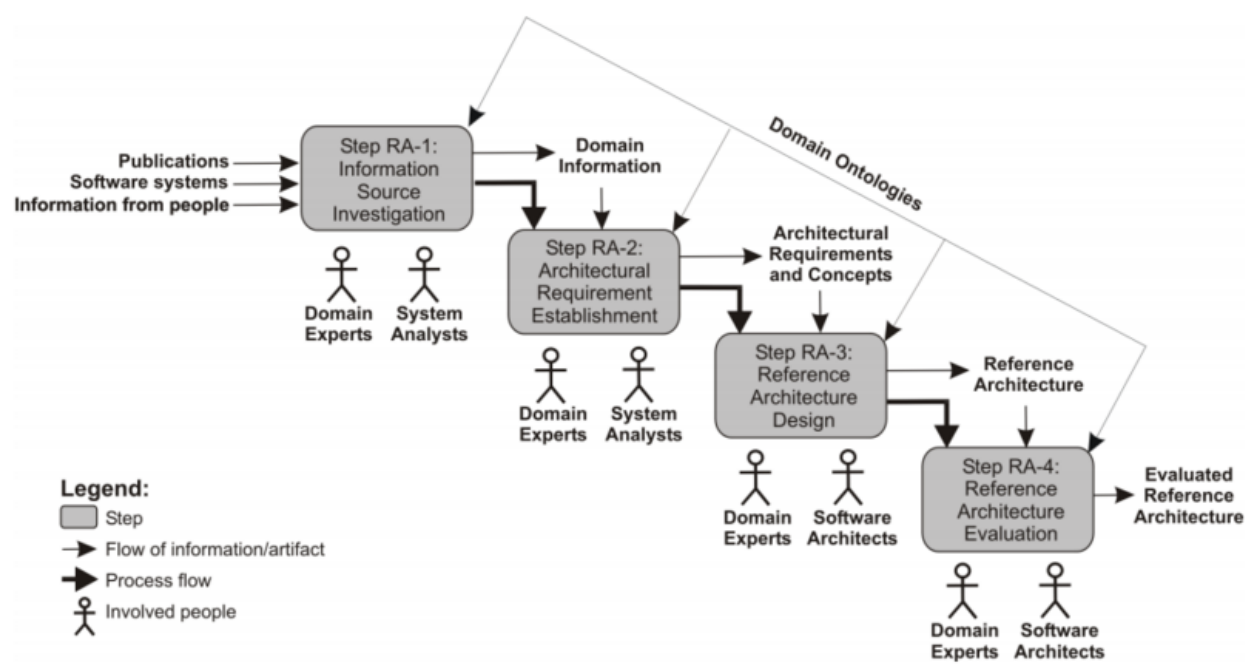

Figure 8 - Structure of ProSA-RA

(NAKAGAWA et al., 2014)

processes, which impact systems and related reference architectures of that domain;

- Application: It contains elements that provide a good understanding about the reference architecture, its capabilities and limitations. It also contains elements related to the business rules (or functionalities) that can be present in software systems built from the reference architecture;

- Infrastructure: It refers to elements that can be used to build the software systems based on the reference architecture. These elements are responsible to enable these systems to automate, for instance, processes, activities, and tasks of a given domain; and

- Crosscuting Elements: It aggregates a set of elements that are usually spread across and/or tangled with elements of other three groups (domain, application, and infrastructure). The communication (that we have identified as internal and external) in the software systems built from the reference architecture, as well as the domain terminology and decisions are present in a spread and tangled way when describing other groups and are, therefore, crosscutting elements.

Considering that RAModel contains possibly all important elements in reference architectures, four main perspectives to use it exist: (i) analysis of reference architecture; (ii) comparative analysis of reference architectures; (iii) suport to the design of SPL (Software Product Line); and (iv) basis for the establishment of reference architectures.

Once these initiatives focus developers on the elements and essential components in a reference architecture, systematizing their building is certainly interesting, aiming at achieving more effective reference architectures, i.e., architectures that could more completely attempt their purpose. In this context, recommendations can be found in (MULLER, 2008; TRIENEKENS et 
al., 2011; REED, 2002; BAYER et al., 2004); however, they are in general high-level guidelines, principles, and recommendations or they are domain-specific processes and, perhaps because this fact, they have not been widely adopted yet.

In this scenario, (NAKAGAWA et al., 2014) presented a process, named ProSA-RA, for the building of reference architectures, focusing on how to design, represent, and evaluate such architectures.

In short, four steps compose this process. Firstly, information sources are selected and investigated (Step RA-1). Secondly, the architectural requirements of the reference architecture are identified (Step RA-2), describing the common functionalities and configurations presented in systems of the target domain. Following, the architectural description of the reference architecture is established (Step RA-3) and an evaluation of the resulting architecture is conducted (Step RA4). The structure of ProSA-RA is illustrated in 8 . Since then, ProSA-RA has been already applied in the establishment of reference architectures for different domains and also supported the evolution of existing ones. Besides that, ProSA-RA considers readability and understandability of reference architectures as fundamental to their dissemination, reuse, and future evolution.

\subsection{Final Remarks}

As presented in this Chapter, software architecture is a fundamental discipline for system development. This is emphasized when the system in question is large, complex, and has many stakeholders involved. Additionally, architectural processes were described, including activities that play an important role to the successful development. These activities are very important during architectural design, and deal directly with quality concerns, such as quality attribute requirement. This emphasize the importance of having a good understand on software quality.

This chapter also defined reference architectures and their relevance and impact in the systems development. In addition, presented conceptual differences between reference architecture, product line architecture, and reference model. Good examples of reference architectures were described for various applications domain. However, there is a lack of work dealing specifically with evolution of reference architectures (NAKAGAWA; OQUENDO; MALDONADO, 2015; KOZIOLEK et al., 2013; NAUMANN et al., 2011).

Focusing attention on proper evolution of reference architectures means to contribute to the quality of the resulting software systems from these architectures. Hence, it is quite interesting to be able to measure the sustainability of these architectures, because sustainability can be one of the ways to prolong the life of reference architectures. As important as the process of establishing these architectures is their longevity, which includes their life-cycle and their maintenance capacity. Therefore, next chapter provides a background about sustainability in the context of software and reference architectures. 
CHAPTER

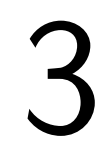

\section{SUSTAINABILITY IN THE CONTEXT OF SOFTWARE AND REFERENCE ARCHITECTURES}

\subsection{Initial Remarks}

Over the last decades, sustainability has emerged as an interdisciplinary area and knowledge about how to achieve sustainable development has grown, while political actions are still in growing discussion (HILTY; LOHMANN; HUANG, 2011). A sustainable world is broadly defined as one in which humans can survive without jeopardizing the continued survival of future generations of humans in a healthy environment (BROWN; HANSON; LIVERMAN, 1987). This view of sustainability allows us to consider the implications of, and necessities for, human existence in the world (PENZENSTADLER et al., 2014). In a broader sense, sustainable development requires the decoupling of economic growth from environmental impacts and from the use of natural resources (HILTY; LOHMANN; HUANG, 2011). In particular, given that decoupling is a basic condition for sustainable development, an analysis of the relationship between Information and Communication Technology (ICT) and sustainable development should then focus on the potential contribution of ICT to implement decoupling strategies. Although there is not much political attention being paid to the ICT for sustainability issue, there are scientific voices pointing out the crucial role that ICT could play for sustainable development in the future. The basic idea is that the distinction of hardware and software in ICT, which is essentially the difference between material and immaterial resources, and the way in which value is created with software could become a paradigm for the decoupled economy of the future (HILTY; LOHMANN; HUANG, 2011). According to (HILTY; HERCHEUI, 2008), the longterm availability of ICT services may enable and foster a transition to a less material-intensive economy. 
In another perspective, sustainability can be also discussed with reference to a concrete system, such as an ecological system, a human network, or a specific software system (PENZENSTADLER et al., 2014). In this sense, global sustainability implies the capacity for endurance given the functioning of all these systems in concert. More specifically, Software Engineering (SE) for Sustainability has developed as a current focus of research as a result of software engineers engaging in issues regarding the impact of software systems on global sustainability (PENZENSTADLER et al., 2014; AMSEL et al., 2011). The goal with sustainable software engineering is to create better software so we will not have to compromise future generation's opportunities (AMSEL et al., 2011).

Sustainability began to play an important role in SE with the ICSE (International Conference on Software Engineering) 2009 Software Engineering for the Planet special session, and the 2009 and 2010 Workshops on Software Research and Climate Change (the latter of which was collocated with ICSE) (AMSEL et al., 2011). Since then, several research initiatives have explored sustainability in the area of Software Engineering (CABOT et al., 2009; BOMFIM et al., 2014; BECKER et al., 2014; CALERO; BERTOA; MORAGA, 2013; NAUMANN et al., 2011; PATRICIA et al., 2014; KERN et al., 2013; AKINLI; ALPTEKIN; BASAR, 2014). In this context, a community interested in sustainability created a document for initiating a conversation among different communities aiming at addressing the challenges of developing sustainable software systems (VENTERS et al., 2015). This document was known as The Karlskrona Manifesto for Sustainability Design (BECKER et al., 2014) and was proposed as a vehicle to be used for effectively communicating key issues, goals, values, and principles of sustainability design (VENTERS et al., 2015). This manifesto proposes principles and commitments (VENTERS et al., 2015; BECKER et al., 2014):

- Sustainability is systemic: Sustainability is never an isolated property. Systems thinking has to be the starting point for the trans-disciplinary common ground of sustainability;

- Sustainability has multiple dimensions: Dimensions are analysed to understand the nature of sustainability in any given situation;

- Sustainability transcends multiple disciplines: Working in sustainability means working with people from across many disciplines, addressing the challenges from multiple perspectives;

- Sustainability is a concern independent of the purpose of the system: Sustainability has to be considered even if the primary focus of the system under design is not sustainability;

- Sustainability applies to both a system and its wider contexts: There are at least two spheres to consider in system design: (i) the sustainability of the system itself; and (ii) how it affects sustainability of the wider system of which it will be part; 
- Sustainability requires action on multiple levels: Whenever measures are taken for sustainability, consideration should be given to opportunity costs - action at other may offer more effective forms of intervention;

- System visibility is a necessary precondition and enabler for sustainability design: Status of the system and its context should be visible at different levels of abstraction and perspectives to enable participation and informed responsible choice;

- Sustainability requires long-term thinking: Benefits and impacts at multiple timescales should be evaluated and long-term indicators included in the evaluation and decisions; and

- It is possible to meet the needs of future generations without sacrificing the prosperity of the current generation: Innovation in sustainability can play out as decoupling present and future needs. By moving away from the language of conflict and the trade-off mindset, it is possible identify and enact choices that benefit both present and future.

Despite this, the lack of sustainability in SE is clearly observed in the trade-off between short-term interests and long-term benefits (BECKER et al., 2014; LAGO et al., 2015). Besides that, sustainability is not supported by traditional SE methods and this lack of support leads to inefficient efforts to address sustainability or complete omission of this important concept (PENZENSTADLER, 2013).

In this scenario, the literature has indicated dimensions of sustainability aiming to understand its nature in any situation. Some authors (LAGO et al., 2015; RAZAVIAN; PROCACCIANTI; TAMBURRI, 2014) consider only four dimensions, namely economic, social, environmental, and technical sustainability. Others authors (OJAMERUAYE; BAHSOON; DUBOC, 2016; BECKER et al., 2014; PENZENSTADLER et al., 2014) present a description with five dimensions, adding the individual dimension of sustainability to the four mentioned above. Next section presents all these dimensions.

\subsection{Dimensions of Sustainability}

Current literature emphasizes the need of a multi-dimensional approach on sustainability:

\section{Social sustainability}

(LAGO et al., 2015) describe that social sustainability focuses on ensuring that current and future generations have the same or greater access to social resources by pursuing generational equity. For software-intensive systems, it encompasses the direct support of social communities in any domain, as well as activities or processes that indirectly create benefits for social communities. In another perspective, (RAZAVIAN; PROCACCIANTI; TAMBURRI, 2014) state that social sustainability entails the resilience by which software systems uphold the fair exchange of information and social status among the actors involved in service exchanges. 
Actors in this case are considered as the people or organizations that assume a relevant role for the purpose of the service exchange. For example, a service owner is an actor during a service exchange. Also, service providers and consumers are actors during the exchange required for contractual agreements to take place. Social sustainability in this case is assured only if both parties can be guaranteed a fair and reciprocal information exchange. For example, travelers through an airport must trust on the reputation of airline companies for their baggage's location, safety and security. Airline reputation as well as traveler rights, as established by governmental rules and regulations, represent social value objects (RAZAVIAN; PROCACCIANTI; TAMBURRI, 2014). Still according to (OJAMERUAYE; BAHSOON; DUBOC, 2016), part of the social sustainability dimension considers political, organizational, and regulatory requirements, and evaluates the ability of the software systems to maintain social capital and preserve social communities and their solidarity in the way they perceive benefits of the software systems over time.

\section{Environmental sustainability}

This dimension revolves around the concept of natural resources and how e-Services make use of them. Due to the pervasive nature of ICT technologies and the worldwide scale at which they operate, software systems are more and more interacting with the natural ecosystem of our planet.(LAGO et al., 2015) describe that environmental sustainability aims to improve human welfare while protecting natural resources, such as water, land, air, minerals, and ecosystem services (BECKER et al., 2014). For software systems, this means addressing ecological requiremts, including energy efficiency and creation of ecological awareness (LAGO et al., 2015). When building a software systems, this dimension can be analysed with respect to cost of energy, efficient algorithms, and development processes (OJAMERUAYE; BAHSOON; DUBOC, 2016).

\section{Economic sustainability}

Focuses on preserving and maintaining capital and financial value (LAGO et al., 2015; BECKER et al., 2014).(RAZAVIAN; PROCACCIANTI; TAMBURRI, 2014) think that economic sustainability is about creating a positive economic value exchange between all the stakeholders participating in software systems. Hence, economic sustainability should consider budget constraints, development and operational costs, market information when available, and the long-term business goals that can relate to one or more functional and/or non-functional requirements (OJAMERUAYE; BAHSOON; DUBOC, 2016).

\section{Individual sustainability}

Evaluates the extent to which the software systems is likely to contribute and support the individual, benefiting from the system over time. Therefore, it is fundamental to consider value aspects related to human capital, e.g., health, education, skills, knowledge, leadership, and access to services (BECKER et al., 2014), while taking product management decisions (OJAMERUAYE; BAHSOON; DUBOC, 2016). 


\section{Technical sustainability,}

Addresses the long-term use of software systems and their appropriate evolution in a constantly changing execution environment (LAGO et al., 2015; RAZAVIAN; PROCACCIANTI; TAMBURRI, 2014).

(PENZENSTADLER, 2013) stated that technical sustainability has the central objective of long-time usage of systems and their adequate evolution with changing surrounding conditions and respective requirements.(VENTERS et al., 2015) proposed that technical sustainability should be considered as a measure of a system's availability, integrity, maintainability, and reliability. In the same perspective, (LAGO et al., 2015) described that technical sustainability addresses the long-term use of software systems and their appropriate evolution in a constantly changing execution environment. It is important to highlight that, in this context, the terms "maintanability" (ISO., 2011), "modifiability" (BENGTSSON et al., 2004) or "evolvability" (BREIVOLD; CRNKOVIC, 2010) are not used as synonym of sustainability because they include the notions of longevity and cos-effectiveness only to a limited extent (DURDIK et al., 2012). According to (DURDIK et al., 2012), the opposite of a sustainable software system is a long-living system that can not be adapted to changing requirements and environments due to unjustifiable costs or even technical infeasibility. Furthermore, sustainability of software systems is closely related to the sustainability of their architectures (KOZIOLEK et al., 2013).

Sustainability of software architectures has gained increasing attention to cope with factors causing architectural changes, such as requirements changes, technological changes, and changes in business strategies and goals. In this scenario, software architecture sustainability can be defined as an ability to tolerate architectural changes throughout a software life cycle (KIM; RYOO; KIM, 2014), or in another words, the architecture's capacity to endure different types of changes through efficient maintenance and orderly evolution over its entire life cycle (AVGERIOU; STAL; HILLIARD, 2013). An effective strategy to achieve sustainability is designing an architecture preemptively, so that it can accommodate future changes to a greater extent with minimal cost. Software architectures are a major driver for the sustainability (i.e., cost-ecient longevity) and evolvability (BASS; CLEMENTS; KAZMAN, 2012; TAYLOR; MEDVIDOVIC; DASHOFY, 2009), because they influence how quickly and correctly a developer is able to understand, analyze, extend, test, and maintain a software system (KOZIOLEK et al., 2013). Evaluating and improving the sustainability of software architecture is thus a major concern for software architects.

Sustainability of software architecture comprises at least the following quality attributes (KOZIOLEK, 2011): maintainability (i.e., analysability, stability, testability, and understandability), modifiability, portability, and evolvability. Moreover, sustainable software architecture can be achieved through adherence to design principles (e.g., modularity, separation of concerns, and conceptual integrity) throughout the entire life cycle. This adherence requires pro-active planning for the long life-time of the system, which can be achieved by periodic evaluations of 
evolution scenario. Therefore, it is desirable to measure the sustainability of a software architecture to determine refactoring actions and avoid poor evolution decisions (KOZIOLEK et al., 2013). However, it is difficult to express software architecture sustainability in a single metric (KOZIOLEK et al., 2013). Relevant information related to such sustainability is spread across requirements, architecture design documents, technology choices, source code, system context, and software architects' implicit knowledge (KOZIOLEK et al., 2013). Furthermore, many aspects influence sustainability, including the design decisions facilitating evolutionary changes, the adherence to good modularization practices, and all related technology choices (KOZIOLEK et al., 2013). Several approaches to improve software architecture sustainability can be found in the literature. We believe that advances obtained to understand and manage sustainability of software architectures are not sufficient for the context of reference architectures, because they are at different abstraction levels. The remainder of this chapter presents a systematic mapping study to analyze the state of art about sustainability in software architectures and reference architectures.

\subsection{Software and Reference Architecture Sustainability: a systematic mapping study}

In this section, we report the procedure accomplished in the conduction phase of our systematic mapping study (SMS), that aims to find sustainability characteristics that are considered for software architectures and reference architectures.

We used the guidelines proposed by (KITCHENHAM; CHARTERS, 2007) and (PETERSEN; VAKKALANKA; KUZNIARZ, 2015). The methodology for conducting comprises (i) research objectives; (ii) research questions; (iii) search strategy; (iv) selection criteria; (v) quality assessment; (vi) selection of studies; and (vii) analysis of results. The protocol we followed can be found in Appendix A .

\subsubsection{Conduction}

After adapting and executing the search strings for each search engine, we found 1591 studies that match our search terms, as detailed in Figure 9.

After that, we removed duplicated entries, remaining 979 unique studies for first selection. In the first selection, these 979 studies were assigned to one reviewer (master student) and the two other reviewers. Every reviewer applied one or more selection criteria defined in the protocol, after reading the paper's title, abstract, and if necessary, introduction and conclusion section. If the reviewers applied different criteria for the same study, each reviewer presented its reasons to convince the others and to try to solve differences. At the end of this first selection, 83 studies were included for second selection, as potentially relevant studies. 


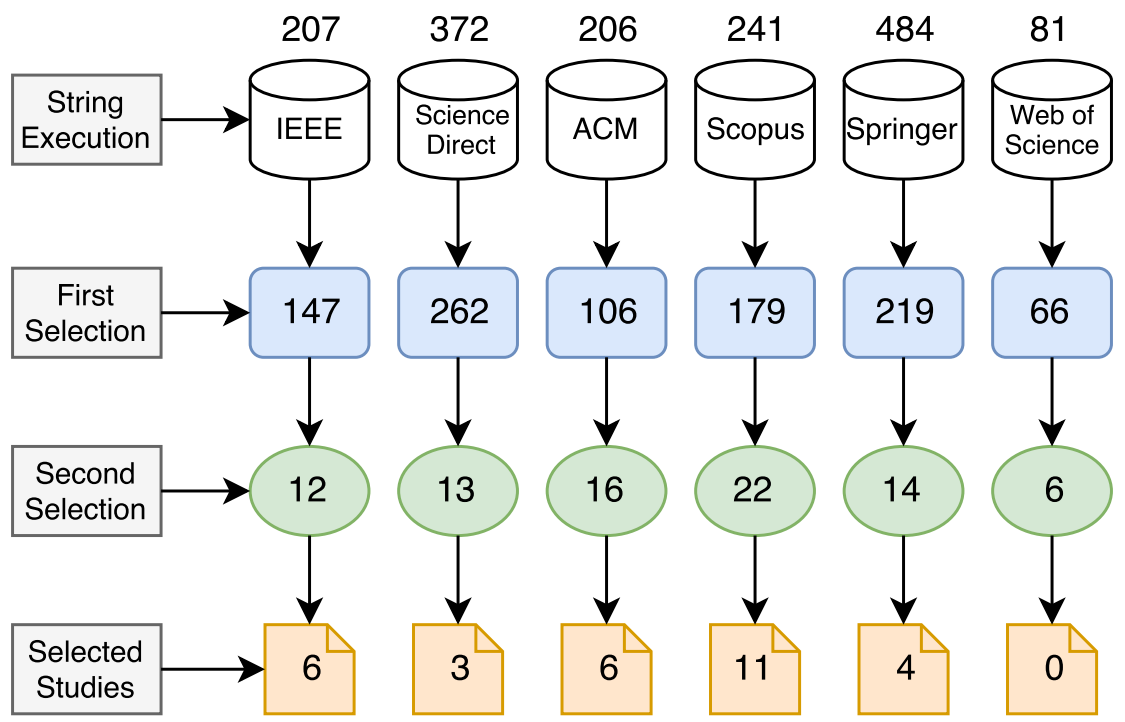

Figure 9 - Number of studies per database

In the second selection, the 83 studies were fully read. Such studies were analyzed considering the inclusion and exclusion criteria. As a result, 30 primary studies were included and 53 studies were excluded. After this, we applied the snowballing technique by checking the references of each selected study, in order no to miss any potentially relevant study. Among all studies evaluated, we selected 5 relevant studies, which had not been previously identified. The final list of selected studies is showed in Table 2

For each study, we calculated the quality score. Seven studies out of 35 present excellent quality, i.e., S19, S20, S21, S25, S28, S31, and S32; 22 studies were considered as of very good quality, i.e., S1, S2, S3, S4, S5, S6, S8, S9, S11, S13, S14, S16, S17, S18, S24, S26, S27, S29, S30, S33, S34, and S35; six studies present good quality, i.e., S7, S10, S12, S15, S22, and S23. Thus, we considered all 35 studies to extract information to answer our research questions.

The next subsections presents the reporting phase of our SM. First, we described the demographic data, i.e., the study classification by author type, publication venue, and publication year. After, some results are detailed. 
Table 2 - Final list of selected studies

\begin{tabular}{|c|c|c|c|}
\hline ID & Title & Reference & Q.A. \\
\hline S1 & $\begin{array}{l}\text { A generic model for sustainability with process- and product- } \\
\text { specific instances }\end{array}$ & (PENZENSTADLER; FEMMER, 2013) & 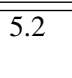 \\
\hline S2 & A Portfolio of Internal Quality Metrics for Software Architects & (STARON; MEDING, 2017) & 5.2 \\
\hline S3 & Aligning Architectures for Sustainability & (ANDERSSON; CAPORUSCIO, 2016) & 5.5 \\
\hline S4 & $\begin{array}{l}\text { An industrial case study on quality impact prediction for evolving } \\
\text { service-oriented software }\end{array}$ & (KOZIOLEK et al., 2011) & 5.7 \\
\hline S5 & $\begin{array}{l}\text { Architecture Knowledge Management During System Evolution: } \\
\text { Observations from Practitioners }\end{array}$ & $\begin{array}{l}\text { (OZKAYA; WALLIN; AXELSSON, } \\
2010)\end{array}$ & 5.7 \\
\hline S6 & Architecture sustainability & (AVGERIOU; STAL; HILLIARD, 2013) & 5.8 \\
\hline S7 & $\begin{array}{l}\text { Building Sustainable Software by Preemptive Architectural Design } \\
\text { Using Tactic-Equipped Patterns }\end{array}$ & (KIM; RYOO; KIM, 2014) & 4.2 \\
\hline S8 & $\begin{array}{l}\text { Chapter One - Managing Trade-Offs in Adaptable Software Archi- } \\
\text { tectures }\end{array}$ & (SCHMERL et al., 2017) & 5.7 \\
\hline S9 & $\begin{array}{l}\text { Cloud architecture continuity: change models and change rules for } \\
\text { sustainable cloud software architectures }\end{array}$ & (PAHL; JAMSHIDI; WEYNS, 2017) & 5.5 \\
\hline S10 & $\begin{array}{l}\text { Comparing Software Architecture Descriptions and Raw Source- } \\
\text { Code: A Statistical Analysis of Maintainability Metrics }\end{array}$ & $\begin{array}{l}\text { (ANJOS; CASTOR; ZENHA-RELA, } \\
2013 \text { ) }\end{array}$ & 5.0 \\
\hline S11 & $\begin{array}{l}\text { Comparison of Scenario-Based Software Architecture Evaluation } \\
\text { Methods }\end{array}$ & (BABAR; GORTON, 2004) & 5.2 \\
\hline S12 & $\begin{array}{l}\text { Component replacement in a long-living architecture: The } 3 \mathrm{RDBA} \\
\text { approach }\end{array}$ & $\begin{array}{l}\text { (POSTMA; AMERICA; WIJNSTRA, } \\
\text { 2004) }\end{array}$ & 4.8 \\
\hline S13 & Design for Sustainability = Runtime Adaptation Evolution & (WEYNS et al., 2015) & 5.1 \\
\hline S14 & Developing a sustainability non-functional requirements framework & (RATURI et al., 2014) & 5.4 \\
\hline S15 & $\begin{array}{l}\text { Diversifying software architecture for sustainability: A value-based } \\
\text { perspective }\end{array}$ & (SOBHY; BAHSOON, 2016) & 5 \\
\hline S16 & $\begin{array}{l}\text { Evolving Industrial Software Architectures into a Software Product } \\
\text { Line: A Case Study }\end{array}$ & $\begin{array}{l}\text { (KOZIOLEK; } \quad \text { WEISS; } \\
\text { HAMER, 2009) }\end{array}$ & 5.4 \\
\hline S17 & $\begin{array}{l}\text { Guidelines and metrics for configurable and sustainable architec- } \\
\text { tural knowledge modelling }\end{array}$ & (CARRILLO et al., 2015) & 5.2 \\
\hline S18 & $\begin{array}{l}\text { Managing the evolution of a software architecture at minimal cost } \\
\text { under performance and reliability constraints }\end{array}$ & $\begin{array}{l}\text { (VITTORIO; } \\
\text { PASQUALINA, 2015) }\end{array}$ & 5.8 \\
\hline S19 & Measuring architecture sustainability & (KOZIOLEK et al., 2013) & 5.8 \\
\hline S20 & $\begin{array}{l}\text { MORPHOSIS: A lightweight method facilitating sustainable soft- } \\
\text { ware architectures }\end{array}$ & (KOZIOLEK et al., 2012) & 6.4 \\
\hline S21 & $\begin{array}{l}\text { NASA's Advanced Multimission Operations System: A Case Study } \\
\text { in Software Architecture Evolution }\end{array}$ & (BARNES, 2012) & 6.4 \\
\hline S22 & Perseverance in Sustainable Software Architecting & $\begin{array}{l}\text { (WEISS; REPETTO; KOZIOLEK, } \\
\text { 2012) }\end{array}$ & 5 \\
\hline S23 & $\begin{array}{l}\text { Reducing Maintenance Costs Through the Application of Modern } \\
\text { Software Architecture Principles }\end{array}$ & (HULSE et al., 1999) & 4.8 \\
\hline S24 & Relating architectural decay and sustainability of software systems & (LE et al., 2016) & 5.5 \\
\hline S25 & Software architecture evolution through evolvability analysis & $\begin{array}{l}\text { (BREIVOLD; CRNKOVIC; LARSSON, } \\
\text { 2012) }\end{array}$ & 6.4 \\
\hline S26 & $\begin{array}{l}\text { Software architecture: A pattern language for building sustainable } \\
\text { software architectures }\end{array}$ & (VöLTER, 2006) & 5.8 \\
\hline S27 & Sustainability guidelines for long-living software systems & (DURDIK et al., 2012) & 5.7 \\
\hline S28 & Sustainable architectural design decisions & (ZDUN et al., 2013) & 6.1 \\
\hline S29 & $\begin{array}{l}\text { Sustainable architectures by combining flexibility and strictness in } \\
\text { Object Teams }\end{array}$ & (HERRMANN, 2004) & 5.5 \\
\hline S30 & $\begin{array}{l}\text { TechSuRe: A method for assessing technology sustainability in long } \\
\text { lived software intensive systems }\end{array}$ & (JANSEN; WALL; WEISS, 2011) & 5.7 \\
\hline S31 & $\begin{array}{l}\text { Ten years of software sustainability at the infrared processing and } \\
\text { analysis center }\end{array}$ & (BERRIMAN et al., 2011) & 6.7 \\
\hline S32 & $\begin{array}{l}\text { Toward Architecture Knowledge Sustainability: Extending System } \\
\text { Longevity }\end{array}$ & (CAPILLA et al., 2017) & 6.1 \\
\hline S33 & $\begin{array}{l}\text { Towards a Sustainable Architectural Design by an Adaptation of the } \\
\text { Architectural Driven Design Method }\end{array}$ & (VILLA et al., 2016) & 5.5 \\
\hline S34 & Virtualize for Architecture Sustainability in Industrial Automation & (BREIVOLD et al., 2013) & 5.8 \\
\hline S35 & Wrapping Architectures for Long-Term Sustainability & (LANDAUER, 2006) & 5.2 \\
\hline
\end{tabular}




\subsubsection{Demographic results}

Figure 10 shows the distribution of selected studies over the time period from 1999 to 2017. From 2010, the number of the published studies has been increasing in general, especially in 2013, where six studies were published. One reason for this could be the introduction of the First International Workshop on Green and Sustainable Software in 2012 and "Evolving Architectures"as main theme of the 8th International ACM Sigsoft Conference on the Quality of Software Architectures in the same year, triggering a awareness in the community.

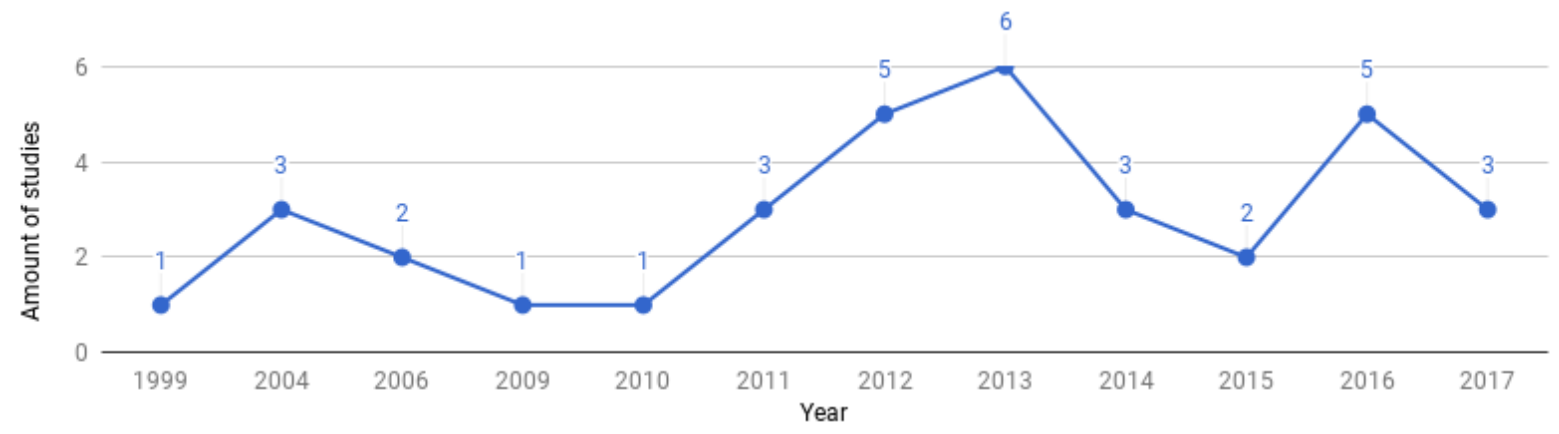

Figure 10 - Distribuction of selected studies over time period.

As shown in Figure 11a, authors of $37.1 \%$ (i.e., 13 studies) come from academia, and authors of $22.9 \%$ of the selected studies (i.e., 8 studies) work in industry. $40 \%$ of the studies (i.e., 14 studies) come from both academia and industry, i.e., most authors are affiliated to academia and work in the industry, or come from academia and have research partnerships in the industry.

The study distribution over publication types is show in Figure 11b. The most popular publication type is conference, with $51.4 \%$ (18 studies). Interesting to highlight that a good part of the studies, $25,7 \%$ (i.e., 9 studies) are consolidated in journals. $17.1 \%$ of the studies, i.e., six studies were published in workshops.

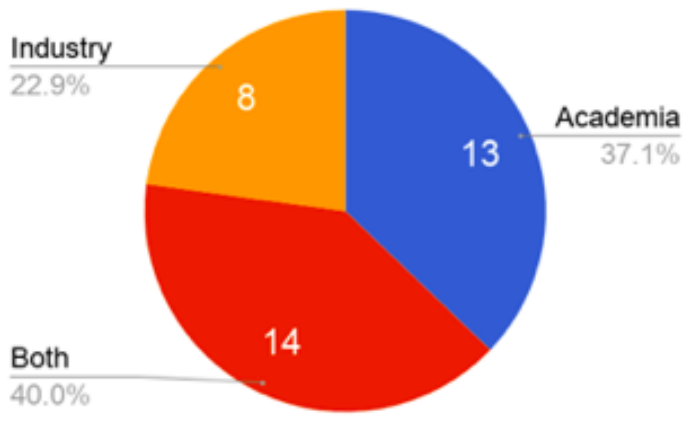

a

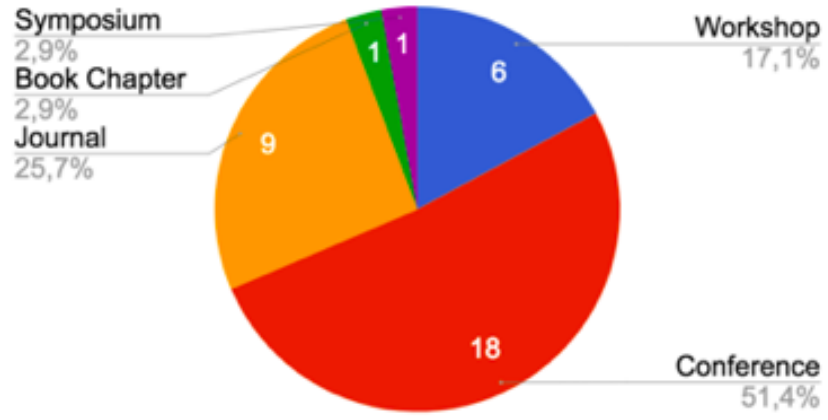

b

Figure 11 - Distribution of selected studies over a) author types; and b) publication types.

Both symposium and book chapter represent $2.9 \%$ each (i.e., one study). Additionally, Table 3 details the publication sources. The selected studies distribute over 27 publication sources, 
which indicates that the research topic of this SM have received a good attention in the software engineering community.

Table 3 - Publication source of selected studies

\begin{tabular}{llc}
\hline Publication source & Type & Studies \\
\hline \hline IEEE Software & Journal \\
European Conference on Software Architecture Workshops (ECSAW) & Conference \\
Working IEEE/IFIP Conference on Software Architecture (WICSA) & Conference & 3 \\
International Conference on the Quality of Software Architectures (QoSA) & Conference & 3 \\
International Conference on Computer Systems and Applications (ICSA) & Conference \\
International Conference on Computational Science and Its Applications (ICCSA) & Conference \\
Workshop on Green in/by Software Engineering (GIBSE) & Wokshop \\
International Conference on Software Quality (SWQD) & Conference \\
International Conference on Software Engineering (ICSE) & Conference \\
ICSE Workshop on Sharing and Reusing Architectural Knowledge (SHARK) & Workshop \\
International Conference on Availability, Reliability and Security Building (ARES) & Conference \\
Managing Trade-offs in Adaptable Software Architectures & Book chapter \\
Journal of Software: Evolution and Process & Journal \\
Asia-Pacific Software Engineering Conference (APSEC) & Conference \\
International Workshop on Green and Sustainable Software (GREENS) & Workshop \\
European Conference on Software Architecture (ECSA) & Conference \\
Science of Computer Programming & Journal \\
ACM SIGSOFT Symposium on Industry Day & Symposium \\
ACM International Conference on Ada (SIGAda) & Conference & 1 \\
The Journal of Systems and Software & Journal \\
European Conference on Pattern Languages of Programs (EuroPLoP) & Conference \\
IEEE International Conference on Software Maintenance (ICSM) & Conference \\
IEE Proceedings - Software & Journal \\
EUROMICRO Conference on Software Engineering and Advanced Applications (SEEA) & 1 \\
Philosophical Transactions of the Royal Society: Mathematical, Physical \& Engineering Sciences & Conference & 1 \\
IEEE International Conference on Computational Science and Engineering Virtualize & Journal \\
International IEEE Workshop on Software Evolvability (SE) & Conference & 1 \\
\hline
\end{tabular}

\subsubsection{RQ-1 Characteristics of software architecture sustainable}

Our first research question investigates quality attributes that are important for software architecture sustainability, based on their occurrence frequency in the selected primary studies. When extracting this data from the selected studies, we observed that the extracted quality attributes did not comply with a uniform quality model.

Although some studies have adopted the ISO/IEC 25010 standard (ISO., 2011), other studies describe attributes defined and used by the authors themselves, such as "Evolvability" (BREIVOLD; CRNKOVIC; LARSSON, 2012), "Composability" (BARNES, 2012), and "Understandability" (LE et al., 2016). Many selected studies only mention a characteristic, but not specify the sub-characteristics; other studies only mention a sub-characteristic. To solve this, we defined and followed the process presented in Figure 12.

In order to map quality attributes to the standard ISO/IEC 25010, we followed a procedure for each quality attribute identified. The procedure is shown in Figure 12. Attributes explicitly defined in their source study follows a different flow than those not defined. If the attribute under the procedure is defined, we compare its definition with the definition of each characteristic within ISO/IEC 25010. If we found a match, then the attribute is mapped into the characteristic of the standard. Otherwise, we compared it with the definition from ISO/IEC 9126-1 and ISO/IEC/IEEE 24765 until we have a match or not. If we had no match, the attribute was considered a new one. 
For attributes with no definition, first we tried to identify if there are any metrics related and reported in the study. If we had metrics, then their information was used to map the attribute into the standard ISO/IEC 25010. Otherwise, we compared the name of the attribute with the names of ISO/IEC 25010, ISO/IEC 9126-1 and ISO/IEC/IEEE 24765 until we had a match or not. In the last case, we considered the attribute as a new one.

We have mapped 10 subcharacteristics within 7 characteristics, in accordance with ISO/IEC 25010 standard, as detailed in Table 4. Changeability and Stability were allocated with Modifiability because they belonged to ISO/IEC 9126-1, replaced by ISO/IEC 25010 in 2011.

Table 4 - ISO/IEC 25010 Characteristics (ISO., 2011)

\begin{tabular}{|c|c|c|}
\hline Characteristic & Sub-Characteristic & Definition \\
\hline \multirow[t]{4}{*}{ 4*Maintainability } & Testability & $\begin{array}{l}\text { Degree of effectiveness and efficiency with which test criteria can } \\
\text { be established for a system, product or component and tests can be } \\
\text { performed to determine whether those criteria have been met. }\end{array}$ \\
\hline & Modularity & $\begin{array}{l}\text { Degree to which a system or computer program is composed of dis- } \\
\text { crete components such that a change to one component has minimal } \\
\text { impact on other components. }\end{array}$ \\
\hline & Reusability & $\begin{array}{l}\text { Degree to which an asset can be used in more than one system, or in } \\
\text { building other assets. }\end{array}$ \\
\hline & Modifiability & $\begin{array}{l}\text { Degree to which a product or system can be effectively and effi- } \\
\text { ciently modified without introducing defects or degrading existing } \\
\text { product quality. }\end{array}$ \\
\hline \multirow[t]{2}{*}{$2 *$ Portability } & Adaptability & $\begin{array}{l}\text { Degree to which a product or system can effectively and efficiently } \\
\text { be adapted for different or evolving hardware, software or other op- } \\
\text { erational or usage environments. }\end{array}$ \\
\hline & Replaceability & $\begin{array}{l}\text { Degree to which a product can replace another specified software } \\
\text { product for the same purpose in the same environment. }\end{array}$ \\
\hline Performance Efficiency & & $\begin{array}{l}\text { Represents the performance relative to the amount of resources used } \\
\text { under stated conditions. }\end{array}$ \\
\hline Reliability & Recoverability & $\begin{array}{l}\text { Degree to which, in the event of an interruption or a failure, a product } \\
\text { or system can recover the data directly affected and re-establish the } \\
\text { desired state of the system. }\end{array}$ \\
\hline Security & Integrity & $\begin{array}{l}\text { Degree to which a system, product or component prevents unautho- } \\
\text { rized access to, or modification of, computer programs or data. }\end{array}$ \\
\hline Context Coverage & Flexibility & $\begin{array}{l}\text { Degree to which a product or system can be used with effective- } \\
\text { ness, efficiency, freedom from risk and satisfaction in contexts be- } \\
\text { yond those initially specified in the requirements }\end{array}$ \\
\hline Compatibility & Interoperability & $\begin{array}{l}\text { Degree to which two or more systems, products or components can } \\
\text { exchange information and use the information that has been ex- } \\
\text { changed. }\end{array}$ \\
\hline
\end{tabular}

Figure 13 illustrates the amount of studies that address each QA. Modifiability was considered by 13 studies (37.1\%); Adaptability appears in 12 studies (34.2\%); Maintainability and Evolvability were considered by 11 (31.4\%) and 10 (28.5\%) studies, respectively. Figure 14 presents the final set of QAs, the primary studies where each QAs was found, and the amount and percentage of studies referring each QA. 


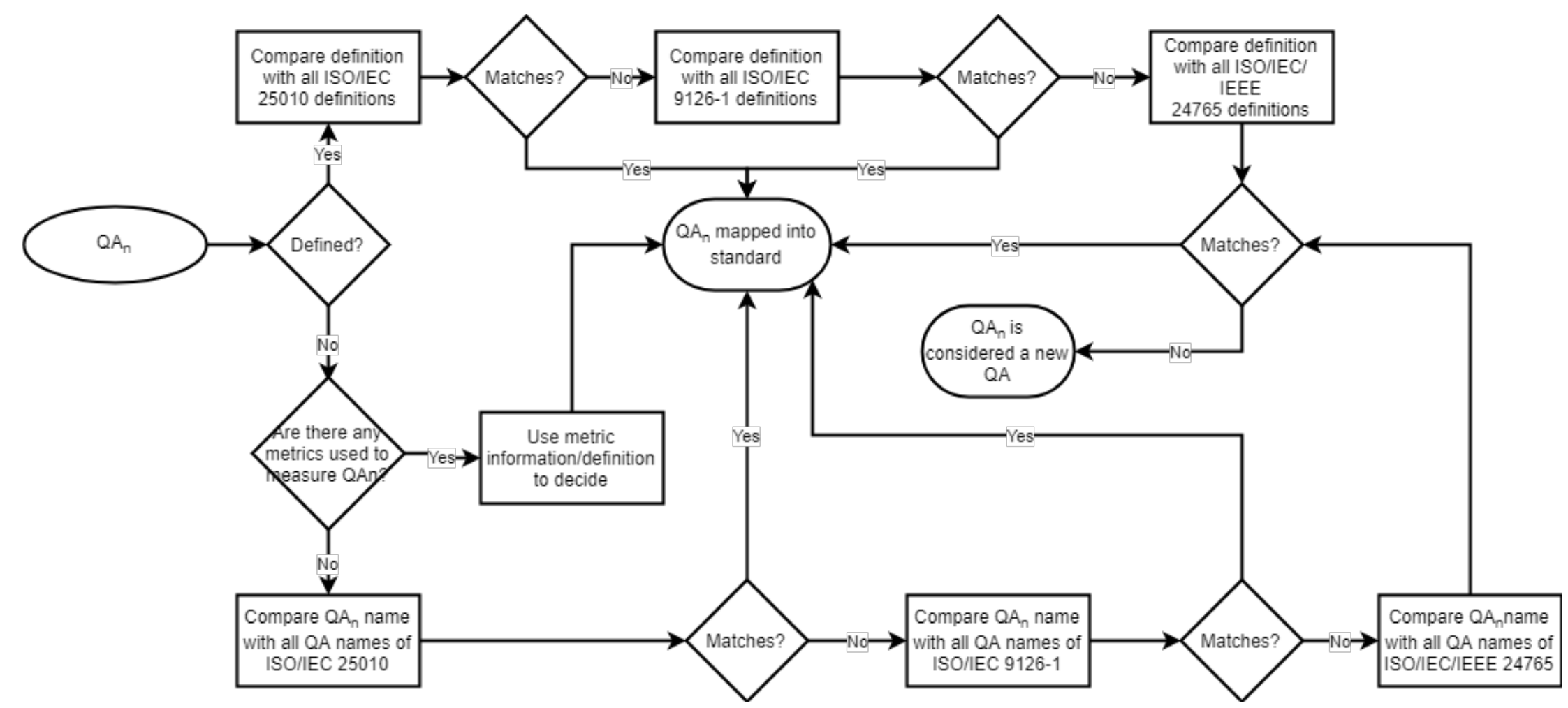

Figure 12 - Process to adapt quality attributes to the standard ISO/IEC 25010 


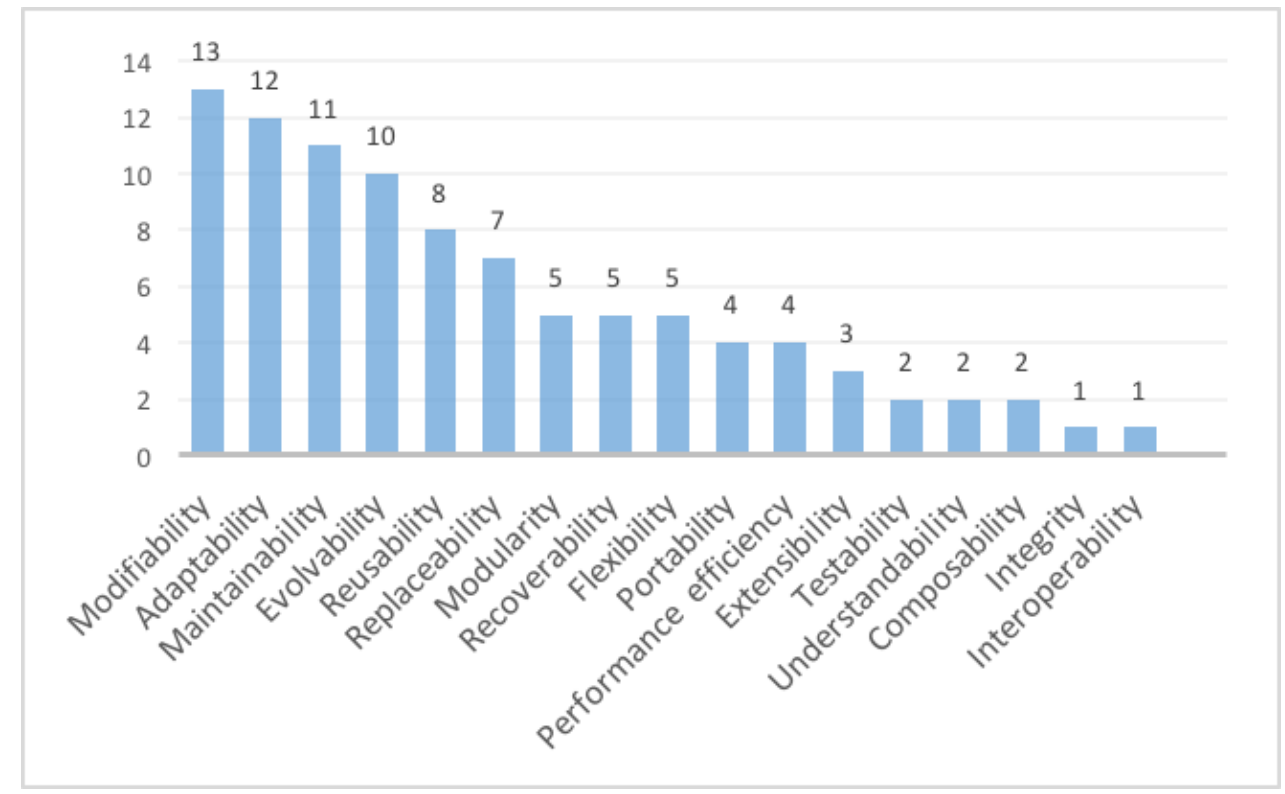

Figure 13 - Amount of studies addressing QAs.

We identified quality attributes that are not defined by none quality model, but they seems to be aligned with the nature of software architecture sustainability. Following, we present a brief description of each these attributes.

- Evolvability: describes "the ability of a system to accommodate changes in its requirements throughout the system's lifespan with the least possible cost while maintaining architectural integrity" (BREIVOLD; CRNKOVIC; LARSSON, 2012). Although it is mapped in 10 studies (S2, S3, S5, S9, S12, S13, S17, S23, S24, and S25), Evolvability is not part of a quality model. Here, it is important to highlight that studies show a distinction with Maintainability (in ISO 25010/2011): this is mostly concerned with fine-grained, short-term, and localized changes, whereas Evolvability is mostly concerned with coarse-grained, long-term, higher-level, radical functional or structural enhancements or adaptations (STARON; MEDING, 2017; OZKAYA; WALLIN; AXELSSON, 2010; BREIVOLD; CRNKOVIC; LARSSON, 2012). In (BREIVOLD; CRNKOVIC; LARSSON, 2012), a software evolvability model is presented, divided into sub-characteristics, such as Analyzability, Changeability, Extensability, and Architectural integrity. In particular, three studies (S5, S25, and S31) describes Extensability as an important attribute to software architecture sustainability. This attribute describes the capability of the software system to enable the implementations of extensions to expand or enhance the system with new features. Examples of measuring attributes include scalability, resource constraints, and compliance to standards (BREIVOLD; CRNKOVIC; LARSSON, 2012).

- Understandability it concerns the degree of understanding of engineers/architects about documentation, structure, components, data or source code via the software system to 
evolve it. For example, in the architectural context, Understandability is impacted by dependency cycle - when changing a component, which belongs to a circular chain, can possibly affect all other components in the cycle; and link overload - when a component has interfaces involved in an excessive number of dependencies on other components, affecting the system's isolation of changes (LE et al., 2016).

- Composability deals with the inter-relationships of components - a highly composable software architecture provides components that can be selected and assembled in various combinations to satisfy specific requirements (BARNES, 2012). In this context, the number of persistent components, number of connectors, and number of components are examples to measure Composability (STARON; MEDING, 2017).

In particular, these attributes that are not defined by none quality model need to be analyzed in more details because they seem to be closely linked to the architecture sustainability, since the studies that define them discuss the life cycle of software architectures and show some metrics that can be used to analyze the architecture longevity. However, these characteristics and definitions are not yet consolidated, unlike the characteristics present in the ISO/IEC 25010, and these studies do not present consolidated data of these metrics applied in practice.

\subsection{Final Remarks}

This chapter presented a panorama about the software architecture sustainability. Sustainability in Software Engineering is relatively new, in particular, in software architecture research area, and most of the publications are concentrated in the last six years.

It is important to mention that this systematic mapping study is underway and we are currently describing approaches found in the literature for software architecture sustainability. As published previously and partially in (VOLPATO et al., 2017), our SMS did not find any work dealing specifically with sustainability on reference architectures. Hence, we centralize our efforts to investigate sustainability on reference architectures.

Next chapter presents our approach to reference architecture sustainability, which is the focus of this project. 


\begin{tabular}{|c|c|c|c|c|c|c|c|c|c|c|c|c|c|c|c|c|c|c|c|c|c|c|c|c|c|c|c|c|c|c|c|c|c|c|c|c|c|}
\hline Characteristic & Subcharact. & s1 & s2 & 535 & 54 & $55 \quad 56$ & 57 & 58 & 59 & $S 10$ & $S 11$ & $\$ 12$ & $S 13$ & $S 14$ & $S 15$ & $S 16$ & S17 & 518 & S19 & $\$ 20$ & S21 & $\$ 22$ & $\$ 23$ & $\$ 24$ & 525 & $\$ 26$ & $\$ 27$ & 528 & 529 & 530 & S31 & 532 & 533 & 534 & S35 & $\#$ & $\%$ \\
\hline \multicolumn{38}{|c|}{ ISO/IEC 25010} \\
\hline Maintainability & & & $x$ & $x$ & $x$, & $x$ & & & & $x$ & & & & & & & $x$ & & $x$ & & & $x$ & $x$ & $x$ & & & & & & & & $x$ & $x$ & & & 11 & 31.4 \\
\hline & Testability & & & & & & & & & & & & & & & & & & $x$ & & & & $x$ & & & & & & & & & & & & & 2 & 5.71 \\
\hline & Modularity & & & $x$ & $x$ & & & & & & & & & & & & & & $x$ & $x$ & & & $x$ & $\mathrm{x}$ & & & & & & & & & & & & 5 & 14.2 \\
\hline & Reusability & & & $x$ & $x$ & $\mathrm{x}$ & & & & & & & & & & & & & $x$ & $x$ & & & $x$ & $\mathrm{x}$ & & & & $\mathrm{x}$ & & & $x$ & & & & & 8 & 22.8 \\
\hline & $\begin{array}{l}\text { Modifiability } \\
\text { (Changeability } \\
+ \text { Stability) }\end{array}$ & & & $x$ & $x$ & $x$ & & & & & $x$ & & & & & & $x$ & & $x$ & $x$ & & & $x$ & $x$ & $x$ & & $x$ & & & & & $x$ & & $x$ & $x$ & 13 & 37.1 \\
\hline \multirow[t]{3}{*}{ Portability } & & & & & & & & & & & & & & & & $\mathrm{x}$ & & & & & & & & & $\mathrm{x}$ & & & & & & $\mathrm{x}$ & & $\mathrm{x}$ & & & 4 & 11.4 \\
\hline & Adaptability & & & $x$ & & & & $\mathrm{x}$ & $\mathrm{x}$ & & & $\mathrm{x}$ & $x$ & & & $x$ & & & & & & $x$ & $x$ & & $x$ & & & & & & $x$ & & $x$ & $x$ & & 12 & 34.2 \\
\hline & Replaceability & & & & & & & & & & & & & & & $x$ & $\mathrm{x}$ & & & & & & & $x$ & $\mathrm{x}$ & & & & & & $x$ & $\mathrm{x}$ & $x$ & & & 7 & 20.0 \\
\hline $\begin{array}{l}\text { Performance } \\
\text { efficiency }\end{array}$ & & & & $x$ & $\mathrm{x}$ & & $x$ & & & & & & & & $\mathrm{x}$ & & & $x$ & & & & & & & & & & & & & & & & & & 4 & 11.4 \\
\hline Reliability & Recoverability & & & $x$ & $\mathrm{x}$ & & $x$ & & & & & & & & & & & $\mathrm{x}$ & & & $\mathrm{x}$ & & & & & & & & & & & & $x$ & & & 5 & 14.2 \\
\hline Security & Integrity & & & & & & & & & & & & & & & & & & & & & & & & $x$ & & & & & & & & & & & 1 & 2.85 \\
\hline Context coverage & Flexibility & & & & & $\mathrm{x}$ & & & & & & & & & $\mathrm{x}$ & & & & & & $\mathrm{x}$ & & & & & & & & & & & & & $\mathrm{x}$ & $\mathrm{x}$ & 5 & 14.2 \\
\hline Compatibility & Interoperability & & & & & & & & & & & & & & & & & & & & $x$ & & & & & & & & & & & & & & & 1 & 2.85 \\
\hline \multicolumn{38}{|c|}{ No QM's } \\
\hline Evolvability & & & $\mathrm{x}$ & $\mathrm{x}$ & & $\mathrm{x}$ & & & $\mathrm{x}$ & & & $\mathrm{x}$ & $x$ & & & & $\mathrm{x}$ & & & & & & $x$ & $x$ & $x$ & & & & & & & & & & & 10 & 28.5 \\
\hline & Extensibility & & & & & $\mathrm{x}$ & & & & & & & & & & & & & & & & & & & $x$ & & & & & & $x$ & & & & & 3 & 8.57 \\
\hline Understandability & & & & & & & & & & & & & & & & & & & & & & & & $\mathrm{x}$ & & & & & $\mathrm{x}$ & & & & & & & 2 & 5.71 \\
\hline Composability & & & & & & & & & & & & & & & & & & & & & $\mathrm{x}$ & & & & & & & & $x$ & & & & & & & 2 & 5.71 \\
\hline & & 0 & 2 & 26 & 6 & 60 & 2 & 1 & 2 & 1 & 1 & 2 & 2 & 0 & 2 & 3 & 4 & 2 & 5 & 3 & 4 & 2 & 7 & 7 & 7 & 0 & 1 & 1 & 2 & 0 & 5 & 3 & 5 & 3 & 2 & & \\
\hline
\end{tabular}

Figure 14 - Quality attributes found in selected studies 

CHAPTER

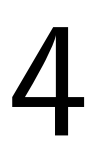

\section{A MODEL FOR REFERENCE ARCHITECTURE SUSTAINABILITY}

\subsection{Initial Remarks}

Chapter 3 discussed sustainability in software architecture. Several initiatives to improve sustainability of these architectures can be found in the literature, but no work focusing explicitly in reference architectures has been proposed. While software architectures constitute the design solution for specific systems, reference architectures operate at a higher level of abstraction for a set of systems in specific domains (VENTERS et al., 2018). Hence, advances obtained to understand and manage sustainability of software architectures are not sufficient for the context of references architectures.

This chapter presents our approach to reference architectures sustainability. Section 4.2 describe our methodology for the establishment of our model. Section 4.3 presents a model for reference architecture sustainability. Section 4.4 describe possibilities for using the model. In Section 4.5 are presented our final remarks.

\subsection{Methodology}

We observe that many reference architectures are proposed, however, many of them have not been adequately evolved. We investigate the contextual factors that influence the continuation of a reference architecture. To establish RASModel, we followed the steps presented in Figure 15. Each step is described in more details below:

- Step 1 - Information Source Investigation: in order to understand problems and challenges that must be overcome to achieve a sustainable architecture, we conducted a systematic mapping to analyze the state of art about sustainability in software architectures 
and in reference architectures. More details about this study are described in Section 3.3. Following, we analyzed 16 references architectures presented in (OLIVEIRA et al., 2010) and other reference architectures previously known and investigated in our research group for over 10 years, from various application domains such as e-commerce, health, awareness systems, automotive, Internet of Things, spacial exploration and smart grid. In this step, we look for documentation, database or any other source of content of these 21 reference architectures, presented previously in the Section 1.2. Besides that, we had the support of specialists with years of experience in research, establishment, and evaluation of reference architectures. This investigation was previously and partially reported in (VOLPATO et al., 2017) (presented in Appendix B).

- Step 2 - Analysis: we investigated the current status of these reference architectures by looking for information available in their websites, documents and/or other studies. Mainly, in activity 2.1, we checked for the existence of new versions, their use and dissemination, existence of consortia or institutions supporting them, and aspects of the reference architectures that were modified or updated. If a reference architecture presented any evidence of sustainability, e.g., updates, modifications, and use, we analyzed which factors showed this. If not, we analyzed the current status of the architecture, since it was established and/or published, and confronted with the observations of the previous architectures, which presented evidence of sustainability. From this, we identified in activity 2.2 a set of factors that served as the basis for the establishment of our model. Here it is important to highlight that we gather factors with close characteristics, naming them as subfactors. In the end of Step 2, a set of factors and subfactors are obtained.

- Step 3 - Establishment: with the set of factors obtained in the previous step, we represent them using the Unified Modeling Language (UML), which is widely understood. Subsequently, we have done a textual description of each factor and subfactor. The output of this step is a first version of RASModel. As is an iterative process, we analyze the model going back to Step 1 to refine descriptions or factors in order not to miss any potentially relevant information. 


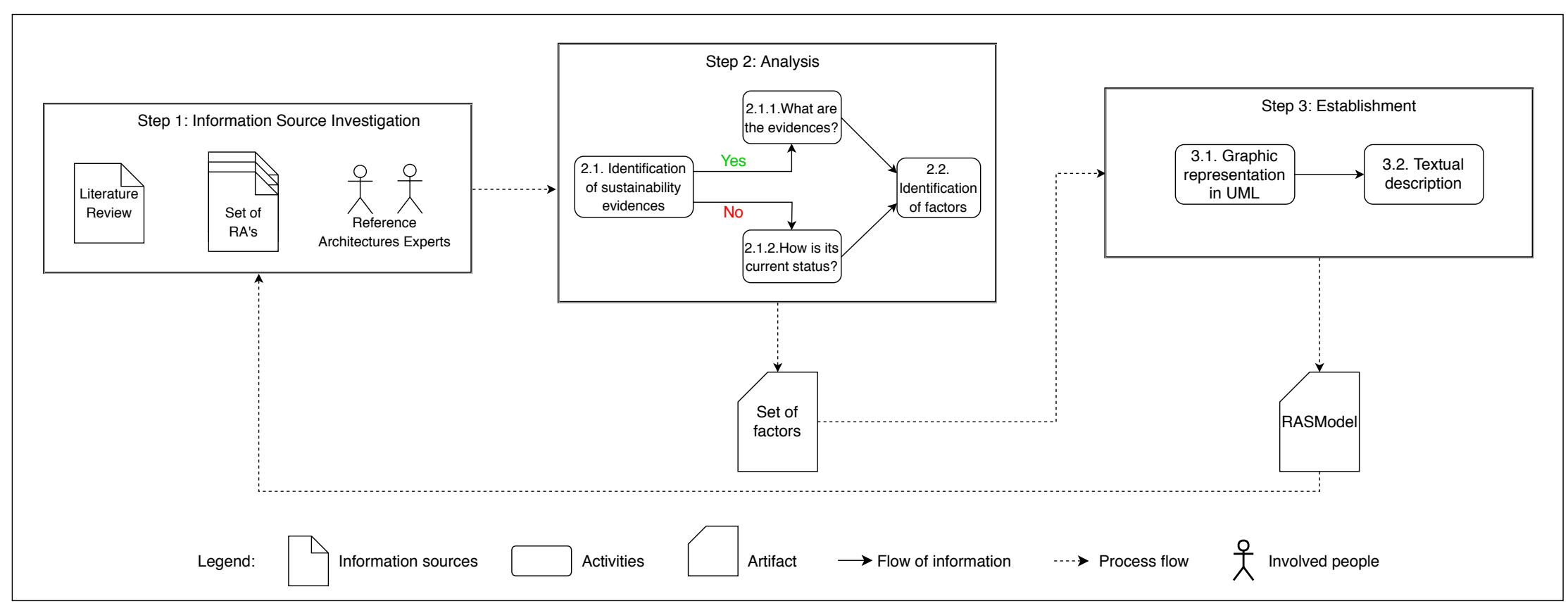

Figure 15 - Methodology for Establishment of RASModel 


\subsection{Reference Architecture Sustainability Model}

Aiming to deal with sustainability specifically of reference architectures, RASModel (Reference Architecture Sustainability Model) is a model for reference architectures sustainability analysis. RASModel considers the ecosystem of a reference architecture, analyzing factors that make these architectures sustainable, i.e., that are important for their existence and continuation.

RASModel is about how reference architectures, itself, can evolve over time. Here, sustainability is seen as an independent concept of quality. This means that sustainability should be considered under various aspects, independently of quality. This model is composed of two groups of factors:

- Primary factors: it contains factors that are aggregated by subfactors. When clearly identified and explicited, they provide a good overview, providing information on the elements that contained of the reference architecture, characterizing them as to their application domain, their context, stakeholders involved, etc..

- Crosscutting factors: it aggregates a set of factors that are usually spread across and/or tangled with all Primary factors.

As illustrated in Figure 16, primary factors and subfactors are: 


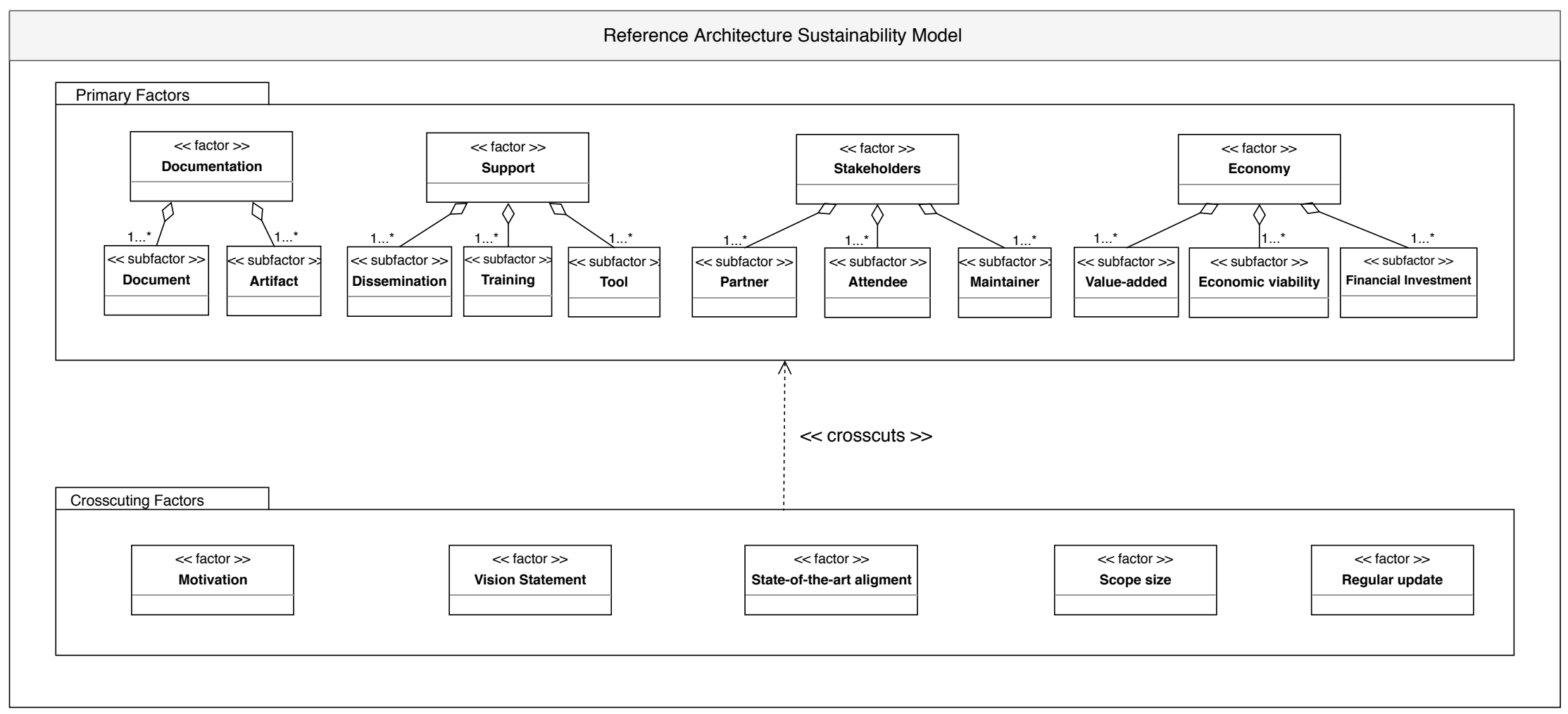

Figure 16 - Reference Architecture Sustainability Model 
- Documentation: it aggregates sub-factors that help and complement in understanding the reference architecture, as well as their appropriate use.

- Document: it is a piece of written, printed, or electronic matter such as PDF's files that provides information or that serves as an official record about the reference architecture. Documentation helps in the sustainability of the reference architecture because if the person in charge of documenting leaves the project, someone can assume without compromising evolution and maintenance of this architecture. For example, aiming at facilitating to deal with a reference architecture, a better understanding of their elements or components is essential to adequately build, use, and evolve such architecture. In this case, a user guide can detail in which situations and how the architecture can be used.

- Artifact: a reference architecture is represented by artifacts that include, for instance, components and connectors, policies, interfaces, protocols, and algorithms. These artifacts can be available through a database, repositories, or another way that facilitates access to the content of this architecture. For example, using a database, one can generate queries and reports that extract a specific subset of the architecture and manipulate the data to tailor it for a particular application.

- Support: it refers to elements that provide support to the reference architecture dissemination.

- Dissemination: it is the way the reference architecture is spread. Considering the value aggregated in reference architecture, it is important that such architecture is widely disseminated through publications, websites, repositories or hosting platforms such as GitHub ${ }^{1}$.

- Training: it is the enablement that guides and instructs one interested in the correct use of the reference architecture. Training can be offered, through courses, workshops or web-based to guide attendees in the architectural instantiation of reference architectures.

- Tool: it is an automated support that allows the manipulation of artifacts of the reference architecture (and their content). A tool can make new users able to manipulate and familiarize themselves with architecture's content, and help in maintaining for users who already use this architecture.

- Stakeholders: This factor refers to the community around the reference architecture that can be strengthened via a consortium composed of companies, research centers, and universities. Partner, Attendee, and Maintainer are considered interested and involved in the reference architecture. 
- Partner: who has the initiative to "start" a reference architecture, i.e., one responsible for their foundation. Companies may have common interests and, thus, consolidate these interests by means of partnerships. Together, these partners building a reference architecture. Besides that, other partners can join after the establishment of the reference architecture, contributing, for example to the expansion of architecture to new standards, legislation, refinement of terminology, and requirements.

- Attendee: who has an interest in adopting/using the reference architecture. Attendees collaborate with Partners, providing feedback on the use of the reference architecture.

- Maintainer: who is involved in the development and maintenance activities of the reference architecture. They are responsible for activities, such as delivering new releases, updating documentation, preparing training methods, and providing tools; i.e., who is manipulate the reference architecture and their content.

It is important to highlight that in this context, a stakeholder can play the three roles Partner, Attendee, and Maintainer - simultaneously, depending on their function in the context of architecture.

- Economy: refers to the set of fundamental information that affects a business or an investment's value. As reference architectures are strongly linked to companies (as well as their mission, vision, and strategy) (MüLLER, 2008), economic factors need to be considered for sustainability of these architectures because a great effort is needed to design, instantiate, and maintain them.

- Value-added: it is the value that the content of the reference architecture has and how this content benefits the application domain where it is inserted. For example, standards, legislation, constraints, goal and needs, domain terminology, and best practices aggregate value in the reference architecture that can standardize systems, reducing costs and efforts. This value-added is the recognition of the benefit obtained by the using the reference architecture, or the facility to develop software systems of a specific application domain or even solve problems of this application domain.

- Economic viability: it is a study that measures/analyzes whether the investment in the building of a reference architecture is feasible or not. In order to use reference architectures, organizations face a fundamental question: "Is it worth investing on the building of an RA?". Organizations need to ensure the feasibility of building an RA by assessing their goals, the resources they can invest and the expected benefits. However, the building of RAs is usually made without evaluating their economic impact (MARTÍNEZ-FERNÁNDEZ et al., 2013b). Therefore, an economic viability study needs to be considered for the reference architecture sustainability. Regarding this, there are some initiatives (MARTÍNEZ-FERNÁNDEZ et al., 2014; MARTÍNEZFERNÁNDEZ et al., 2013b) addressing economic models to precisely evaluate the 
benefit of reference architecture to make informed decisions about adoption of an existing or build a new reference architecture.

- Financial investment: it is the amount of money, resources, and time needed to build and maintain a reference architecture (MARTÍNEZ-FERNÁNDEZ et al., 2013a). Financial investment is necessary because building a reference architecture is not a trivial task, and involves the effort of several professionals, such as domain specialists, engineers, and architects, consuming a considerable amount of time and resources.

The crosscuting factors are:

- Motivation: it is the purpose that motivates the existence of a reference architecture. This motivation must be reasoned and aligned with the application domain, and benefits should be explicit. Architects can document a motivation's justification describing the mission, vision, and strategy that are needed to add the future direction. Some motivations behind reference architectures are (MARTÍNEZ-FERNÁNDEZ et al., 2013b) (i) to systematically reuse knowledge and software elements when developing concrete software architectures for new systems and thereby harvest potential savings through reduced cycle time, cost, risk and increased quality; (ii) to help with the evolution of a set of systems that stem from the same reference architecture; and (iii) to ensure standardization and interoperability. Motivation can also be for social reasons, such as improving transport services and health for communities.

- Scope size: it is the ambit ("sphere") of the reference architecture, including "things", such as systems that covers, number of partners, attendees, and maintainers. Reference architectures are indicated when the scope increases and multiple product creations are coupled (MüLLER, 2008), and are very attractive when organizations become large and distributed in order to develop new systems or new versions of systems (MARTÍNEZFERNÁNDEZ, 2013). Hence, a reference architecture is not sustainable for the simple and close situation, for example, a single system created at one location, by one vendor, in one organizational entity.

- Vision Statement: a vision statement is a reference architecture's roadmap, indicating both what this architecture wants to become and guiding transformational initiatives by setting a defined direction for the reference architecture's growth. In other words, a vision statement is an aspirational description of what an reference architecture would like to achieve or accomplish in the mid-term or long-term future. Can range in length from short sentences to multiple pages, and are also formally written and referenced in architecture documents.

- State-of-the-art alignment: it is the current knowledge application domain that is considered necessary to be included in reference architecture. For example, domain terminology 
should be widely accepted by the community related to that domain. Thus, it is important that the description of the reference architecture is aligned with the state of the art, so that it is well adopted and understood.

- Regular update: it refers to the continuous update in elements (e.g., documentation, artifacts, dissemination issues) related to the reference architecture. The adoption of new versions policies and updates is a good practice, so that the reference architecture is refined as application domain advance.

\subsection{Use of the Model}

Considering that RASModel contains factors and subfactors important for sustainability of reference architectures, two perspectives to use it exist:

- Reference architecture sustainability analysis: several reference architectures have not been updated since their first version, as stated before. These reference architectures can be analyzed and confronted with RASModel, aiming at identifying factors or subfactors that give evidence of their sustainability. If a factor (or some factors/subfactors) are missing, and if feasible, they could be inserted in these architectures to increase their sustainability.

- Support to the building reference architectures more sustainable: RASModel can be used as an guide before and during the building of reference architectures. For example, a consortium may focus only on building a reference architecture itself, investigating sources of information, identifying requirements, and describing configurations and functionality. However, they ignore the dissemination way of architecture to make it known, or if a training will be offered for their correct use, or if this architecture will be compatible with existing tools to support architectural instantiation. By using RASModel, these new architectures will have more chances to evolve, sustaining itself over time.

\subsection{Final Remarks}

In this chapter was presented the RASModel, a model that aims to contribute to the sustainability of reference architectures. The set of suggested factors and subfactors are intended to indicate elements that are generally neglected during the design of a reference architecture, but which can make these architectures more sustainable.

The next chapter presents the evaluation of this model, carried out with specialists through a survey. 

CHAPTER

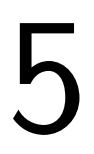

\section{REFERENCE ARCHITECTURE MODEL \\ EVALUATION}

In this chapter we present the evaluation of our reference architecture model, as previously presented in Chapter 4. For this, a survey with experts was conducted to validate the model regarding its completeness and composition. Survey is a method to collect and summarize evidence from a large representative sample of the overall population of interest; is not just the instrument (questionnaire or checklist) for gathering information, but it is a comprehensive system for collecting information to describe, compare or explain knowledge, attitudes and behavior (MOLLÉRI; PETERSEN; MENDES, 2016; PFLEEGER; KITCHENHAM, 2001). In particular, in Software Engineering (SE), surveys are one of the most frequently used research methods for conducting empirical investigation studies (MOLLÉRI; PETERSEN; MENDES, 2016).

Software Engineering (SE) research differs from other disciplines, regarding its objectives and subjects. Objectives are often related to improving the development process or to explore novel techniques and methods. The subjects of such studies usually involve well-qualified professionals with strong opinions regarding their areas of interest (MOLLÉRI; PETERSEN; MENDES, 2016). Many SE researches have made effective use of surveys, with relevant research topics addressed by surveys including (i) empirical research methods; (ii) software design models and patters; and (iii) software development process (MOLLÉRI; PETERSEN; MENDES, 2016). Besides that, with the advent of the internet, distributing and managing data collection instruments became easier, including saving answers automatically and 24/7 data collection availability. This ability to collect large amount of data without large cost for interviewing or postage as well as the ability to process answers without a manual data entry from paper-based questionnaires into a computer makes electronic surveys attractive (MOLLÉRI; PETERSEN; MENDES, 2016; PUNTER et al., 2003). 


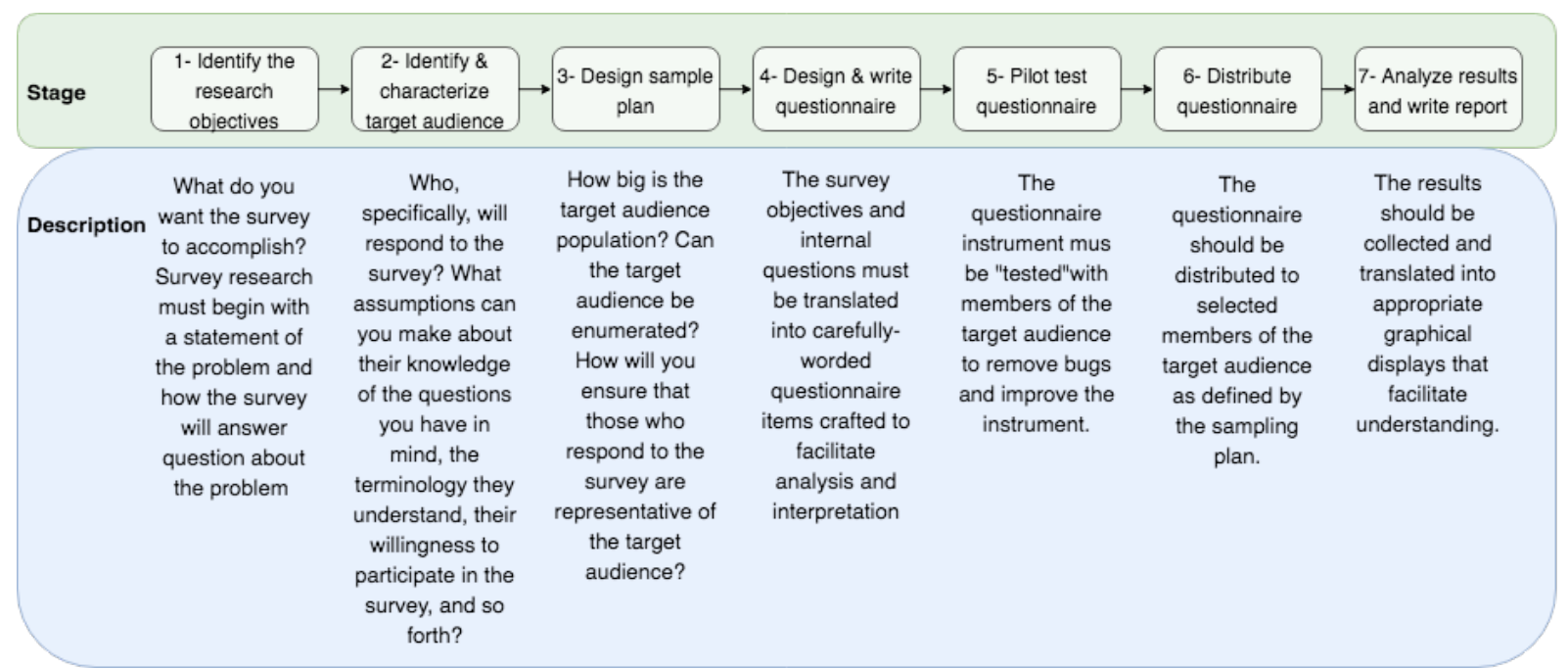

Figure 17 - Activities in the process to perform survey. Adapted from (KASUNIC, 2005)

\subsection{Conducting a survey}

In this evaluation, we used the process to perform surveys described in (KASUNIC, 2005). The process is divided into following stages: (i) identify the research objectives, (ii) identify and characterize target audience, (iii) design sampling plan, (iv) design and write questionnaire, (v) pilot test questionnaire, (vi) distribute questionnaire, and (vii) analyze results and write report, as showed in Figure 17. The following sections provide details about each stage.

\subsubsection{Identify research objectives}

The survey research objectives provide scope and guidance for internal questions the researches has about the problem or issue (KASUNIC, 2005). In order to establish the objectives of the survey we used the Goal-Question-Metric approach proposed in (BASILI, 1992). This approach is useful when you want to improve something and was initially proposed for software engineering topics, such as processes, methods, and models. It is composed by three main concepts (goal, question, and metric) developed in a top-down fashion, starting from goal and finishing at metric. A goal has one or more question that helps understand how that goal will be assessed or achieved. Metrics are finally used to quantitatively answer each question established for a goal. They can be objective (depends only on the object being measured and does not change from different points-of-view) or subjective (depends both on the object being measured and the point-of-view adopted).

For our survey, we identified three objectives, as show in Table 5. Goals 1 and 2 represent an improvement of the preliminary model in relation to its completeness and soundness. Goal 3 was identified to help us understand the applicability of the model when finished. 
Table 5 - Goals, questions, and metrics for survey

\begin{tabular}{|c|c|c|}
\hline Goal & Question & Metric \\
\hline $\begin{array}{l}1-\text { Evaluate the complete- } \\
\text { ness of the model }\end{array}$ & $\begin{array}{l}\text { 1- Are these factors/subfactors appro- } \\
\text { priate to indicate sustainability in Ref- } \\
\text { erence Architectures? } \\
\text { 2- There is another factor that your con- } \\
\text { sider important, that is not listed? } \\
\text { 3- If the answer to the previous ques- } \\
\text { tion was YES, describe which factor } \\
\text { that is not on the list you consider im- } \\
\text { portant? }\end{array}$ & $\begin{array}{l}\text { - Factors/subfac- } \\
\text { tors weighting; } \\
\text { - Factors/subfactors } \\
\text { added or removed }\end{array}$ \\
\hline $\begin{array}{l}2 \text { - Establish scale of impor- } \\
\text { tance of each subfactor for } \\
\text { reference architecture sus- } \\
\text { tainability }\end{array}$ & $\begin{array}{l}1 \text { - In your opinion, what is the scale of } \\
\text { importance of these factors/subfactors } \\
\text { for reference architecture sustainabil- } \\
\text { ity? }\end{array}$ & $\begin{array}{l}\text { Scale of impor- } \\
\text { tance }\end{array}$ \\
\hline $\begin{array}{l}3 \text { - Understand the usefulness } \\
\text { of the model }\end{array}$ & $\begin{array}{l}\text { 1- Do experts believe the model, when } \\
\text { finished, will be useful for reference } \\
\text { architecture sustainability analysis? }\end{array}$ & Yes/No \\
\hline
\end{tabular}

\subsubsection{Identify \& characterize target audience}

This stage is a two-step that begins with identifying the population that this survey needs to describe. In this context, a population refers to all the members of a specific group, and can be defined in terms of demography, geography, occupation, time, or some combinations of these factors (KASUNIC, 2005).

Aiming to address our objectives, we consider the ideal target audience for this questionnaire should be composed by individuals with experience in researching or developing reference architectures and sustainability in software engineering. More specifically, as reference architecture is very specific research area, we defined our population according to the occupation of respondents, considering the following aspects:

- Jobs and responsibilities;

- Education level;

- Experience about research area

The information derived from the audience analysis is indispensable, because the questionnaire items must be written from the perspective of the respondent, not the perspective of the researcher. Also, it means that special care should be given to writing questionnaire items using vocabulary familiar to the respondent. 


\subsubsection{Design sampling plan}

According to the guidelines in (KASUNIC, 2005), two primary considerations should drive decisions that will determine how individuals will be selected to participate in the survey, and the required size of the sample:

- If the search results are intended to be generalized for a larger population, then a probabilistic sample is required;

- If the search results are considered exclusive to the individuals participating in the survey, then a non-probability sample will suffice.

In particular, a non-probability sample uses human judgment in selecting respondents. Examples of the use of non-probability samples include (KASUNIC, 2005) (i) distributing questionnaires to participants at a conference or event; (ii) polling a set of individuals considered to be experts in an area of interest; and (iii) distributing questionnaires using the Web and allowing individuals to decide for themselves whether they want to participate.

Therefore, as our respondents target are experts in reference architecture and sustainability, a probabilistic sample is not required.

\subsubsection{Design \& write questionnaire}

In particular, a web-based survey can be developed by using two approaches (PUNTER et al., 2003). The first option is to program the HTML-pages and scripts yourself. The second option is to use a commercially available tool for on-line surveys. We decided for the second option using the online survey tool LimeSurvey ${ }^{1}$. According to the guidelines in (PUNTER et al., 2003), the amount of questions should be carefully considered. The more questions are asked the more time does it take to complete it. If the respondents consider this time as too high they will not start answering. Thus, as a basic rule, the questionnaire should not get too long. One way to achieve this is to restrict questions to the specific topic that has to be addressed according to specified survey goal (PUNTER et al., 2003).

The structure of the final web questionnaire is following:

\section{1st Page - Introduction}

In the first page we begin stating the estimated time required to fulfill the questionnaire (20 minutes). We briefly describe this research project, its goals and the role of the questionnaire within it. We make it clear that the identify of each respondent will be preserved along their responses for each question (only the combination of data from each respondent will be 
published).

\section{2nd Page - Participant Information}

To characterize the subjects of our sample and enable data analysis, we asked respondents the following information:

- Age;

- Country of residence;

- Education level (graduate, master, phd, post-doc);

- Current occupation;

- Application domains in which the participant have experience;

- Years of experience developing/researching;

- Classification of previous experience with reference architecture;

- Experience/knowledge with reference architecture design

\section{3rd Page - Factors and Subfactors}

In this page, we start introducing what are sustainability factors, and their subfactors for judgment and give instructions for participants on how to answer the questions for each factor (and subfactors) presented in the preliminary model.

The name of the factors and their subfactors is given along with its definition. For each of them, participants must answer if (i) "Strongly disagree"; or (ii) "Disagree"; or (iii) "Neither agree nor disagree"; or (iv) "Agree"; or (v) "Strongly Agree". Additionally, we asked if there is any subfactor that the participant considers relevant for reference architecture sustainability but was not present in our model, and, if "Yes", indicate subfactor that is missing.

Following, participants judged the importance of each factor, and subfactors for reference architecture sustainability. The evaluation is done by selecting a value in a likert-scale ranging from 1 to 5, where:

1 - Not at all important;

2 - Slightly important;

3 - Moderately important;

4 - Very important;

5 - Extremely important. 
The last page begins asking participants if they think the RASModel will be useful to support reference architecture sustainability analysis. We also asked if they think the our model will be useful to support the building of reference architectures sustainable. The answer is given in a 5-point linkert-scale: 1 -Strongly disagree; 2 - Disagree; 3 - Neither agree nor disagree; 4 Agree; and 5 - Strongly agree.

Finally, a text field is left for participants, so they can provide any additional information they consider useful for the research.

\subsubsection{Pilot test questionnaire}

A pilot test is a simulation of your survey implementation carried out on a small scale with members of your target population and are conducted to expose problems or weaknesses in the questions, questionnaire layout, process or technology, in case when web-based questionnaire is used. (KASUNIC, 2005). To find problems before we distribute the questionnaire for our audience, we asked 2 researches from our research group that are also part of the population to pilot it as if their answers would be included in final results. Additionally, we asked 2 researches not related to this research from our laboratory to pilot the test and report their thoughts. This helped us identify problems regarding the way we present our questionnaire and other minor problems.

During the pilot test, we evaluated the questions to determine if:

- there is confusion resulting from the instructions;

- the right questions are being asked;

- the questions are understandable; the order of the questions seems logical

- answer choices are appropriate and no answer choice have been overlooked;

- there are any terms are note understood or are open to multiple interpretations

Besides that, as we used a Web-based questionnaire, we also evaluated the technology to determine if:

- erroneous input caused a problem;

- respondents were able to navigate easily from screen to screen;

- error messages were perceived as friendly and helpful;

- there were lag times that caused the respondent to wait before performing a task in the questionnaire; 
- input data was correctly recorded in the database;

- data was lost because it was not saved properly

After considering the feedback from testers we finished the design of our questionnaire. It can be found in Appendix C.

\subsubsection{Distribute the questionnaire}

The questionnaire will be distributed to every subject at June 30 directly via e-mail (system generated link). Eligible participants for the survey will be found analyzing CV of members of laboratories from our institute that work with reference architectures and individuals that have developed their research within the context of reference architectures. To increase response rate, we will send a reminder one week after the distribution of questionnaire and one day before deadline.

\subsubsection{Analyze results and write report}

For data analysis, we will employ R-Studio ${ }^{2}$ to preprocess raw data exported from LimeSurvey, generate descriptive statistics, perform factor analysis, and plot charts for analysis and publication.

In the next sections, we report the results of the survey.

\subsection{Data collection}

As expected, data collection happened for two weeks using the LimeSurvey platform. At total, we received 10 answer, most from $\mathrm{PhD}$. students, researches, software engineers, and software architects. Figure 18 shows the summary for participant's information.

Most participants aged from 22 to 50 years (9/10) with only one participant with more than 50 years. This concentration is due to many participants being Ph.D. students $(6 / 10)$ or recently finished their master's and Ph.D. degree. With most participants from Brazil (8/10), we also had two international participants, one from Spain and another from Germain. Six participants are associated with some institution as professor or lecture. Five are currently working as software engineer or software architect.

Regarding application domains, the experience of participants is concentrated between the domain's healthcare (3/10) and Internet of Things (3/10), followed by robotics (2/10), and smart city (2/10). One participant has experience in the automotive domain, another in avionic and other in the industrial domain.

$2<$ https://www.rstudio.com> 
Most of the participants (8/10) have between 1 and 5 years of experience with reference architectures, and two participants have more than 10 years of experience. The experience of participants was mostly concentrated in academic research (10/10), design (4/10), domain analysis (3/10), assessment (2/10), and industrial (1/10). Eight participants with experience in reference architecture are familiar with domain analysis, followed by requirement analysis (7/10), reference architecture design (7/10), and reference architecture evaluation (4/10). 


\begin{tabular}{|l|r|r|}
\hline Ages & F. & \multicolumn{2}{|l|}{$\%$} \\
\hline Less than 21 years & 0 & $0 \%$ \\
\hline 22 - 30 years & 3 & $30 \%$ \\
\hline 31 - 40 years & 4 & $40 \%$ \\
\hline 41 - 50 years & 2 & $20 \%$ \\
\hline 51 years or more & 1 & $10 \%$ \\
\hline Total & 10 & $100 \%$ \\
\hline
\end{tabular}

\begin{tabular}{|l|r|r|}
\hline Experience & F. & \multicolumn{2}{|l|}{$\%$} \\
\hline Less than 1 year & 0 & $0 \%$ \\
\hline $1-5$ years & 8 & $80 \%$ \\
\hline 5 - 10 years & 0 & $0 \%$ \\
\hline More than 10 years & 2 & $20 \%$ \\
\hline Total & 10 & $100 \%$ \\
\hline
\end{tabular}

\begin{tabular}{|l|r|r|}
\hline Country & F. & \multicolumn{1}{l|}{$\%$} \\
\hline Brazil & 8 & $80 \%$ \\
\hline Spain & 1 & $10 \%$ \\
\hline Germain & 1 & $10 \%$ \\
\hline Total & 10 & $100 \%$ \\
\hline
\end{tabular}

\begin{tabular}{|l|r|l|}
\hline Domain & F. & $\%$ \\
\hline Automotive & 1 & $10 \%$ \\
\hline Avionics & 1 & $10 \%$ \\
\hline Healthcare & 3 & $30 \%$ \\
\hline Industrial & 1 & $10 \%$ \\
\hline Robotics & 2 & $20 \%$ \\
\hline Smart city & 2 & $20 \%$ \\
\hline Internet of Things & 3 & $30 \%$ \\
\hline Other & 3 & $30 \%$ \\
\hline
\end{tabular}

\begin{tabular}{|l|r|r|}
\hline Education & F. & \multicolumn{1}{l|}{$\%$} \\
\hline Undergraduate student & 0 & $0 \%$ \\
\hline Bachelor's degree & 0 & $0 \%$ \\
\hline Master's student & 1 & $10 \%$ \\
\hline Master's degree & 0 & $0 \%$ \\
\hline Ph.D student & 6 & $60 \%$ \\
\hline Ph.D degree & 3 & $30 \%$ \\
\hline Total & 10 & $100 \%$ \\
\hline
\end{tabular}

\begin{tabular}{|l|r|r|}
\hline Ocupation & F. & \multicolumn{1}{l|}{$\%$} \\
\hline Undergraduate student & 0 & $0 \%$ \\
\hline Master's student & 1 & $10 \%$ \\
\hline Ph.D candidate & 6 & $60 \%$ \\
\hline Researcher & 5 & $50 \%$ \\
\hline Lecturer & 1 & $10 \%$ \\
\hline Professor & 5 & $50 \%$ \\
\hline Software Engineer & 2 & $20 \%$ \\
\hline Software Architect & 3 & $30 \%$ \\
\hline
\end{tabular}

\begin{tabular}{|l|r|r|}
\hline Expertise & F. & $\%$ \\
\hline Domain analysis & 3 & $30 \%$ \\
\hline Design & 4 & $40 \%$ \\
\hline Assessment & 2 & $20 \%$ \\
\hline Maintenance & 0 & $0 \%$ \\
\hline Academic research & 10 & $10 \%$ \\
\hline Industrial research & 1 & $10 \%$ \\
\hline
\end{tabular}

\begin{tabular}{|l|r|l|}
\hline $\begin{array}{l}\text { Experience (arch. } \\
\text { Process) }\end{array}$ & F. & $\%$ \\
\hline Domain analysis & 8 & $80 \%$ \\
\hline Requirement analysis & 7 & $70 \%$ \\
\hline Arch. Design & 7 & $70 \%$ \\
\hline Arch. Evaluation & 4 & $40 \%$ \\
\hline
\end{tabular}

Figure 18 - Participant information summary 


\subsection{Data analysis}

In this section, we cover the descriptive statistics for data gathered from sustainability factors evaluation question and final considerations question group.

\subsubsection{Sustainability factors}

\section{Documentation}

Regarding factor Documentation, 60\% (6/10) of the participants "Strongly agree" that this factor and their subfactors present in our model influence the reference architecture sustainability, as showed in Figure 19.

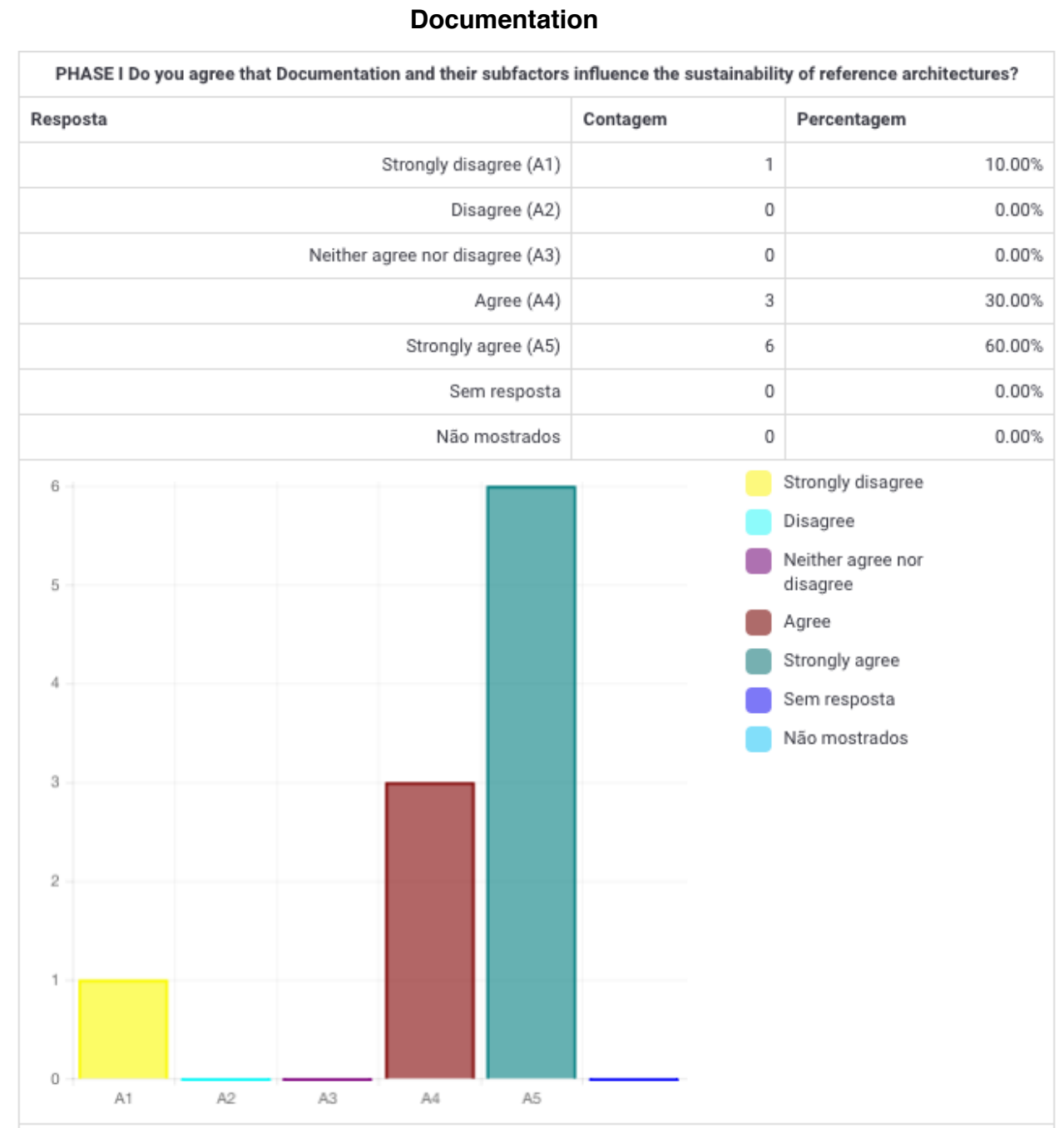

Figure 19 - Documentation statistics

$30 \%$ replied "Agree". Only one participant replied "Strongly disagree", but no justification was recorded. As for the Documentation subfactors, Figure 20 shows the statistics. $60 \%$ of the participants "Agree" and 30\% "Strongly agree" that the subfactor Document is important 
for reference architecture sustainability. Similarly, 50\% of the respondents "Agree" and 40\% "Strongly agree" that Artifact influences the sustainability. Both in Document and Artifact, only one respondent replied "Strongly disagree" and did not provide details of the choice.

When asked if is there any subfactor Documentation that they consider relevant for reference architecture sustainability but was not present in RASModel, two respondents replied yes. They suggested:

(i) "Guideline or help document with information about how to work with RA"; and

(ii) "An instantiation manual to support one to instantiate a concrete version of that reference architecture".

\section{Support}

$60 \%$ "Agree" and 30\% "Strongly agree" that Support and their subfactors influences the reference architecture sustainability, as showed in Figures 21 and 22.

$70 \%$ of the respondents "Agree" and 20\% "Strongly agree" with respect to the subfactor Dissemination. One participant "Strongly disagree" and did not provide any comment on his response. Regarding Training, 40\% of the participants "Strongly agree". 30\% "Agree" and 20\% "Neither agree nor disagree". One participant "Strongly disagree".

$40 \%$ of the respondents "Strongly agree" and 30\% "Agree" about Tool influencing the reference architecture sustainability. Two participants "Neither agree nor disagree", and one participant "Strongly disagree". No additional comments were recorded in the questionnaire. 
Document

Artifact

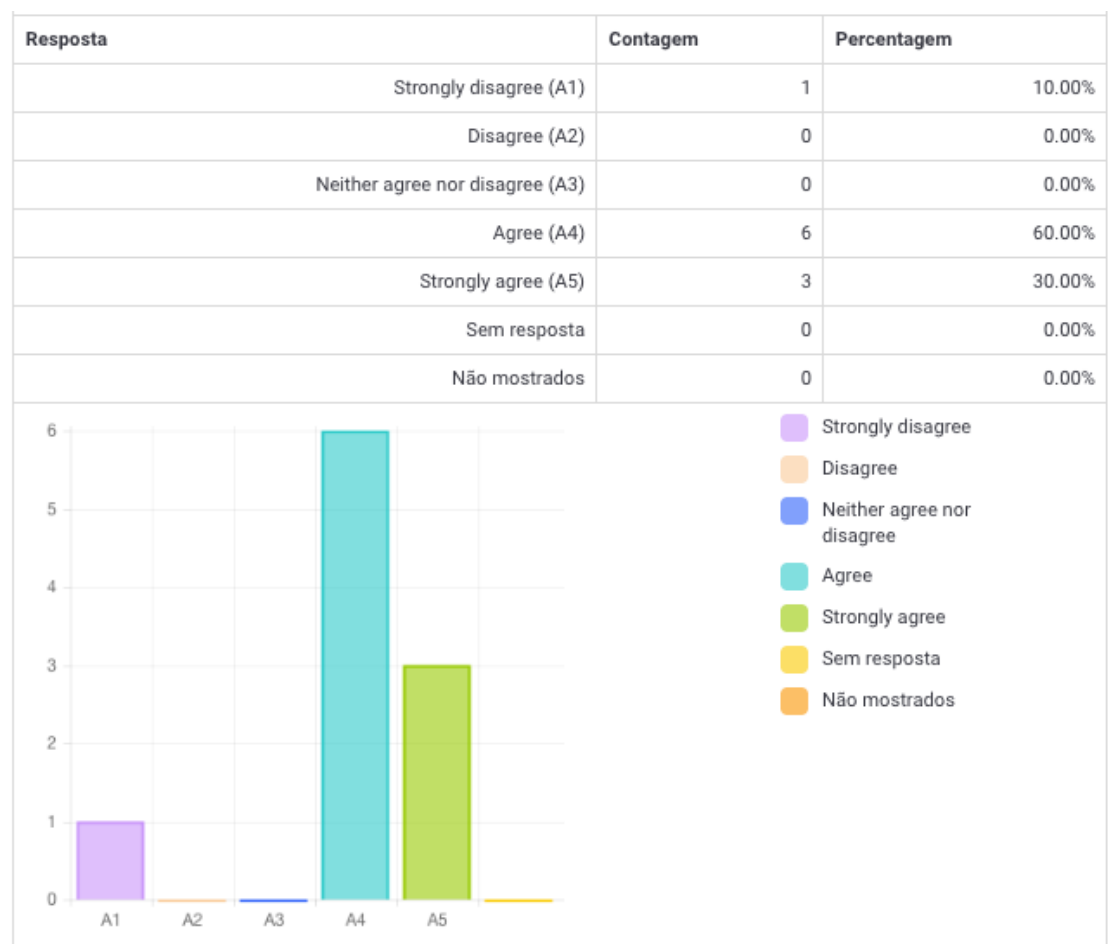

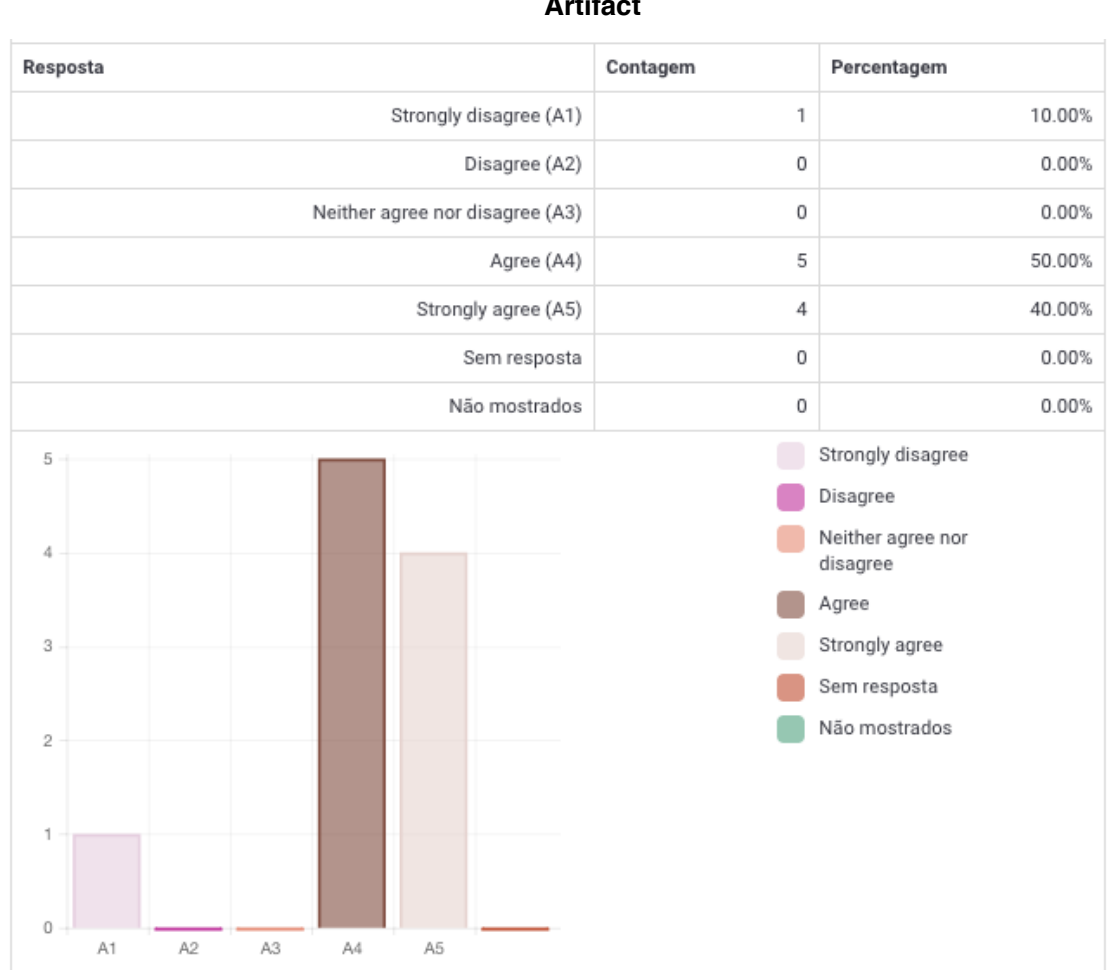

Figure 20 - Document and Artifact statistics 


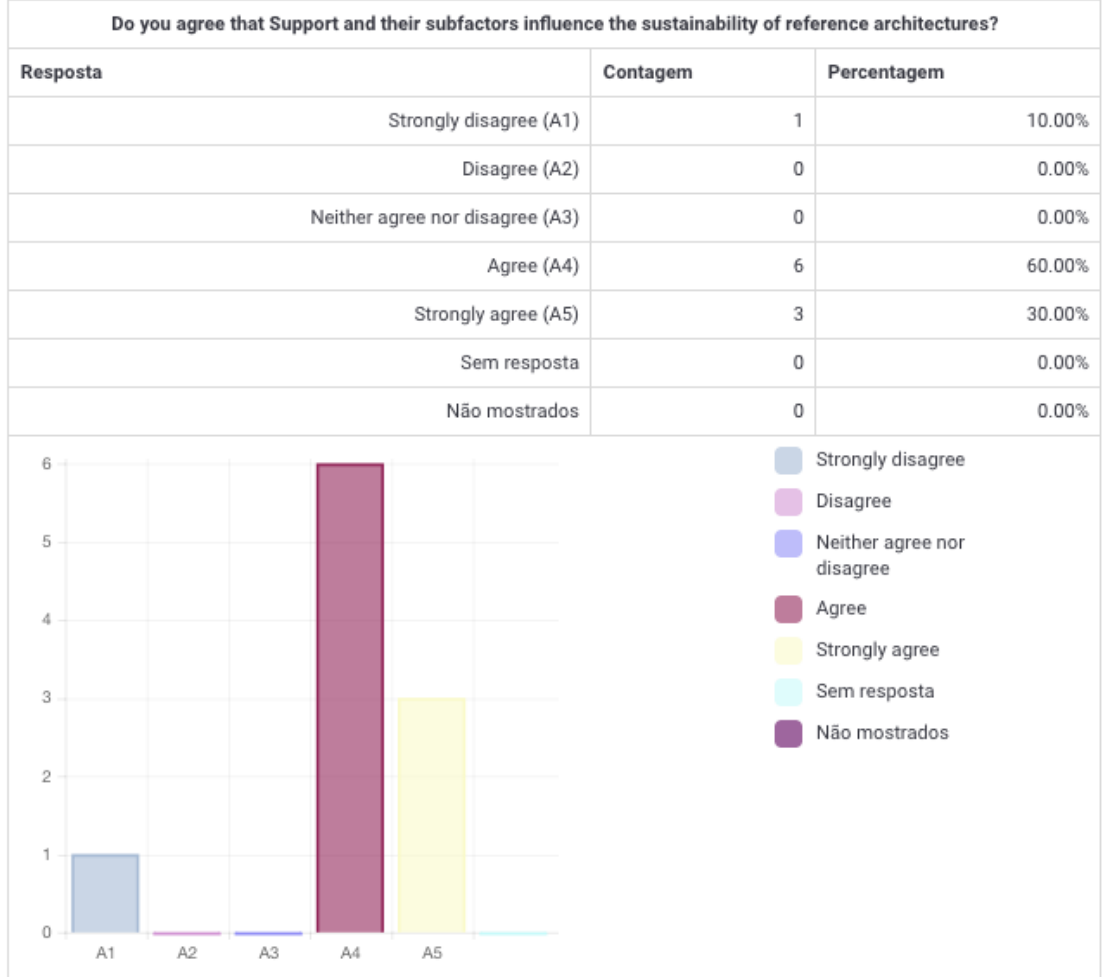

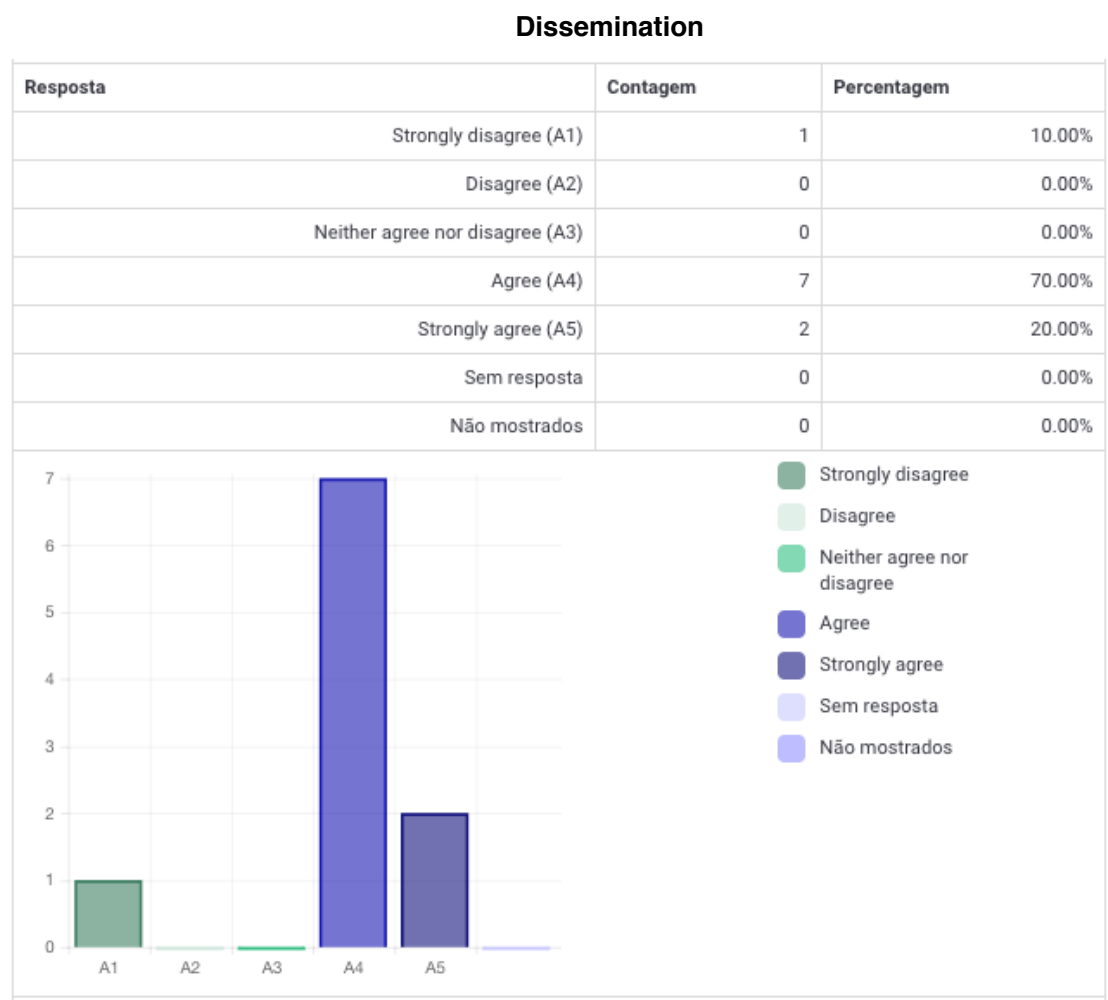

Figure 21 - Support and Dissemination statistics 
Training

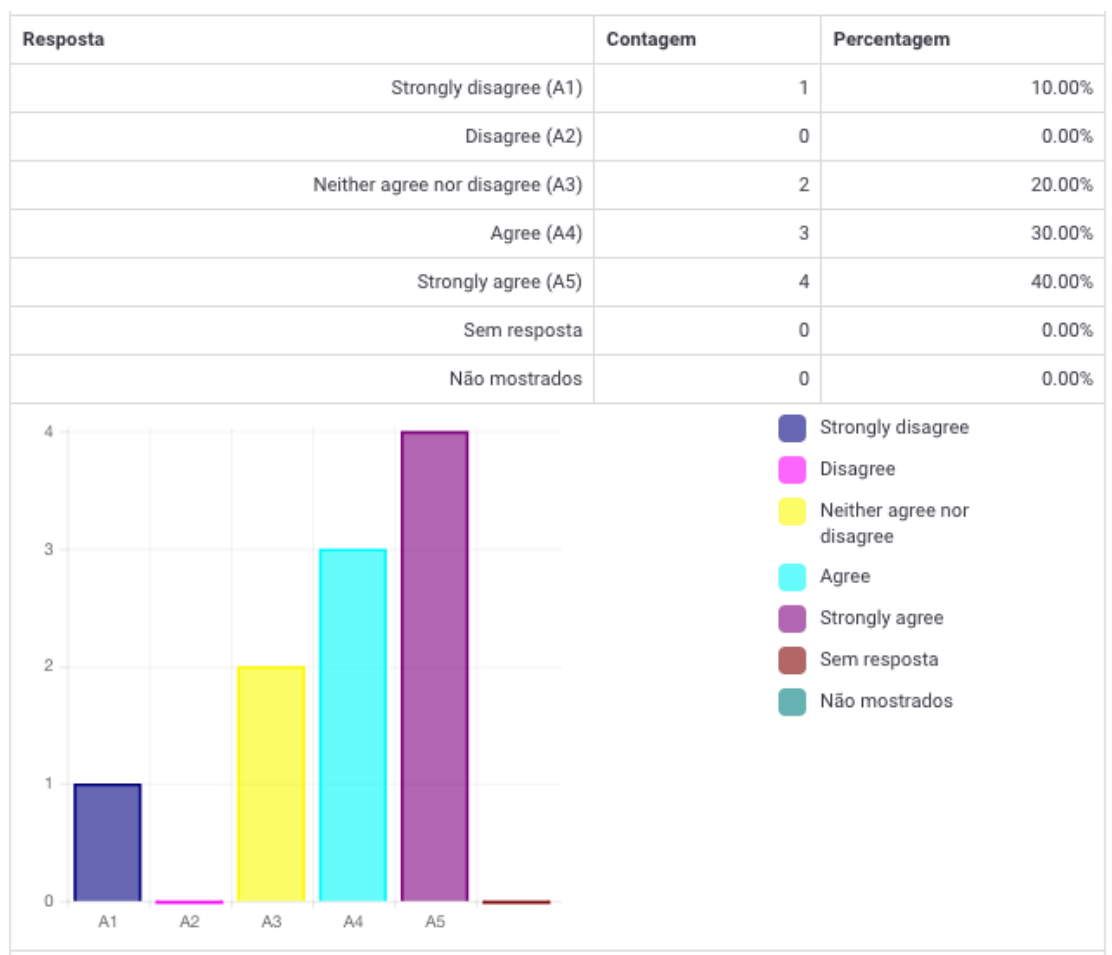

Tool

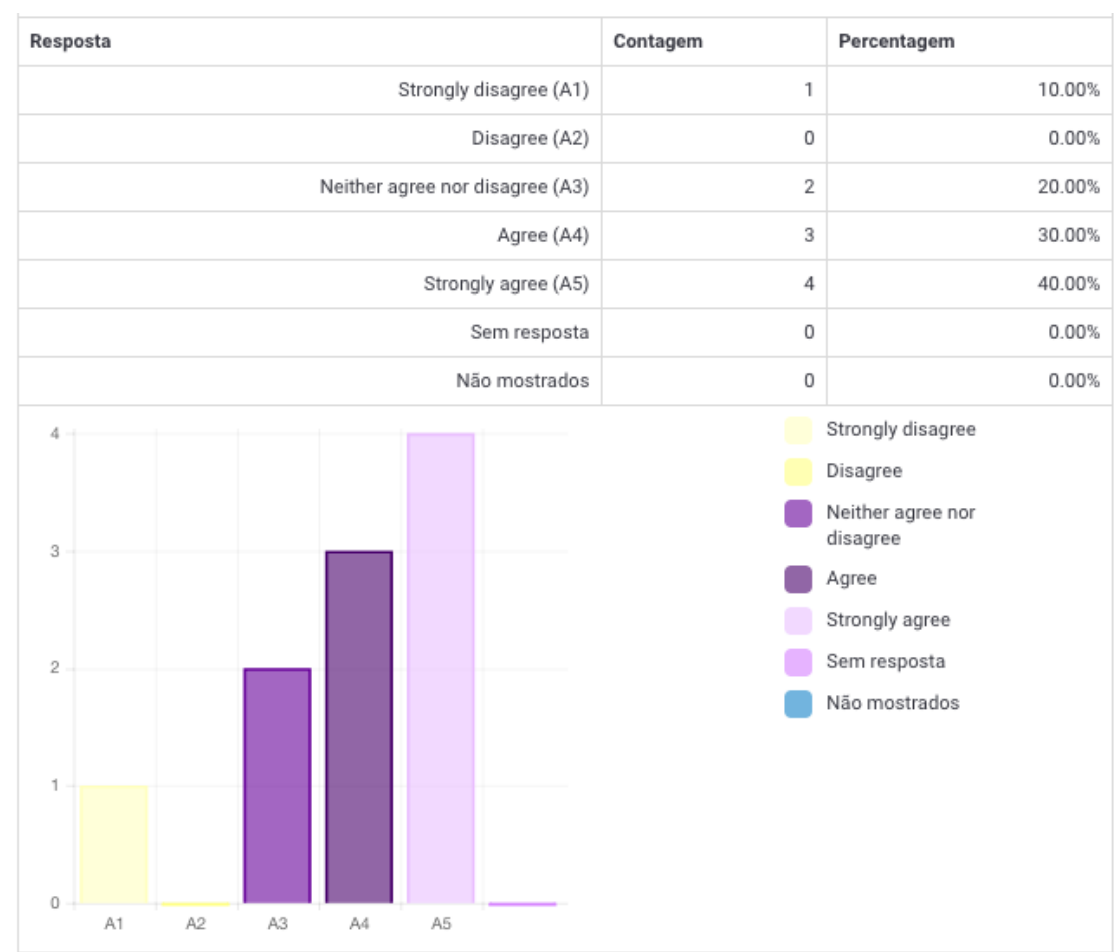

Figure 22 - Training and Tool statistics 


\section{Stakeholder}

In general, $70 \%$ of the participants "Strongly agree" and 20\% "Agree" that the factor Stakeholder, i.e., the community around the reference architecture that can be represented via a consortium composed of companies, research centers, and universities, influences the sustainability of reference architectures. However, one participant "Strongly disagree" about this and did not describe reasons. Figures 23 and 24 show the statistics about this factor and their subfactors.

Regarding Partner (who has the initiative to "start" a reference architecture), we observed that $70 \%$ of the participants "Agree" and 20\% "Strongly Agree". "Neither agree nor disagree" was replied by one participant. In turn, 50\% "Agree" and 40\% "Strongly Agree" that Attendee (who has an interest in adopting/using the reference architecture) is a Stakeholder that influences the sustainability. As well as Partner, one participant replied that "Neither agree nor disagree".

$50 \%$ of the respondents "Agree" and 40\% "Strongly Agree" that the subfactor Maintainer influences the sustainability. One participant (1/10) "Neither agree nor disagree" with this subfactor described in RASModel. No participant considered the lack of some Stakeholder subfactor.

\section{Economy}

Figures 25 and 26 describes the statistics about Economy. 30\% of the respondents "Strongly Agree" and 30\% "Agree" that this factor is important for sustainability, i.e., 60\% proved favorable with respect to this factor. However, $40 \%$ "Neither agree nor disagree". In particular, according to the participants, 50\% "Neither agree nor disagree" that Value-added, i.e., the value that the content of the reference architecture has and how this content benefits the application domain where it is inserted, influences the sustainability. On the other hand, 50\% agreed, where $30 \%$ "Strongly agree" and 20\% "Agree".

Regarding Economic viability, the study that measures/analyzes whether the investment in the building of a reference architecture is feasible or not, $50 \%$ of the respondents agreed, where 30\% replied "Agree" and 20\% "Strongly agree". "Neither agree nor disagree" was replied by $40 \%$ and "Disagree" by $10 \%$ of the participants.

$40 \%$ of the respondents replied "Agree" and 30\% replied "Strongly agree" for Financial investment, i.e., the amount of money, resources, and time needed to build and maintain a reference architecture. 30\% "Neither agree nor disagree" that this subfactor influences the reference architecture sustainability.

When asked if is there any subfactor Economy that they consider relevant but was not present in RASModel, no participant replied yes. 
Partner

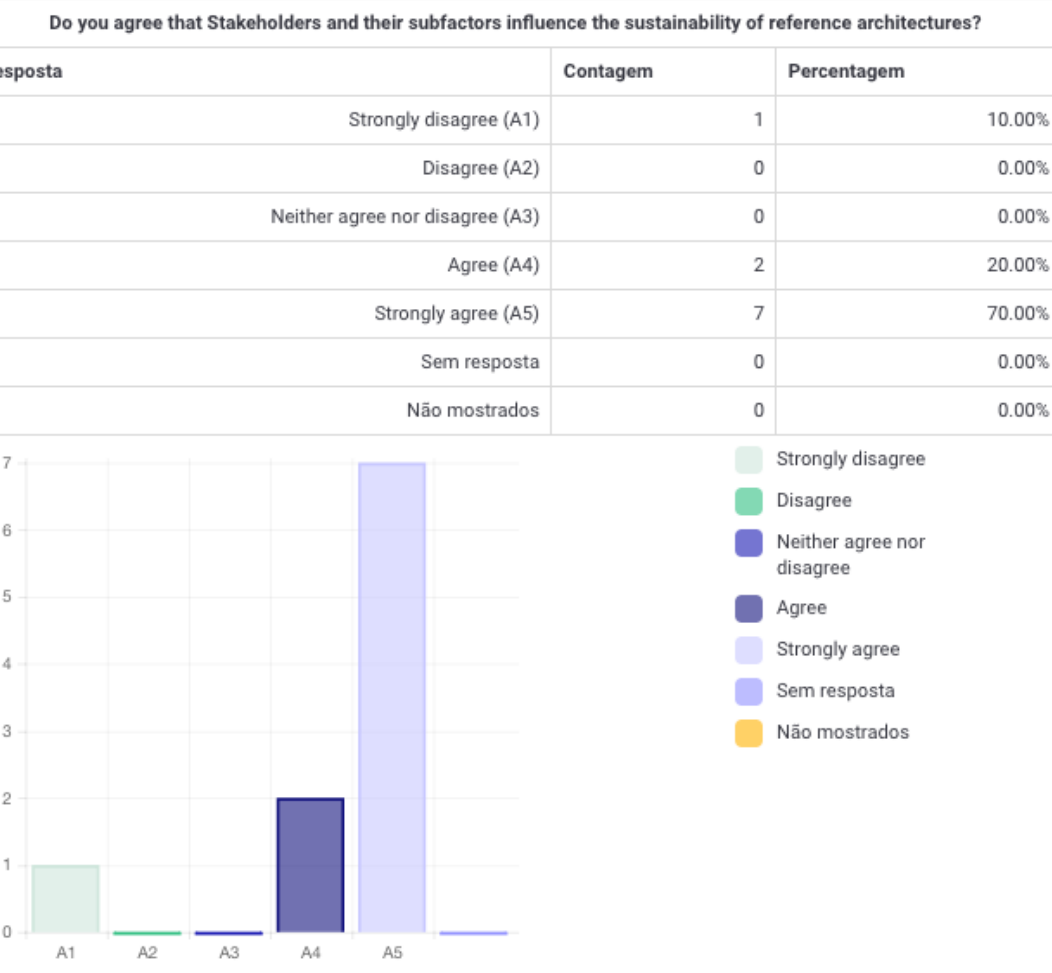

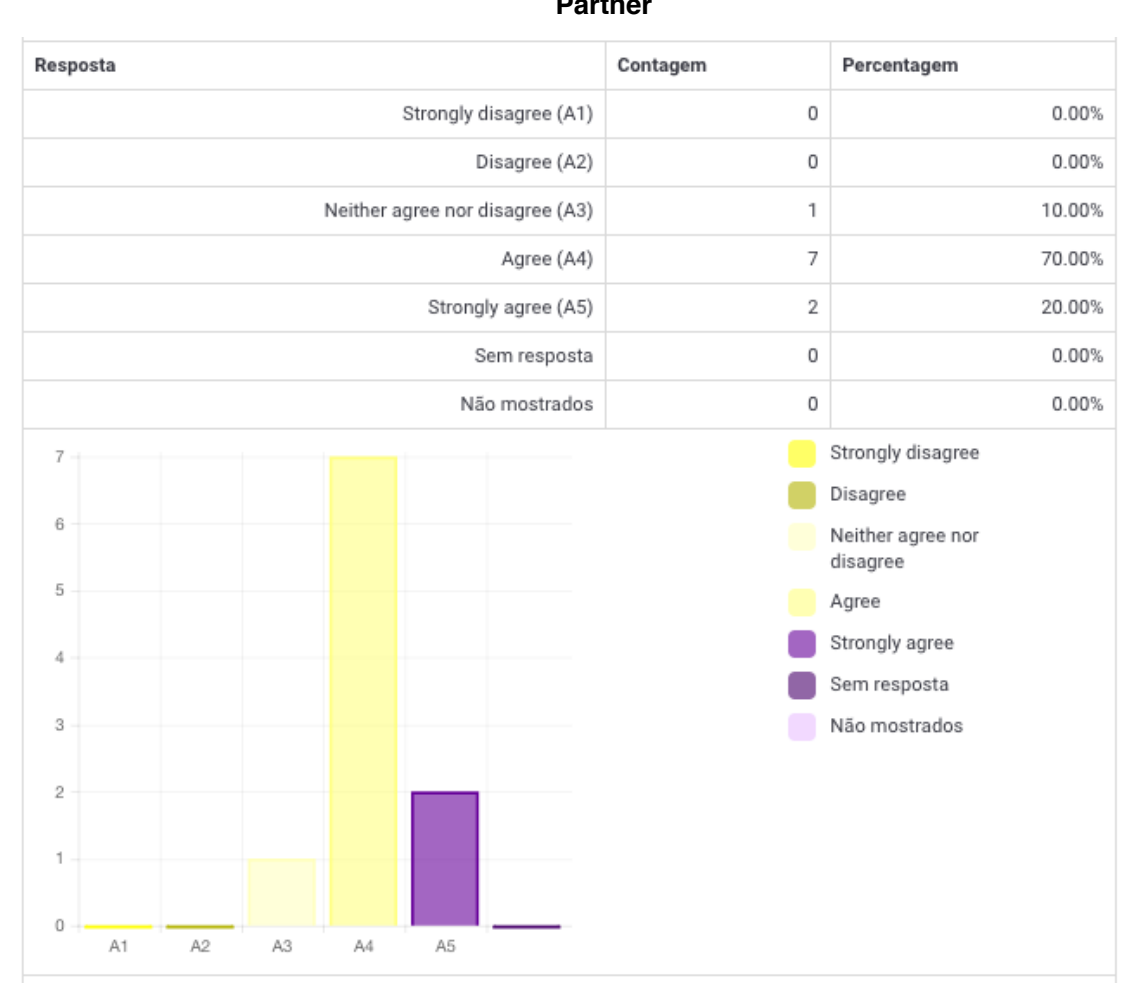

Figure 23 - Factor Stakeholder and subfactor Partner statistics 
Attendee

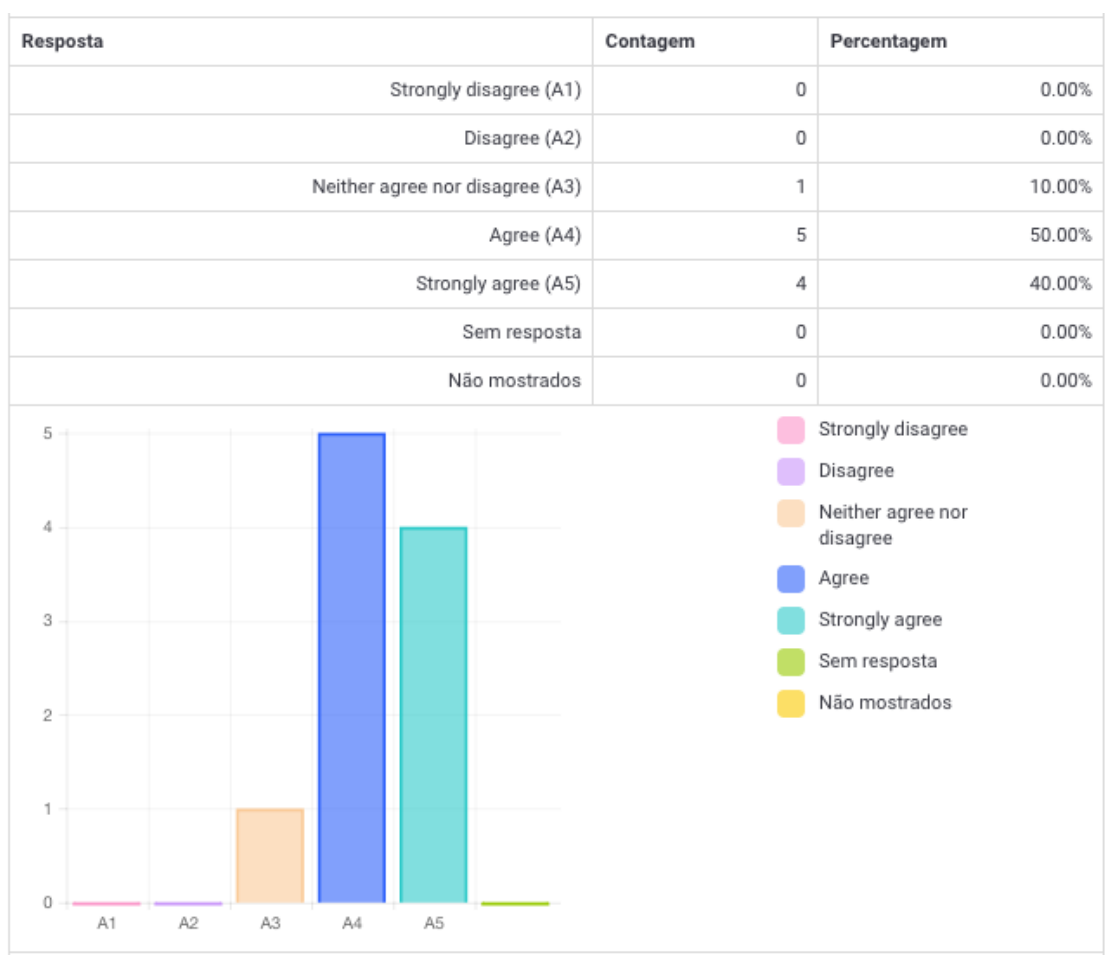

Maintainer

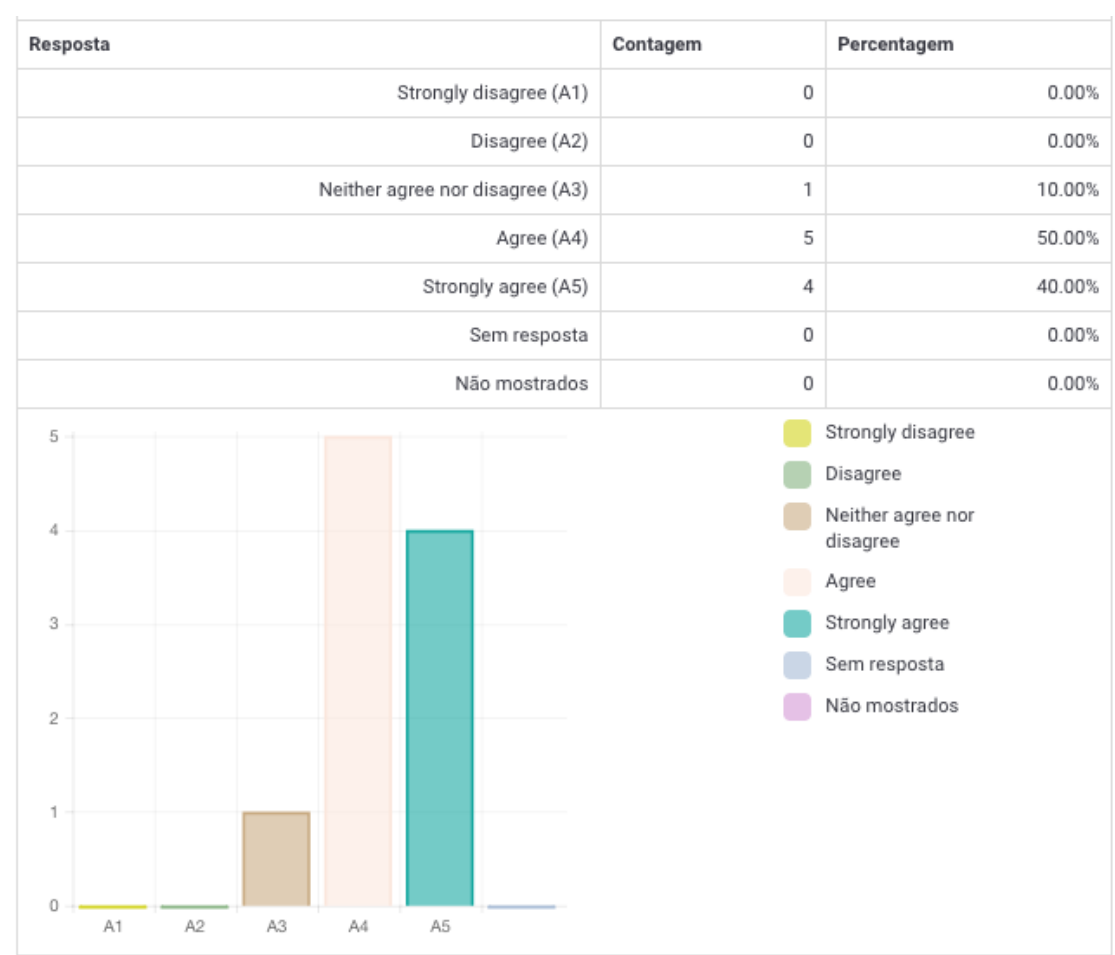

Figure 24 - Attendee and Maintainer statistics 
Value-added

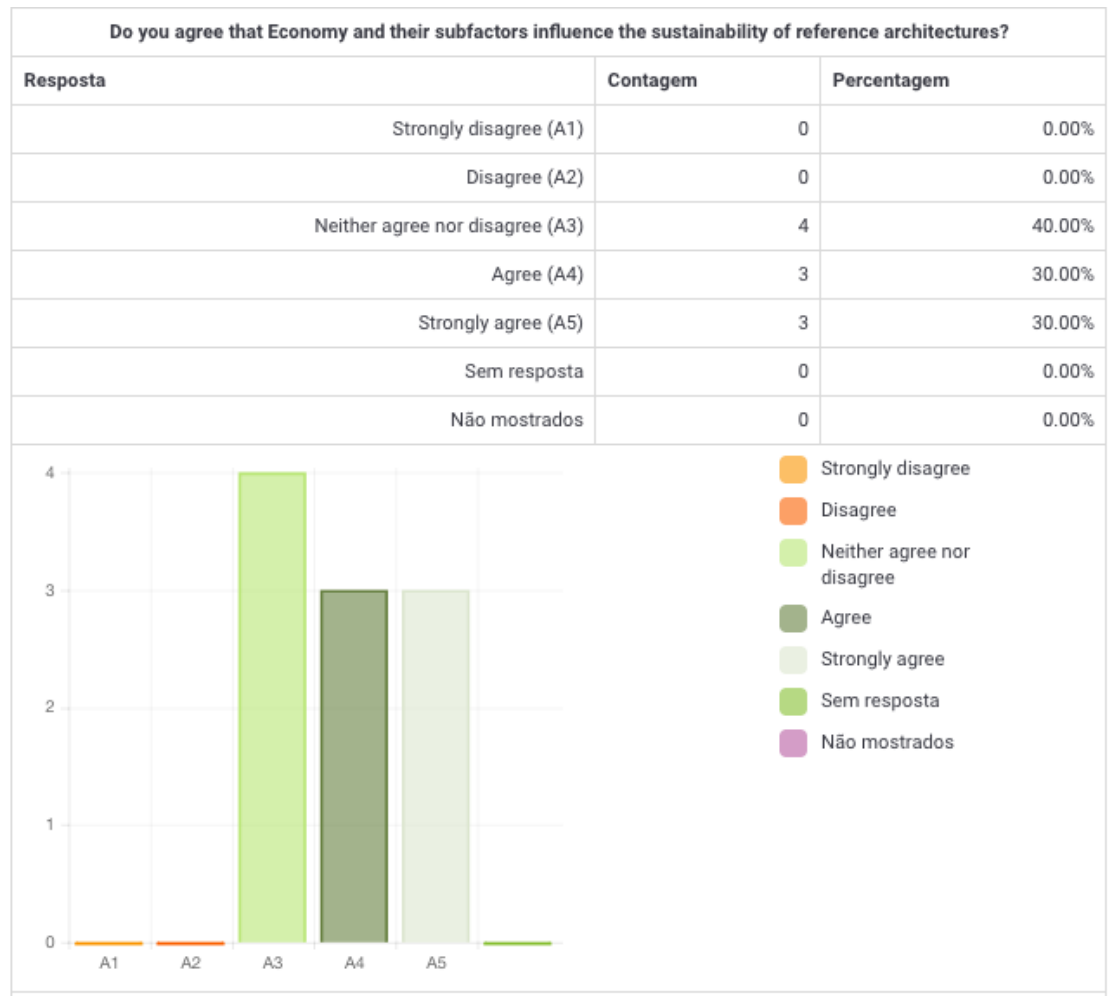

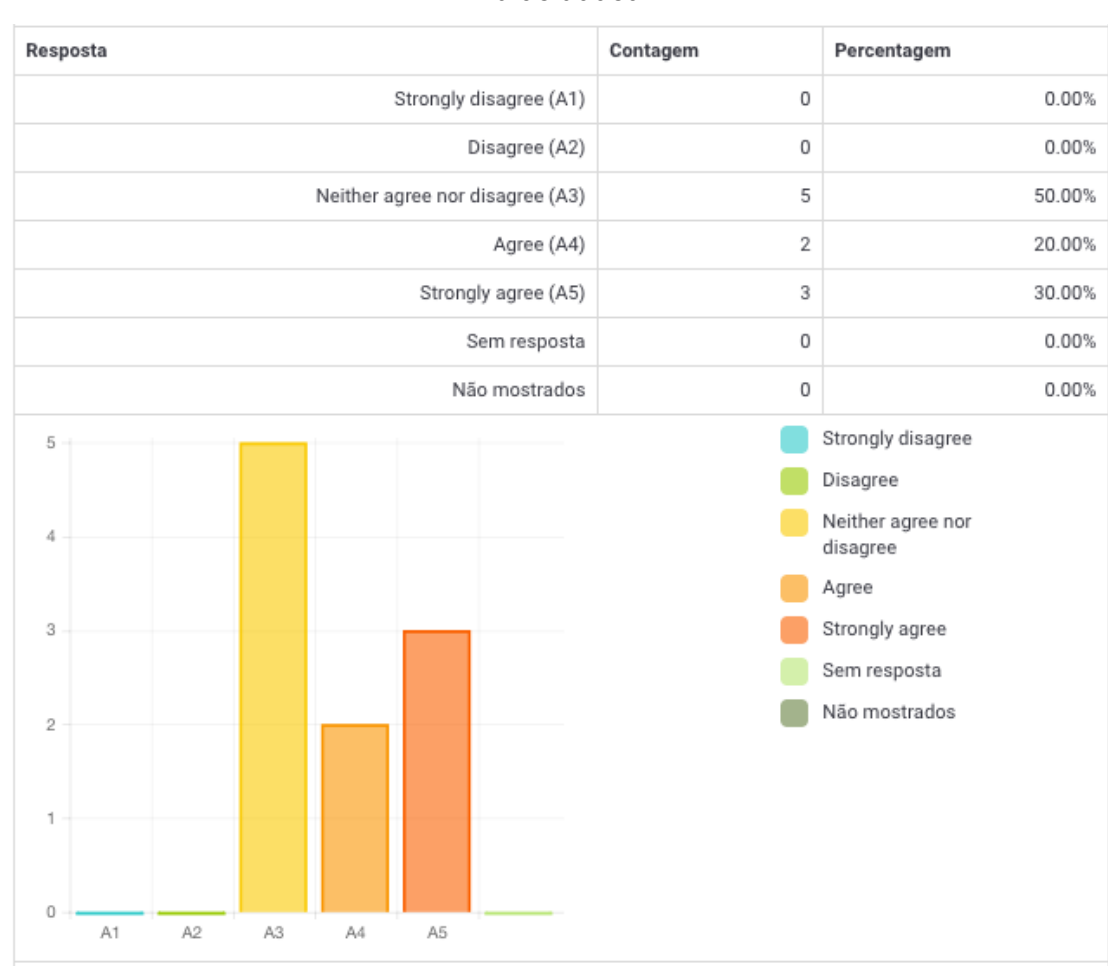

Figure 25 - Factor Economy and subfactor Value-added statistics 
Economic viability

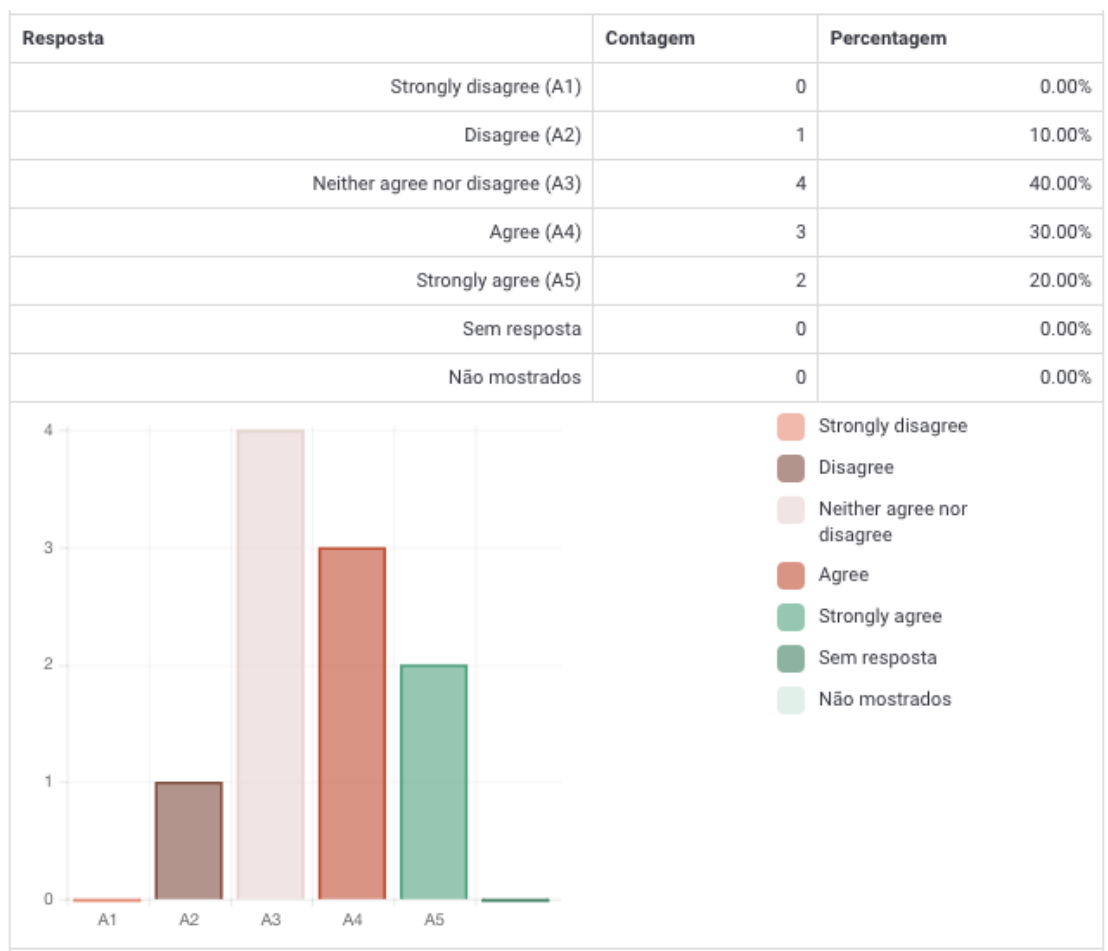

Financial investment

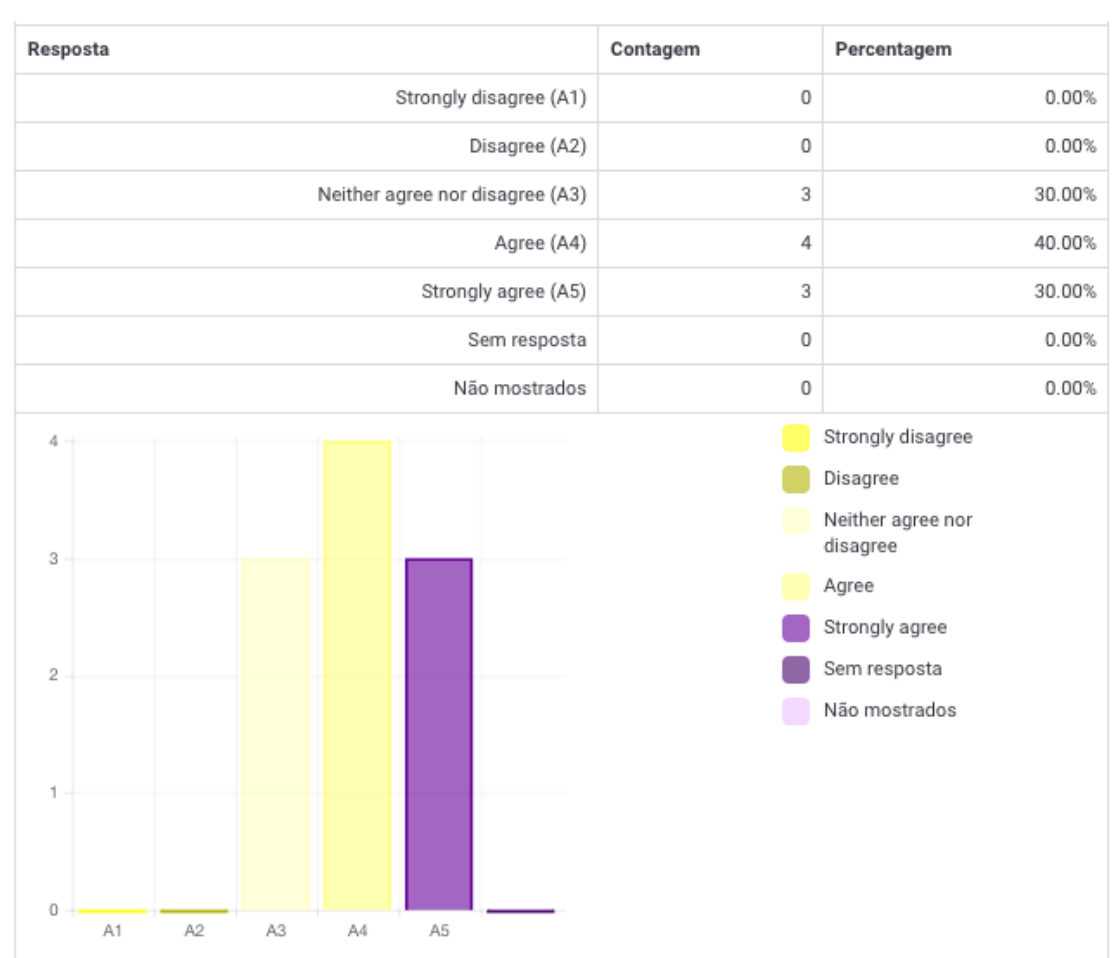

Figure 26 - Economic viability and Financial investment statistics 


\section{Motivation}

Motivation is the purpose that motivates the existence of a reference architecture and must be reasoned and aligned with the application domain, and benefits should be explicit. When asked if this factor influences the reference architecture sustainability, 50\% of the participants replied "Strongly agree. 20\% replied "Agree", and 20\% replied "Neither agree nor disagree". Only one participant (10\%) disagreed with this factor, as showed in Figure 27.

\section{Scope size}

In RASModel, Scope size is the ambit of the reference architecture, including systems that covers, number of partners, attendees, and maintainers, i.e., the "sphere" of the reference architecture.

$80 \%$ of the participants "Agree" that this factor influences the sustainability. $10 \%$ replied "Neither agree nor disagree" and 10\% replied "Disagree". Figure 27 show these results.

\section{Vision Statement}

This factor is described as the reference architecture's roadmap, indicating both what this architecture wants to become and guiding transformational initiatives by setting a defined direction for the reference architecture's growth. As illustrate the Figure 28, 40\% of the participants replied with neutrality ("Neither agree nor disagree"). However, 60\% agreed, where 40\% replied "Agree" and 20\% "Strongly agree".

\section{State-of-the-art alignment}

Is the current knowledge application domain that is considered necessary to be included in reference architecture. Figure 28 shows the statistics with respect to this factor.

$60 \%$ of the participants "Agree" and 30\% "Strongly agree" that State-of-the-art alignment influences the sustainability. Only one participant "Strongly disagree" about this factor.

\section{Regular Updates}

It refers to the continuous update in elements, such as documentation, artifacts, and dissemination issues, related to the reference architecture.

As showed in Figure 29, 70\% of the participants "Strongly agree" and 30\% "Agree" that this factor influences the reference architecture sustainability.

Regarding these Crosscutting factors, no additional comments were registered by the participants. 
Motivation

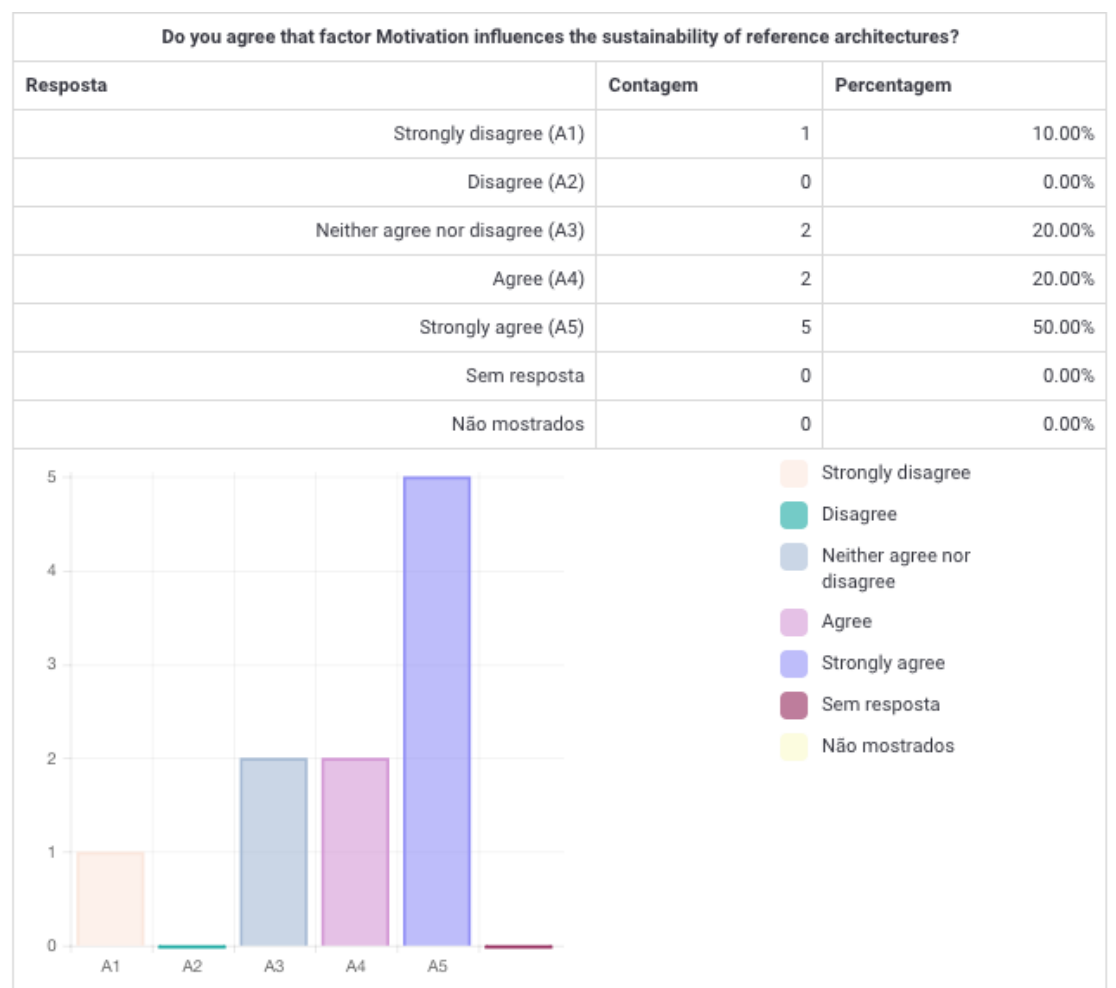

Scope size

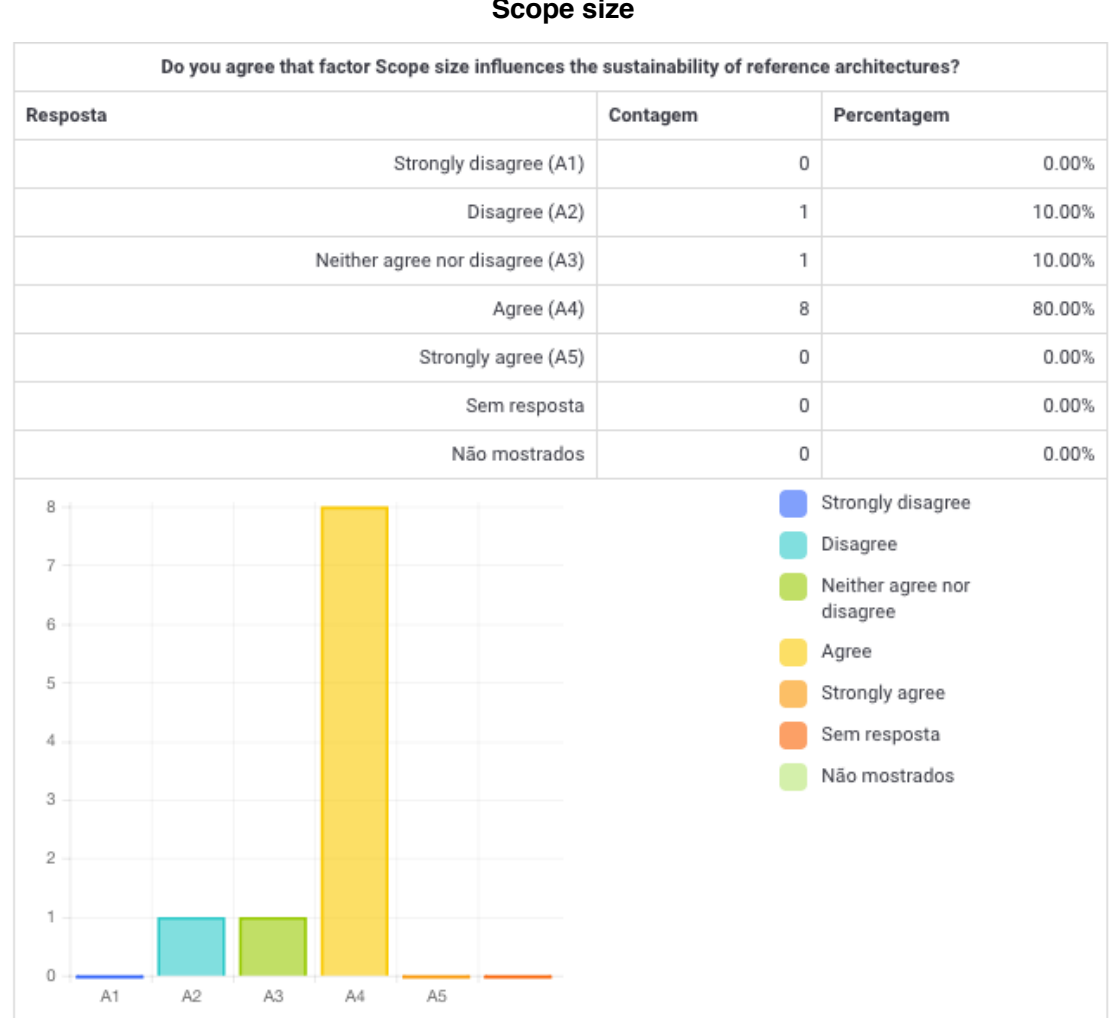

Figure 27 - Motivation and Scope size statistics 
Vision statement

State-of-the-art alignment

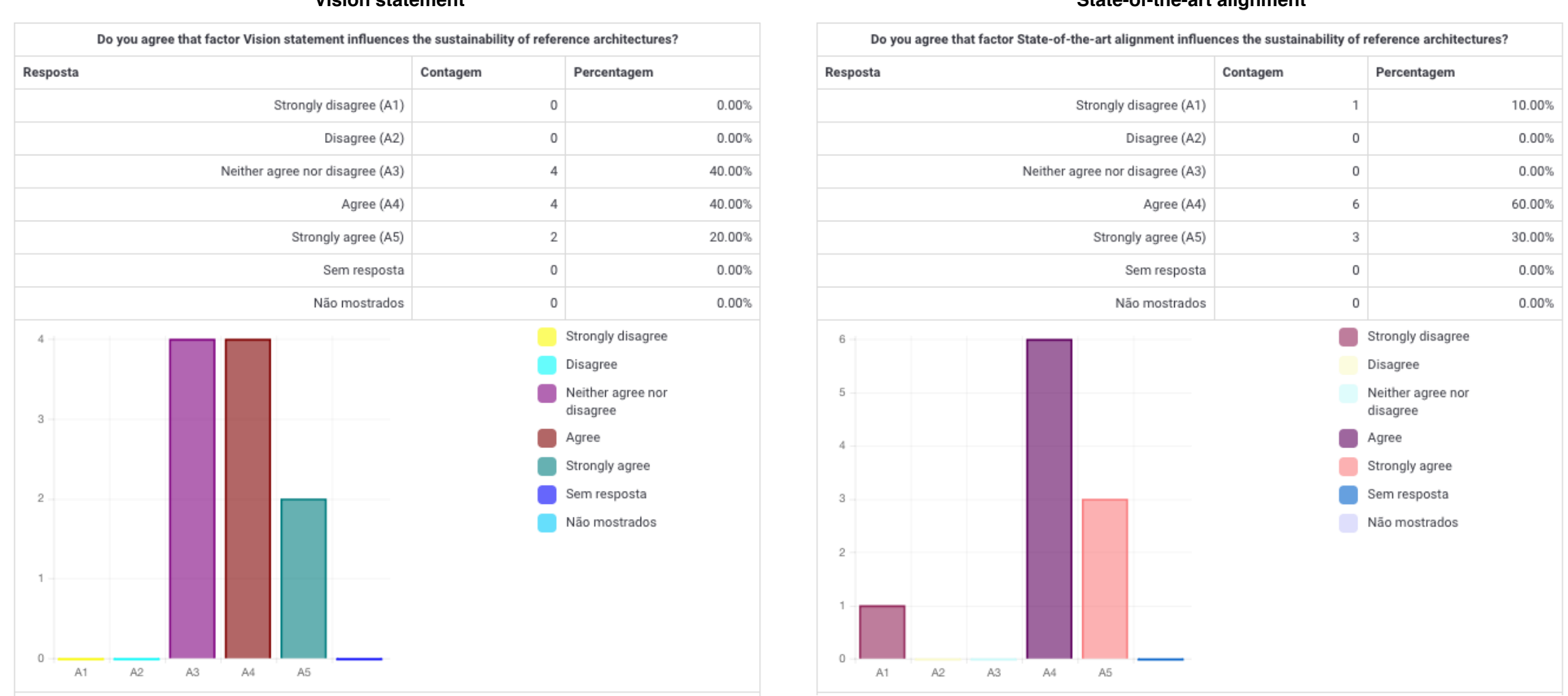

Figure 28 - Vision Statement and State-of-the-art alignment statistics 


\section{Regular updates}

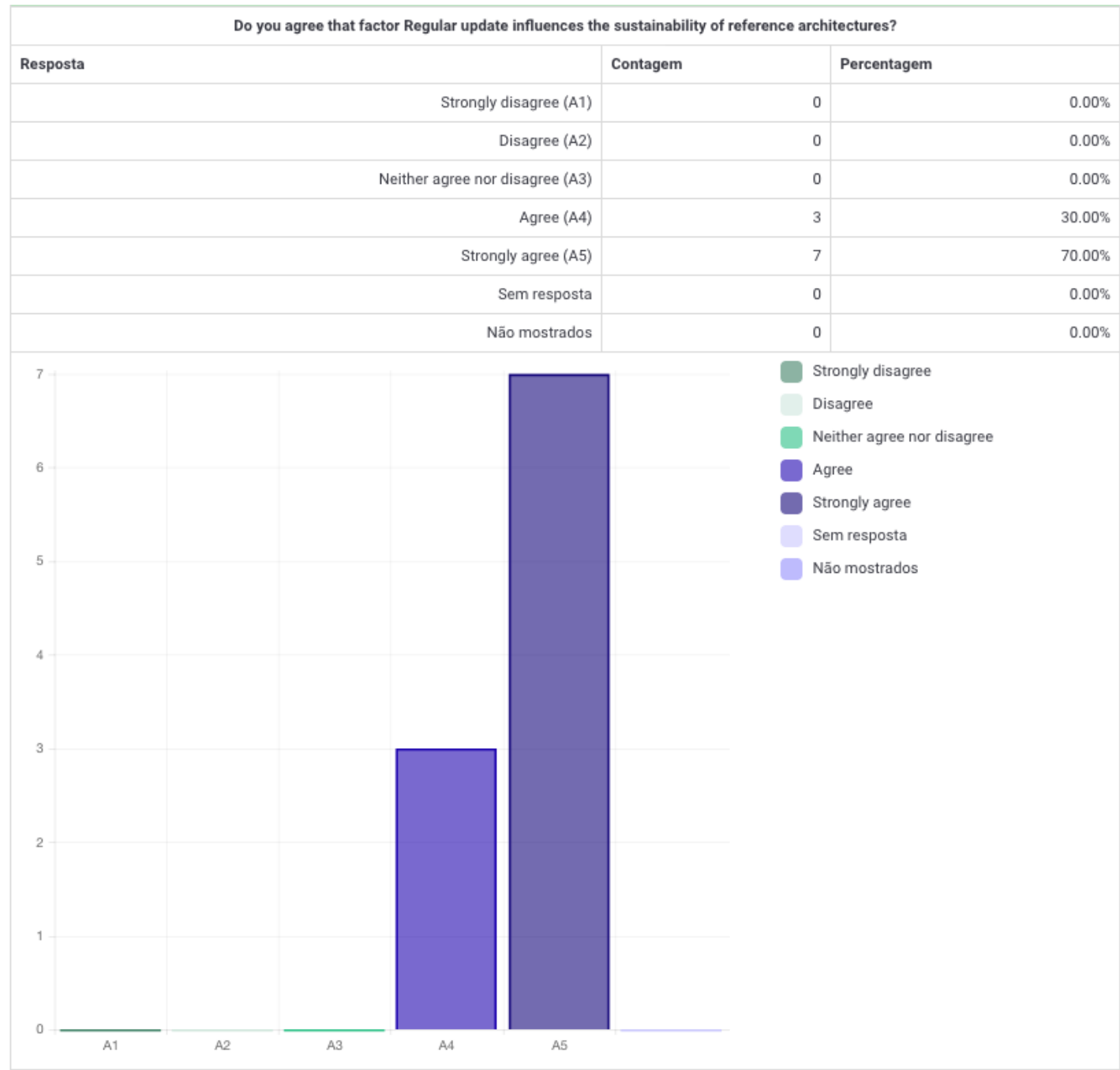

Figure 29 - Regular updates statistics

After judging the degree of agreement of the factors and subfactors in the RASModel, the participants judged the level of importance of these factors and subfactors for the reference architecture sustainability, according to the follow scale:

1. Not at all important;

2. Slightly important;

3. Moderately important;

4. Very important;

5. Extremely important

Figure 30 shows the barplot of means achieved by each factor and subfactor, grouped by colors that are representing the factors (Crosscutting, Documentation, Economy, Stakeholders, and Support). 


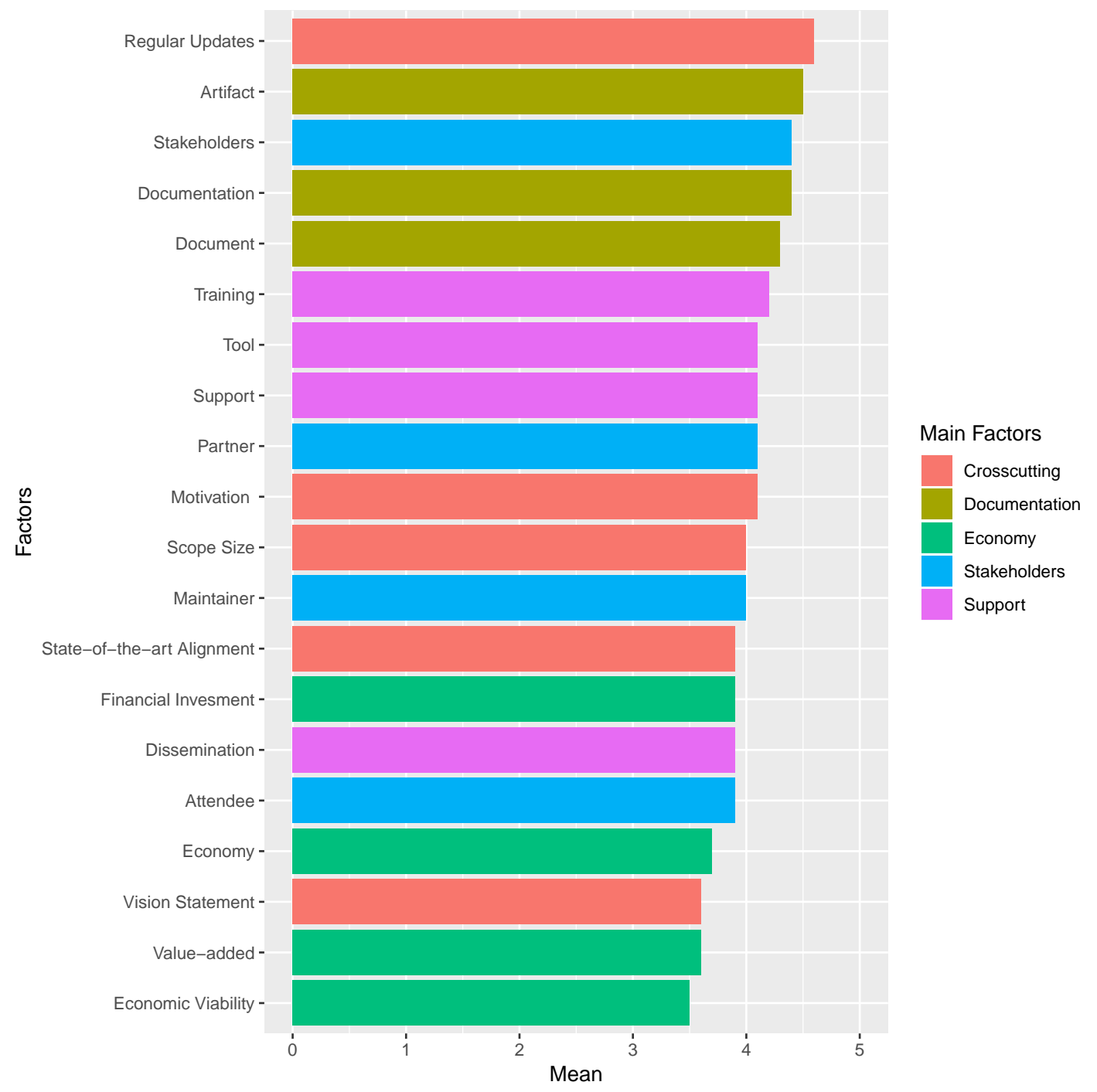

Figure 30 - Boxplot of each factor and subfactor regarding score achieved in linkert-scale

Regular updates was the factor with the highest level of importance judged by participants. An interesting observation is that all factors related to the Documentation were, on average, judged as "Very important" for reference architecture sustainability.

No factor or subfactor was judged as "Not at all important" or "Slightly important". Economic viability and Value-added were the subfactors that received the lowest score, where the average was between "Moderately important" and "Very important".

\subsubsection{Final considerations}

In final considerations page, we asked participants to give us feedback regarding the usefulness of the RASModel, their opinion on model completeness, and finally, a text area for any additional information participants consider relevant to this research.

Concerning RASModel usefulness, most participants (80\%) "Agree" that the model can 
be useful to support reference architecture sustainability analysis. One participant "Strongly agree", while another was neutral. No participant answered "Strongly disagree" or "Disagree". In another words, $90 \%$ of the participants believe that RASModel is useful to reference architecture sustainability, i.e., our model can be useful to indicate whether a reference architecture is sustainable or not. Figure 31 show statistics for this question.

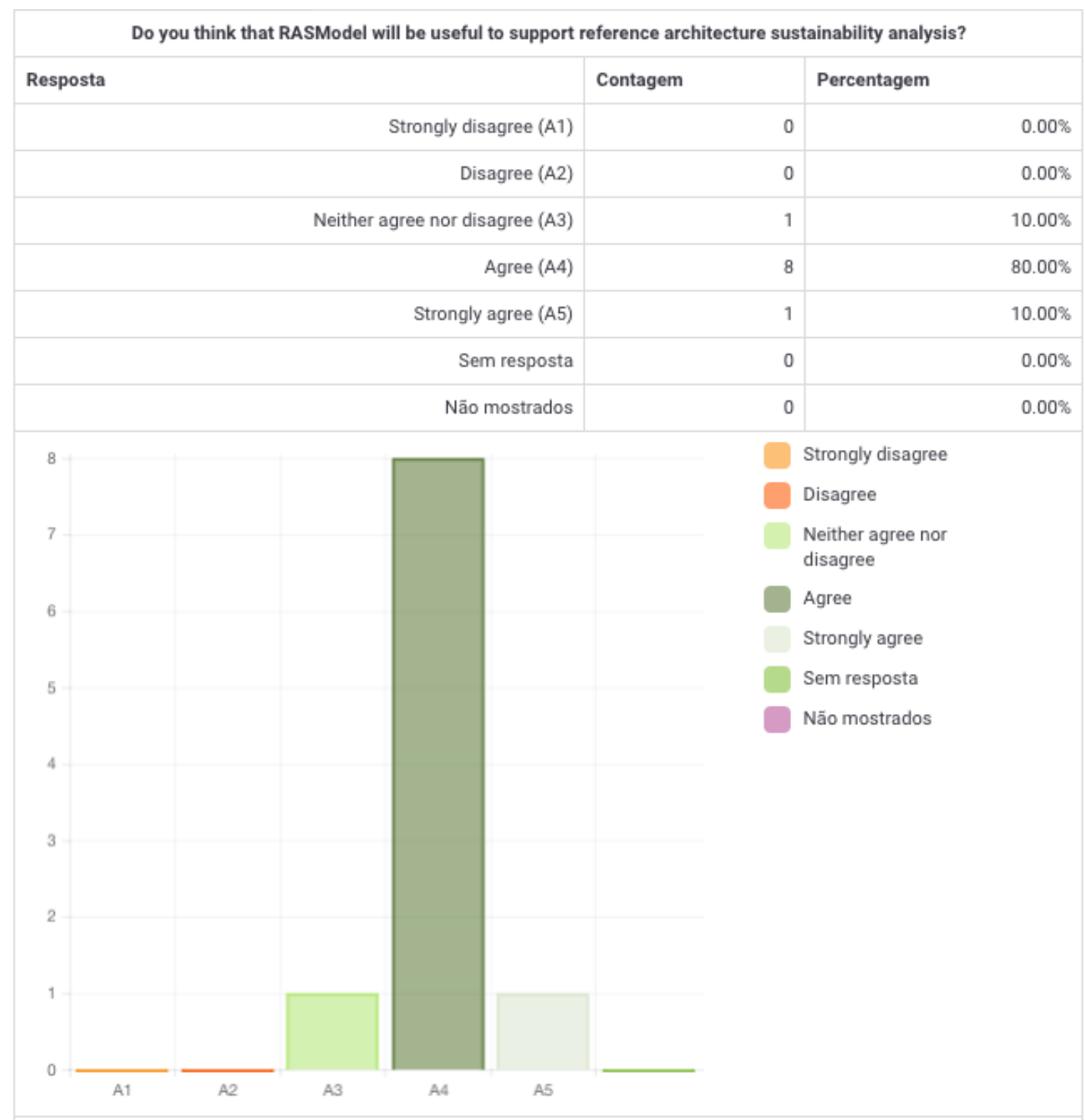

Figure 31 - Usefulness of the RASModel for sustainability analysis

We also asked participants if they think that RASModel can be useful for building newly sustainable reference architectures. Regarding this, 70\% answered "Agree" and 10\% answered "Strongly agree", i.e., $80 \%$ of the participants pointed that agree. One participant was neutral, while another "Disagree". No participant answered "Strongly disagree", as showed in Figure 32. Hence, our model can be useful for the design of reference architectures more sustainable. 


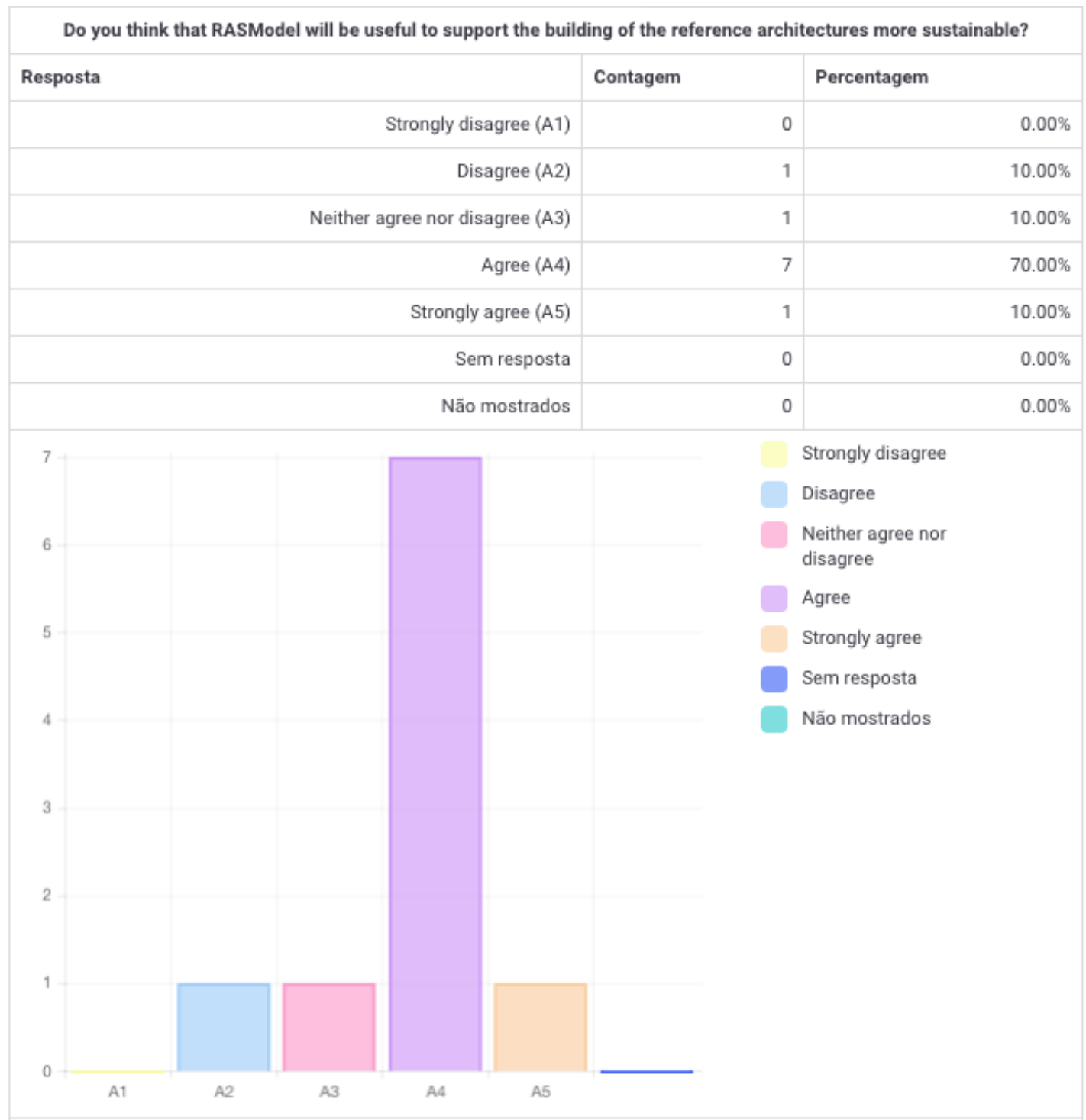

Figure 32 - Usefulness of the RASModel for building reference architectures sustainable

The answer from the participants that disagree or are neutral regarding the RASModel were giving in text format. In summary two participants commented. One participant described that the model would greatly benefit from a guideline supporting its use and that the identification of factors and subfactors was important, but only with this information, the participant would not know how to use RASModel.

Another participant commented that estimating software sustainability using reference architecture is hard to achieve because of the long evolution cycles in well-know reference architectures, and suggested a focus on software and product-specific architectures.

\subsubsection{Discussion of results}

While the questionnaire was running, only one participant requested more specific information to answer the questions. Hence, we understood that the information contained in the 
questionnaire was sufficient and appropriate for the participants to respond appropriately to each question.

Regarding the acceptability of factors and subfactors included in the preliminary model, we understood that most participants agree that all of them should be, in fact, in the RASModel. This is supported by the fact that when asked if there was any factor or subfactor important but that was not present in the model, only two participants indicated. One indicated guideline or help documentation with information about how to work with reference architecture, while another indicated as instantiation manual to support one to instantiate a concrete version of that reference architecture.

As expected, Regular updates was the factor that had the highest percentage of acceptability, with $90 \%$, is that of these, $70 \%$ "Strongly agree". The factor Documentation followed the same trend, where $60 \%$ of participants answered "Strongly agree" and 30\% "Agree", a total of 90\%. Stakeholders also presented a high rate of acceptability, with $90 \%$ of participants agreeing, where $70 \%$ "Agree", and 20\% "Strongly agree".

In a similar way, Support presented $90 \%$ of acceptability, where $60 \%$ of participants answered "Agree", and 30\% answered "Strongly agree".

We also believe that the Crosscutting Factors presented in RASModel were well understood by the participants, because they all presented an acceptability of over half, between $60 \%$ and $90 \%$. 

CHAPTER

6

RASMODEL APPLICATION EXAMPLE

In order to complement the evaluation presented in Chapter 5, this chapter presents an example of the application of the RASModel. For this, we confronted RASModel with ARC-IT (Reference Architecture for Cooperative and Intelligent Transportation) ${ }^{1}$.

We studied all documentation related to this reference architecture, including architecture description documents, key concepts document, requirements, cost analysis, and standards development plan. ARCT-IT is a merge between two previously architectures, as illustrated in Figure 33.

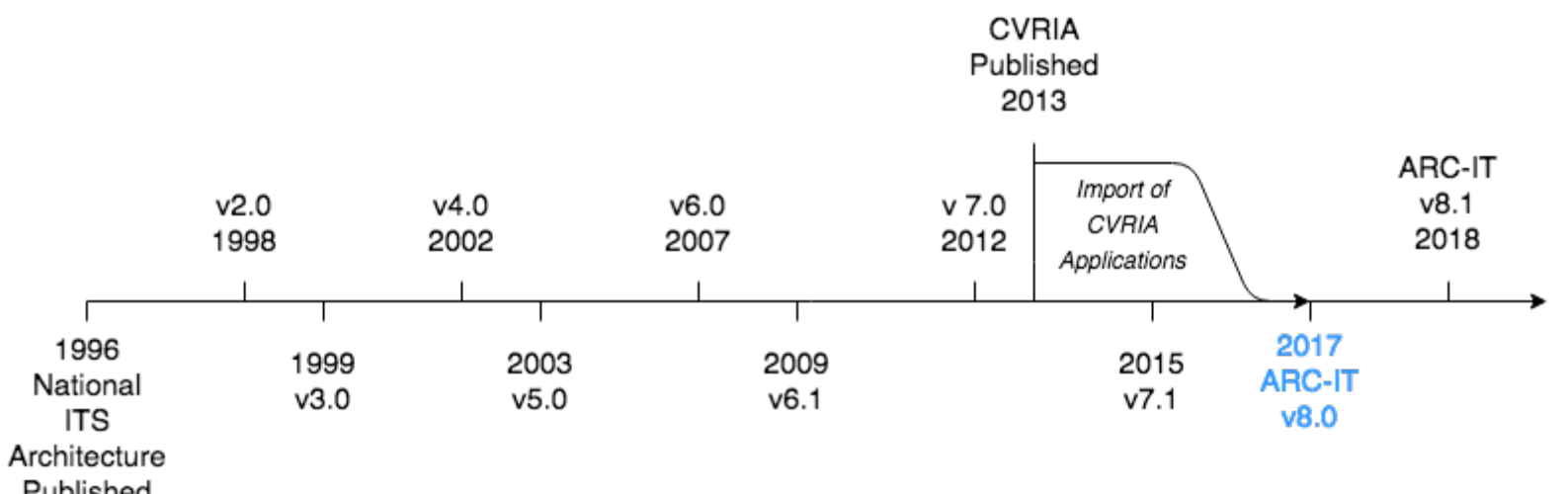

Figure 33 - Timeline with ARC-IT releases

First, National ITS Architecture was published in 1996 by the United States Department of Transportation (US-DOT) ${ }^{2}$, as a consistent framework to guide the planning and deployment of ITS and support for public agencies to assist with development, maintenance, and improvement of their transportation system. From 2013, with the increase of connected vehicle technologies, CVRIA (Connected Vehicles Reference Implementation Architecture) was designed to establish a framework for integrating connected vehicle technologies and identifying interfaces for stan- 
dardization. Many of concepts and features of the National ITS Architecture v7.1 (latest version) remained, but the terminology was updated for consistency with current best practices and the scope and content were updated to represent the latest thinking in ITS. ARC- IT is the latest version of the National ITS Architecture with the merge of the latest version of CVRIA (v2.2). Hence, this reference architecture seems to be adequate to be used to illustrate the use of our proposal, as an external reference architecture of our research group.

More specifically, Section 6.1 describes an overview of ARC-IT. Section 6.2 analyzes the Primary Factors of RASModel observed in ARC-IT. Subsequently, Section 6.3 analyzes the Crosscuting Factors.

\subsection{Application Context}

With the rapid increase of modern economical and technical development, Intelligent Transportation Systems (ITS) have become more important and essential for a country. ITS are based on the increasing demands of the transportation development. They integrate information, communications, computer, and other technologies and applies them in the field of transportation to build an integrated system of people, roads, and vehicles by utilizing advanced data communication technologies. ITS can establish a large, full-functioning, real-time, accurate, and efficient transportation management system. ITS makes service object's focus change from road managers to road users. To achieve this purpose, ITS uses advanced technology to provide drivers with the road information and convenient services to reduce traffic congestion and to increase road capacity (AN; LEE; SHIN, 2011).

In this context, ARC-IT is an initiative of the US-DOT that provides a common framework for planning, defining, and integrating intelligent transportation systems (USA, 2018). ARC-IT is a reference architecture that (USA, 2018):

- Provides common basis for planners and engineers with differing concerns to conceive;

- Design and implement systems using a common language as a basis for delivering ITS;

- Includes artifacts that answer concerns relevant to a large variety of stakeholders;

- Provides tools intended for transportation planners, architects and system engineers to conceive of and develop regional architectures, and scope and develop projects.

More specifically, ARC-IT includes a set of interconnected components that are organized into four views that focus on four different architectures perspectives, as show in Figure 34:

1. Enterprise view: considers the policies, funding incentives, working arrangements, and jurisdictional structure that support the technical layers of the architecture. It provides the 


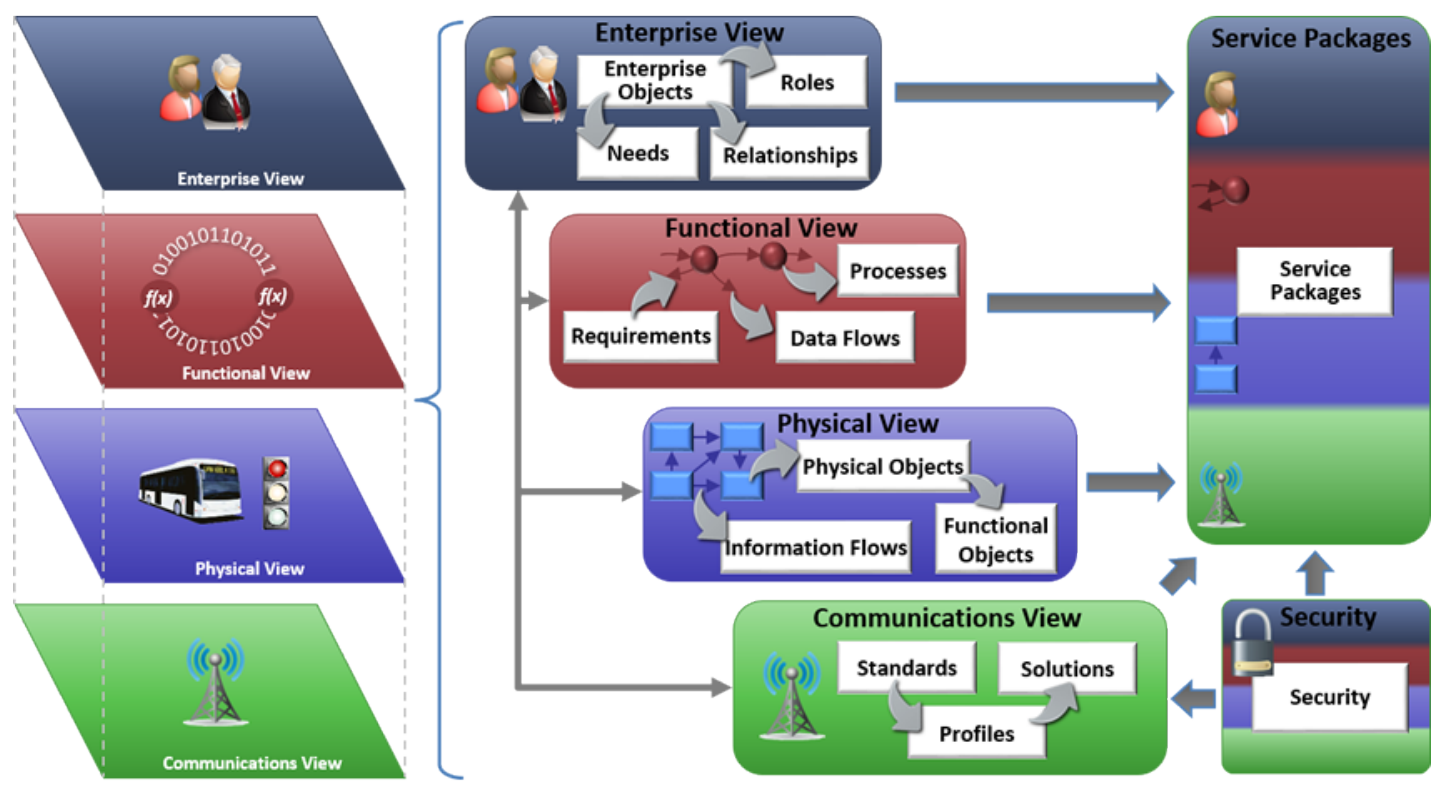

Figure 34 - ARC-IT Overview (USA, 2018)

basis for understanding who the implementers will be and the roles these implementers could take in implementing ITS. The Enterprise Viewpoint is also the source for objectives and goals for the surface transportation system. It also includes the policies and processes for architecture use to support transportation planning and project development. The Enterprise View Application Diagrams supports each connected vehicle application, as showed in Figure 35. These diagrams are focused on identifying the relationships between the institutions and people involved in four phases of an application's lifecycle: development/installation, operations, maintenance, and certification. Enterprise view diagrams are tightly coupled with Physical View diagrams: every system involved in the Operations phase appears as a Physical Object in the Physical View. Stakeholders that take an acquisition, maintenance, installation, operations, certification, policy or user role will find many of their concerns addressed in the Enterprise Viewpoint. The Enterprise Viewpoint enables the stakeholder to answer questions such as:

- Who is responsible for providing transportation-related user services?

- Who is responsible for installation, operations and maintenance of ITS services, applications and devices?

- What relationships need to exist between transportation operators to facilitate services between and within jurisdictions?

- What relationships need to exist between the providers of services and the consumers of services?

ARC-IT Enterprise view defines the following objects: 
- Enterprise Object: An organization or individual that interacts with other Enterprise Objects and/or physical objects. An Enterprise Object may be a component of another larger Enterprise Object, which may in turn be a component of a third, even larger, Enterprise Object. Enterprise Objects may participate wholly or in part in other Enterprise Objects (e.g., a Device Developer is a component of Auto Manufacturer but also participates in Standards Body).

- Resource: An asset that can support the achievement of enterprise objects. This may be a physical or virtual element and may be of limited availability. All physical objects are resources, but other resources may include policies and documents.

- Relationship: Formal or informal coordination between Enterprise Objects; e.g. agreements, contracts, funding, expectations.

- Role: The way in which an object participates in a relationship; an object's set of behaviors and actions associated with the relationship of that object with other objects. 
(2B) vehicle environmental data

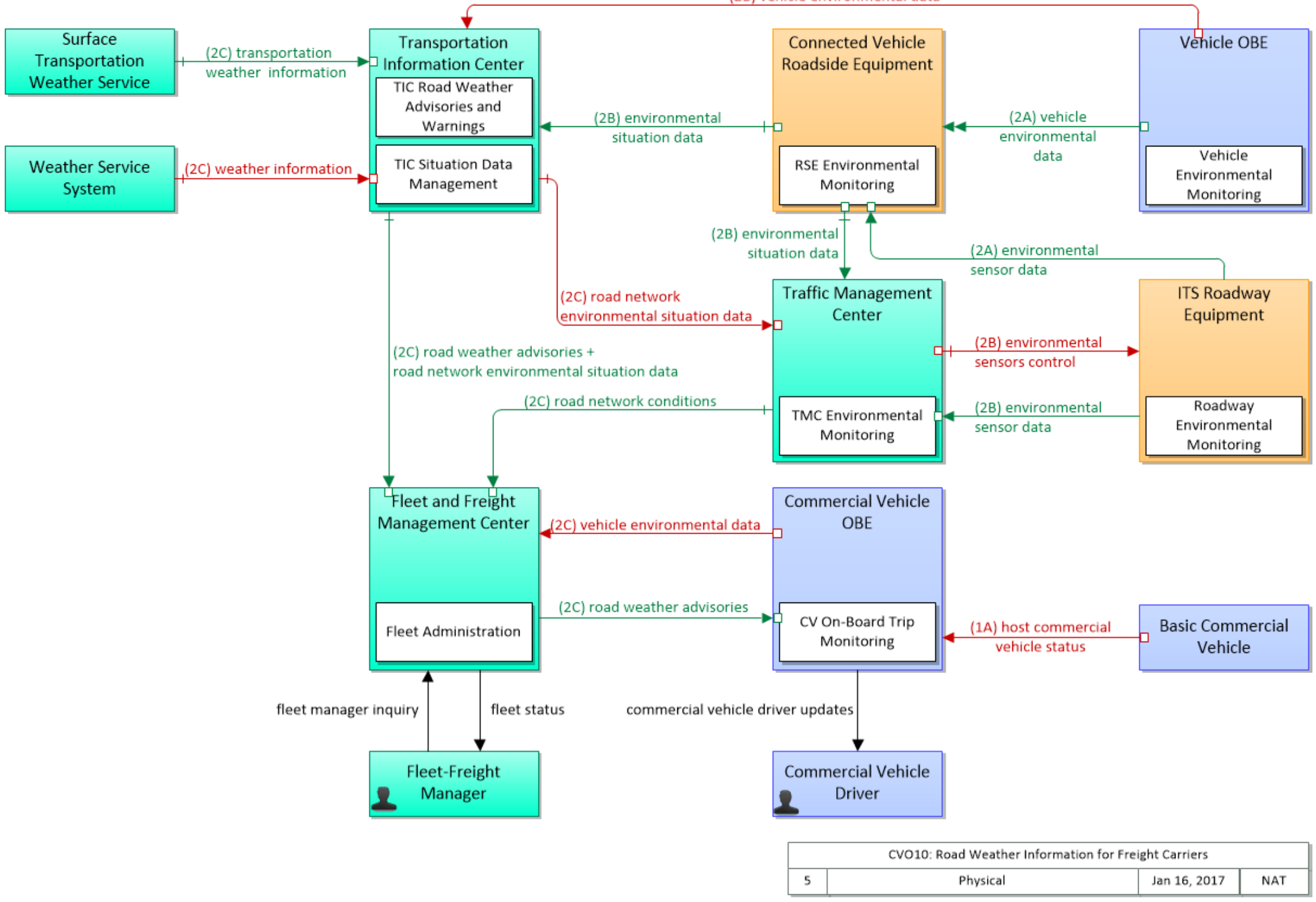

Figure 35 - Example of a Enterprise View with Physical View diagram (USA, 2018) 
2. Functional view: provides an analysis of abstract functional elements and their logical interactions. This is in direct contrast to the physical and communications viewpoints that focus on engineering concerns of how functions are implemented, where they are allocated, how they transfer information, which protocols are used, and what method is used to implement them. In other words, the Functional talks about "the what" while the Physical and Communications are more concerned with "the how."

Stakeholders that take a project development role in an ITS deployment may be informed by the functional viewpoint, in particular the requirements, which are allocated to functional objects in the Physical View. Mostly, this would be stakeholders filling the role of Service Provider, Application Developer or Device Developer. The functional view can help these stakeholders answer questions such as:

- What kinds of data are required to implement a given service?

- What functionality is required to implement a given service?

Structural artifacts of this viewpoint are:

- Process: a function or activity that is required to support service package needs. A Process performs actions to achieve an objective or to support actions of another process. This may involve data collection, data transformation, data generation, data generation or processing in performing those actions. The most detailed processes (sometimes called primitives) are defined in Process Specifications (P-Specs).

- Process Specification (p-spec): the textual definition of the most detailed processes. The process specification includes an overview, a set of functional requirements, and a complete set of inputs and outputs.

- Data Flows: representations of data flowing between processes or between a process and an external physical object (or terminator) in the functional view. Data flows are aggregated together to form high-level information flows in the physical view.

- Terminator: an external physical object that represents a system beyond the architecture boundary. A terminator may be a source and/or a sink for information.

Figure 36 illustrates an example of Functional view associated with a physical object called "Commercial Vehicle Driver". In short, Commercial Vehicle Driver represents the people that operate vehicles transport goods, including both long haul trucks and local pick-up and delivery vans. As it is an external physical object, its is a terminator. Data flow such as drive information, CVO pass/pull-in message, alert response, and trip log information represent the processes between sources and destinations.

3. Physical view: represents physical elements that operate in the field and the backoffice, the functionality contained within those elements, the roles elements play in delivering 


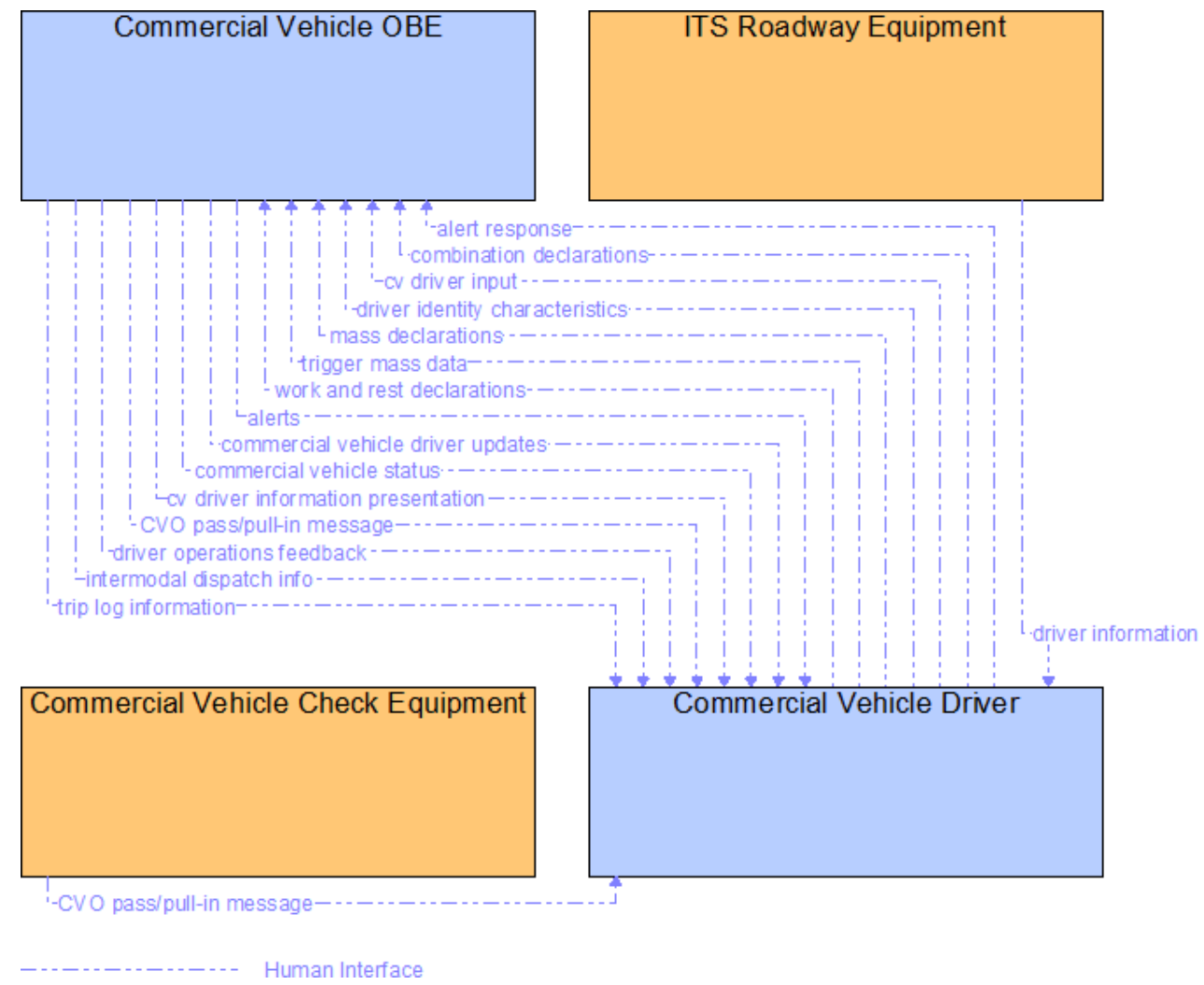

Figure 36 - Example of ARC-IT Funciontal View

user services, and the connections between those elements, as showed in Figure 35. This view provides the basis for Service Packages, which are a concise, comparatively easy to read and follow diagrammatic artifact that communicates notions of service delivery, functionality, information exchange and concerns related to those concepts. The Physical Viewpoint enables the engineer to answer questions such as:

a) What physical entities are involved in the delivery of a given service?

b) What interfaces are required between different physical elements?

c) What functionality is allocated to physical entities?

d) What are the security considerations for information exchanged between physical elements?

e) What are the security considerations for physical devices?

The Physical Viewpoint defines the following objects:

- Physical Object (P-Object): Person, place, or thing that participates in ITS. Physical Objects are defined in terms of the applications they support, the processing they include, and their interfaces with other physical objects. They are grouped into five classes: Center, Field, Support, Traveler and Vehicle. Physical Objects are defined with scope such that they are under the control of a single Enterprise Object. 
- Center: an element that provides application, management, administrative, and support functions from a fixed location not in proximity to the road network. The terms "back office" and "center" are used interchangeably. Center is traditionally a transportation-focused term, evoking management centers to support transportation needs, while back office generally refers to commercial applications;

- Field: infrastructure proximate to the transportation network which performs surveillance (e.g. traffic detectors, cameras), traffic control (e.g. signal controllers), information provision (e.g. Dynamic Message Signs (DMS)) and local transaction (e.g., tolling, parking) functions. Typically governed by transportation management functions running in centers. Field also includes connected vehicle roadside equipment and other non-DSRC wireless communications infrastructure that provides communications between mobile elements and fixed infrastructure.

- Support: a center that provides a non-transportation specific service. Typically these are enabling functions, such as communications facilitation, security or management;

- Traveler: equipment used by travelers to access transportation services pre-trip and en-route. This includes equipment owned and operated by the traveler as well as equipment owned by transportation and information providers.

- Vehicle: vehicles, including driver information and safety systems applicable to all vehicle types.

- Mobile: all vehicles, and mobile Traveler p-objects.

- Functional Object: The building blocks of the physical objects of the physical view. Functional objects group similar processes of a particular Physical Object together into an "implementable" package. The grouping also takes into account the need to accommodate various levels of functionality. Since Functional Objects are both the most detailed components of the physical view and tied to specific service packages, they provide the common link between an interface-oriented architecture definition and deployment-oriented applications. Functional Objects provide the functionality defined by P-Specs in the Functional View.

- Information Flow: Information that is exchanged between physical objects in the physical view. Information flows and their associated communication requirements provide the highest-level definition of interfaces. Information flows are related to entity relationships in the Enterprise View, and are more fully detailed in the Communications View. Information Flows are characterized by Flow Characteristics, which imply various communications protocol standards. They are always accompanied by a provision agreement relationship. Such relationships are formal if both participants are centers, support or field equipment. They are nearly always informal if between 
two mobile objects. If between mobile and fixed, the relationship may be formal if personalized or individually targeted information is exchanged.

- Triple: The combination of P-Object source, Information Flow and P-Object destination. The Triple is the foundational structure used to define an interface.

- Subsystem: Physical object with defined functionality. Inside the ARC-IT system boundary.

- Terminator: Physical object without defined functionality. Outside the ARC-IT system boundary.

- Service Package (Physical) Diagram: A summary diagram illustrating all of the P-Objects, Functional Objects and Information Flows likely needed to support the Service Package. Service Package diagrams may support more than one use case. Physical Service Package diagrams use the following graphics to illustrate physical elements:

4. Communication view: defines how physical objects communicate. It defines communications standards and profiles that are combined into communications solutions that specify how information can be reliably and securely shared between physical objects.

Figure 37 illustrates a profile that identify the chiefly lower layer standards required to perform passive monitoring of Wi-Fi devices.

An interface specification should be defined for any implementation, using this stacks and standards as the basis for that specification. In some cases the specification may be quite simple, as the standards in question offer necessary definitions of dialogs, messages and data elements. In other cases the specification will have to describe a great deal more, depending on the availability of necessary information.

Finally, Security includes three main concerns: (i) information security, that deals with securing the origin, transmittal and destination of information; (ii) operational security, that deals with protecting the physical devices participating in the connected vehicle environment (CVE) from physical and environmental threats; and (iii) personnel security, that ensure that personnel do not inadvertently or maliciously cause harm to CVE assets and have the proper training necessary to respond to security related incidents. Finally, service packages are a service-oriented entry point that makes it easy to view a vertical slice of ARC-IT that spans all four views for a particular ITS service (e.g., traffic signal control).

\subsection{Primary factors}

First, we analyze the Primary Factors, i.e., factors that provide information on the elements that contained of the reference architecture. 


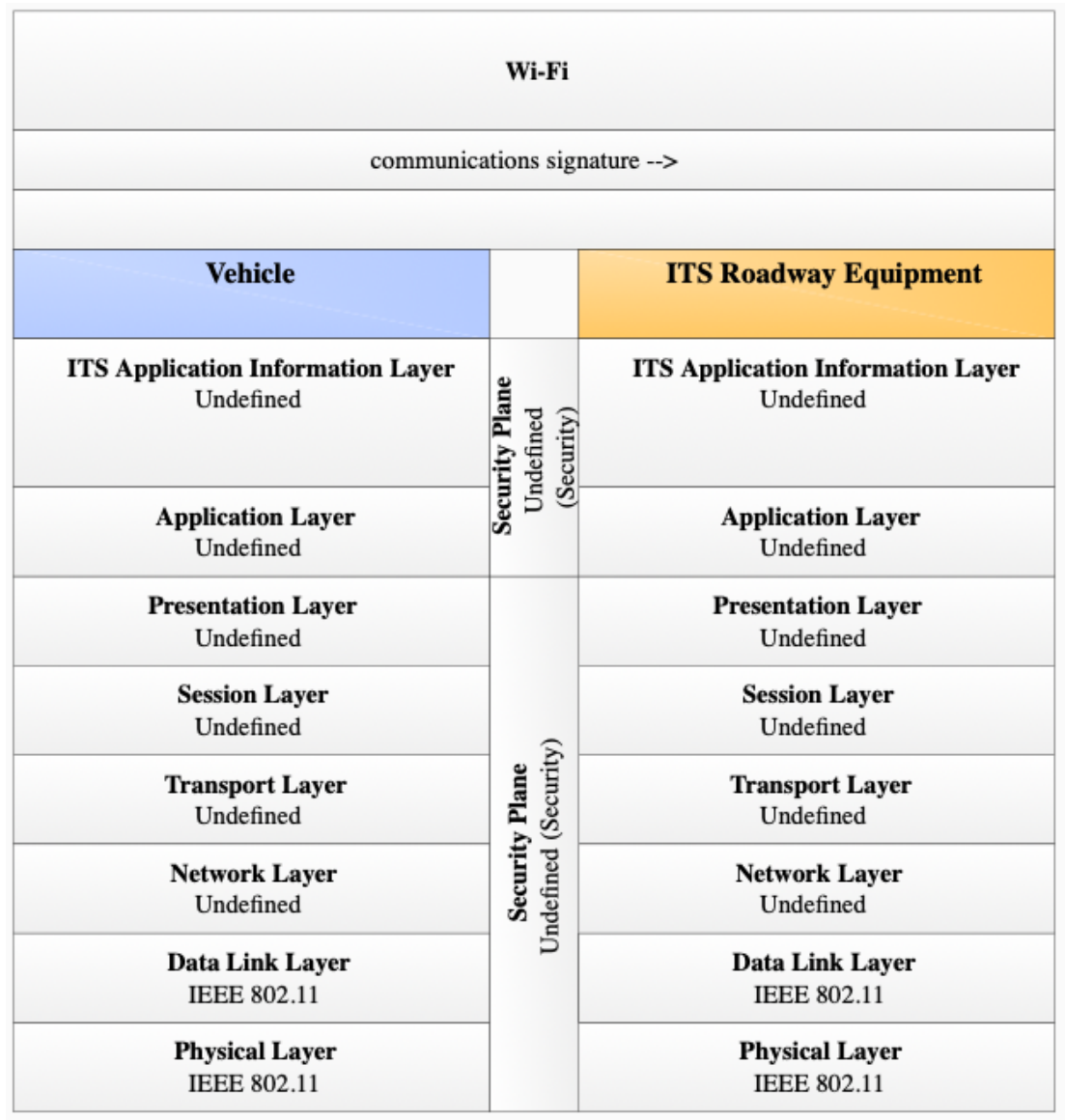

Figure 37 - Example of ARC-IT Communication View

\subsubsection{Documentation}

\section{Document}

ARC-IT provides documents with information on certain aspects of the content and use of the architecture that may be beneficial to a number of readers. These documents are available as compressed PDF files and fall into two categories: (i) Architecture usage, describing ways to use and apply the architecture; and (ii) Architecture description, describing some aspects of the architecture. Table 6 shows some available documents of the ARC-IT.

Table 6 - Available ARC-IT documents

\begin{tabular}{|c|c|}
\hline Document & URL \\
\hline Key Concepts Document & < <https://bit.ly/2ILXeZw> \\
\hline Regional ITS Architecture Guidance & $<$ https://bit.ly/2KpLVMe> \\
\hline Connected Vehicle Environment Primer & $<$ https://bit.ly/2tRSXyo > \\
\hline User Services & $<$ https://bit.ly/2MFyy7k> \\
\hline Architecture Definition & <https://bit.ly/2MFFCB7> \\
\hline Implementation Strategy & $<$ https://bit.ly/2IHNQWM> \\
\hline Standards & $<$ https://bit.ly/2NiKjSy> \\
\hline Security & $<$ https://bit.ly/2IHoAjE > \\
\hline ARC-IT Guidance Document & $<$ https://bit.ly/2tX254M> \\
\hline
\end{tabular}




\section{Artifact}

ARC-IT also provides a database that is the source for the architecture content and website products. Table 7 summarizes the available ARC-IT database, its description, and URL for access.

Table 7 - Available ARC-IT databases

\begin{tabular}{|c|c|c|}
\hline Database & Description & URL \\
\hline Communications & $\begin{array}{l}\text { Defines all the communications protocols and related stan- } \\
\text { dards that have been identified to date for each of the ARC- } \\
\text { IT interfaces. }\end{array}$ & < <ttps://bit.ly/2tWMq5D> \\
\hline Enterprise & $\begin{array}{l}\text { Defines the enterprise objects, resources, and coordination } \\
\text { between the objects along with their connection to the Phys- } \\
\text { ical View components. }\end{array}$ & <https://bit.ly/2yXGiQn> \\
\hline Functional & $\begin{array}{l}\text { Defines all the processes, data flows, and data stores in the } \\
\text { ARC-IT Functional View. This also includes traceability for } \\
\text { each process to the Requirements. }\end{array}$ & $<$ https://bit.ly/2KBkNt3> \\
\hline Physical & $\begin{array}{l}\text { Defines all physical objects, functional objects, intercon- } \\
\text { nects, and information flows in the Physical View and their } \\
\text { connection with the Functional View components. }\end{array}$ & $<$ https://bit.ly/2yYMDuz> \\
\hline Planning & $\begin{array}{l}\text { Defines the planning goals, objectives, and performance } \\
\text { measures and their relationship to the service packages. }\end{array}$ & $<$ https://bit.ly/2KAexBH> \\
\hline Requirements & $\begin{array}{l}\text { Defines the user needs for each service package and the } \\
\text { functional requirements that support each need. }\end{array}$ & $<$ https://bit.ly/2IFZMs5> \\
\hline Security & $\begin{array}{l}\text { Defines the confidentiality, integrity, and availability analy- } \\
\text { sis for each information flow triple. Defines device security } \\
\text { classes and assigns these to each physical object, per service } \\
\text { package. }\end{array}$ & $<$ https://bit.ly/2tP5TFc $>$ \\
\hline Service Packages & $\begin{array}{l}\text { Defines the service packages and their relationship to the } \\
\text { physical objects, functional objects, and information flows } \\
\text { in the Physical View. }\end{array}$ & $<$ https://bit.ly/2lLwVtu> \\
\hline
\end{tabular}

\subsubsection{Support}

\section{Dissemination}

As for the dissemination, we note that ARC-IT is disseminated through a website (<https://local.iteris.com/arc-it/index.html $>$ ) that provides all information and is constantly updated. Besides that, this architecture is disseminated by US-DOT, a government agency responsible for the management of the transportation system of the United States.

\section{Training}

As an example in the context of ARC-IT, US-DOT offers training courses and workshops related to ARC-IT Architecture, and Systems Engineering, as showed in Table 8. 
Table 8 - ARC-IT training

\begin{tabular}{|c|c|c|c|}
\hline Topic area & Web-Based Training & On-Site Training & Workshops \\
\hline ARC-IT Architecture & $\begin{array}{l}\text { - ARC-IT Web Training } \\
\text { - Use and Maintenance } \\
\text { Web }\end{array}$ & ARC-IT 101 / Refresher & $\begin{array}{l}\text { - Architecture Develop- } \\
\text { ment Workshop } \\
\text { - Use and Maintenance } \\
\text { Workshop }\end{array}$ \\
\hline Systems Engineering & & $\begin{array}{l}\text { Systems } \\
\text { Training }\end{array}$ & $\begin{array}{l}\text { Systems Engineering for } \\
\text { ARC-IT Workshop }\end{array}$ \\
\hline
\end{tabular}

\section{Tool}

Regarding this subfactor, ARC-IT offers two tools that enable regional and project architects to manipulate ARC-IT content and produce regional and project architectures. These tools are:

$R A D-I T$ (Regional Architecture Development for Intelligent Transportation): focuses in on regional planning and the development of Operations Concepts, the high level enterprise and physical views. It requires an understanding of the stakeholders community and the ITS services that are provided and planned for in the region. In addition, this tool provides all of the functionally with a modern user interfaces, and the linkages necessary to support future evolution of the toolset. RAD-IT Version 8.1.61 is available for download in $<$ https://local.iteris. com/arc-it/html/resources/radit.html $>$.

SET-IT (Systems Engineering Tool for Inteliggent Transportation): provides a single software tool that integrates drawing and database tools with the ARC-IT so that users can develop project architectures for pilots, test beds and early deployments. This tool, in your version 8.1.61, is available for download in <https://local.iteris.com/arc-it/html/forms/setitform.php $>$.

Besides that, the Office of the Assistant Secretary for Research and Technology of the United States Department of Transportation offers two other tools for ARC-IT deployment support:

Test Procedure Generator (TPG): automates the development of test procedures for ARC-IT Standards. Agencies can use the test procedures generated by the TPG to help determine an implementation's conformance to the ARC-IT Standards. TPG is availabl in $<$ https://www. standards.its.dot.gov/DeploymentResources/Tools\#c2c>.

Center to Center (C2C) Reference Implementation (RI) Tool: supports efficient deployment of systems using $\mathrm{C} 2 \mathrm{C}$ communications by providing a means to verify conformance to $\mathrm{C} 2 \mathrm{C}$ standards. The $\mathrm{C} 2 \mathrm{C}$ Interface may be between to traffic management centers or any two centers that need to coordinate (regionally or locally) the management of a corridor, arterial, incident mitigation, event management and more. This tool is available in $<$ https://www.standards.its.dot.gov/DeploymentResources/Tools\#c2c $>$. 


\subsubsection{Stakeholders}

In ARC-IT, US-DOT (United States Department of Transportation) is a Partner, because they are responsible for ARC-IT foundation, and also play the role of Maintainer, because they have a "Architecture Team" < (https://bit.ly/2KG7O9E) $>$ that manipulates the ARC-IT content. As some Attendees, ARC-IT was adopted by regional governments in cities such as New York City and Tampa, and some states such as Wyoming, and Michigan. In addition, the government of Mexico and Canada has adopted ARC-IT in pilot projects and provided feedback to US-DOT.

\subsubsection{Economy}

\section{Value-added}

Regarding this, ARC-IT presents a Performance and Benefits Study where describe benefits obtained by their adoption. The complete study is available in <https://local.iteris. com/arc-it/documents/perfben/perfben.pdf $>$.For example, this document describes that ARC-IT contributes to developing consensus standards for ITS (Intelligent Transportation Systems). Such standards, have the following benefits and impacts:

Expanded markets and lower costs: open interface standards may result in an expanded market for ITS products and services, with resulting price competition and lower final costs to the end user. Such an expanded market may in turn result in network externalities, where simply having more users may mean additional cost reductions or increased benefits for users (e.g. route guidance, dynamic ridesharing, or regional traffic management);

Compatibility: open interface standards also provides many technical benefits to the end user, including: portability, interoperability, and easier data exchange between ITS applications;

Technology innovation: ITS standards may impede the long-term adoption of innovative technologies surrounding a given standard. For example, wide-area wireless communication standards for ITS could be "locked in" to a certain technology before more useful or cost-effective technologies have a chance. Thus, a standard may lead to an ITS industry settling on inferior technology. However, a standard may also serve to promote rapid technology development and innovation for specific components. The net impact on technology development is not easily quantified;

Vendor interests: The long-term benefits of standards to ITS product and service vendors may be very favorable. In markets such as for ITS, industry consensus standards can result in the development or expansion of the market altogether;is the contribution generated by the reference architecture within the application domains that is inserted. In other words, it is analyzing the impact of the reference architecture in the application. For instance, a reference architecture can standardize and guide the development of intelligent cooperative vehicle design in the context of a smart city. Thus, this architecture has an added value in order to help governments plan mobility policies and for civil society to have more security and efficiency to use transport. 


\section{Economic viability}

ARC-IT has a study with Cost Analysis (available in <https://local.iteris.com/arc-it/ documents/cost/cost.pdf $>$ ), and Risk Analysis (available in $<$ https://local.iteris.com/arc-it/documents/ risk/risk.pdf>).Cost Analysis has two purposes. First, it develops a high level cost estimate of the expenditures that are associated with implementing ITS components. Second, it is a costing tool for implementers, by providing unit prices and systems costs of ITS subsystems. On the other hand, Risk Analysis presents an analysis of potential critical risks that may delay or prevent the deployment of ITS technologies, and recommends mitigation plans which will eliminate of reduce these risks to the deployment process.

\section{Financial investment}

As the application domain of ARC-IT is ITS, architecture's resources are classified into likely stakeholder responsibility for funding (as presented in the Cost Analysis Document (available in <https://local.iteris.com/arc-it/documents/cost/cost.pdf >), as showed in Table 9.

Table 9 - ARC-IT resources investment

\begin{tabular}{ll}
\hline Stakeholder & $\begin{array}{l}\text { Percent of Total Funding Re- } \\
\text { quirements }\end{array}$ \\
\hline \hline Government & $12 \%$ \\
Commercial & $7 \%$ \\
Individual & $81 \%$ \\
\end{tabular}

\subsection{Crosscuting factors}

In this section, we present the observations in ARC-IT as to the factors that are usually spread across and/or tangled with all Primary Factors.

\subsubsection{Motivation}

The main motivation of ARC-IT is "planning, defining, and integrating ITS (Intelligent Transportation Systems)" (USA, 2018). The document "Mission Definition" (available in <https: //local.iteris.com/arc-it/documents/mission/mission.pdf>) was developed to explain the original motivation of the architecture development effort, and was update over the years to include the revisions in its motivation.

\subsubsection{Vision Statement}

ARC-IT described a document with it Vision Statement that sketches a number of possible scenarios of ITS development over the next 20 years. This document is available in $<$ https://local.iteris.com/arc-it/documents/vision/vision.pdf $>$. Besides that, ARC-IT presents a vision statement with respect to investments over 20 years, as shown in Figure 38 . The chart 
shows the 14 subsystems of ARC-IT and their investment between 1-5 years, 6-11 years, and 12-20 years. These investments are divided between government, commercial, and individual initiatives, as showed earlier in Table 9. 


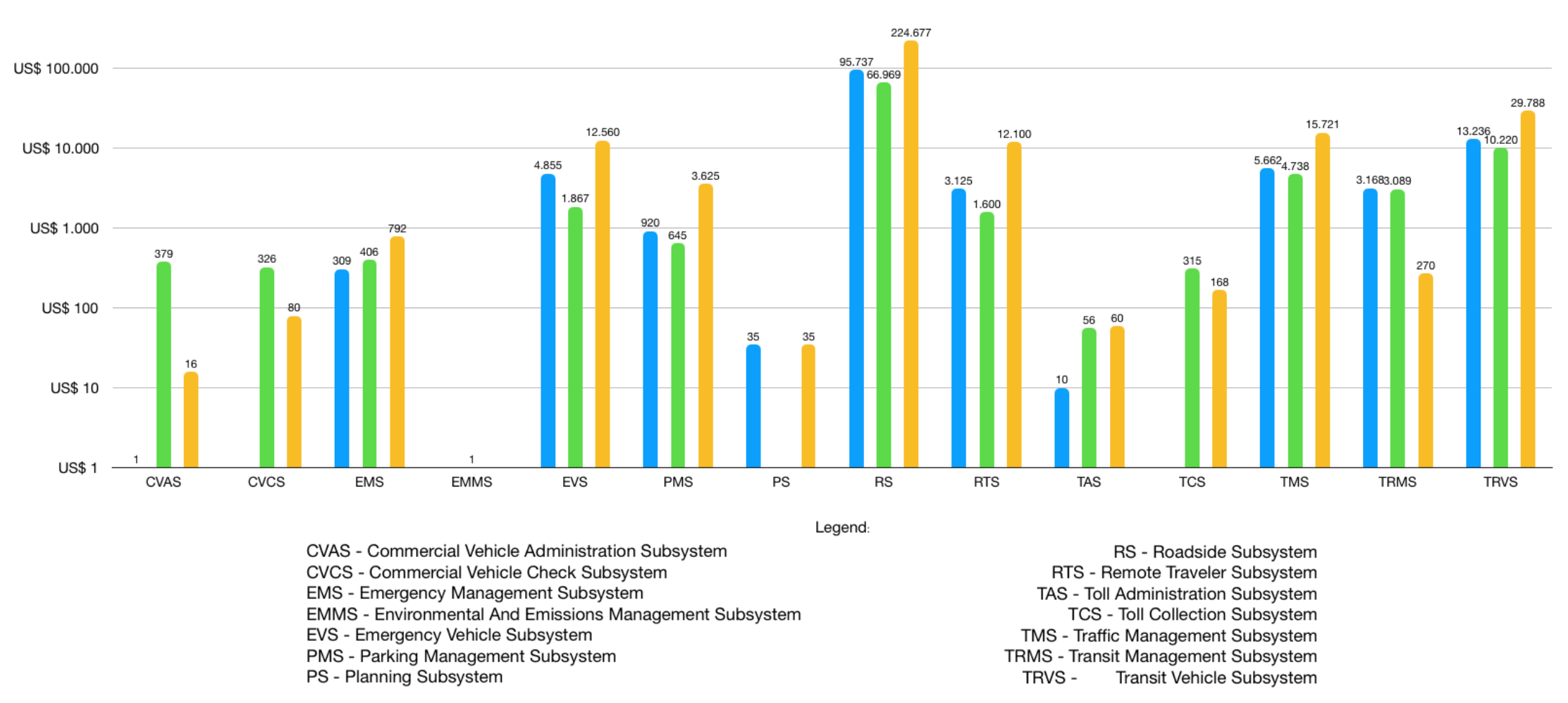

Figure 38 - Vision statement with financial investment over 20 years of ARC-IT 


\subsubsection{State-of-the-art Alignment}

Regarding this factor, ARC-IT has a "Standards Development Plan" (available in <https: //local.iteris.com/arc-it/documents/sdp/sdp.pdf $>$ ) that discusses the issues that were involved in the development of system interface standards and the relationship of ITS standards to the architecture. It was created as a guide for standards developers during the initial stages of the ITS standards program, and has led to many new ITS standards since then. As a result of enhancements to the architecture since this document was published, there are now additional candidate architecture flows to be considered for future standardization.

For example, the version 7.0 of this architecture described 22 communications profiles that were developed following closely the naming practices of the OSI (Open Systems Interconnection) Model. In the latest version, 8.1, ARC-IT describes 25 communication profiles. In particular, DSRC-UDP (Vehicle-to-Vehicle/Infrastructure using UDP) is one of these profiles that describe a set of standards applicable to broadcast, frequent, medium latency vehicle-to-vehicle and vehicle-to-infrastructure communications using the User Datagram Protocol (UDP). As showed in Figure 39, this communication profile dropped to support the IEE 802 MAC in Data Link Layer and update the communication standard in Presentation Layer, replacing the standard ISO ASN.1 DER to ISO.ASN.1 UPER, that was introduced in 2015.

\subsubsection{Scope Size}

For instance, ARC-IT has a scope that covers 12 areas of systems:

1 - Commercial Vehicle Operations;

2- Data Management;

3 - Mainteinance and Construction;

4 - Parking Management;

5 - Public Safety;

6 - Public Transportation;

7 - Support;

8 - Sustainable Travel;

9 - Traffic Management;

10 - Traveler Information;

11 - Vehicle Safety;

12 - Weather

More information about this areas and ARC-IT scope is available in <https://local.iteris. com/arc-it/html/servicepackages/servicepackages-areaspsort.html>. 
Version 7.0

\begin{tabular}{|c|c|c|}
\hline \multicolumn{3}{|c|}{ DSRC-UDP } \\
\hline \multicolumn{3}{|c|}{ information flow --> } \\
\hline Source Physical Object & & Destination Physical Object \\
\hline $\begin{array}{l}\text { ITS Application Information Layer } \\
\text { information standards }\end{array}$ & \multirow{2}{*}{ 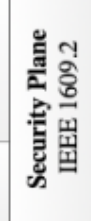 } & $\begin{array}{l}\text { ITS Application Information Layer } \\
\text { information standards }\end{array}$ \\
\hline $\begin{array}{l}\text { Application Layer } \\
\text { Undefined }\end{array}$ & & $\begin{array}{l}\text { Application Layer } \\
\text { Undefined }\end{array}$ \\
\hline $\begin{array}{l}\text { Presentation Layer } \\
\text { ISO ASN.1 DER }\end{array}$ & \multirow{6}{*}{ 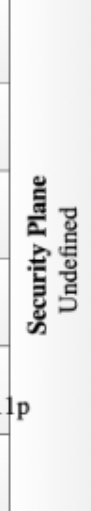 } & $\begin{array}{l}\text { Presentation Layer } \\
\text { ISO ASN.1 DER }\end{array}$ \\
\hline $\begin{array}{l}\text { Session Layer } \\
\text { IETF DTLS }\end{array}$ & & $\begin{array}{l}\text { Session Layer } \\
\text { IETF DTLS }\end{array}$ \\
\hline $\begin{array}{l}\text { Transport Layer } \\
\text { IETF UDP }\end{array}$ & & $\begin{array}{l}\text { Transport Layer } \\
\text { IETF UDP }\end{array}$ \\
\hline $\begin{array}{l}\text { Network Layer } \\
\text { IETF IPv6 }\end{array}$ & & $\begin{array}{l}\text { Network Layer } \\
\text { IETF IPv6 }\end{array}$ \\
\hline $\begin{array}{l}\text { Data Link Layer } \\
\text { IEEE 1609.4, IEEE } 802 \text { MAC, IEEE } 802.11\end{array}$ & & $\begin{array}{c}\text { Data Link Layer } \\
\text { IEEE 1609.4, IEEE } 802 \text { MAC, IEEE } 802.11\end{array}$ \\
\hline $\begin{array}{l}\text { Physical Layer } \\
\text { IEEE 802.11p }\end{array}$ & & $\begin{array}{l}\text { Physical Layer } \\
\text { IEEE } 802.11 \mathrm{p}\end{array}$ \\
\hline
\end{tabular}

Version 8.1

\begin{tabular}{|c|c|c|}
\hline \multicolumn{3}{|c|}{ DSRC-UDP } \\
\hline \multicolumn{3}{|c|}{ information flow --> } \\
\hline Source Physical Object & & Destination Physical Object \\
\hline $\begin{array}{l}\text { ITS Application Information Layer } \\
\text { information standards }\end{array}$ & \multirow{2}{*}{ 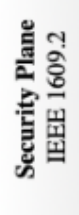 } & $\begin{array}{l}\text { ITS Application Information Layer } \\
\text { information standards }\end{array}$ \\
\hline $\begin{array}{l}\text { Application Layer } \\
\text { Undefined }\end{array}$ & & $\begin{array}{l}\text { Application Layer } \\
\text { Undefined }\end{array}$ \\
\hline $\begin{array}{l}\text { Presentation Layer } \\
\text { ISO ASN.1 UPER }\end{array}$ & \multirow{6}{*}{ 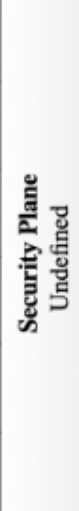 } & $\begin{array}{l}\text { Presentation Layer } \\
\text { ISO ASN.1 UPER }\end{array}$ \\
\hline $\begin{array}{l}\text { Session Layer } \\
\text { Undefined }\end{array}$ & & $\begin{array}{l}\text { Session Layer } \\
\text { Undefined }\end{array}$ \\
\hline $\begin{array}{l}\text { Transport Layer } \\
\text { IETF UDP }\end{array}$ & & $\begin{array}{l}\text { Transport Layer } \\
\text { IETF UDP }\end{array}$ \\
\hline $\begin{array}{l}\text { Network Layer } \\
\text { IETF IPv6 }\end{array}$ & & $\begin{array}{l}\text { Network Layer } \\
\text { IETF IPv6 }\end{array}$ \\
\hline $\begin{array}{l}\text { Data Link Layer } \\
\text { IEEE 1609.4, IEEE 802.11 }\end{array}$ & & $\begin{array}{c}\text { Data Link Layer } \\
\text { IEEE 1609.4, IEEE } 802.11\end{array}$ \\
\hline $\begin{array}{l}\text { Physical Layer } \\
\text { IEEE } 802.11\end{array}$ & & $\begin{array}{l}\text { Physical Layer } \\
\text { IEEE } 802.11\end{array}$ \\
\hline
\end{tabular}

Legend:

$\rightarrow$ Removed

Added

Figure 39 - Updates in DSRC-UDP Communication Profile 


\subsubsection{Regular Update}

Analyzing the ARC-IT life-cycle, we observed a total number of 25 releases, from the very beginning of ARC-IT until now which represents a period of 5 years. In this scenario, ARCIT presented a total of 28 corrections, 78 improvements, and 23 adaptations in their life-cycle. These, 16 corrections (60\% of total) and 45 improvements (58\% of total) were made only in 2013, when CVRIA applications were imported. Hence, in 2013, ARC-IT had the largest number of versions released.

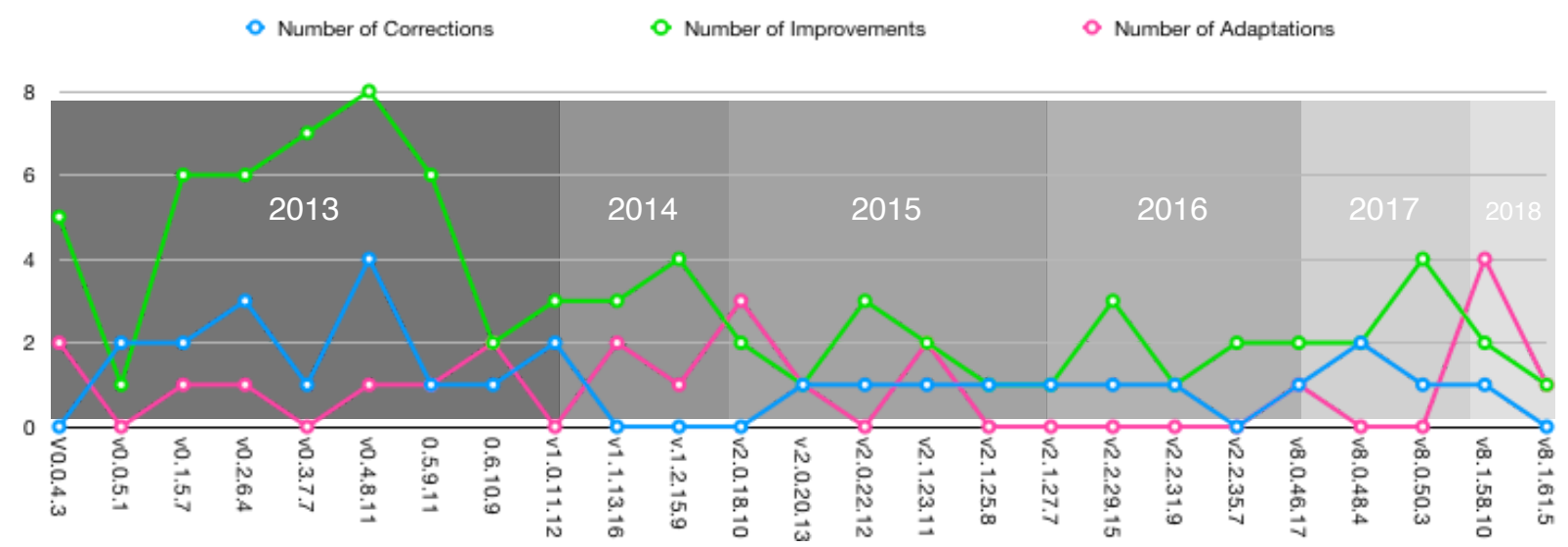

Figure 40 - ARC-IT updates

Confronting our model with ARC-IT, we observed that the factors present in the RASModel evidenced the sustainability of this architecture.

Although our investigation has covered the life-cycle of the last five years, considering since its establishment and publication, ARC-IT has demonstrated sustainable over 22 years. It is important to mention that since it was established, in its first version in 1996, ARC-IT has already defined some crosscutting factors, such as Motivation and Vision Statement. Over the releases the Primary factors were consolidated and, in the last five years, received constant updates to correspond with the State-of-the-art Alignment, and Scope size.

The data presented in this chapter illustrated how the RASModel can be used to analyze the sustainability of a reference architecture, and showed what characterizes a sustainable reference architecture. 

CHAPTER

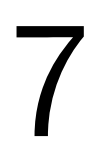

(1)

\section{CONCLUSIONS}

\subsection{Contributions}

Reference architectures represent an important contribution to application domains by promoting the reuse of the architectural project and understanding about such application domain. Considering the relevance and impact of these architectures in the systems development, contributions in design, representation, evaluation, and use of reference architectures are found. However, there is a lack of work dealing with the evolution of reference architectures, i.e., reference architectures are built but their continuity is a neglected issue. As software systems, technologies, and development approaches are constantly changing, the reference architecture evolution is extremely important.

In this work, we established a model, which contains factors and subfactors that we suggested to give evidences of the sustainability of reference architectures. The established model, RASModel, was further presented to experts in the field for an evaluation regarding model usefulness and completeness. The majority of participants agreed that the model is useful to support reference architecture sustainability analysis and the building of the reference architectures sustainable.

As a complement, we presented in Chapter 6 an example of application of the RASModel, analyzing the five year life cycle of a reference architecture for intelligent transportation systems. Identifying the factors present in the RASModel, we showed the sustainability of this architecture, which was designed and published 22 years ago.

\subsection{Limitations}

As a limitation of this work, we can cite that due to the difficulty of accessing the content and documentation of the analyzed reference architectures, we confront our model with 
a Type 1 reference architecture, according to the types of reference architectures described in Subsection 2.3.1. We believe that for other types of reference architectures, other factors should be explored, for example for reference architectures designed to be implemented in a single organization. In this case, in particular, the Stakeholder and their subfactors, present in RASModel, would not be appropriate.

\subsection{Future works}

For future work, we intend to elaborate a guideline supporting the use of the RASModel, as suggested by one participant in the questionnaire. In addition, we intend to confront our model with other reference architectures.

Besides that, we are planning to apply the RASModel in the design of a sustainable reference architecture, as a way to consolidate our model for this purpose. 
ADOLPHS, P.; EPPLE, U. Reference Architecture Model Industry 4.0 (RAMI4.0). [S.1.], 2015. Citation on page 39.

AKINLI, S. K.; ALPTEKIN, G. I.; BASAR, B. A. evaluation of software product quality attributes and environmental attributes using anp decision framework. In: 3rd International Workshop on Requirement Engineering for Sustainability (RE4SuSy 2014). Karlskrona, Sweden: [s.n.], 2014. p. 37-44. Citation on page 44.

ALliANCE, O. OSGi Alliance Specifications. 2017. Available: <http://www.osgi.org/ Specifications/>. Citation on page 39.

AMSEL, N.; BRAHIM, Z.; MALIK, A.; TOMLINSON, B. Toward sustainable software engineering. In: 33rd International Conference on Software Engineering (ICSE 2011). Waikiki, USA: [s.n.], 2011. p. 976-979. Citations on pages 20 and 44.

AN, S. h.; LEE, B.; SHIN, D. A survey of intelligent transportation systems. In: Third International Conference on Computational Intelligence, Communication Systems and Networks (CICSyN 2011). Bali, Indonesia: [s.n.], 2011. p. 332-337. Citation on page 98.

ANDERSSON, J.; CAPORUSCIO, M. Aligning architectures for sustainability. In: 10th European Conference on Software Architecture Workshops (ECSAW 2016). Copenhagen, Denmark: [s.n.], 2016. p. 13:1-13:6. Citation on page 50.

ANGELOV, S.; GREFEN, P. An e-contracting reference architecture. Journal of Systems and Software, v. 81, n. 11, p. 1816-1844, Nov. 2008. Citation on page 39.

ANGELOV, S.; GREFEN, P.; GREEFHORST, D. D. A classification of software reference architectures: Analyzing their success and effectiveness. In: 8th Working IEEE/IFIP Conference on Software Architecture (WICSA 2009) and 3rd European Conference on Software Architecture (ECSA 2009). Cambridge, UK: [s.n.], 2009. p. 141-150. Citations on pages 20, 22, 32, 34, 36, and 40 .

ANGELOV, S.; TRIENEKENS, J.; GREFEN, P. Towards a Method for the Evaluation of Reference Architectures: Experiences from a Case. In: 2nd European Conference on Software Architecture (ECSA 2008). Paphos, Cyprus: [s.n.], 2008. p. 225-240. Citation on page 19.

ANJOS, E.; CASTOR, F.; ZENHA-RELA, M. Comparing software architecture descriptions and raw source-code: A statistical analysis of maintainability metrics. In: 13th International Conference on Computational Science and Its Applications (ICCSA 2013). Ho Chi Minh City, Vietnam: [s.n.], 2013. p. 199-213. Citation on page 50.

ARSANJANI, A.; ZHANG, L. J.; ELLIS, M.; ALLAM, A.; CHANNABASAVAIAH, K. Software architectures that last. IEEE Computer Society, v. 9, n. 3, p. 10-17, 2007. Citations on pages 21 and 39 . 
AUTOSAR. AUTOSAR (AUtomotive Open System ARchitecture). 2017. Available: <http: //www.autosar.org/>. Citations on pages 20, 21, 22, and 39.

AVGERIOU, P.; STAL, M.; HILLIARD, R. Architecture sustainability. IEEE Software, v. 30, n. 6, p. 40-44, December 2013. Citations on pages 20, 47, and 50.

BABAR, M. A.; DINGSYR, T.; LAGO, P.; VLIET, H. van. Software Architecture Knowledge Management: Theory and Practice. [S.1.]: Springer Publishing Company, 2009. Citation on page 26 .

BABAR, M. A.; GORTON, I. Comparison of scenario-based software architecture evaluation methods. In: 11th Asia-Pacific Software Engineering Conference (APSEC 2004). Busan, Korea: [s.n.], 2004. p. 600-607. Citation on page 50.

BARNES, J. M. Nasa's advanced multimission operations system: A case study in software architecture evolution. In: 8th International ACM SIGSOFT Conference on Quality of Software Architectures (QoSA 2012). Bertinoro, Italy: [s.n.], 2012. p. 3-12. Citations on pages 50,52 , and 56.

BASILI, V. R. Software Modeling and Measurement: The Goal/Question/Metric Paradigm. [S.1.], 1992. Citation on page 70.

BASS, L.; CLEMENTS, P.; KAZMAN, R. Software Architecture in Practice. 3rd. ed. [S.1.]: Addison-Wesley Professional, 2012. Citations on pages 19, 26, 27, 30, 32, and 47.

BAYER, J.; FORSTER, T.; GANESAN, D.; GIRARD, J.; JOHN, I.; KNODEL, J.; KOLB, R.; MUTHIG, D. Definition of Reference Architectures based on Existing Systems. [S.1.], 2004. Citations on pages 20,41, and 42 .

BECKER, C.; CHITCHYAN, R.; DUBOC, L.; EASTERBROOK, S.; MAHAUX, M.; PENZENSTADLER, B.; NAVAS G, R.; SALINESI, C.; SEYFF, N.; VENTERS, C. C.; CALERO, C.; KOÇAK, S. A.; BETZ, S. The karlskrona manifesto for sustainability design. Cornell University Library, v. 1, 2014. Citations on pages 44, 45, and 46.

BENGTSSON, P.; LASSING, N.; BOSCH, J.; VLIET, H. V. Architecture-level modifiability analysis (ALMA). Journal of Systems and Software, v. 69, n. 1-2, p. 129-147, 2004. Citation on page 47.

BERRIMAN, G.; GOOD, J.; DEELMAN, E.; ALEXOV, A. Ten years of software sustainability at the infrared processing and analysis center. Philosophical Transactions of the Royal Society A: Mathematical, Physical and Engineering Sciences, v. 369, n. 1949, p. 3384-3397, 2011. Citation on page 50 .

BOMFIM, C.; NUNES, W.; DUBOC, L.; SCHOTS, M. Modelling sustainability in a procurement system: An experience report. In: 22nd International Requirements Engineering Conference (RE 2014). Karlskrona, Sweden: [s.n.], 2014. p. 402-411. Citation on page 44.

BONETTA, D.; PAUTASSO, C. An architectural style for liquid web services. In: 9th Working IEEE/IFIP Conference on Software Architecture (WICSA 2011). Boulder, USA: [s.n.], 2011. p. 232-241. Citation on page 22.

BOSCH, J. Design and Use of Software Architectures: Adopting and Evolving a Productline Approach. [S.1.]: Addison-Wesley, 2000. Citations on pages 27 and 31. 
BREHM, N.; MARX, G. J. Web service-based specification and implementation of functional components in federated erp-systems. In: 10th International Conference on Business Information Systems (BIS 2007). Poznan, Poland: [s.n.], 2007. p. 133-146. Citations on pages 21 and 22 .

BREIVOLD, H.; CRNKOVIC, I. A systematic review on architecting for software evolvability. In: 21st Australian Software Engineering Conference (ASWEC 2010). Auckland, New Zealand: [s.n.], 2010. p. 13-22. Citation on page 47.

BREIVOLD, H.; CRNKOVIC, I.; LARSSON, M. Software architecture evolution through evolvability analysis. The Journal of Systems and Software, Elsevier Science Inc., v. 85, n. 11, p. 2574-2592, 2012. Citations on pages 50, 52, and 55.

BREIVOLD, H.; JANSEN, A.; SANDSTRöM, K.; CRNKOVIC, I. Virtualize for architecture sustainability in industrial automation. In: 16th IEEE International Conference on Computational Science and Engineering. Sydney, Australia: [s.n.], 2013. p. 409-415. Citation on page 50 .

BROEK, G. V. D.; CAVALlO, F.; WEHRMANN, C. AALIANCE Ambient Assisted Living Roadmap. Amsterdam, The Netherlands: IOS Press, 2014. Citations on pages 20 and 39.

BROWN, B.; HANSON, M.; LIVERMAN, D. Global sustainability: Toward definition. Environmental Management, v. 11, n. 6, p. 713-719, 1987. Citation on page 43.

BROWN, P.; ESTEFAN, J. A.; LASKEY, K.; MCCABE, F.; THORNTON, D. OASIS Reference Architecture Foundation for Service Oriented Architecture. [S.1.], 2012. Citations on pages 21 and 39.

CABOT, J.; EASTERBROOK, S.; HORKOFF, J.; LESSARD, L.; LIASKOS, S.; MAZON, J. N. Integrating sustainability in decision-making processes: A modelling strategy. In: 31st International Conference on Software Engineering (ICSE 2009). Vancouver, Canada: [s.n.], 2009. p. 207-210. Citation on page 44.

CALERO, C.; BERTOA, M. F.; MORAGA, M. A. Sustainability and quality: Icing on the cake. In: 2nd International Workshop on Requirements Engineering for Sustainable Systems (RE4SuSy 2013). Rio de Janeiro, Brazil: [s.n.], 2013. p. 50-59. Citation on page 44.

CAPILLA, R.; NAKAGAWA, E.; ZDUN, U.; CARRILLO, C. Toward architecture knowledge sustainability: Extending system longevity. IEEE Software, v. 34, n. 2, p. 108-111, 2017. Citation on page 50.

CARRILLO, C.; CAPILLA, R.; ZIMMERMANN, O.; ZDUN, U. Guidelines and metrics for configurable and sustainable architectural knowledge modelling. In: 9th European Conference on Software Architecture (ECSA 2015). Dubrovnik, Croatia: [s.n.], 2015. p. 631-635. Citation on page 50.

CHOI, H.; LIM, C.; KIM, J. Defining reference architecture for NTIS development. In: 11th International Conference on Advanced Communication Technology (ICACT 2009). Gangwon-Do, Korea: [s.n.], 2009. p. 284-287. Citations on pages 21 and 22.

CLEMENTS, P.; BASS, L. The business goals viewpoint. IEEE Software, v. 27, n. 6, p. 38-45, 2010. Citations on pages 19 and 26. 
CLOUTIER, R.; MüLLER, G.; VERMA, D.; NILCHIANI, R.; HOLE, E.; BONE, M. The concept of reference architectures. Systems Engineering, Wiley Subscription Services, Inc., A Wiley Company, v. 13, n. 1, p. 14-27, 2010. Citation on page 22.

CONSORTIUM, I. I. IIRA (Industrial Internet Reference Architecture). 2017. Available: $<$ http://www.iiconsortium.org/IIRA.htm>. Citation on page 39.

The Industrial Internet of Things Volume G1: Reference Architecture, version 1.8. 2017. Available: <http://www.iiconsortium.org/IIRA.htm>. Citations on pages 20, 21, and 22.

CONTINUA. Continua Health Alliance. 2017. Available: <http://continuaalliance.org/>. Citations on pages 20,21, 22, and 39 .

DAGNINO, A.; STOLL, P.; WEISS, R. Software architectures that last. ABB Review, n. 3, p. 40-49, 2011. Citation on page 26.

DEBAUD, J.; FLEGE, O.; KNAUBER, P. Pulse-dssa and mdash: a method for the development of software reference architectures. In: Third International Workshop on Software Architecture (ISA 1998). Orlando, USA: [s.n.], 1998. p. 25-28. Citation on page 33.

DELGADO, J. C. Architectural styles for distributed interoperability. Information Resources Management Journal, v. 26, n. 4, p. 40-65, 2013. Citation on page 22.

DEMIR, K. A. Multi-view software architecture design: Case study of a mission-critical defense system. Computer and Information Science, v. 8, n. 4, p. 12-31, 2015. Citation on page 28.

DILLON, T. S.; WU, C.; CHANG, E. Reference architectural styles for service-oriented computing. In: IFIP International Conference on Network and Parallel Computing (NPC 2007). Dalian, China: [s.n.], 2007. p. 543-555. Citation on page 21.

DRAKE, B. G.; HOFFMAN, S. J.; BEATY, D. W. Human exploration of mars, design reference architecture 5.0. In: 2010 IEEE Aerospace Conference. Big Sky, USA: [s.n.], 2010. p. 1-24. Citations on pages 20, 21, and 39 .

DURDIK, K.; KLATT, B.; KOZIOLEK, H.; KROGMANN, K.; STAMMEL, J.; WEISS, R. Sustainability guidelines for long-living software systems. In: 28th International Conference on Software Maintenance (ICSM 2012). Riva del Garda, Italy: [s.n.], 2012. p. 517-526. Citations on pages 47 and 50.

DURO, N.; MOREIRA, F.; ROGADO, J.; REIS, J.; PECCIA, N. Technology harmonization developing a reference architecture for the ground segment software. In: 2005 IEEE Aerospace Conference. Big Sky, USA: [s.n.], 2005. p. 3968-3979. Citations on pages 21 and 22.

FAEGRI, T.; HALLSTEINSEN, S. A software product line reference architecture for security. In: KäKöLA, T.; DUENAS, J. (Ed.). Software Product Lines. [S.1.]: Springer Berlin Heidelberg, 2006. p. 275-326. ISBN 978-3-540-33252-7. Citation on page 39.

FIORAVANTI, F.; SPINU, M.; CAMPANAI, M. AXMEDIS as the service oriented architecture for the media: Is it feasible? In: 3rd International Conference on Automated Production of Cross Media Content for Multi-Channel Distribution (AXMEDIS 2007). [S.1.: s.n.], 2007. p. 264-269. Citation on page 21. 
GALSTER, M.; AVGERIOU, P. Empirically-grounded reference architectures: A proposal. In: 7th International ACM Sigsoft Conference on the Quality of Software Architectures (QoSA 2011). Boulder, USA: [s.n.], 2011. p. 153-158. Citation on page 20.

GARLAN, D.; PERRY, D. E. Introduction to the special issue on software architecture. IEEE Transaction Software Engineering, v. 21, n. 4, p. 269-274, 1995. Citation on page 25.

GEORGE, F. Just Enough Software Architecture: a risk-driven approach. [S.1.]: Marshall Brainerd, 2010. Citations on pages 19 and 26.

GOMAA, H. Designing Software Product Lines with UML. [S.1.]: Object Technology Series, Addison-Wesley, 2004. Citation on page 33.

GROSSKURTH, A.; GODFREY, M. A reference architecture for web browsers. In: 21st IEEE International Conference on Software Maintenance (ICSM 2005). Budapest, Hungary: [s.n.], 2005. p. 661-664. Citation on page 39.

HEESCH, U. V.; GERMANY, C.; ELORANTA, V.; AVGERIOU, P.; KOSKIMIES, K.; HARRISON, N. Decision-Centric Architecture Reviews. IEEE Software, v. 31, n. 1, p. 69-76, 2014. Citation on page 31.

HEMALATHA, T.; ATHISHA, G.; JEYANTHI, S. Dynamic web service based image processing system. In: 16th International Conference on Advanced Computing and Communications (ADCOM 2008). Chennai, India: [s.n.], 2008. p. 323-328. Citation on page 21.

HERRMANN, S. Sustainable architectures by combining flexibility and strictness in object teams. IEE Proceedings Software, v. 151, n. 2, p. 57-66, 2004. Citation on page 50.

HIGH, R.; KINDER, S.; GRAHAM, S. IBM's SOA Foundation An Architectural Introduction and Overview. [S.1.], 2005. Citation on page 39.

HILTY, L.; LOHMANN, W.; HUANG, E. Sustainability and ict - an overview of the field. In: 25th EnviroInfo 2011: Innovations in Sharing Environmental Observation and Information. Ispra, Italy: [s.n.], 2011. p. 13-28. Citation on page 43.

HILTY, L. M.; HERCHEUI, M. D. Ict and sustainable development. What Kind of Information Society? Governance, Virtuality, Surveillance, Sustainability, Resilience, v. 328, p. 227-235, 2008. Citation on page 43.

HOFMEISTER, C.; KRUCHTEN, P.; NORD, R. L.; OBBINK, H.; RAN, A.; AMERICA, P. Generalizing a Model of Software Architecture Design from Five Industrial Approaches. In: 5th Working IEEE/IFIP Conference on Software Architecture. Washington, EUA: IEEE Computer Society, 2005. p. 77-88. Citations on pages 28 and 31.

A general model of software architecture design derived from five industrial approaches. Journal of Systems and Software, Elsevier, v. 80, n. 1, p. 106-126, 2007. Citations on pages 28,29 , and 30.

HOFMEISTER, C.; NORD, R.; SONI, D. Applied software architecture. [S.1.]: AddisonWesley Professional, 2000. Citations on pages 27 and 28.

HULSE, C.; EDGERTON, S.; UBNOSKE, M.; VAZQUEZ, L. Reducing maintenance costs through the application of modern software architecture principles. In: 1999 Annual ACM SIGAda International Conference on Ada (SIGAda 1999). California, USA: [s.n.], 1999. p. 101-110. Citation on page 50. 
ISO. ISO/IEC 25010:2011 Systems and software engineering - Systems and software Quality Requirements and Evaluation (SQuaRE) - System and software quality models. [S.1.], 2011. Citations on pages 47, 52, and 53.

ISO/IEC/IEEE 42010. Systems and software engineering - Architecture description. 2010. Citations on pages 28 and 30 .

JANSEN, A.; WALL, A.; WEISS, R. Techsure - a method for assessing technology sustainability in long lived software intensive systems. In: 37th EUROMICRO Conference on Software Engineering and Advanced Applications (SEAA 2011). Oulu, Finland: [s.n.], 2011. p. 426434. Citation on page 50.

KASUNIC, M. Designing an Effective Survey. [S.1.], 2005. Citations on pages 70, 71, 72, and 74.

KAZMAN, R.; KLEIN, M.; CLEMENTS, P. ATAM: Method for Architecture Evaluation. [S.1.], 2000. 83 p. Citation on page 31.

Kazman, R. and Asundi, J. and Klein, M. Quantifying the Costs and Benefits of Architectural Decisions. In: 23rd International Conference on Software Engineering (ICSE 2001). Washington, USA: [s.n.], 2001. p. 297-306. Citation on page 31.

KERN, E.; DICK, M.; NAUMANN, S.; GULDNER, A.; JOHANN, T. Green software and green software engineering: Definitions, measurements, and quality aspects. In: 1st International Conference of ICT for Sustainability (ICT4S 2013). Zürich, Switzerland: [s.n.], 2013. p. 87-94. Citation on page 44.

KIM, D.; RYOO, J.; KIM, S. Building sustainable software by preemptive architectural design using tactic-equipped patterns. In: 9th International Conference on Availability, Reliability and Security (ARES 2014). Fribourg, Switzerland: [s.n.], 2014. p. 484-489. Citations on pages 47 and 50.

KITCHENHAM, B.; CHARTERS, S. Guidelines for performing Systematic Literature Reviews in Software Engineering. [S.1.], 2007. Citation on page 48.

KOZIOLEK, H. Sustainability evaluation of software architectures: A systematic review. In: 7th International ACM Sigsoft Conference on the Quality of Software Architectures (QoSA 2011). Boulder, Colorado, USA: [s.n.], 2011. p. 3-12. Citation on page 47.

KOZIOLEK, H.; DOMIS, D.; GOLDSCHMIDT, T.; VORST, P.; WEISS, R. J. Morphosis: A lightweight method facilitating sustainable software architectures. In: 10th Joint Working Conference on Software Architecture (WICSA 2012) 6th European Conference on Software Architecture (ECSA 2012). Helsinki, Finland: [s.n.], 2012. p. 253-257. Citation on page 50.

KOZIOLEK, H.; DOMIS, D.; GOLDSCHMIDT, T.; VORST, P. Measuring architecture sustainability. IEEE Software, v. 30, n. 6, p. 54-62, 2013. Citations on pages 20, 42, 47, 48, and 50 .

KOZIOLEK, H.; SCHLICH, B.; BILICH, C.; WEISS, R.; BECKER, S.; KROGMANN, K.; TRIFU, M.; MIRANDOLA, R.; KOZIOLEK, A. An industrial case study on quality impact prediction for evolving service-oriented software. In: 33rd International Conference on Software Engineering (ICSE 2011). Honolulu, Hawai: [s.n.], 2011. p. 776-785. Citation on page 50. 
KOZIOLEK, H.; WEISS, R.; DOPPELHAMER, J. Evolving industrial software architectures into a software product line: A case study. In: 5th International Conference on the Quality of Software Architectures: Architectures for Adaptive Software Systems (QoSA 2009). East Stroudsburg, USA: [s.n.], 2009. p. 177-193. Citation on page 50.

KRUCHTEN, P. The rational unified process: an introduction. [S.1.]: Addison-Wesley Professional, 2004. Citations on pages 27, 28, and 29.

KRUCHTEN, P.; OBBINK, H.; STAFFORD, J. The past, present, and future for software architecture. IEEE Software, IEEE Computer Society Press, v. 23, n. 2, p. 22-30, Mar. 2006. Citations on pages 26 and 27.

KRUCHTEN, P. B. The 4+1 view model of architecture. IEEE Software, v. 12, n. 6, p. 42-50, 1995. Citation on page 28.

LAGO, P.; KOcAK, S. A.; CRNKOVIC, I.; PENZENSTADLER, B. Framing sustainability as a property of software quality. ACM Commun, v. 58, n. 10, p. 70-78, Sep. 2015. Citations on pages $20,45,46$, and 47.

LAN, J.; LIU, Y.; CHAI, Y. A solution model for service-oriented architecture. In: 7th World Congress on Intelligent Control and Automation (WCICA 2008). Chongqing, China: [s.n.], 2008. p. 4184-4189. Citation on page 21.

LANDAUER, C. Wrapping architectures for long-term sustainability. In: 2nd International IEEE Workshop on Software Evolvability (SE 2006). Philadelphia, USA: [s.n.], 2006. p. 44-49. Citation on page 50.

LE, D.; CARRILLO, C.; CAPILLA, R.; N, M. Relating architectural decay and sustainability of software systems. In: 13th Working IEEE/IFIP Conference on Software Architecture (WICSA 2016). Venice, Italy: [s.n.], 2016. p. 178-181. Citations on pages 50, 52, and 56.

LEPPANIEMI, J.; LINNA, P.; SOINI, J.; JAAKKOLA, H. Toward a flexible service-oriented reference architecture for situational awareness systems in distributed disaster knowledge management. In: International Conference on Management of Engineering Technology (PICMET 2009). Portland, USA: [s.n.], 2009. p. 959-965. Citation on page 21.

LIU, L.; THANHEISER, S.; SCHMECK, H. A reference architecture for self-organizing serviceoriented computing. In: 21st International Conference on Architecture of Computing Systems (ARCS 2008). Dresden, Germany: [s.n.], 2008. p. 205-219. Citations on pages 21 and 22.

MACKENZIE, C.; LASKEY, K.; MCCABE, F.; BROWN, P.; METZ, R. OASIS Reference model for Service Oriented Architecture 1.0. [S.1.], 2006. Citation on page 21.

MARTÍNEZ-FERNÁNDEZ, S. Towards supporting the adoption of software reference architectures : An empirically-grounded framework. In: 11th International Doctoral Symposium on Empirical Software Engineering (IDoESE 2013). Baltimore, USA: [s.n.], 2013. p. 1-8. Citation on page 66.

MARTÍNEZ-FERNÁNDEZ, S.; AYALA, C. P.; FRANCH, X.; MARQUES, H. M.; AMELLER, D. A framework for software reference architecture analysis and review. In: XVI Iberoamerican Conference on Software Engineering (CIbSE 2013). Montevideo, Uruguay: [s.n.], 2013. p. 89-102. Citation on page 66. 
MARTÍNEZ-FERNÁNDEZ, S.; AYALA, C. P.; FRANCH, X.; MARQUES, H. M. REARM: A reuse-based economic model for software reference architectures. In: 13th International Conference on Software Reuse (ICSR 2013). Pisa, Italy: [s.n.], 2013. p. 97-112. Citations on pages 65 and 66 .

MARTÍNEZ-FERNÁNDEZ, S.; AYALA, C. P.; FRANCH, X.; MARTINS, M. H.; AMELLER, D. Towards guidelines for building a business case and gathering evidence of software reference architectures in industry. Journal of Software Engineering Research and Development, v. 2, n. 1, p. 1-27, 2014. Citation on page 65.

MOLLÉRI, J. S.; PETERSEN, K.; MENDES, E. Survey guidelines in software engineering: An annotated review. In: 10th ACM/IEEE International Symposium on Empirical Software Engineering and Measurement (ESEM 2016). Ciudad Real, Spain: [s.n.], 2016. p. 58:1-58:6. Citation on page 69.

MULLER, G. Right sizing reference architectures; how to provide specific guidance with limited information. In: 18th Annual International Symposium of the International Council on Systems Engineering (INCOSE 2008). Utrecht, The Netherlands: [s.n.], 2008. v. 18, n. 1, p. 2047-2054. Citations on pages 20, 41, and 42.

MURAKAMI, E.; SARAIVA, A. M.; RIBEIRO, L. C. M.; CUGNASCA, C. E.; HIRAKAWA, A. R.; CORREA, P. L. P. An infrastructure for the development of distributed service-oriented information systems for precision agriculture. Computers and Electronics in Agriculture, v. 58, n. 1, p. $37-48,2007$. Citation on page 21 .

MüLLER, G. A reference architecture primer. 2008. Available: <http://goo.gl/Kx8sG2>. Citations on pages 19, 32, 36, 37, 38, 65, and 66.

MüLLER, G.; HOLE, E. White paper: Reference Architectures; Why, What and How. [S.1.], 2007. Citation on page 22.

NAKAGAWA, E. Y.; ANTONINO, P. O.; BECKER, M. Exploring the use of reference architectures in the development of product line artifacts. In: 15th International Software Product Line Conference (KOPLE 2011 at SPLC 2011). Munich, Germany: [s.n.], 2011. p. 1-8. Citation on page 34 .

NAKAGAWA, E. Y.; ANTONINO, P. O.; BECKER, M.; GRUHN, V.; BOOK, M. Reference architecture and product line architecture: A subtle but critical difference. In: 5th European Conference on Software Architecture (ECSA 2011). Essen, Germany: [s.n.], 2011. p. 207211. Citation on page 33.

NAKAGAWA, E. Y.; FERRARI, F. C.; SASAKI, M. M. F.; MALDONADO, J. C. An aspectoriented reference architecture for software engineering environments. Journal of Systems and Software, v. 84, n. 10, p. 1670-1684, 2011. Citation on page 39.

NAKAGAWA, E. Y.; GUESSI, M.; MALDONADO, J.; FEITOSA, D.; OQUENDO, F. Consolidating a process for the design, representation, and evaluation of reference architectures. In: 11th Working IEEE/IFIP Conference on Software Architecture (WICSA 2014). Sydney, Australia: [s.n.], 2014. p. 143-152. Citations on pages 41 and 42.

NAKAGAWA, E. Y.; OQUENDO, F.; BECKER, M. RAModel: A reference model of reference architectures. In: 6th European Conference on Software Architecture (ECSA 2012). Helsinki, Finland: [s.n.], 2012. p. 1-5. Citations on pages 19, 20, and 40. 
NAKAGAWA, E. Y.; OQUENDO, F.; MALDONADO, J. C. Reference architectures. In: Software Architecture 1. [S.1.]: John Wiley Sons, Ltd, 2015. p. 55-82. Citations on pages 19, $20,32,33,34,36,38,39,40$, and 42.

NAKAGAWA, E. Y.; SIMAO, A. S.; FERRARI, F.; MALDONADO, J. C. Towards a reference architecture for software testing tools. In: 19th International Conference on Software Engineering Knowledge Engineering (SEKE 2007). Boston, USA: [s.n.], 2007. p. 157-162. Citation on page 38.

NAUMANN, S.; DICK, M.; KERN, E.; JOHANN, T. The \{GREENSOFT \} model: A reference model for green and sustainable software and its engineering. Sustainable Computing: Informatics and Systems, v. 1, n. 4, p. 294 - 304, 2011. Citations on pages 42 and 44.

OJAMERUAYE, B.; BAHSOON, R.; DUBOC, L. Sustainability debt: A portfolio-based approach for evaluating sustainability requirements in architectures. In: 38th International Conference on Software Engineering Companion (ICSE 2016). Austin, Texas: [s.n.], 2016. p. 543-552. Citations on pages 45 and 46.

OLIVEIRA, L. B. R.; FELIZARDO, K. R.; FEITOSA, D.; NAKAGAWA, E. Y. Reference models and reference architectures based on service-oriented architecture: A systematic review. In: 4th European Conference on Software Architecture (ECSA 2010). Copenhagen, Denmark: [s.n.], 2010. p. 360-367. Citations on pages 21 and 60.

OLIVEIRA, L. B. R.; NAKAGAWA, E. Y. A service-oriented reference architecture for software testing tools. In: 5th European Conference on Software Architecture (ECSA 2011). Essen, Germany: [s.n.], 2011. p. 405-421. Citation on page 38.

OZKAYA, I.; WALLIN, P.; AXELSSON, J. Architecture knowledge management during system evolution: Observations from practitioners. In: ICSE Workshop on Sharing and Reusing Architectural Knowledge (SHARK 2010. Cape Town, South Africa: [s.n.], 2010. p. 52-59. Citations on pages 50 and 55 .

PAHL, C.; JAMSHIDI, P.; WEYNS, D. Cloud architecture continuity: Change models and change rules for sustainable cloud software architectures. Journal of Software: Evolution and Process, v. 29, n. 2, 2017. Citation on page 50.

PAPAZOGLOU, M. P.; TRAVERSO, P.; DUSTDAR, S.; LEYMANN, F. Sservice-oriented computing: a research roadmap. International Journal of Cooperative Information Systems, v. 17 , n. 02 , p. 223-255, 2008. Citation on page 39.

PATRICIA, L.; NIKLAUS, M.; MAURIZIO, M.; HAUSI, M. A.; GIUSEPPE, S. Leveraging energy efficiency to software users: Summary of the 2nd Greens Workshop, at ICSE 2013. SIGSOFT Software Engineering Notes, v. 39, n. 1, p. 36-38, Feb. 2014. Citation on page 44.

PENZENSTADLER, B. Towards a definition of sustainability in and for software engineering. In: 28th Annual ACM Symposium on Applied Computing. Coimbra, Portugal: [s.n.], 2013. p. 1183-1185. Citations on pages 45 and 47.

PENZENSTADLER, B.; FEMMER, H. A generic model for sustainability with process- and product-specific instances. In: Workshop on Green in/by Software Engineering (GIBSE 2013). Fukuoka, Japan: [s.n.], 2013. p. 3-8. Citation on page 50. 
PENZENSTADLER, B.; RATURI, A.; RICHARDSON, D.; CALERO, C.; FEMMER, H.; FRANCH, X. Systematic mapping study on software engineering for sustainability (SE4S). In: 18th International Conference on Evaluation and Assessment in Software Engineering (EASE 2014). London, United Kingdom: [s.n.], 2014. p. 14:1-14:14. Citations on pages 20, 43, 44 , and 45.

PERISTERAS, V.; FRADINHO, M.; LEE, D.; PRINZ, W.; RULAND, R.; IQBAL, K.; DECKER, S. CERA: a collaborative environment reference architecture for interoperable CWE systems. Service Oriented Computing and Applications, v. 3, n. 1, p. 3-23, 2009. Citation on page 21.

PETERSEN, K.; VAKKALANKA, S.; KUZNIARZ, L. Guidelines for conducting systematic mapping studies in software engineering: An update. Information and Software Technology, v. 64 , p. 1-18, 2015. Citation on page 48.

PFLEEGER, S. L.; KITCHENHAM, B. A. Principles of survey research: Part 1: Turning lemons into lemonade. ACM SIGSOFT Software Engineering Notes, v. 26, n. 6, p. 16-18, 2001. Citation on page 69 .

POHL K.AND BOCKLE, G.; LINDEN, F. van der. Software Product Line Engineering: Foundations, Principles, and Techniques. [S.1.]: Springer, Heidelberg, 2005. Citation on page 33.

POSTMA, A.; AMERICA, P.; WIJNSTRA, J. G. Component replacement in a long-living architecture : The 3rdba approach. In: 4th Working IEEE/IFIP Conference on Software Architecture (WICSA 2004). Oslo, Norway: [s.n.], 2004. p. 89-98. Citation on page 50.

PUNTER, T.; CIOLKOWSKI, M.; FREIMUT, B.; JOHN, I. Conducting on-line surveys in software engineering. In: International Symposium on Empirical Software Engineering (ISESE 2003). Rome, Italy: [s.n.], 2003. p. 80-88. Citations on pages 69 and 72.

PUTHAL, D.; SAHOO, B. P. S.; MISHRA, S.; SWAIN, S. Cloud computing features, issues, and challenges: A big picture. In: 7th International Conference on Computational Intelligence and Communication Networks (CICN 2015). Jabalpur, India: [s.n.], 2015. p. 116-123. Citation on page 22 .

RAMANATHAN, S.; ALEXANDER, M.; KERR, G. The ibm telecommunications service delivery platform. IBM Systems Journal, v. 47, n. 3, p. 433-443, Jul 2008. Citation on page 21.

RAN, A. Ares conceptual framework for software architecture. Software Architecture for Product Families Principles and Practice, p. 1-29, 2000. Citations on pages 27 and 29.

RATURI, A.; PENZENSTADLER, B.; TOMLINSON, B.; RICHARDSON, D. Developing a sustainability non-functional requirements framework. In: 3rd International Workshop on Green and Sustainable Software (GREENS 2014). Hyderabad, India: [s.n.], 2014. p. 1-8. Citation on page 50.

RAZAVIAN, M.; PROCACCIANTI, G.; TAMBURRI, D. Four-dimensional sustainable eservices. In: 28th International Conference on Informatics for Environmental Protection (EnviroInfo 2014). Oldenburg, Germany: [s.n.], 2014. p. 221-228. Citations on pages 20, 45, 46 , and 47. 
REDWINE JR., S. T.; RIDDLE, W. E. Software technology maturation. In: 8th International Conference on Software Engineering (ICSE 1985). Los Alamitos, USA: IEEE Computer Society Press, 1985. p. 189-200. Citation on page 25.

REED, P. Reference architecture: The best of best practices. 2002. Available: <http://www. $\mathrm{ibm.com/developerworks/rational/library/2774.html>.} \mathrm{Citations} \mathrm{on} \mathrm{pages} \mathrm{20,} \mathrm{39,} \mathrm{41,} \mathrm{and} 42$.

REIFF-MARGANIEC, S.; TRUONG, H.; CASELLA, G.; DORN, C.; DUSTDAR, S.; MORETZKY, S. The inContext pervasive collaboration services architecture. In: First European Conference on Towards a Service-Based Internet (ServiceWave 2008). Madrid, Spain: [s.n.], 2008. p. 134-146. Citation on page 21.

SAFY, F. Z.; RAMLY, M. M.; SALAH, A. Runtime monitoring of SOA applications: Importance, implementations and challenges. In: 7th International Symposium on Service Oriented System Engineering (SOSE 2013). San Francisco, USA: [s.n.], 2013. p. 315-319. Citation on page 22 .

SCHMERL, B.; KAZMAN, R.; ALI, N.; GRUNDY, J.; MISTRIK, I. Chapter one - managing trade-offs in adaptable software architectures. In: MISTRIK, I.; ; ALI, N.; KAZMAN, R.; GRUNDY, J.; SCHMERL, B. (Ed.). Managing Trade-Offs in Adaptable Software Architectures. 1st. ed. Boston: Morgan Kaufmann, 2017. p. 1 - 13. Citation on page 50.

SEI. A Framework for Software Product Line Practice, Version 5.0. 2017. Available: <http: //www.sei.cmu.edu/productlines/>. Citation on page 33 .

SHAW, M.; CLEMENTS, P. The golden age of software architecture. IEEE Software, v. 23, n. 2, p. 31-39, 2006. Citation on page 25.

SOBHY, D.; BAHSOON, R. Diversifying software architecture for sustainability: A valuebased perspective. In: 10th European Conference on Software Architecture (ECSA 2016). Copenhagen, Denmark: [s.n.], 2016. p. 55-63. Citation on page 50.

SONI, D.; NORD, R. L.; HOFMEISTER, C. Software architecture in industrial applications. In: 17th International Conference on Software Engineering (ICSE 1995). Seattle, USA: [s.n.], 1995. p. 196-196. Citation on page 28.

STARON, M.; MEDING, W. A portfolio of internal quality metrics for software architects. In: 9th International Conference on Software Quality (SWQD 2017). Vienna, Austria: [s.n.], 2017. p. 57-69. Citations on pages 50, 55, and 56.

STRICKER, V.; LAUENROTH, K.; CORTE, P.; GITTLER, F.; PANFILIS, S. D.; POHL, K. Creating a reference architecture for service-based systems - A pattern-based approach. In: TSELENTIS, G.; GALIS, A.; GAVRAS, A.; KRCO, S.; LOTZ, V.; SIMPERL, E.; STILLER, B.; ZAHARIADIS, T. (Ed.). Towards the Future Internet - Emerging Trends from European Research. [S.1.]: IOS Press, 2010. p. 149-160. Citation on page 39.

TAYLOR, R. N.; MEDVIDOVIC, N.; DASHOFY, E. M. Software Architecture: Foundations, Theory, and Practice. [S.1.]: Wiley Publishing, 2009. Citation on page 47.

TRIENEKENS, J.; ANGELOV, S.; GREFEN, P.; KUSTERS, R. Quality of software reference architectures. In: IADIS International Conference Information Systems (IS 2011). Avila, Spain: [s.n.], 2011. p. 145-152. Citations on pages 41 and 42. 
UNIVERSAAL. The UniversAAL Reference Architecture. 2017. Available: <http://www. universaal.org/>. Citation on page 39.

USA. Architecture Reference for Cooperative and Intelligent Transportation ARC-IT. 2018. Available: <https://local.iteris.com/arc-it/>. Citations on pages 20, 21, 22, 39, 98, 99, 101, and 110.

VENTERS, C.; BECKER, C.; BETZ, S.; CHITCHYAN, R.; DUBOC, L.; EASTERBROOK, S.; PENZENSTADLER, B.; RODRIGUEZ-NAVAS, G.; SEYFF, N. Mind the gap: Bridging the sustainable software systems research divide. In: UK-SHCI: Workshop on Sustainable HCI in the UK. Lincoln, United Kingdom: [s.n.], 2015. p. 1-4. Citations on pages 44 and 47.

VENTERS, C. C.; CAPILLA, R.; BETZ, S.; PENZENSTADLER, B.; CRICK, T.; CROUCH, S.; NAKAGAWA, E. Y.; BECKER, C.; CARRILLO, C. Software sustainability: Research and practice from a software architecture viewpoint. Journal of Systems and Software, v. 138, p. 174-188, 2018. Citation on page 59.

VILLA, L.; CABEZAS, I.; LOPEZ, M.; CASAS, O. Towards a sustainable architectural design by an adaptation of the architectural driven design method. In: 16th International Conference on Computational Science and Its Applications (ICCSA 2016). Beijing, China: [s.n.], 2016. p. 71-86. Citation on page 50.

VITTORIO, C.; RAFFAELA, M.; PASQUALINA, P. Managing the evolution of a software architecture at minimal cost under performance and reliability constraints. Science and Computer Programing, Elsevier North-Holland, Inc., v. 98, n. P4, p. 439-463, 2015. Citation on page 50.

VOLPATO, T.; OLIVEIRA, B. R. N.; GARCÉS, L.; CAPILLA, R.; NAKAGAWA, E. Y. Two perspectives on reference architecture sustainability. In: 11th European Conference on Software Architecture Workshops (ECSAW 2017). Canterbury, United Kingdom: [s.n.], 2017. p. 188-194. Citations on pages 56 and 60.

VöLTER, M. Software architecture: A pattern language for building sustainable software architectures. In: 11th European Conference on Pattern Languages of Programs (EuroPLoP 2006). [S.1.: s.n.], 2006. p. 31-66. Citation on page 50.

WEISS, R. J.; REPETTO, D.; KOZIOLEK, H. Perseverance in sustainable software architecting. In: 2012 ACM SIGSOFT Symposium on Industry Day (Industry dAY 2012). Bertinoro, Italy: [s.n.], 2012. p. 11-14. Citation on page 50.

WEYNS, D.; CAPORUSCIO, M.; VOGEL, B.; KURTI, A. Design for sustainability = runtime adaptation evolution. In: 9th European Conference on Software Architecture (ECSA 2015). Dubrovnik, Croatia: [s.n.], 2015. p. 621-627. Citation on page 50.

WEYRICH, M.; EBERT, C. Reference architectures for the internet of things. IEEE Software, v. 33, n. 1, p. 112-116, 2016. Citation on page 39.

ZDUN, U.; CAPILLA, R.; TRAN, H.; ZIMMERMANN, O. Sustainable architectural design decisions. IEEE Software, v. 30, n. 6, p. 46-53, 2013. Citation on page 50.

ZHENG, Q.; DONG, B.; TIAN, F.; CHEN, W. A service-oriented approach to integration of e-learning information and resource management systems. In: 12th International Conference on Computer Supported Cooperative Work in Design (CSCWD 2008). Xi' an, China: [s.n.], 2008. p. 1047-1052. Citation on page 21. 
ZIMMERMANN, O.; KOPP, P.; PAPPE, S. Architectural knowledge in an SOA infrastructure reference architecture. In: Software Architecture Knowledge Management: Theory and Practice. [S.1.]: Springer Berlin Heidelberg, 2009. p. 217-241. Citation on page 21. 

APPENDIX

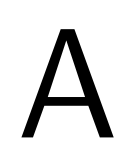

SYSTEMATIC MAPPING PROTOCOL ABOUT SUSTAINABILITY IN SOFTWARE ARCHITECTURE 


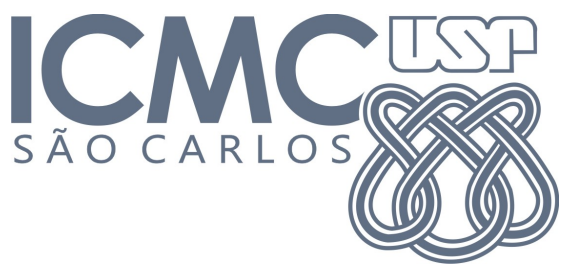

Universidad

Rey Juan Carlos

\section{Software Architecture Sustainability: \\ A Systematic Mapping}

Tiago Volpato*, Brauner R. N. Oliveira*,

Lina M. Garcés Rodríguez*, Rafael Capilla†, and Elisa Y. Nakagawa*.

July 23, 2018

\footnotetext{
*.Instituto de Ciências Matemáticas e de Computação (ICMC) - Universidade de São Paulo (USP)

${ }^{\dagger}$ Universidad Rey Juan Carlos
} 


\section{Contents}

1 Introduction 3

2 Systematic Mapping Protocol 4

2.1 SM Objective . . . . . . . . . . . . . . . . . . . . 4

2.2 Question Quality and Amplitude ... . . . . . . . . . . . . 5

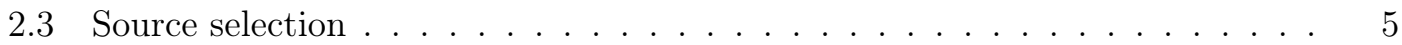

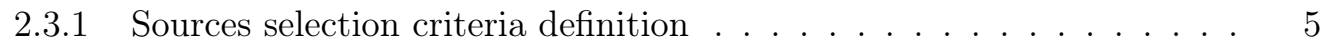

2.3 .2 Studies languages . . . . . . . . . . . . . . . . . . 6

2.3 .3 Sources identification . . . . . . . . . . . . . . . . . 6

2.4 Study Selection . . . . . . . . . . . . . . . . . . . . 7

2.4.1 Studies Inclusion and Exclusion Criteria Definition . . . . . . . . 8

2.5 Procedures for Studies Selection . . . . . . . . . . . . . . . . . . 9

2.6 Data Extraction Strategy _. . . . . . . . . . . . . . . . . . . 11

2.7 Synthesis of the Extracted Data . . . . . . . . . . . . . . . . 11

3 Protocol Validation $\quad 11$

4 Report the Review 12 


\section{INTRODUCTION}

Software systems should be designed to be operable for decades, mainly in domains of largescale applications, such as telecommunication, transportation, robotics, health and smart grids [1]. These domains applications naturally evolve over time, and as a consequence of this continuous evolution, software systems must become more versatile, flexible, energyefficient, customizable and configurable by adapting to changing operational contexts, environment or system characteristics [2]. In other words, software systems must become more sustainable. In this sense, sustainability is the ability to modify a software system based on customer needs and deploy these modifications [3]. Here, customer needs encompasses any other action that impacts on a change in the system in its current state, such as requirement changes, new technologies, integration between systems and design decisions. Regarding this, there are many initiatives that explore software system sustainability $[3,4,5,6,7,8,9]$.

In another perspective, software architectures have a fundamental role in determining the quality of software systems, because is the set of structures needed to reason about the system, comprising software elements, relations among them, and properties of both [10]. Thus, sustainability of software systems is closely related to the sustainability of their architectures [1], and in this scenario, sustainability can be defined as the architecture's capacity to endure different types of changes through efficient maintenance and orderly evolution over its entire life cycle [11]. In order to systematically manage this changes, it is necessary to have a clear understanding on the state of the art of architecture sustainability (AS).

In this context, a systematic literature review (SLR) will be conducted aiming to obtain a deep understanding on how sustainability in the context of software architecture and reference architecture has been addressed. For this, we will follow the guidelines proposed by Kitchenham and Charters [12]. This process provides a reliable means and establishes methods for conducting a comprehensive literature review based on three clearly defined phases: (i) planning; (ii) conducting; and (iii) reporting the review. During the planning phase, the need for a review is identified and the review protocol is developed. In the review protocol, the following items are specified: (i) Question formularization; (ii) Source selection; (iii) Study selection; and (iv) Procedures for studies selection, among others. In the conducting phase, all the tasks that were defined in the protocol are executed. Firstly, the primary studies are selected according to the inclusion criteria. Secondly, the quality of these studies is evaluated and, finally, all the relevant data are extracted and synthesized. Finally, in the reporting phase, the results of the review are reported.

In the remainder of this document is detailed the protocol of this SLR. 


\section{Systematic Mapping Protocol}

\subsection{SM OBJECTIVE}

Our mapping study aims:

1. To get a comprehensive understanding of the concept of sustainability in the context of software architecture and what aspects are involved (such as technical, economic);

2. To get an overview of the current state of the research on software architecture, including changes that affect it and which activities, guidelines, practices, or others approaches are being used;

3. To identify promising directions for future research on software architecture.

To accomplish the SLR goal, we have defined three research questions with some subquestions:

RQ1: Which quality attributes (QA's) make the architecture sustainable?

According to the Karlskrona Manifesto [13], there is a tendency to treat sustainability as a desirable quality of the system that should be considered once other priorities have been established. The same document describes the principle that sustainability is systemic, i.e., it is never an isolated property. Whereas sustainability is not in competition with a specific set of quality attributes against which it has to be balanced, it is fundamental precondition for the continued existence of the system and influences many of the goals to be considered in systems design. In this case, should architecture sustainability be considered as a concept (at the same level of the software quality) having its own characteristics and sub-characteristics? Or should be architecture sustainability included as a new characteristic into the quality models for architecture? With this RQ-1, we intend to map which attributes are relevant to make a sustainable architecture.

RQ2: Which approaches report techniques to evaluate sustainability in software architectures?

Software architecture changes are inevitable. When a change affects the architecture, the original architectural model must be updated to ensure that the system remains flexible and continues to function as originally designed [14]. However, as an architectural environment is complex, the behavior of one component can affect the behavior of another components. As to deal with architectural interventions is not a trivial task, we want to know what approaches have been used to manage architectural changes that affect sustainability. Here, we use "approach" as a generic term, which can represent, for example, tools, frameworks, 
good practices, guidelines, activities, and models. With this RQ, we intend to achieve the second objective of this study.

RQ3: Which are the industry and research efforts promoting sustainable architectures?

We intend to outline both research and industry recent initiatives with regards to explicitly addressing sustainability in the context of software architectures and provide a roadmap of emerging research themes in the area of sustainable software architectures highlighting recent trends, and open issues and research challenges.

\subsection{Question Quality And Amplitude}

We have also defined the PICO (Population, Intervention, Comparison and Outcomes)[15] for our SLR, presented as follow:

Population: It identifies the population group observed by the intervention.

The population of our SLR is: "Studies that address sustainability in Software Architecture or Reference Architecture".

InTERVEnTION: It refers to what will be observed in the context of the SLR.

The intervention of this SLR is represented by the sustainability concepts, especially technical sustainability, and its characteristics.

COMPARISON: It defines what is compared in the context of the SLR.

It is possible to compare different approaches to architecture sustainability.

Outcomes: It expresses the results of the SLR.

Particularly, considering our SLR, the main result is the analysis and characterization of the studies proposed in the literature, that report software architecture or reference architecture sustainability.

\subsection{SOURCE SELECTION}

In this section, we have selected the sources where searches for primary studies will be executed.

\subsubsection{SourCes SELECTION CRITERIA DEFinition}

Here we have defined which criteria will be used to evaluate studies sources, i.e., which characteristics make these sources candidate to be used in the SLR execution.

There are three types of sources that will be considered in this SLR: 
- Publication databases: Aiming at establishing which publication databases will be used to find the primary studies, we have used the following criteria [16]: coverage (large number of conferences proceedings, journals, and indexed books in different knowledge areas), content update (publications are regularly updated); availability (full text of the papers is available); quality of results (accuracy of the results obtained by the search); and versatility export (a mechanism to export the results of the search is available). The databases selected are presented in Table 2.1;

Table 2.1: Selected publication databases

\begin{tabular}{|l|l|}
\hline Source & URL \\
\hline ACM Digital Library & http://dl.acm.org/ \\
\hline IEEE Xplore & http://ieeexplore.ieee.org/Xplore/home.jsp \\
\hline ScienceDirect & http://www.sciencedirect.com/ \\
\hline Scopus & http://www.scopus.com/ \\
\hline SpringerLink & http://link.springer.com/ \\
\hline Web of Science & http://apps.webofknowledge.com/ \\
\hline
\end{tabular}

- Related works: We will also consider the snowball technique proposed by Ridley [17] to cover the whole research area. This technique will allow to identify and examine research works cited in the studies selected.; and

- Specialist: We will also consider studies suggested by specialists of sustainability and software architecture domains. Although the indication of studies by specialists can be considered as bias, we will adopt this source aiming not to lose any important evidence.

\subsubsection{Studies LANGUAGes}

As the chosen language may restrain the sources identification, we have defined the languages in which obtained primary studies must be written. Considering this SLR, the defined language is English, because most of research in Computer Science have been reported in this language.

\subsubsection{Sources identification}

This item aims at selecting sources for the mapping execution. We have defined the methods used to execute the search for primary studies. In addition, we have identified the keywords and the search string that will be used to search primary studies. 
PRIMARY STUDY SEARCH METHODS: The search aims at the identification of candidate primary studies that answer the research questions and that would be either included or excluded to the final set of review studies.

We will use automatic search. By automatic search, we mean a search performed by executing search strings on search engines of publication databases.

KEYwORDS: The main keywords are "Software Architecture", and "Sustainability". Following, the main keywords and their related terms are:

- Software Architecture: Reference Architecture.

- Sustainability: Longevity, Sustainable, Long-living

As our focus is architecture (not software systems), we used the term "software architecture" in our string. The term "reference architecture" was also applied, because describes software architecture in a more abstract level. In addition to sustainability, we use search terms related, e.g. "longevity", "sustainable", and "long-living". Here, it is important highlight that we do not use terms such as "maintainability" [18], "modifiability" [19], or "evolvability" [20] because they are properties of specific qualities, while sustainability is systemic, i.e., sustainability is never an isolated property [13].

SEARCH STRING: It combine keywords and their synonymous arranged in such a way that the highest amount of relevant studies is obtained from search engines.

For each query part, a list of alternative keywords will be used and connected through logical OR to form a more expressive query. The search string and its adaptation to each database is presented in the Table 2.2 .

SourCES LIST: The publication databases selected for our SLR are shown in Table 2.1. According to Dybå et al. [21], these databases are efficient to conduct SLR in the context of Software Engineering. Furthermore, Scopus has been added, since it is considered the largest database of abstracts and citations [12];

\subsection{Study Selection}

In this section we describe the process and the criteria for studies selection and evaluation. 
Table 2.2: Searches in databases

\begin{tabular}{|c|c|}
\hline Database & Search String \\
\hline IEEE Xplore & $\begin{array}{l}\text { (("software architecture" OR "reference architecture") AND ("sustain- } \\
\text { ability" OR "longevity" OR "sustainable" OR "long-living")) }\end{array}$ \\
\hline Science Direct & $\begin{array}{l}\text { ("software architecture" OR "reference architecture") and (sustainability } \\
\text { OR longevity OR sustainable OR "long-living") }\end{array}$ \\
\hline $\begin{array}{l}\text { ACM Digital Li- } \\
\text { brary }\end{array}$ & $\begin{array}{l}\text { (("software architecture" OR "reference architecture") AND (sustainabil- } \\
\text { ity OR longevity OR sustainable OR "long-living")) }\end{array}$ \\
\hline Scopus & $\begin{array}{l}\text { ( ( "software architecture" OR "reference architecture" ) AND ( sustain- } \\
\text { ability OR longevity OR sustainable OR "long-living")) }\end{array}$ \\
\hline SpringerLink & $\begin{array}{l}\text { ("software architecture" OR "reference architecture") AND (sustainabil- } \\
\text { ity OR longevity OR sustainable OR "long-living") }\end{array}$ \\
\hline Web of Science & $\begin{array}{l}\text { (software architecture OR reference architecture) AND (sustainability } \\
\text { OR longevity OR sustainable OR long-living) }\end{array}$ \\
\hline
\end{tabular}

\subsubsection{Studies Inclusion And Exclusion Criteria Definition}

This subsection presents the criteria by which studies will be evaluated to decide if they must be selected or not in the context of the SLR.

The Inclusion Criteria (IC) or Exclusion Criteria (EC) make it possible to include primary studies that are relevant to answer the research questions and exclude studies that do not answer them. The IC/EC will be used in every stage are listed as follows:

\section{INCLUSION CRITERIA (IC):}

IC1 The primary study is related to sustainability specifically in the context of software architecture or reference architecture. Papers on sustainability in software engineering (in general) or sustainability in software systems (but that not contain details on the software architecture of these system) should not be included; and

IC2 The primary study proposes or uses any method/framework/approach/technique to make more sustainable software architecture; and

EXCLUSION CRITERIA (EC):

EC1 The primary study is a table of contents, short course description, or summary of a conference/workshop; 
EC2 The primary study is a previous version of a more complete study about the same research;

EC3 The primary study is written in a language other than english;

EC4 The full text of the primary study is not available;

EC5 The primary study is out of the SM objective;

EC6 The full paper is not available;

\subsection{Procedures for Studies Selection}

Aligned with Dybå and Dingsøyr [22], there are four stages of filtering the article set to produce the primary study data set.

\section{Stage 1. First Selection}

1. To debug the primary studies set, we will make a selection of the papers that are repeated in different databases. This depuration will be made with JabRef Reference Manager tool.

2. Based on the debugged set of studies, the title, abstract and conclusions, if necessary, of each primary study will be read, and the inclusion and exclusion criteria will be applied.

The studies in this selection phase will be divided to three members of the team (one Master and two Ph.D. students) and possible doubts will be resolved by consensus with their supervisor (reference architecture and sustainability specialist). We will not apply an agreement measure because the number of researchers involved in the mapping study is not significantly large.

For each data source mentioned in Table 2.1, we will document the number of papers that have been returned. In addition, we will record the number of papers left for each venue after primary study selection on the basis of title and abstract. Moreover, the number of papers finally selected from each source will be recorded.

\section{Stage 2. Second Selection}

1. Each primary study selected will be read in full and analyzed according to inclusion and exclusion criteria.

2. In addition, the related works cited by these studies will be evaluated intending to cover the whole research area.

3. If the decision about the inclusion or exclusion of a study is not clear, this study will be analyzed by the supervisor (specialist). When a disagreement occurs, consensus will be conducted. 
4. As in Stage 1, the number of papers finally selected from each source will be recorded.

\section{Stage 3. Quality Assessment}

All selected papers which were included in the review will undergo a quality assessment. Thus, each study will be evaluated against a set of questions with regard to the used method and the quality of the reporting.

Based on the quality assessment of primary studies proposed by Kitchenham and Chartes [23], we established a checklist containing seven quality criteria to analyse the quality of each included primary study.

Quality criteria are:

Q1: Is there a rationale for why the study was undertaken?

Q2: Is an overview about the state of art of the area in which the study is developed presented?

Q3: Is there an adequate description of the context in which the work was carried out?

Q4: Is a clear justification about the methods used during the study provided?

Q5: Are there a clear statement of contributions and sufficient data to support them?

Q6: Are the credibility and limitations of their findings explicitly discussed?

Q7: Are the perspectives of future works discussed?

For each question, the following scale-point will be applied: (i) the study fully meets a given quality criterion (1 point); (ii) the study meets the quality criterion to some extend (0.5 point); and (iii) the study does not meet this quality criterion (0 point). Table 2.3 shows the quality classification according to each score.

Table 2.3: Quality classification of primary studies

\begin{tabular}{ll}
\hline Score & Classification of Studies \\
\hline \hline $6.1-7.0$ & Excellent \\
$5.1-6.0$ & Very good \\
$4.1-5.0$ & Good \\
$3.1-4.0$ & Average \\
$2.1-3.0$ & Fair \\
$1.1-2.0$ & Poor \\
$0-1.0$ & Very poor \\
\hline
\end{tabular}




\subsection{Data Extraction Strategy}

During the data collection phase, we will collect a set of variables that describe each primary study. Data collection will be handled by the students and their supervisor. Every researcher involved will complete data extraction for every primary study separately. Then the three values of each variable (obtained by each researcher) will be compared to each other and the final value of the variable will be assigned to the primary study after discussion on every researcher's opinion. If three or more researchers assigned the same value to one variable this value will be assign to the variable without further discussion. In any other case, after a debate among the authors, a value will be assigned to every variable. We will not apply an agreement measure because the number of researchers involved in the mapping study is not significantly large. However, all conflicts will be recorded.

The Table 2.4 presents the data that will be extracted from every study.

Table 2.4: Extracted variables list

\begin{tabular}{|l|l|} 
V01. Author & V09. Changes \\
V02. Year & V10. Approach \\
V03. Title & V11. Approach Name \\
V04. Source & V12. Architecture life-cycle stage \\
V05. Keywords & V13. Challenges for Sustainability \\
V06. Publication Type & V14. Relevant references \\
V07. Author Type & V15. Comments \\
V08. Sustainability characteristics & \\
\hline
\end{tabular}

\subsection{Synthesis of the Extracted Data}

Relationships between extracted variables and research questions are provided in the Table 2.5, accompanied by the synthesis or analysis methods used on the data.

\section{Protocol VAlidation}

The SLR will be validated in three parts: 
Table 2.5: Data synthesis format

\begin{tabular}{|l|l|l|}
\hline $\begin{array}{l}\text { Research } \\
\text { Question }\end{array}$ & Variables Used & Synthesis Method \\
\hline RQ1 & {$[\mathrm{V} 08, \mathrm{~V} 13]$} & Descriptive statistics and descriptive synthesis. \\
\hline RQ2 & {$[\mathrm{V} 09, \mathrm{~V} 10, \mathrm{~V} 11, \mathrm{~V} 12]$} & Descriptive statistics and descriptive synthesis. \\
\hline RQ3 & {$[\mathrm{V} 13]$} & Descriptive statistics and descriptive synthesis. \\
\hline
\end{tabular}

1. The pilot $\longrightarrow$ testing the process:

Researchers will use a subset of resources to test the process. Problems in replicating the process may be identified, and the process will be refined accordingly.

Gaps in searches may be identified, and search terms and resources will be changed to include missing papers.

2. Data extraction:

Reliability of how to extract details from papers will be tested. An independent researcher (not involved in the pilot) will be given a set of accepted papers and asked to fill in the data extraction form.

3. External reviewers will review the protocol.

\section{REPORT THE REVIEW}

When reporting our study, we will a) discuss findings (description of primary studies, results of any quantitative summaries, and details of any meta-analysis), b) present a discussion (principal findings, strengths and weaknesses of the review (also in relation to other reviews), and the meaning of findings, such as applicability of findings, benefits, adverse effects and risks), c) discuss conclusions, including recommendations, such as practical implications for software development, implications for practitioners, and unanswered questions and implications for future research, and $\mathbf{d}$ ) elaborate on limitations of the review.

\section{REFERENCES}

[1] H. Koziolek, D. Domis, T. Goldschmidt, and P. Vorst, "Measuring architecture sustainability", IEEE Software, vol. 30, no. 6, pp. 54-62, 2013.

[2] B. H. Cheng, R. Lemos, H. Giese, P. Inverardi, J. Magee, J. Andersson, B. Becker, N. Bencomo, Y. Brun, B. Cukic, G. Marzo Serugendo, S. Dustdar, A. Finkelstein, C. Gacek, K. Geihs, V. Grassi, G. Karsai, H. M. Kienle, J. Kramer, M. Litoiu, S. Malek, R. Mirandola, H. A. Müller, S. Park, M. Shaw, M. Tichy, M. Tivoli, D. Weyns, and J. Whittle, "Software engineering for self-adaptive systems", chapter Software Engineering for Self-Adaptive Systems: A Research Roadmap, pp. 1-26. 2009. 
[3] R. C. Seacord, J. Elm, W. Goethert, G. A. Lewis, D. Plakosh, J. Robert, L. Wrage, and M. Lindvall, "Measuring software sustainability", in International Conference on Software Maintenance (ICSM 2003), Amsterdam, The Netherlands, 2003, pp. 450-459.

[4] B. Penzenstadler and H. Femmer, "A generic model for sustainability with processand product-specific instances", in Workshop on Green in/by Software Engineering (GIBSE 2013), Fukuoka, Japan, 2013, pp. 3-8.

[5] C. Calero, M. F. Bertoa, and M. A. Moraga, "A systematic literature review for software sustainability measures", in 2nd International Workshop on Green and Sustainable Software (GREENS 2013), San Francisco, California, 2013, pp. 46-53.

[6] P. Lago, Q. Gu, and P. Bozzelli, "A systematic literature review of green software metrics", Tech. Rep., Vrije Universiteit, 2014.

[7] P. Lago, S. A. Koçak, I. Crnkovic, and B. Penzenstadler, "Framing sustainability as a property of software quality", ACM Commun, vol. 58, no. 10, pp. 70-78, Sept. 2015.

[8] I. Ozkaya and R. Nord, "Improving software sustainability through data-driven technical debt management", Tech. Rep., Software Engineering Institute, Carnegie Mellon University, 2015.

[9] S. Naumann, M. Dick, E. Kern, and T. Johann, "The greensoft model: A reference model for green and sustainable software and its engineering", Sustainable Computing: Informatics and Systems, vol. 1, no. 4, pp. 294 - 304, 2011.

[10] L. Bass, P Clements, and R. Kazman, Software Architecture in Practice, AddisonWesley Professional, 3rd edition, 2012.

[11] P. Avgeriou, M. Stal, and R. Hilliard, "Architecture sustainability", IEEE Software, vol. 30, no. 6, pp. 40-44, December 2013.

[12] B. A. Kitchenham and S. Charters, "Guidelines for performing systematic literature reviews in software engineering. Technical Report EBSE 2007-001.", Tech. Rep., Keele University and Durham University, UK,, 2007.

[13] C. Becker, R. Chitchyan, L Duboc, S. Easterbrook, M. Mahaux, B. Penzenstadler, R. Navas, G, C. Salinesi, N. Seyff, C. C. Venters, C. Calero, S. A. Koçak, and S. Betz, "The karlskrona manifesto for sustainability design", Cornell University Library, vol. $1,2014$.

[14] B.J. Williams and J.C. Carver, "Characterizing software architecture changes: A systematic review", Information and Software Technology, vol. 52, no. 1, pp. 31 $51,2010$. 
[15] J. Biolchini, P. Mian, A. Natali, and G. Travassos, "Systematic Review in Software Engineering. Technical report (TRES679/05)", Tech. Rep., PESC - COPPE/UFRJ, 2005.

[16] O. Dieste, A. Grimán, and N. Juristo, "Developing search strategies for detecting relevant experiments", Empirical Software Engineering, vol. 14, no. 5, pp. 513-539, 2009.

[17] D. Ridley, The Literature Review: A Step-by-Step Guide for Students, SAGE Study Skills Series. SAGE Publications, 2012.

[18] ISO., "ISO/IEC 25010:2011 Systems and software engineering - Systems and software Quality Requirements and Evaluation (SQuaRE) - System and software quality models", Tech. Rep., International Organization for Standardization (ISO), 2011.

[19] P. Bengtsson, N. Lassing, J. Bosch, and H. V. Vliet, "Architecture-level modifiability analysis (ALMA)", Journal of Systems and Software, vol. 69, no. 1-2, pp. 129-147, 2004.

[20] H.P. Breivold and I. Crnkovic, "A systematic review on architecting for software evolvability", in 21st Australian Software Engineering Conference (ASWEC 2010), Auckland, New Zealand, April 2010, pp. 13-22.

[21] T. Dybå, T. Dingsøyr, and G. K. Hanssen, "Applying systematic reviews to diverse study types: An experience report", in First International Symposium on Empirical Software Engineering and Measurement (ESEM 2007), Washington, DC, USA, 2007, pp. 225-234, IEEE Computer Society.

[22] T. Dybå and T. Dingsøyr, "Strength of evidence in systematic reviews in software engineering", in Second ACM-IEEE International Symposium on Empirical Software Engineering and Measurement (ESEM 2008), New York, NY, USA, 2008, ESEM '08, pp. 178-187, ACM.

[23] B. Kitchenham and S. Charters, "Guidelines for performing systematic literature reviews in software engineering", Tech. Rep., Keele University and Durham University, 2007. 

APPENDIX

B

PAPER: TWO PERSPECTIVES ON REFERENCE ARCHITECTURE SUSTAINABILITY 


\section{Two Perspectives on Reference Architecture Sustainability}

\author{
Tiago Volpato \\ University of São Paulo \\ São Carlos, Brazil \\ tiagovolpato@usp.br
}

\author{
Brauner R. N. Oliveira \\ University of São Paulo \\ São Carlos, Brazil \\ brauner@usp.br
}

\author{
Lina Garcés \\ University of São Paulo \\ São Carlos, Brazil \\ linamgr@icmc.usp.br
}

\author{
Rafael Capilla \\ Rey Juan Carlos University \\ Madrid, Spain \\ rafael.capilla@urjc.es
}

\author{
Elisa Yumi Nakagawa \\ University of São Paulo \\ São Carlos, Brazil \\ elisa@icmc.usp.br
}

\begin{abstract}
In the context of software architectures, sustainability has been investigated as an important quality property to assess how well these architectures support changes over time. Several initiatives to achieve sustainable software architectures/systems can be already found. In parallel, reference architectures have served as an effective support to facilitate and standardize the development and evolution of software systems, including in complex, critical application domains. By encompassing valuable knowledge of specific domains, the reference architectures survival is considered of utmost importance, however, the most of such architectures have not been updated since their first version. Furthermore, there is a lack of works investigating how a reference architectures, by itself, can become sustainable and/or can contribute to develop sustainable systems in a domain. The main contribution of this paper is to provide a first view about sustainability on reference architectures. Resulting from our expertise on reference architectures, we bring out the two perspectives on their sustainability: (i) sustainability IN reference architectures; and (ii) sustainability OF reference architectures. In particular, for the perspective OF, we analyzed 20 existing reference architectures to assess their sustainability, and we found most of them were not updated over time. Hence, we also provide an initial set of aspects that could contribute to address sustainability of those architectures.
\end{abstract}

\section{CCS CONCEPTS}

-Software and its engineering $\rightarrow$ Software architectures; Sustainability;

\section{KEYWORDS}

Software architecture, Reference architecture, Sustainability

Permission to make digital or hard copies of all or part of this work for personal o classroom use is granted without fee provided that copies are not made or distributed for profit or commercial advantage and that copies bear this notice and the full citation on the first page. Copyrights for components of this work owned by others than ACM must be honored. Abstracting with credit is permitted. To copy otherwise, or republish, to post on servers or to redistribute to lists, requires prior specific permission and/or a fee. Request permissions from permissions@acm.org.

ECSA '17, Canterbury, United Kingdom

(C) 2017 ACM. 978-1-4503-5217-8/17/09...\$15.00

DOI: $10.1145 / 3129790.3129815$

\section{ACM Reference format:}

Tiago Volpato, Brauner R. N. Oliveira, Lina Garcés, Rafael Capilla, and Elisa Yumi Nakagawa. 2017. Two Perspectives on Reference Architecture Sustainability. In Proceedings of ECSA '17, Canterbury, United Kingdom, September 11-15, 2017, 7 pages.

DOI: $10.1145 / 3129790.3129815$

\section{INTRODUCTION}

Software architectures have played an essential role in determining the quality of software systems, which are constructed to satisfy organization's business goals [7]. Reference architectures, are a special type of software architectures that provide a characterization of software systems functionalities in specific application domains, such as automotive [5], e-Commerce [33] and health systems [26], and technological domains, such as Service-Oriented Architecture $[4,59]$. Considering their importance, important contributions in topics such as design, representation, evaluation and appropriate use of reference architectures can be found [3, 25, 38, 44]. However, few contributions on their evolution have been done. Updating and continuing a reference architecture is extremely important because stakeholders requirements, business models, software development processes, and technologies are constantly changing, hence, their respective reference architectures also need to evolve to be a well representation of software systems in their domains. In consequence, the rich knowledge contained in reference architectures can become outdated and economic investment be wasted if their evolution is not contemplated.

In another perspective, the term sustainability has called the attention of the scientific community regarding its economic, social, environmental, and technical dimensions. In the context of software architecture, sustainability can be defined as the ability to tolerate architectural modifications throughout software life cycle [29]. Architectural modifications are needed to accommodate changes in requirements, technology or in business strategies and goals. Several approaches to improve software architecture sustainability can be found in the literature, but no work focusing explicitly in reference architectures has been proposed. We believe that advances obtained to understand and manage sustainability of software architectures are not sufficient for the context of reference architectures. In this way, this paper intends to be a blueprint to understand reference architectures sustainability.

Specifically, our goal is to outline a view of sustainability on reference architectures bringing out two perspectives: (i) sustainability IN reference architectures, detailing what is important for such 
architectures to support the development of sustainable concrete software architectures, and (ii) sustainability $\mathbf{O F}$ reference architectures, describing how the reference architectures, itself, can evolve over time. We analyzed a set of reference architectures previously identified aiming to check their current state, looking for evidence that shows whether they have been evolved and how they have supported changes over time. Moreover, we used some results obtained at conducting a systematic mapping (SM) that aimed to investigate how sustainability has been treated in software architecture and in particular, in reference architectures.

This paper is organized as follows. Section 2 describes a background on reference architecture, providing definitions and an overview of how to design and represent them; this section also introduces software architecture sustainability. Section 3 presents the 20 reference architectures analyzed. Section 4 introduces the two perspectives of sustainability on reference architectures. Finally, Section 5 presents our conclusions and future work.

\section{BACKGROUND}

In this section, we present a brief overview on reference architectures, including definition, uses, and examples, as well as a background on sustainability in software architectures.

\subsection{Reference architectures}

A reference architecture is a special type of software architecture that has successfully supported the development, standardization, and evolution of systems. By definition, it is an architecture that contains knowledge about designing concrete architectures for a specific application domain, supported by a domain terminology that is well understood, unambiguously and unified [43]. In the same perspective, the objective of a reference architecture is to facilitate and guide the design of concrete architectures for new systems, new versions or extensions of similar products, to support the evolution of a set of systems that stem from the same reference architecture, or to standardize different systems [25].

A reference architecture presents several possibilities of use [43]: (i) application domain standardization; (ii) extraction of new architectures; (iii) reuse of software systems; and (iv) evolution of existing software systems. Hence, reference architectures have been proposed for different domains, such as automotive [5], SOA-based systems [12], space exploration [21], and ambient assisted living [17]. Recently, reference architectures have also been proposed to assist the development of solutions for the Internet of Things (IoT) $[1,15]$, which brings up challenges, such as specific software interfaces, software dependability, and particular approaches for security, maintainability, and sustainability [56]

Considering their relevance, some works discuss the engineering of reference architectures. Nakagawa et al. [44] proposed a reference model for reference architectures (RAModel) that provides information about elements (and their relationships) that can be present in reference architectures, independently from the application domain or purpose of them. This model can be used to [44] (i) analyze reference architectures; (ii) compare references architectures; (iii) support the design of software product line (SPL); and (iv) establish reference architectures.
On the other perspective, Angelov et al. [3] describe a framework to support the analysis of reference architectures in terms of relationships among their context, goals, and architecture design/specification. Nakagawa et al. [42] present ProSA-RA, a process that systematizes the design, representation, and evaluation of reference architectures. In short this process consists of four steps [42]: (i) information source investigation, (ii) architectural requirement establishment, (iii) reference architecture design, and (iv) reference architecture evaluation. Other initiatives can be found in $[8,39,50,55]$; however, in general, they are high-level guidelines, principles, and recommendations or domain-specific processes and, perhaps because of this fact, they have not been widely adopted yet. Besides that, no study addresses the evolution of these architectures.

\subsection{Software architecture sustainability}

Research on sustainability in software engineering has gained importance as a result of the need to create better software and therefore avoid compromising future generations opportunities [2, 45]. In the context of software systems, technical sustainability addresses the long-term use of such systems and their appropriate evolution in a constantly changing execution environment [32, 49]. In industrial automation, for instance, the sustainability of software systems is necessary, because industrial devices have long lifecycles [31]. Moreover, sustainability of software systems is closely related to the sustainability of their architectures [31]. In this scenario, sustainability can be defined as the architecture's capacity to endure different types of changes through efficient maintenance and orderly evolution over its entire life cycle [6].

In order to understand problems and challenges that must be overcome to achieve a sustainable architectures, we conduced a SM to analyze the state of art about sustainability in software architectures and in reference architectures. We used the following search databases: ACM Digital Library, IEEE Xplore, Springer Link, ScienceDirect, Scopus, and Web of Science. We used the following search string:

$$
\begin{gathered}
\text { (("software architecture" OR "reference architecture") } \\
\text { AND ("sustainability" OR "longevity" OR "sustainable" } \\
\text { OR "long-living")) }
\end{gathered}
$$

A total of 1891 primary studies were obtained considering all sources of studies. After screening the studies, we identified 159 unique studies.

We observed that several studies pointed out to problems and challenges for software architectures sustainability. For instance, Avgeriou et al. [6] present some changes that affect the sustainability of architectures, such as changes in requirement and design decisions. Moreover, the authors distinguished differences among three approaches to deal with changes in the architecture, namely refactoring, renovating, and rearchitecting, listed in an order of increasing severity. In short, refactoring is a less harsh approach to provide sustainability in architectures, having positive impacts to extend them or change them by modifying only a few internal elements. Renovating is to reconstruct one or more essential elements from scratch, whenever refactoring is no longer effective. However, when architecture is subject to significant changes, it is necessary 


\begin{tabular}{|c|c|c|c|c|}
\hline ID & Reference Architecture & Publication Year & Update & Authors \\
\hline RA-1 & Reference Architecture for the Ground Segment Software & 2005 & No & Duro et al. [23] \\
\hline RA-2 & S3 - Service-Oriented Solution Stack & 2007 & Yes & Arsanjani et al. [4] \\
\hline RA-3 & FERP Reference Architecture for ERP Systems & 2007 & No & Brehm and Gomez [10] \\
\hline RA-4 & Reference Architecture for Service-Oriented Computing & 2007 & No & Dillon et al. [20] \\
\hline RA-5 & AXMEDIS Architecture for Automating Production of Cross Media Content & 2007 & Yes & Fioravanti et al. [24] \\
\hline RA-6 & Reference Architecture for Precision Agriculture (PA) & 2007 & No & Murakami et al. [41] \\
\hline RA-7 & Reference Architecture for Image Processing System & 2008 & No & Hemalatha et al. [28] \\
\hline RA-8 & Reference Architecture for e-Commerce Patterns & 2008 & No & Lan et al. [33] \\
\hline RA-9 & Reference Architecture for Self-organizing Service-Oriented Computing & 2008 & No & Liu et al. [36] \\
\hline RA-10 & inContext Pervasive Collaboration Services Architecture (PCSA) & 2008 & No & Reiff-Marganiec et al. [51] \\
\hline RA-11 & SOELA - Service-oriented e-Learning Reference Architecture & 2008 & No & Zheng et al. [58] \\
\hline RA-12 & Reference Architecture for Telecommunications Service Providers (TSPs) & 2008 & Yes & Ramanathan et al. [48] \\
\hline RA-13 & Reference Architecture for National Science and Technology Information Service Development & 2009 & No & Choi et al. [14] \\
\hline RA-14 & CERA - Reference Architecture for interoperable Collaborate Work Environment Systems & 2009 & No & Peristeras et al. [46] \\
\hline RA-15 & Reference Architecture for Situational Awareness Systems & 2009 & No & Leppaniemi et al. [34] \\
\hline RA-16 & Service-Oriented Architecture Infrastructure Reference Architecture & 2009 & Yes & Zimmermann et al. [59] \\
\hline RA-17 & AUTOSAR - AUTomotive Open System ARchitecture & 2013 & Yes & AUTOSAR. [5] \\
\hline RA-18 & IIRA - Industrial Internet Reference Architecture & 2017 & Yes & Consortium [16] \\
\hline RA-19 & CONTINUA & 2013 & Yes & CONTINUA. [17] \\
\hline RA-20 & DRA 5.0 - Mars Design Reference Architecture & 2010 & Yes & Drake et al. [21] \\
\hline
\end{tabular}

Table 1: Reference Architectures analyzed [18]

to analyze them and design a new architecture (rearchitecting) by modifying and/or rebuilding some existing components or building new ones that offer new features. Similarly, Koziolek [30] conduced a systematic literature review aiming to evaluate scenario-based methods to support sustainability evaluation and categorize architectural level metrics according to design principles. Koziolek et al. [31] reported experiences with sustainability measurement in the architecture of a large-scale industrial control system. In this study, a multi perspective approach called Morphosis was adopted focusing on modifications of some aspects, such as requirements, architecture, design, and source code. Durdik et al. [22] reported their experiences from applying various techniques to yield sustainable architectural design decisions in industrial and research projects. With this experience, the authors described guidelines for achieving sustainable decisions, such as (i) use of a minimalist approach for the initial documentation; (ii) ensure consistency between decisions and requirements with the architectural design/code; and (iii) use existing architectural knowledge. Carrillo et al. [13] describe a configurable meta-model whose goal is to achieve architectural knowledge (AK) sustainability and a set of criteria suggests ways to estimate the technical sustainability of AK. Other important initiatives that address sustainability in software architecture can be found in $[27,53,54,57]$. However, our SM did not find any work dealing specifically with sustainability on reference architectures.

\section{AN OVERVIEW OF SUSTAINABLE REFERENCE ARCHITECTURES}

In order to understand the evolution of reference architectures, we analyzed 16 reference architectures presented in de Oliveira et al. [18] and other reference architectures previously known and investigated in our research group. We investigated their current status by looking for information available in their websites and/or other studies. Mainly, we checked for the existence of new versions, their use and dissemination, existence of consortia or institutions supporting them, and aspects of the reference architectures that were modified or updated. It is worth highlighting that the 16 analyzed reference architectures are framed in the domain of ServiceOriented Architecture (SOA), a promising architectural style that has been widely adopted to develop software-intensive systems for different and even critical application domains. Table 1 summarizes the reference architectures analyzed, presenting their year of publication and whether they have been updated or not.

From the 20 reference architectures, we identified 12 as outdated, since we did not find evidence (publications, projects or websites) indicating updates or initiatives for using or disseminating them. Among these architectures, as an example, we can cite the reference architecture for disasters and emergencies management [35], published in 2009. This architecture was designed based on the OASIS reference model for SOA Mackenzie et al. [37]. This model has been updated in recent years (i.e., in 2009 and 2012), with updates in standards and supporting new technologies. However, this reference architecture was not updated regarding new versions of OASIS, as expected. Another reference architecture investigated and that has not been evolved intends to support projects of web services applications [20]. More specifically, this architecture includes three architectural styles, namely Matchmaker, Broker, and Peer-to-Peer. However, we observed an evolution in the way that web services have been developed, e.g., how to exchange coherent information and services among systems [19]. New architectural styles, such as liquid Web Services [9] and Structural Service [19], were proposed to improve implementation of Web services, providing mechanisms for interoperability, scalability, deployment, and composability $[9,19]$. Regarding reference architectures for Web services, we observed that this reference architecture does not follow such evolution and, consequently, web services applications designed from this architecture do not benefit from these improvements. If this reference architecture is continuously updated, it could serve as a support for the development and standardization 


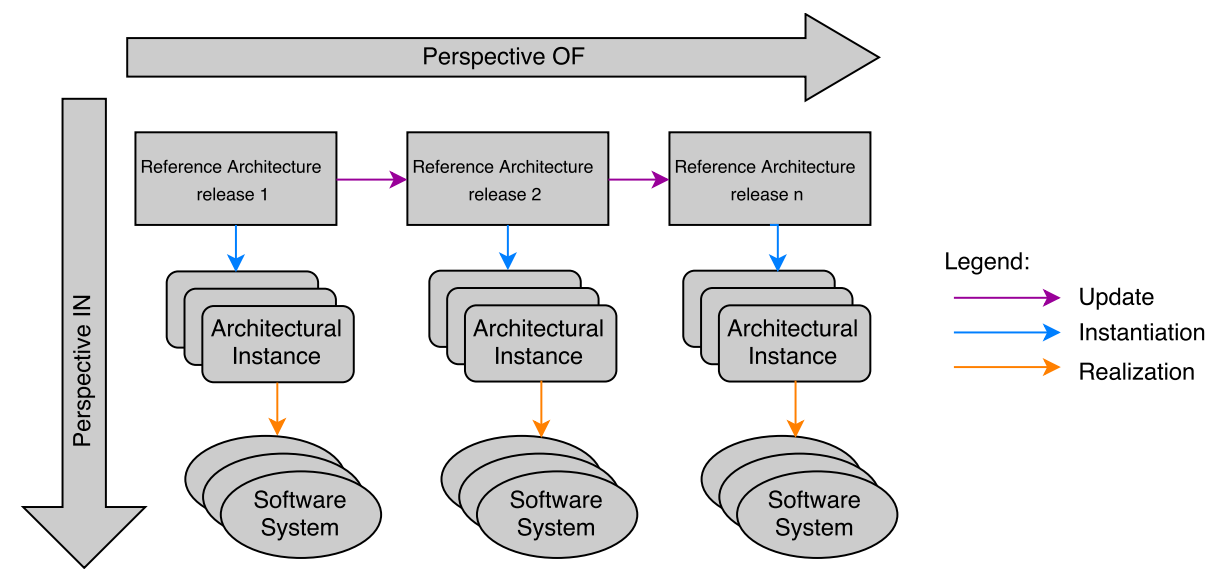

Figure 1: Two Perspectives on Reference Architecture Sustainability: "IN" and "OF"

of Web services, such as in telecommunication [52] and Cloud Computing [47], which have required more and more integration and interoperability.

In the same way, several other relevant reference architectures were proposed $[11,14,23,36]$; however, no studies were found indicating updates or any consortium/institution disseminating or using them, differently from what was observed in other reference architectures that are constantly updated and have been widely used $[4,5,15,17,21]$. Such architectures are continually evolved, adopting policies such as launch of new releases, refinement of concepts, and revision of documentation.

Among these examples, IIRA (Industrial Internet Reference Architecture) [15] is a standard-based open architecture for industrial internet systems that encompasses IoT, machines, computers, and people, enabling intelligent industrial operations using advanced data analytics for transformation business outcome. This architecture has broad industry applicability to drive interoperability, to map applicable technologies, and to guide technology and standard development describing common characteristics, features, and patterns well understood, which have been defined in the Industrial Internet Consortium (IIC) ${ }^{1}$.

Initially designed in 2015 (version 1.7), it was recently upgraded in 2017 to version 1.8 [16], delivering implementable results that reflect new technologies, new concepts, and new applications as they emerge. For example, this latest version introduces a refinement of viewpoints and describes more appropriately key crosscutting concerns and their associated system characteristics, such as safety and security. Furthermore, version 1.8 introduces the Layered Databus Architecture Pattern, a common architecture across IoT systems in multiple industries, offering benefits as: (i) fast deviceto-device integration, (ii) automatic data and application discovery, (iii) scalable integration, and (iv) hierarchical subsystem isolation, enabling development of complex system designs. In a similar way, S3 (A Service-Oriented Reference Architecture) [4] also continually presents new versions, as the industry evolves and SOA concepts are refined. In their latest version, released in 2014, new ontologies were included to the use of SOA in particular sectors of commerce

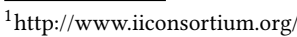

and industry. In the same perspective, CONTINUA [17] received continuous updates. Since its first version, in 2008, six new versions were launched, and as it is refined, its documentation that initially had 231 pages, currently presents 654 pages.

These examples that reference architectures must evolve continuously and must be actively maintained and refactored because outdated reference architectures may stifle changes and innovation and could affect the entire class of systems supports of them [40]. A great effort is usually necessary to design reference architectures; hence, it is quite interesting to keep it useful in middle- and long-time. If these architectures are outdated and do not follow changes in the application domains, they will not longer support the development, standardization, and evolution of systems of such domains.

\section{PERSPECTIVES OF SUSTAINABILITY ON REFERENCE ARCHITECTURES}

Based on our experience, of more than 10 years, at investigating and establishing reference architectures, we can see sustainability in the context of reference architectures from two perspectives: (i) sustainability IN reference architectures; and (ii) sustainability OF reference architectures, as illustrated in Figure 1.

\subsection{Sustainability IN reference architectures}

The elements of a reference architecture found in RAModel [44] such as non-functional requirements, architectural descriptions, patterns, and laws can be instantiated for a particular software architecture to support the development of specific software systems. This process of instantiation characterizes the perspective "IN", which addresses the capability of reference architectures to support the establishment of sustainable architectures for software systems. Regarding this perspective, there are already works that explore it, as described earlier. However, when a software architecture is instantiated from a reference architecture, this architectural instance can evolve individually, generating new knowledge that can be used as a feed back to the reference architecture and therefore, 
Table 2: Aspects observed in Reference Architectures analyzed

\begin{tabular}{|c|c|c|c|c|c|c|c|c|c|c|c|c|c|c|c|c|c|c|c|c|}
\hline \multirow[b]{2}{*}{ Aspects } & \multicolumn{20}{|c|}{ Reference Architectures ID } \\
\hline & RA-1 & RA-2 & RA-3 & RA-4 & RA-5 & RA-6 & RA-7 & RA-8 & RA-9 & RA-10 & RA-11 & RA-12 & RA-13 & RA-14 & RA-15 & RA-16 & RA-17 & RA-18 & RA-19 & RA-20 \\
\hline 1 & & $\checkmark$ & & & $\checkmark$ & & & & & & & $\checkmark$ & & & & $\checkmark$ & $\checkmark$ & $\checkmark$ & $\checkmark$ & $\checkmark$ \\
\hline 2 & & $\checkmark$ & & & $\checkmark$ & & & & & & & $\checkmark$ & & & & $\checkmark$ & $\checkmark$ & $\checkmark$ & $\checkmark$ & $\checkmark$ \\
\hline 3 & & & & & & & & & & & & $\checkmark$ & & & & $\checkmark$ & $\checkmark$ & $\checkmark$ & & \\
\hline 4 & & & & & $\checkmark$ & & & & & & & $\checkmark$ & & & & $\checkmark$ & $\checkmark$ & & & $\checkmark$ \\
\hline
\end{tabular}

contributing to its evolution. Hence, the perspective "IN" can work as a trigger for changes in the perspective "OF". The opposite is also true. New releases of a reference architecture can imply changes in their architectural instances, requiring software architects to do some sort of refactoring, renovating or even rearchitecting to adjust them.

\subsection{Sustainability OF reference architectures}

On the other hand, perspective "OF" refers to how the reference architecture itself can be sustainable. In this perspective, sustainability must be seen as a quality attribute of reference architectures, i.e., their ability to endure different types of changes over time, as illustrated in Figure 1. Analyzing the existing scenario of reference architectures, it is evident that some particular aspects can affect their sustainability. Table 2 summarizes four aspects observed as result of analyzing the 20 reference architectures.

(1) Existence of a consortium or institution supporting the reference architecture. As reference architecture are designed for a class of systems, it is important that a consolidated community demonstrate interest in this architecture. These consortium or institutions may originate both industry and academy, and are committed to disseminating these architectures, such as vehicle manufacturers, suppliers and other companies from the electronics, semiconductor and software industry that develop AUTOSAR [5], IIC that support IIRA [16] and Personal Connected Health Alliance, that develop CONTINUA [17]. In particular, among the reference architectures analyzed, we observed that eight of them (RA-2, RA-5, RA-12, RA-16, RA-17, RA-18, RA-19, and RA-20) are maintained by companies or consortia.

(2) Refinement of reference architecture as application domain advance. For example, the inclusion of new ontology to extend the use of SOA in the latest version of S3 [4], and the introduction of a new architecture pattern in the version 1.8 of IIRA [16] show that alignment of a reference architecture to the state of practice is crucial for their continuation. In our investigation, we detected that the architectures RA-2, RA-5, RA-12, RA-16, RA-17, RA-18, RA-19, and RA-20 were refined in accordance with the understanding and review of application domains concepts.

(3) Inclusion of new stakeholders. New stakeholders can mean new visions or new business goals. For example, since 2015 , other companies have joined to the IIC and so was necessary to refine viewpoints of IIRA [16] to describe new context of business, usage, operation, and implementation.

(4) Decisions that are retained over time. Because reference architectures are located at a higher level of abstraction, their design is intended to transcend today's available technologies. Capabilities should be specified independently of how they are to be implemented, i.e., with neutrality.

\section{CONCLUSION AND FUTURE WORKS}

In this paper, we described two perspectives about sustainability in the context of reference architectures. Perspective "IN" is about understanding how sustainable concrete architectures can be instantiated from reference architecture. In this sense, an open research question is what should be considered in a reference architecture (e.g., guidelines, best practices, or methods) so that concrete architectures instantiated from them achieve sustainability? Moreover, regarding new knowledge that an instantiated architecture can generate, an open issue is how to feedback this new knowledge to the reference architecture to benefit others architectures also supported by such reference architecture? Our work, as discussed here, is a first step towards emphasizing sustainability on reference architectures, generally neglected in other studies. Furthermore, the Perspective "OF" is about the ability that the reference architecture itself have to evolve over time. Reflecting in this perspective "OF", some of main issues are: (i) what concepts need to be established and included in architectural processes so that they derive sustainable reference architectures?; (ii) what activities need to be systematized and included in the project of sustainable reference architectures?; and (iii) what knowledge about the application domain, e.g., stakeholders, standards or legislations, should be included to achieve sustainability of reference architectures?

As a future work, we intend to make a more specific investigation of this research topic, for instance, identifying methods, approaches, frameworks, or guidelines to achieve sustainability on software architectures and verify if they are applicable in the context of reference architectures. Furthermore, we intend to refine these aspects that seem to influence sustainability on reference architectures.

\section{ACKNOWLEDGMENTS}

This work is supported by the Brazilian funding agency FAPESP (Grant 2013/20317-9, 2016/16870-2, and 2017/06195-9).

\section{REFERENCES}

[1] P. Adolphs and U. Epple. 2015. Reference Architecture Model Industry 4.0 (RAMI4.0). Technical Report. ZVEI - German Electrical and Electronic Manufacturer's Association.

[2] N. Amsel, Z. brahim, A. Malik, and B. Tomlinson. 2011. Toward Sustainable Software Engineering (NIER Track). In 33rd International Conference on Software Engineering (ICSE 2011). 976-979.

[3] S. Angelov, P. Grefen, and D. Greefhorst. 2009. A classification of software reference architectures: Analyzing their success and effectiveness. In foint Working IEEE/IFIP Conference on Software Architecture European Conference on Software Architecture (WICSA/ECSA 2009. 141-150. 
[4] A. Arsanjani, L. J. Zhang, M. Ellis, A. Allam, and K. Channabasavaiah. 2007. S3: A Service-Oriented Reference Architecture. IT Professional 9, 3 (May 2007), 10-17.

[5] AUTOSAR. 2013. AUTOSAR (AUtomotive Open System ARchitecture). (2013). http://www.autosar.org/

[6] P. Avgeriou, M. Stal, and R. Hilliard. 2013. Architecture Sustainability. IEEE Software 30, 6 (December 2013), 40-44.

[7] L. Bass, P. Clements, and R. Kazman. 2012. Software Architecture in Practice (3rd ed.). Addison-Wesley Professional.

[8] J. Bayer, T. Forster, D. Ganesan, J. Girard, I. John, J. Knodel, R. Kolb, and D. Muthig. 2004. Definition of Reference Architectures based on Existing Systems. Technical Report. Fraunhofer IESE.

[9] D. Bonetta and C. Pautasso. 2011. An Architectural Style for Liquid Web Services. In 9th Conference on Software Architecture (WICSA 2011). Boulder, Colorado, USA, 232-241.

[10] N. Brehm and J. M. Gomez. 2007. Web Service-Based Specification and Implementation of Functional Components in Federated ERP-Systems. In 10th International Conference on Business Information Systems (BIS 2007). Poznan, Poland, 133-146.

[11] N. Brehm and G. J. Marx. 2007. Web Service-Based Specification and Implementation of Functional Components in Federated ERP-Systems. In 10th International Conference on Business Information Systems (BIS 2007). Poznan, Poland, 133-146.

[12] P. Brown, J. A. Estefan, K. Laskey, F. McCabe, and D. Thornton. 2012. OASIS Reference Architecture Foundation for Service Oriented Architecture. Technical Report. OASIS Standard.

[13] C. Carrillo, R. Capilla, O. Zimmermann, and U. Zdun. 2015. Guidelines and Metrics for Configurable and Sustainable Architectural Knowledge Modelling. In 9th European Conference on Software Architecture (ECSA 2015). 631-635.

[14] H Choi, C. Lim, and J Kim. 2009. Defining reference architecture for NTIS development. In 11th International Conference on Advanced Communication Technology (ICACT 2009). Gangwon-Do, Korea, 284-287.

[15] Industrial Internet Consortium. 2015. IIRA (Industrial Internet Reference Architecture, version 1.7. (2015). http://www.iiconsortium.org/IIRA.htm

[16] Industrial Internet Consortium. 2017. The Industrial Internet of Things Volume G1: Reference Architecture, version 1.8. (2017). http://www.iiconsortium.org/ IIRA.htm

[17] CONTINUA. 2013. Continua Health Alliance. (2013). http://continuaalliance.org/

18] L. B. R. de Oliveira, K. R. Felizardo, D. Feitosa, and E. Y. Nakagawa. 2010. Reference Models and Reference Architectures Based on Service-Oriented Architecture: A Systematic Review. In 4th European Conference on Software Architecture (ECSA 2010). Copenhagen, Denmark, 360-367

[19] J. C. Delgado. 2013. Architectural Styles for Distributed Interoperability. Information Resources Management fournal 26, 4 (2013), 40-65.

[20] T. S. Dillon, C. Wu, and E. Chang. 2007. Reference Architectural Styles for Service-Oriented Computing. In IFIP International Conference on Network and Parallel Computing (NPC 2007). Dalian, China, 543-555.

[21] B. G. Drake, S. J. Hoffman, and D. W. Beaty. 2010. Human exploration of Mars, Design Reference Architecture 5.0. In 2010 IEEE Aerospace Conference. Big Sky, USA, $1-24$.

[22] K. Durdik, B. Klatt, H. Koziolek, K. Krogmann, J Stammel, and R Weiss. 2012. Sustainability guidelines for long-living software systems. In 28th International Conference on Software Maintenance (ICSM 2012). Riva del Garda, Italy, 517-526.

[23] N. Duro, F. Moreira, J. Rogado, J. Reis, and N. Peccia. 2005. Technology harmonization - developing a reference architecture for the ground segment software. In 2005 IEEE Aerospace Conference. Big Sky, USA, 3968-3979.

[24] F. Fioravanti, M. Spinu, and M. Campanai. 2007. AXMEDIS as the Service Oriented Architecture for the Media: Is It Feasible?. In 3rd International Conference on Automated Production of Cross Media Content for Multi-Channel Distribution (AXMEDIS 2007). 264-269.

[25] M. Galster and P. Avgeriou. 2011. Empirically-grounded Reference Architectures: A Proposal. In 7th International ACM Sigsoft Conference on the Quality of Software Architectures (QoSA 2011). Boulder, Colorado, USA, 153-158.

[26] L. Garces, A. Ampatzoglou, P. Avgeriou, and Nakagawa E. Y. 2015. A Comparative Analysis of Reference Architectures for Healthcare in the Ambient Assisted Living Domain. In EEE 28th International Symposium on ComputerBased Medical Systems (CBMS'15). Sao Carlos, SP, Brazil, 270-275.

[27] S. Giesecke, J. Friebe, and M. Frenzel. 2011. Long-Term Software Architecture Management with Multi-technology Tool Support. In 15th European Conference on Software Maintenance and Reengineering(CSMR 2011). 321-324.

[28] T. Hemalatha, G. Athisha, and S. Jeyanthi. 2008. Dynamic Web Service Based Image Processing System. In 16th International Conference on Advanced Computing and Communications (ADCOM 2008). Chennai, India, 323-328.

[29] D. Kim, J. Ryoo, and S. Kim. 2014. Building Sustainable Software by Preemptive Architectural Design Using Tactic-Equipped Patterns. In 9th International Conference on Availability, Reliability and Security (ARES 2014). Fribourg, Switzerland, 484-489.

[30] H. Koziolek. 2011. Sustainability Evaluation of Software Architectures: A Systematic Review. In 7th International ACM Sigsoft Conference on the Quality of Software Architectures (QoSA 2011). Boulder, Colorado, USA, 3-12.
[31] H. Koziolek, D. Domis, T. Goldschmidt, and P. Vorst. 2013. Measuring Architecture Sustainability. IEEE Software 30, 6 (December 2013), 54-62.

[32] P. Lago, S. A. Koçak, I. Crnkovic, and B. Penzenstadler. 2015. Framing Sustainability As a Property of Software Quality. ACM Commun 58, 10 (Sept. 2015), $70-78$.

[33] J. Lan, Y. Liu, and Y. Chai. 2008. A solution model for Service-oriented architecture. In 7th World Congress on Intelligent Control and Automation (WCICA 2008). Chongqing, China, 4184-4189.

[34] J. Leppaniemi, P. Linna, J. Soini, and H. Jaakkola. 2009. Toward a flexible serviceoriented reference architecture for situational awareness systems in distributed disaster knowledge management. In Portland International Conference on Management of Engineering Technology (PICMET 2009). Portland, United States, 959-965.

[35] J. Leppaniemi, P. Linna, J. Soini, and H. Jaakkola. 2009. Toward a flexible serviceoriented reference architecture for situational awareness systems in distributed disaster knowledge management. In International Conference on Management of Engineering Technology (PICMET 2009). Portland, USA, 959-965.

[36] L. Liu, S. Thanheiser, and H. Schmeck. 2008. A Reference Architecture for Self-organizing Service-Oriented Computing. In 21st International Conference on Architecture of Computing Systems (ARCS 2008). Dresden, Germany, 205-219.

[37] C. Mackenzie, K Laskey, F. McCabe, P. Brown, and R Metz. 2006. OASIS Reference model for Service Oriented Architecture 1.0. Technical Report. OASIS Standard.

[38] S. Martínez-Fernández, C. Ayala, and X. Franch. 2012. A Reuse-Based Economic Model for Software Reference Architectures. Technical Report. Departament d'Enginyeria de Serveis i Sistemes d'Informació, Barcelona, Spain.

[39] G. Muller. 2008. Right Sizing Reference Architectures; How to provide specific guidance with limited information. In 18th Annual International Symposium of the International Council on Systems Engineering (INCOSE 2008), Vol. 18. Utrecht, The Netherlands, 2047-2054.

[40] G. Muller and E. Hole. 2007. White paper: Reference Architectures; Why, What and How. Technical Report. Embedded Systems Institute.

[41] E. Murakami, A. M. Saraiva, L. C. M. Ribeiro, C. E. Cugnasca, A. R. Hirakawa, and P. L. P. Correa. 2007. An infrastructure for the development of distributed service-oriented information systems for precision agriculture. Computers and Electronics in Agriculture 58, 1 (2007), 37 - 48.

[42] E. Y. Nakagawa, M. Guessi, J.C. Maldonado, D. Feitosa, and F. Oquendo. 2014. Consolidating a Process for the Design, Representation, and Evaluation of Reference Architectures. In 11th Working IEEE/IFIP Conference on Software Architecture (WICSA 2014). Sydney, Australia, 143-152.

[43] E. Y. Nakagawa, P. Oliveira Antonino, and M. Becker. 2011. Reference Architecture and Product Line Architecture: A Subtle But Critical Difference. In 5th European Conference on Software Architecture (ECSA 2011). Essen, Germany, 207-211.

[44] E. Y. Nakagawa, F. Oquendo, and M. Becker. 2012. RAModel: A Reference Model of Reference Architectures. In 6th European Conference on Software Architecture (ECSA 2012). Helsinki, Finland, 1-5.

[45] B. Penzenstadler, A. Raturi, D. Richardson, C. Calero, H. Femmer, and X. Franch. 2014. Systematic Mapping Study on Software Engineering for Sustainability (SE4S). In 18th International Conference on Evaluation and Assessment in Software Engineering (EASE 2014). 14:1-14:14.

[46] V. Peristeras, M. Fradinho, D. Lee, W. Prinz, R. Ruland, K. Iqbal, and S. Decker 2009. CERA: a collaborative environment reference architecture for interoperable CWE systems. Service Oriented Computing and Applications 3, 1 (2009), 3-23.

[47] D. Puthal, B. P. S. Sahoo, S. Mishra, and S. Swain. 2015. Cloud Computing Features, Issues, and Challenges: A Big Picture. In 7th International Conference on Computational Intelligence and Communication Networks (CICN 2015). Jabalpur, India, 116-123.

[48] S. Ramanathan, M. Alexander, and G. Kerr. 2008. The IBM telecommunications service delivery platform. IBM Systems fournal 47, 3 (Jul 2008), 433-443.

[49] M. Razavian, G. Procaccianti, and D.A. Tamburri. 2014. Four-Dimensional Sustainable E-Services. In 28th International Conference on Informatics for Environmental Protection (EnviroInfo 2014). Oldenburg, Germany, 221-228.

[50] P. Reed. 2002. Reference architecture: The best of best practices. (2002). http: //www.ibm.com/developerworks/rational/library/2774.html

[51] S. Reiff-Marganiec, H. Truong, G. Casella, C. Dorn, S. Dustdar, and S. Moretzky. 2008. The inContext Pervasive Collaboration Services Architecture. In First European Conference on Towards a Service-Based Internet (ServiceWave 2008). Madrid, Spain, 134-146.

[52] F. Z. Safy, M. M. Ramly, and A. Salah. 2013. Runtime Monitoring of SOA Applications: Importance, Implementations and Challenges. In 7th International Symposium on Service Oriented System Engineering (SOSE 2013). San Francisco, USA, 315-319.

[53] S. Sherman and I. Hadar. 2012. Identifying the need for a sustainable architecture maintenance process. In 5th International Workshop on Cooperative and Human Aspects of Software Engineering (CHASE 2012). 132-134.

[54] D. Sobhy and R. Bahsoon. 2016. Diversifying Software Architecture for Sustainability: A Value-based Perspective. In 10th European Conference on Software Architecture (ECSA 2016). 55-63. 
[55] J.J.M. Trienekens, S.A. Angelov, P.W.P.J. Grefen, and R.J. Kusters. 2011. Quality of software reference architectures. In IADIS International Conference Information Systems (IS 2011). Avila, Spain, 145-152.

[56] M. Weyrich and C. Ebert. 2016. Reference Architectures for the Internet of Things. IEEE Software 33, 1 (2016), 112-116.

[57] U. Zdun, R. Capilla, H. Tran, and O. Zimmermann. 2013. Sustainable Architectural Design Decisions. IEEE Software 30, 6 (2013), 46-53.

[58] Q. Zheng, B. Dong, F. Tian, and W. Chen. 2008. A service-oriented approach to integration of e-learning Information and Resource Management Systems. In 12th International Conference on Computer Supported Cooperative Work in Design (CSCWD 2008). Xi'an, China, 1047-1052.

[59] O. Zimmermann, P. Kopp, and S. Pappe. 2009. Architectural Knowledge in an SOA Infrastructure Reference Architecture. Springer Berlin Heidelberg, 217-241. 
APPENDIX

QUESTIONNAIRE FOR RASMODEL

EVALUATION 


\section{RASModel (Reference Architecture Sus- tainability Model) Validation}

Thanks for accepting our invitation! This survey should take between $15-20$ minutes.

\section{SURVEY DESCRIPTION}

This survey aims the evaluation of a model, called RASModel (Reference Architecture Sustainability Model), with factors and subfactors that could impact the sustainability of reference architectures. In this context, sustainability is defined as the capacity of the reference architecture to endure different types of changes though efficient maintenance and orderly evolution over its entire life cycle. By encompassing valuable knowledge of specific domains, the reference architectures survival is considered of utmost importance, however, the most of such architectures have not been updated since their first version.

In short, these factors were established based on (i) a systematic mapping study; (ii) investigative study in 21 reference architectures; and (iii) support of specialists with more 10 years of experience in research, establishment, and evaluation of reference architectures.

The first version of RASModel is showed bellow and is composed of two groups of factors:

- Primary factors: it contains four main factors that are composed of their subfactors. When clearly identified and explicit, they provide a good overview, providing information on the elements contained in the reference architectures, characterizing them as to their application domain, their context, stakeholders involved, etc..

- Crosscutting factors: it aggregates five factors that are usually spread across and/or tangled with all Primary factors. 


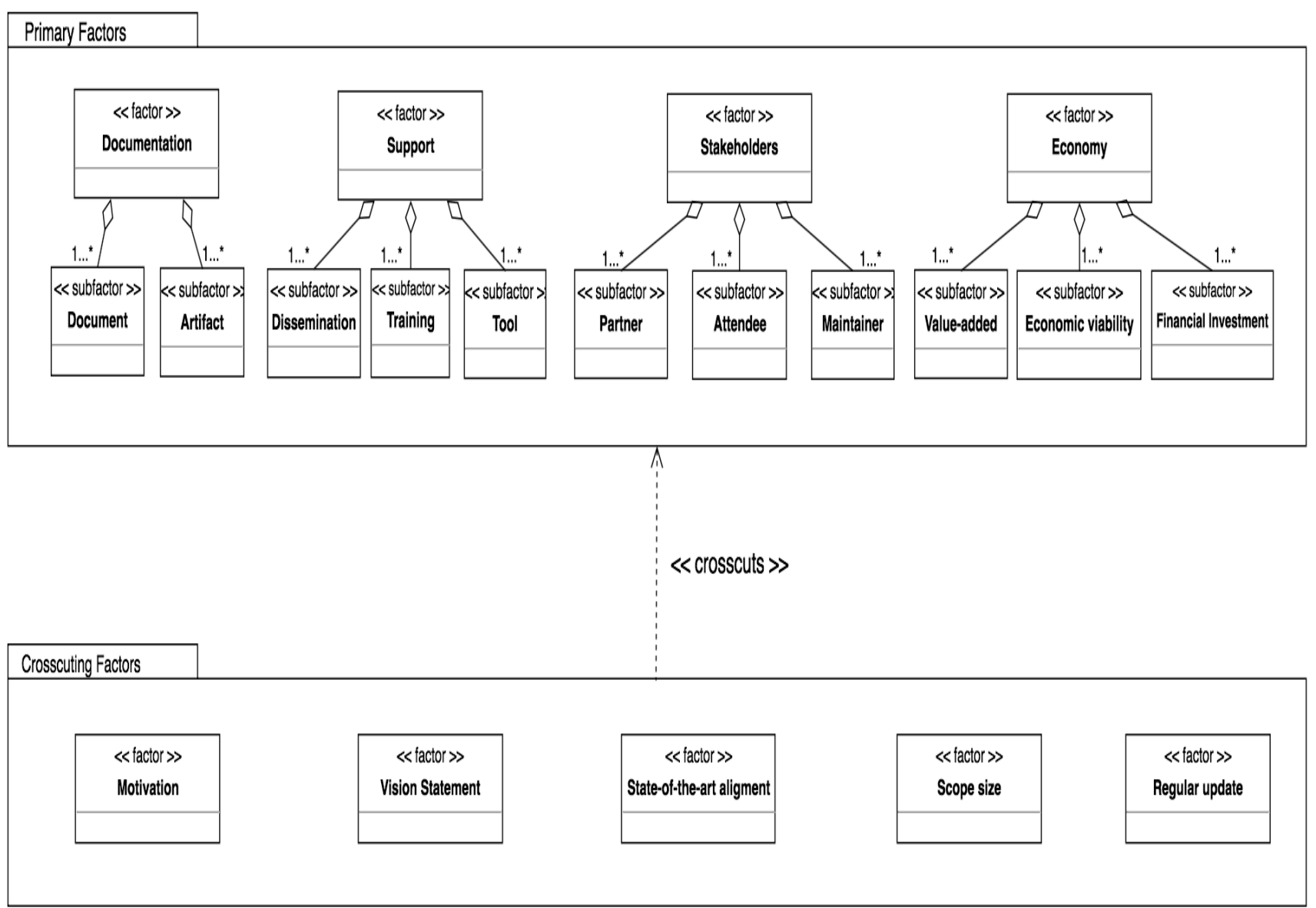

\section{THIS SURVEY IS COMPOSED OF THREE PARTS:}

1 - Participant information: here you have to provide some information about you and your professional experience;

2 - Factors and subfactors: here we ask you to evaluate the set of factors and subfactors contained in RASModel and answer about the importance of each factor.

3 - Final considerations: here you will answer about the utility of RASModel. You can also submit additional information that you consider important.

\section{SURVEY DATES}

1st reminder: Aug 4, 2018

2nd reminder: Aug 6, 2018

Deadline: Aug 9, 2018

Tip: you can save your answers at any time and resume later.

Confidentiality Remarks: all information provided by you in this survey is completely confidential. It will be only used in this study and will not be analyzed individually within the information provided by other participants. 
This research is supported by the Brazilian agency FAPESP (http://www.bv.fapesp.br/en/bolsas/169483/sustainability-measurement-in-reference-architectures/) (http://www.bv.fapesp.br/en/bolsas/169483/sustainability-measurement-in-referencearchitectures/)

There are 33 questions in this survey. 


\section{Participant Information}

Provide some information about you

*Age

(- Choose one of the following answers

less than 21 years

between 22 and 30 years

between 31 and 40 years

between 41 and 50 years

51 years or more

*Country of residence

*Education

(9 Choose one of the following answers

Undergraduate student 
Bachelor's degree

Master's student

Master's degree

Ph.D. student

Ph.D. degree

*Current occupation

( Check all that apply

Undergraduate student

Master's student

Ph.D. candidate

Researcher

Lecturer

Professor

Software Engineer

Software Architect

Other:

*Please, select one or more application domains in which you have had research or practical experience.

(- Check all that apply 
Automotive

Avionics

Healthcare

Industrial

Robotics

Smart city

Internet of Things

Other:

* How many years do you have of experience (such as research, design, establishment, and evaluation) with Reference Architectures?

(9) Choose one of the following answers

less than 1 year

between 1 and 5 years

between 5 and 10 years

more than 10 years

*How do you classify your expertise with Reference Architectures?

(- Check all that apply

Domain analysis 
Design

Assessment

Maintenance

Academic Research

Industrial Research

Other:

*Please, select phases related to the reference architectures construction that you have experience.

(- Check all that apply

Domain analysis

Requirement analysis

Reference Architecture design

Reference Architecture evaluation

Other: 


\section{Sustainability factors}

This part is divided into two phases:

(I) you will indicate if each factor and its subfactors can influence the reference architecture sustainability;

(II) you will indicate the level of importance of each factor and its subfactors to the reference architecture sustainability.

Please, answer each question based on your experience with Reference Architectures.

\section{*PHASE I}

Do you agree that Documentation and their subfactors influence the sustainability of reference architectures?

\section{(9 This question is mandatory}

(C) Please complete all parts.

\begin{tabular}{|c|c|c|c|c|c|}
\hline & $\begin{array}{l}\text { Strongly } \\
\text { disagree }\end{array}$ & Disagree & $\begin{array}{c}\text { Neither } \\
\text { agree nor } \\
\text { disagree }\end{array}$ & Agree & $\begin{array}{c}\text { Strongly } \\
\text { agree }\end{array}$ \\
\hline $\begin{array}{l}\text { Documentation aggregates } \\
\text { subfactors that help and com- } \\
\text { plement in understanding the } \\
\text { reference architecture, as well } \\
\text { as their appropriate use. }\end{array}$ & & & & & \\
\hline $\begin{array}{r}\text { (Subfactor) Document: it is a } \\
\text { piece of written, printed, or } \\
\text { electronic matter such as PDF`s } \\
\text { files that provide information or } \\
\text { that serve as an official record } \\
\text { about the reference } \\
\text { architecture. }\end{array}$ & & & & & \\
\hline
\end{tabular}


(Subfactor) Artifact: a reference architecture is represented by artifacts that include, for instance, components and connectors, domain standards, interfaces, and protocols. These artifacts can be available through repositories, or another way that facilitates access to the content of this architecture.

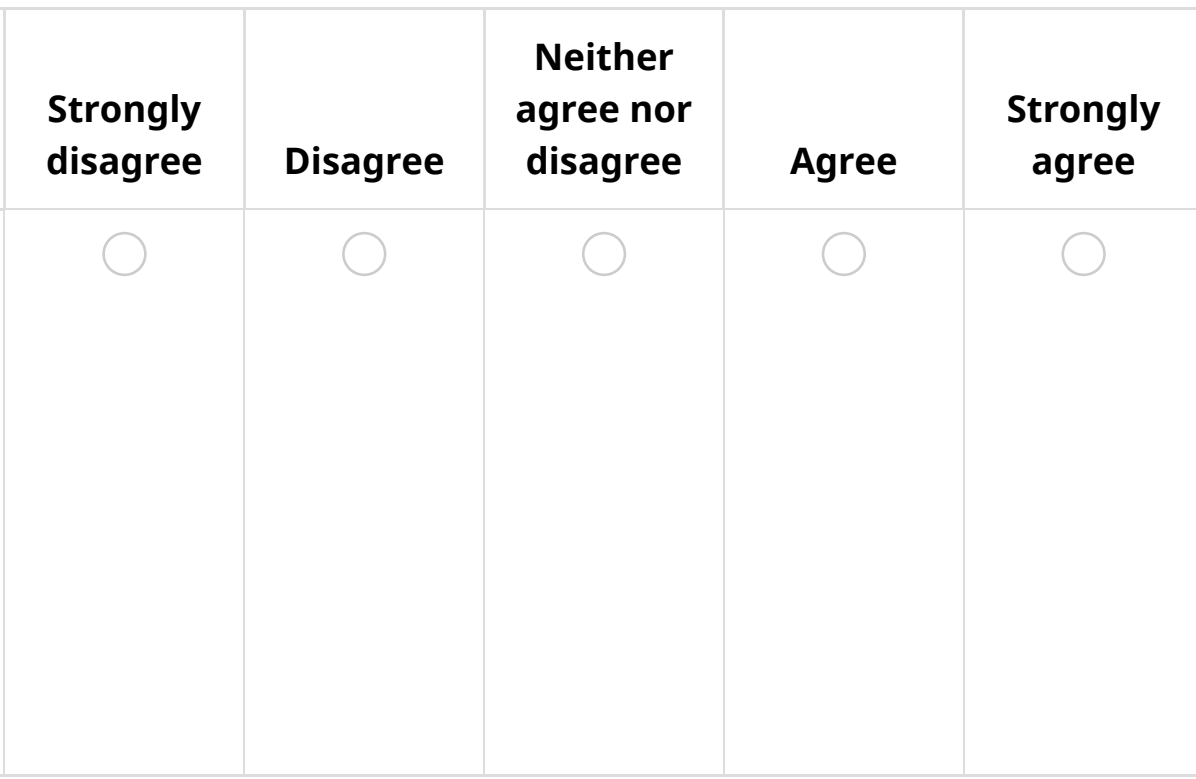

*Is there any subfactor Documentation that you consider relevant for reference architecture sustainability but was not present in RASModel? (If "Yes", please, indicate subfactor that is missing)

(- Choose one of the following answers

\section{( This question is mandatory}

Yes

No

Please enter your comment here:

*Do you agree that Support and their subfactors influence the sustainability of reference architectures?

() This question is mandatory

(C) Please complete all parts.

\begin{tabular}{|c|c|c|c|c|c|}
\hline & $\begin{array}{l}\text { Strongly } \\
\text { disagree }\end{array}$ & Disagree & $\begin{array}{l}\text { Neither } \\
\text { agree nor } \\
\text { disagree }\end{array}$ & Agree & $\begin{array}{c}\text { Strongly } \\
\text { agree }\end{array}$ \\
\hline $\begin{array}{r}\text { Support: it refers to elements } \\
\text { that provide support to the ref- } \\
\text { erence architecture } \\
\text { dissemination. }\end{array}$ & & & & & \\
\hline
\end{tabular}


(Subfactor) Dissemination: it is the way that the reference architecture is spread, such as websites, repositories or hosting plataforms

(Subfactor) Training: it is the enablement that guides and instructs one interested in the correct use of the reference architecture, and can be offered, through courses, workshops or web-based.

(Subfactor) Tool: it is an automated support that allows the manipulation of artifacts of the reference architecture (and their content).

*Is there any subfactor Support that you consider relevant for reference architecture sustainability but was not present in RASModel? (If "Yes", please, indicate subfactor that is missing)

(1) Choose one of the following answers

\section{( This question is mandatory}

Yes

No

Please enter your comment here:

Do you agree that Stakeholders and their subfactors influence the sustainability of reference architectures? 
Stakeholder: This factor refers to the community around the reference architecture that can be strengthened via a consortium composed of, for instance, companies, research centers, and universities.

(Subfactor) Partner: who has the initiative to building a reference architecture, i.e., one responsible for their foundation.

(Subfactor) Attendee: who has an interest in adopting/using the reference architecture.

(Subfactor) Maintainer: who is involved in the development and maintenance activities of the reference architecture (such as delivering new releases, updating documentation, and preparing training methods).

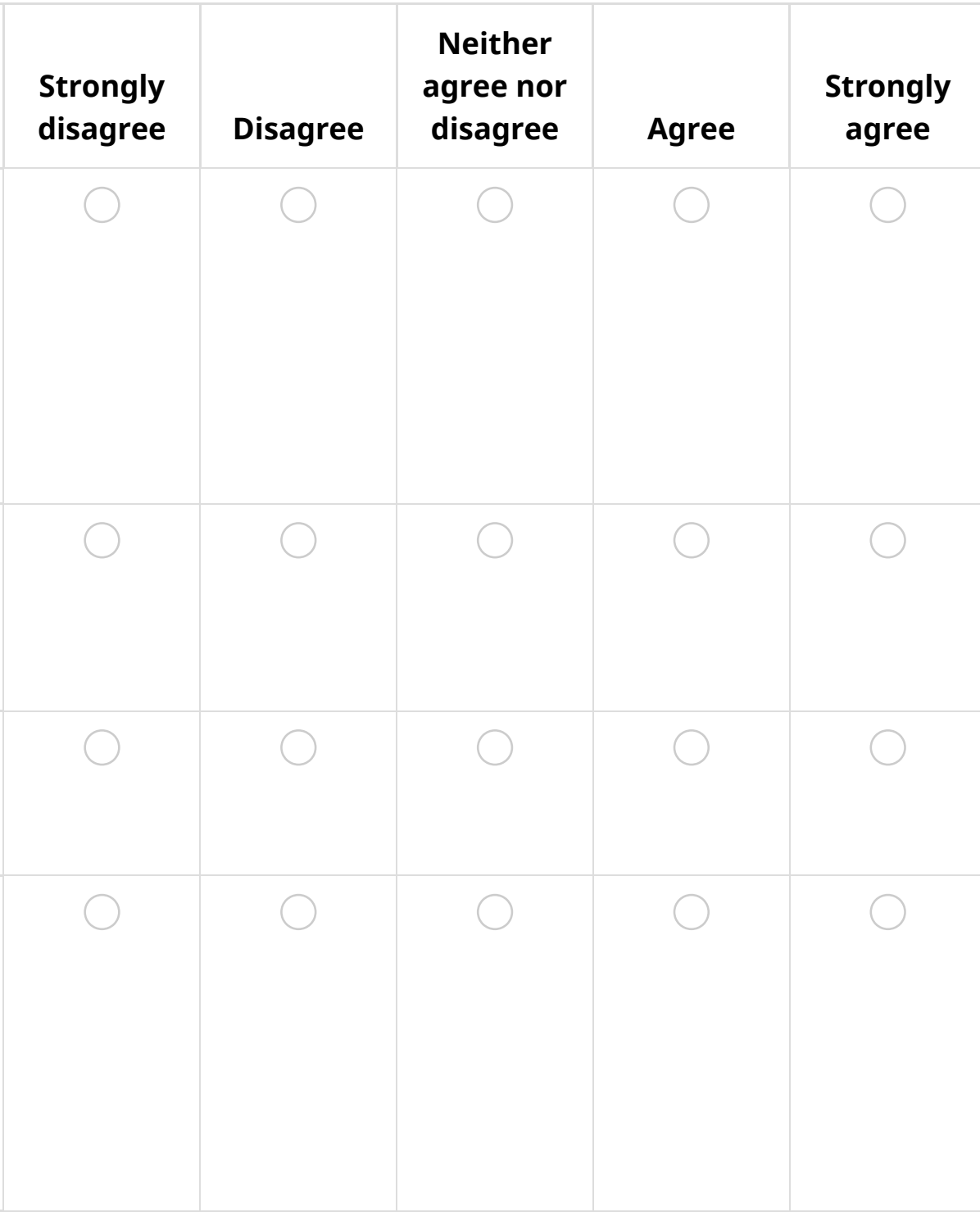

*Is there any subfactor Stakeholder that you consider relevant for reference architecture sustainability but was not present in RASModel? (If "Yes", please, indicate subfactor that is missing)

(9) Choose one of the following answers

\section{(- This question is mandatory}

Yes

No

Please enter your comment here: 
*Do you agree that Economy and their subfactors influence the sustainability of reference architectures?

\section{(9 This question is mandatory}

(D Please complete all parts.

\begin{tabular}{|c|c|c|c|c|c|}
\hline & $\begin{array}{l}\text { Strongly } \\
\text { disagree }\end{array}$ & Disagree & $\begin{array}{l}\text { Neither } \\
\text { agree nor } \\
\text { disagree }\end{array}$ & Agree & $\begin{array}{c}\text { Strongly } \\
\text { agree }\end{array}$ \\
\hline \multicolumn{6}{|l|}{$\begin{array}{l}\text { Economy: it refers to the set of } \\
\text { fundamental information that } \\
\text { affects a business or an invest- } \\
\text { ment's value. }\end{array}$} \\
\hline \multicolumn{6}{|l|}{$\begin{array}{l}\text { (Subfactor) Value-added: it is } \\
\text { the value that the content of } \\
\text { the reference architecture has } \\
\text { and how this content benefits } \\
\text { the application domain where it } \\
\text { is inserted. }\end{array}$} \\
\hline \multicolumn{6}{|l|}{$\begin{array}{l}\text { (Subfactor) Economic viability: it } \\
\text { is the measures/analyzes about } \\
\text { the feasibility of the investment } \\
\text { in the building of a reference } \\
\text { architecture. }\end{array}$} \\
\hline $\begin{array}{l}\text { (Subfactor) Financial Invest- } \\
\text { ment: it is the amount of mon- } \\
\text { ey, resources, and time needed } \\
\text { to build and maintain a refer- } \\
\text { ence architecture. }\end{array}$ & & & & & \\
\hline
\end{tabular}

*Is there any subfactor Economy that you consider relevant for reference architecture sustainability but was not present in RASModel? (If "Yes", please, indicate subfactor that is missing)

(1) Choose one of the following answers

\section{(- This question is mandatory}

Yes

No

Please enter your comment here: 
*Do you agree that factor Motivation influences the sustainability of reference architectures?

(- This question is mandatory

(C Please complete all parts.

\begin{tabular}{|c|c|c|c|c|c|}
\hline & $\begin{array}{l}\text { Strongly } \\
\text { disagree }\end{array}$ & Disagree & $\begin{array}{l}\text { Neither } \\
\text { agree nor } \\
\text { disagree }\end{array}$ & Agree & $\begin{array}{c}\text { Strongly } \\
\text { agree }\end{array}$ \\
\hline $\begin{array}{l}\text { Motivation: it is the purpose } \\
\text { that motivates the existence of } \\
\text { a reference architecture. This } \\
\text { motivation must be reasoned } \\
\text { and aligned with the applica- } \\
\text { tion domain, and benefits } \\
\text { should be explicit. }\end{array}$ & & & & & \\
\hline
\end{tabular}

*Do you agree that factor Scope size influences the sustainability of reference architectures?

(- This question is mandatory

(C) Please complete all parts.

\begin{tabular}{|c|c|c|c|c|c|}
\hline & $\begin{array}{l}\text { Strongly } \\
\text { disagree }\end{array}$ & Disagree & $\begin{array}{l}\text { Neither } \\
\text { agree nor } \\
\text { disagree }\end{array}$ & Agree & $\begin{array}{c}\text { Strongly } \\
\text { agree }\end{array}$ \\
\hline $\begin{array}{l}\text { Scope size: it is the ambit } \\
\text { ("sphere") of the reference ar- } \\
\text { chitecture, including "things", } \\
\text { such as systems that covers, } \\
\text { number of partners, attendees, } \\
\text { and maintainers. }\end{array}$ & & & & & \\
\hline
\end{tabular}

*Do you agree that factor Vision statement influences the sustainability of reference architectures?

(- This question is mandatory

(- Please complete all parts.

\begin{tabular}{|c|c|c|c|c|}
\hline $\begin{array}{l}\text { Strongly } \\
\text { disagree }\end{array}$ & Disagree & $\begin{array}{l}\text { Neither } \\
\text { agree nor } \\
\text { disagree }\end{array}$ & Agree & $\begin{array}{c}\text { Strongly } \\
\text { agree }\end{array}$ \\
\hline
\end{tabular}


Vision Statement: it is a reference architecture `s roadmap, indicating both what this architecture wants to become and guiding transformational initiatives by setting a defined direction for the reference architecture `s growth.

\begin{tabular}{|l|l|c|c|c|}
\hline $\begin{array}{l}\text { Strongly } \\
\text { disagree }\end{array}$ & Disagree & $\begin{array}{c}\text { Neither } \\
\text { agree nor } \\
\text { disagree }\end{array}$ & Agree & $\begin{array}{c}\text { Strongly } \\
\text { agree }\end{array}$ \\
\hline & & & & \\
\hline & & & \\
& & & \\
& & & \\
& & & \\
& & & \\
& & & \\
& & & \\
\end{tabular}

Do you agree that factor State-of-the-art alignment influences the sustainability of reference architectures?

( This question is mandatory

(C) Please complete all parts.

\begin{tabular}{|c|c|c|c|c|c|}
\hline & $\begin{array}{l}\text { Strongly } \\
\text { disagree }\end{array}$ & Disagree & $\begin{array}{l}\text { Neither } \\
\text { agree nor } \\
\text { disagree }\end{array}$ & Agree & $\begin{array}{c}\text { Strongly } \\
\text { agree }\end{array}$ \\
\hline $\begin{array}{l}\text { State-of-the-art alignment: is } \\
\text { the current knowledge applica- } \\
\text { tion domain that is considered } \\
\text { necessary to be included in ref- } \\
\text { erence architecture. }\end{array}$ & & & & & \\
\hline
\end{tabular}

*Do you agree that factor Regular update influences the sustainability of reference architectures?

\section{(9 This question is mandatory \\ (D) Please complete all parts.}

\begin{tabular}{|c|c|c|c|c|c|}
\hline & $\begin{array}{l}\text { Strongly } \\
\text { disagree }\end{array}$ & Disagree & $\begin{array}{l}\text { Neither } \\
\text { agree nor } \\
\text { disagree }\end{array}$ & Agree & $\begin{array}{c}\text { Strongly } \\
\text { agree }\end{array}$ \\
\hline $\begin{array}{l}\text { Regular update: it refers to the } \\
\text { continuous update in elements } \\
\text { (e.g., documentation, artifacts, } \\
\text { dissemination issues) related to } \\
\text { the reference architecture. }\end{array}$ & & & & & \\
\hline
\end{tabular}


Please, indicate for each factor and its subfactors a level of importance for the reference architecture sustainability, according to the follow scale:

1- Not at all important;

2- Slightly important;

3- Moderately important;

4- Very important;

5- Extremely important

\section{Primary Factors:}

\section{Documentation}

(- This question is mandatory

(C) Please complete all parts.

\begin{tabular}{|r|r|r|r|r|r|}
\hline & $\mathbf{1}$ & $\mathbf{2}$ & $\mathbf{3}$ & $\mathbf{4}$ & $\mathbf{5}$ \\
\hline Documentation & & & & \\
\hline Document & & & & \\
\hline Artifact & & & & & \\
\hline
\end{tabular}

\section{*Support}

(- This question is mandatory

(D Please complete all parts.

\begin{tabular}{|r|r|r|r|r|r|}
\hline & $\mathbf{1}$ & $\mathbf{2}$ & $\mathbf{3}$ & $\mathbf{4}$ & $\mathbf{5}$ \\
\hline Support & & & & \\
\hline Dissemination & & & & \\
\hline Training & & & & \\
\hline Tool & & & & & \\
\hline
\end{tabular}

*Stakeholders

(- This question is mandatory

(- Please complete all parts.

\begin{tabular}{|r|c|c|c|c|c|}
\hline & $\mathbf{1}$ & $\mathbf{2}$ & $\mathbf{3}$ & $\mathbf{4}$ & $\mathbf{5}$ \\
\hline Stakeholders & & & & & 0 \\
\hline
\end{tabular}




\begin{tabular}{|r|r|r|r|r|r|}
\hline & $\mathbf{1}$ & $\mathbf{2}$ & $\mathbf{3}$ & $\mathbf{4}$ & $\mathbf{5}$ \\
\hline Partner & & & & \\
\hline Attendee & & & & \\
\hline Maintainer & & & & \\
\hline
\end{tabular}

*Economy

(- This question is mandatory

(C) Please complete all parts.

\begin{tabular}{|c|c|c|c|c|c|}
\hline & 1 & 2 & 3 & 4 & 5 \\
\hline Economy & & & & & \\
\hline Value-added & & & & & \\
\hline Economic Viability & & & & & \\
\hline Financial Invesment & & 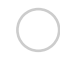 & & & \\
\hline
\end{tabular}

*

Motivation

(- This question is mandatory

(- Please complete all parts.

\section{Crosscutting Factors:}

\begin{tabular}{|c|c|c|c|c|c|}
\hline & 1 & 2 & 3 & 4 & 5 \\
\hline Motivation & C & 0 & & 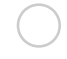 & ( \\
\hline
\end{tabular}

*Vision Statement

(- This question is mandatory

(C Please complete all parts.

\begin{tabular}{|c|c|c|c|c|c|}
\hline & 1 & 2 & 3 & 4 & 5 \\
\hline Vision Statement & & & & & 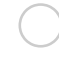 \\
\hline
\end{tabular}


( This question is mandatory

(C Please complete all parts.

\begin{tabular}{|r|c|c|c|c|c|}
\hline & $\mathbf{1}$ & $\mathbf{2}$ & $\mathbf{3}$ & $\mathbf{4}$ & $\mathbf{5}$ \\
\hline State-of-the-art Alignment & & & & & \\
\hline
\end{tabular}

\section{*Scope Size}

( This question is mandatory

C Please complete all parts.

\begin{tabular}{|r|c|c|c|c|c|}
\hline & $\mathbf{1}$ & $\mathbf{2}$ & $\mathbf{3}$ & $\mathbf{4}$ & $\mathbf{5}$ \\
\hline Scope Size & & 0 & 0 & 0 & \\
\hline
\end{tabular}

\section{*Regular Updates}

(- This question is mandatory

C Please complete all parts.

\begin{tabular}{|c|c|c|c|c|c|}
\hline & 1 & 2 & 3 & 4 & 5 \\
\hline Regular updates & & & & & ( \\
\hline
\end{tabular}




\section{Final Considerations}

*Do you think that RASModel will be useful to support reference architecture sustainability analysis?

() Choose one of the following answers

Strongly disagree

Disagree

Neither agree nor disagree

Agree

Strongly agree

*Do you think that RASModel will be useful to support the building of the reference architectures more sustainable?

(- Choose one of the following answers

Strongly disagree

Disagree

Neither agree nor disagree

Agree

Strongly agree 
Feel free to leave any information you consider useful for this research. 


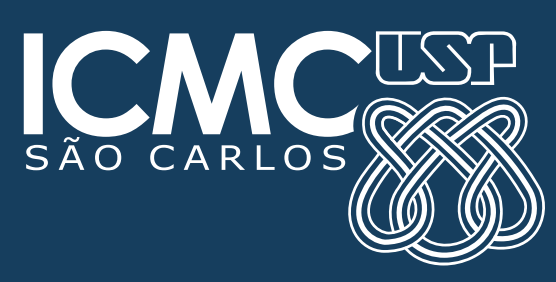

